\title{
Feindbild Jude, Feindbild Großstadt. Antisemitismus und Großstadtfeindschaft im völkischen Denken
}

\author{
Dissertation \\ zur Erlangung des Doktorgrades \\ der Sozialwissenschaftlichen Fakultät \\ der Georg-August-Universität Göttingen \\ vorgelegt von \\ Bodo Kahmann \\ geboren in Böblingen
}

Göttingen, 2016 


\section{Inhalt}

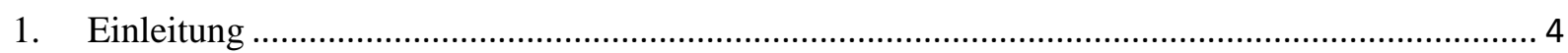

1.1. Thema und Fragestellungen der Studie ............................................................................. 4

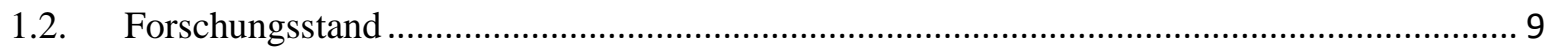

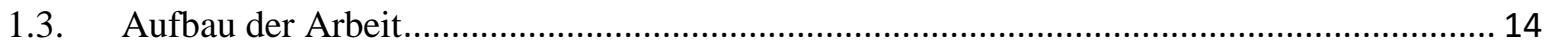

2. Geschichte und Theorie(n) des modernen Antisemitismus ....................................................... 16

3. Theoretische Zugänge zum Zusammenhang von Antisemitismus und Großstadtfeindschaft........ 25

3.1. Talcott Parsons: The Sociology of Modern Anti-Semitism ………….................................. 25

3.2. Arnold M. Rose: Anti-Semitism's Root in City-Hatred.................................................... 31

3.3. Moishe Postone: Die Logik des Antisemitismus................................................................. 36

3.4. Shulamit Volkov: Antisemitismus als kultureller Code ..................................................... 44

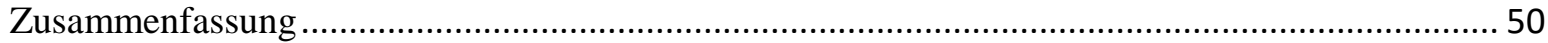

4. Historische Genese der Großstadtfeindschaft in Deutschland ................................................... 52

4.1. Der hygienisch-medizinische Stadtdiskurs im 18. und 19. Jahrhundert.............................. 53

4.2. Großstadtfeindschaft im Kaiserreich und in der völkischen Bewegung ............................. 58

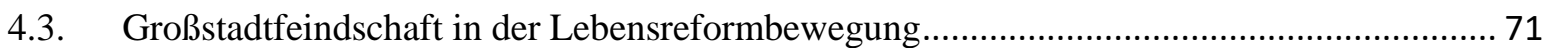

4.4. Großstadtfeindschaft in der Jugendbewegung und der Weimarer Republik .......................... 78

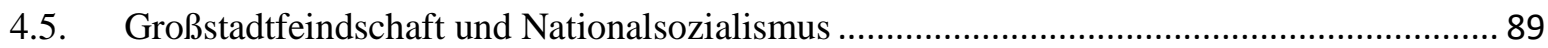

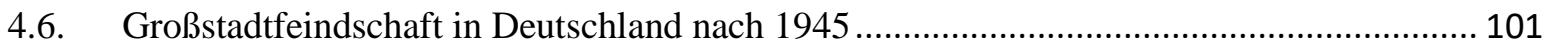

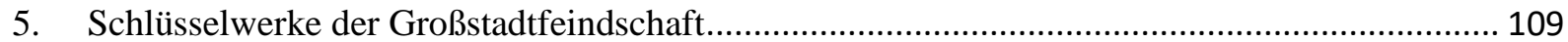

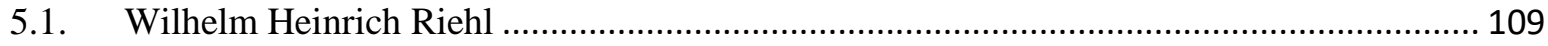

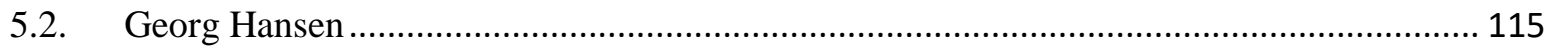

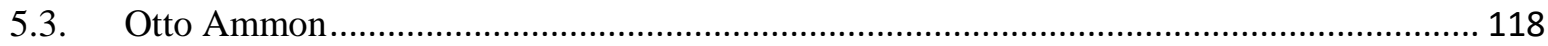

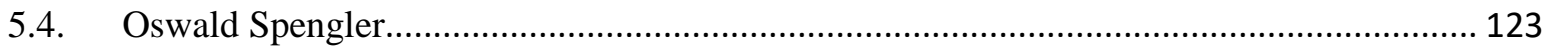

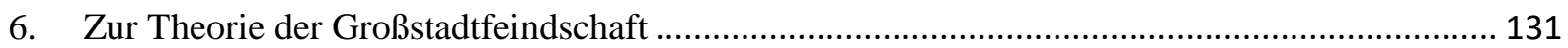

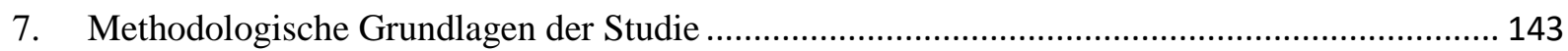

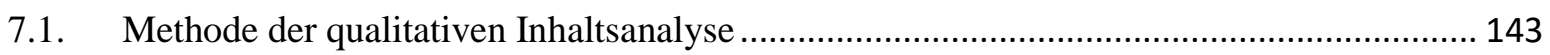

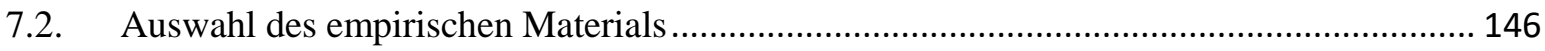

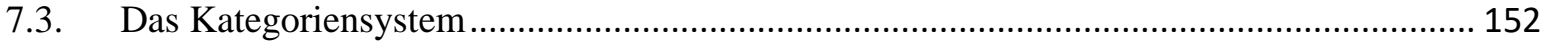

8. Antisemitismus und Großstadtfeindschaft in völkischen Texten ................................................ 155

8.1. Die Personifizierung der Verstädterung in den Juden ................................................... 155

8.1.1. Die entwurzelnde Wirkung des , jüdischen Geistes“................................................... 155

8.1.2. Die entwurzelnde Wirkung von Geld und Handel ................................................... 158 
Zusammenfassung der ersten Kategorie

8.2. Unterschiedliche Anpassungsfähigkeit von Juden und Deutschen an die Großstadt .......... 163

8.2.1. Der nichtstädtische Charakter der Germanen ............................................................. 163

8.2.2. Die Großstadt als „Rassengrab“ und als Ort negativer Selektion.................................. 166

8.2.3. „Zersetzung“ völkischer Identität in den Großstädten ................................................ 170

8.2.4. Anpassungsfähigkeit der Juden an die Großstadt.................................................... 173

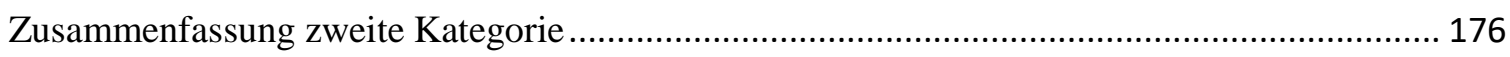

8.3. Sexualität, Großstadt und Judentum........................................................................... 177

8.3.1. Die (weiblichen) Verlockungen der Großstadt........................................................... 177

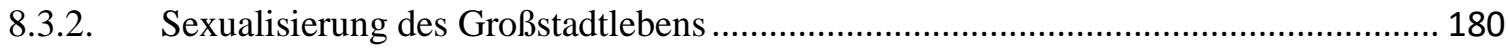

8.3.3. Erosion der Geschlechterdifferenz in den Großstädten .............................................. 184

8.3.4. Prostitution, Judentum und Großstadt ................................................................... 188

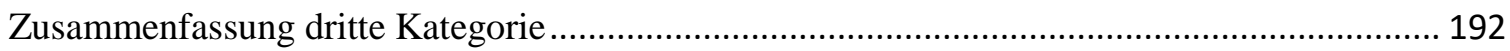

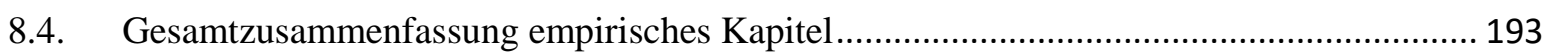

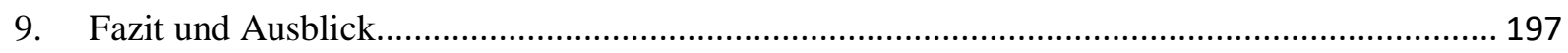

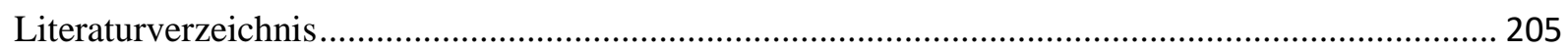

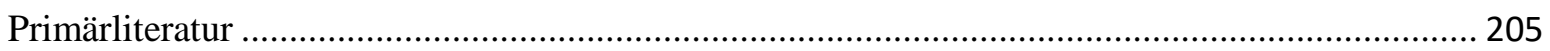

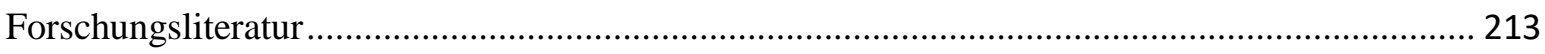




\section{Einleitung}

\subsection{Thema und Fragestellungen der Studie}

Die Frage nach dem Verhältnis des modernen Antisemitismus zur modernen Gesellschaft begleitet die Antisemitismusforschung seit ihren Anfängen. Wie der Begriff des modernen Antisemitismus bereits impliziert, wird die sich im letzten Drittel des 19. Jahrhunderts unter den gesellschaftlichen, politischen und kulturellen Bedingungen der Hochindustrialisierung transformierende Judenfeindschaft in der Forschung als ein Phänomen der Moderne begriffen, das terminologisch von vormodernen Erscheinungsformen der Judenfeindschaft unterschieden wird. Genuin modern am Antisemitismus ist jedoch nur sein historischer und sozialer Entstehungszusammenhang, nicht seine ideologischen und politischen Inhalte und Zielsetzungen. Reinhard Rürup hat den modernen Antisemitismus des späten 19. Jahrhunderts als den radikalen Kern einer vielfältigen, postliberalen Protestbewegung beschrieben, die sich gegen die Grundprinzipien der bürgerlichen Gesellschaft richtet: Menschen- und Bürgerrechte, liberal-kapitalistische Wirtschaftsordnung und eine säkularisierte, traditionskritische Kultur (vgl. Rürup 1987: 118).

Der Antisemitismus ist insofern zugleich modern und antimodern, als er darauf abzielt Aufklärung und Demokratie mit den Mitteln der Moderne zu bekämpfen. Für diese These lässt sich in der Geschichte der antisemitischen Bewegung im Kaiserreich und der Weimarer Republik eine Reihe von empirischen Belegen finden. Zwei Beispiele sollen dies verdeutlichen: Antisemitische Agitatoren bedienten sich stets neuester Propagandatechniken und Medien und wiesen somit keine Berührungsängste mit der zeitgenössischen technologischen Entwicklung auf. Der Rassenantisemitismus des späten 19. und des beginnenden 20. Jahrhunderts versuchte seine Thesen und Argumente auf der Höhe des damaligen Erkenntnis- und Forschungstandes der mit „Rassenfragen“ beschäftigten und akademisch-institutionell abgesicherten Disziplinen wie der Anthropologie oder der Rassenhygiene $\mathrm{zu}$ entwickeln. Es ist insofern unzweifelhaft, dass der moderne Antisemitismus Aspekte der Moderne in sich aufgenommen hat und nur aus ihr heraus zu begreifen ist. Die Aufklärung und die mit ihr zusammenhängende naturwissenschaftliche Emanzipation sind einerseits die Bedingung für die Entstehung des modernen Antisemitismus, wie Samuel Salzborn in Anlehnung an die Dialektik der Aufklärung hervorhebt, und stellen andererseits seine Begrenzung dar, da sie das Potential ,zur 
Selbstreflexion und kritischen Aufhebung der Unmündigkeit“" in sich bergen. Der moderne Antisemitismus ist daher zugleich die Wahrheit wie auch die Negation der bürgerlichen Gesellschaft (vgl. Salzborn 2010: 317-318).

Wichtige Impulse verdanken die Antisemitismusforschung und deren Diskussion über das ambivalente Verhältnis zwischen Antisemitismus und Moderne der Theorie von Moishe Postone (vgl. Postone 1982). Im Mittelpunkt seiner Antisemitismus-Theorie steht die These, dass der moderne Antisemitismus eine fetischisierte Form des Antikapitalismus darstellt, zu dessen ideologischem Kern eine positive Wahrnehmung der modernen Technik und der industriellen Produktion gehört, während die als abstrakt rezipierte Zirkulationssphäre der Ökonomie in den Juden personifiziert und bekämpft wird. Die These, dass der moderne Antisemitismus nicht gegen alle Phänomene der modernen Industriegesellschaft Opposition bezieht, griff wenige Jahre später der amerikanische Historiker Jeffrey Herf in seiner einflussreichen Studie Reactionary Modernism auf um sie anhand der positiven Technikrezeption rechter Intellektueller aus dem Umfeld der Konservativen Revolution und des Nationalsozialismus empirisch nachzuweisen (vgl. Herf 1984). Andere Studien sind einem ähnlichen Erkenntnisinteresse gefolgt: Das Verhältnis zivilisationskritischer, antidemokratischer und antisemitischer Ideologien, Bewegungen und Parteien zur Moderne wurde im Besonderen hinsichtlich der Rezeption der modernen Technik (vgl. Sieferle 1984; Rohkrämer 1999), der Akzeptanz bzw. Ablehnung des bürokratischen und technischnaturwissenschaftlichen Rationalisierungsprozesses und der Frage nach der Befürwortung des Grades der Inklusion/Exklusion in die gesellschaftlichen Funktionssysteme der Moderne diskutiert (vgl. Breuer 2010a).

Vergleichsweise wenig beachtet wurden bisher die Großstadtwahrnehmung und die Großstadtrezeption von Strömungen und Bewegungen, die in einen ideologischen Konflikt mit der Modernisierung geraten sind. Dies gilt auch für die antisemitische Bewegung, die sich als Untersuchungsgegenstand in besonderer Weise eignet, da sie als Reaktion auf die vielfältigen Modernisierungsprozesse des 19. Jahrhunderts entstanden ist. Die sich im 19. Jahrhundert entwickelnden Großstädte des Industriezeitalters waren sowohl Ursache als auch Folge eines umfassenden und allgemeinen Modernisierungsprozesses in Deutschland und können als Laboratorien der Moderne begriffen werden. In der Antisemitismusforschung existiert daher ein Konsens dahingehend, dass eine abwehrende Reaktion auf die Verstädterung und auf die Ausformung des modernen Großstadtlebens Merkmale des modernitätsfeindlichen Impetus des modernen Antisemitismus darstellen (vgl. z.B. Postone 
1982: 16; Rensmann 2004: 73; Haury 2004: 95; Salzborn 2010: 322). Bisher blieb es jedoch bei dieser Feststellung, ohne dass dieser Zusammenhang systematisiert und mit der historischen Genese großstadtfeindlichen Denkens in Verbindung gebracht worden wäre. Dass ein ideengeschichtlicher Vergleich naheliegend ist, zeigt sich daran, dass in allen großen westlichen Industriestaaten während des 19. Jahrhunderts und verstärkt infolge der zweiten industriellen Revolution im letzten Drittel des Jahrhunderts großstadtfeindliche Strömungen hervortraten (vgl. Lees 1985; speziell zu den USA: Conn 2014). Der amerikanische Stadthistoriker Andrew Lees kommt in seiner vergleichenden Untersuchung zu dem Ergebnis, dass die Polarität zwischen der Ablehnung und der Befürwortung der Großstadtentwicklung in Deutschland am größten war und dass das großstadtfeindliche Denken in keiner anderen Industrienation so stark ausgeprägt und verbreitet war: „Without question, Germany produced the most extreme polarization of opinion. It was also the country in which anti-urban hatreds were most pervasive" (Lees 1985: 311).

Obwohl zwischen der ideologischen Ausformung des modernen Antisemitismus und der Großstadtfeindschaft eine zeitliche Koinzidenz existiert, waren die großstadtfeindliche(n) und die antisemitische(n) Bewegung(en) des Kaiserreichs nicht identisch und entwickelten sich unabhängig voneinander. Die Großstadtfeindschaft entwickelte sich im ausgehenden 19. Jahrhundert einerseits zu einem konstitutiven Bestandteil eines breiten Spektrums von Heimat-, Erneuerungs- und Reformbewegungen, die über keine einheitliche Weltanschauung verfügten und mit vielfältigen geistigen und politischen Strömungen der Zeit verbunden waren. Andererseits wurde die negative Betrachtung der Großstadtentwicklung Gegenstand wissenschaftlicher und sich als solcher verstehenden Diskurse und Debatten, an denen sowohl akademisch autorisierte als auch autodidaktisch geschulte Sprecher partizipierten. Maßgeblich geprägt wurden die zeitgenössischen wissenschaftlichen Debatten über die Land-StadtWanderung von sozialbiologistischen, sozialdarwinistischen und rassenhygienischen Untersuchungen (vgl. Pfeil 1972: 48-53). Das gemeinsame Ziel der verschiedenen großstadtfeindlichen Strömungen bestand darin, die Binnenwanderung in die Großstädte umzukehren oder sie zumindest abzubremsen und eine Innere Kolonisation in Form einer Besiedlung des ländlichen Raums und einer Stärkung des Landlebens zu forcieren.

Die Argumente der großstadtfeindlichen und der antisemitischen Publizistik des Kaiserreichs durchdrangen sich nicht notwendigerweise. Im großstadtfeindlichen Lager stellte der Antisemitismus keine mehrheitsfähige Position dar. Inhaltliche Berührungspunkte gab es zwar sowohl in den Schriften der für die Entwicklung der Großstadtfeindschaft maßgeblichen 
Autoren $^{1}$ als auch in den Traktaten einflussreicher Antisemiten. So beschrieb Wilhelm Heinrich Riehl (1823-1897), der Ideengeber der Großstadtfeindschaft, in seiner Naturgeschichte des Volkes die Juden und die Großstädte bereits in den 1850er Jahren als eine Gefahr für das deutsche Bauerntum. Otto Glagau (1834-1892) führte in seiner in den 1870er Jahren erschienen Artikelserie über den Börsen- und Gründungs-Schwindel in Berlin aus, dass das an sich ungesunde Klima Berlins den Juden gut bekomme und sie sich in der Hauptstadt „heftig“ vermehrten (vgl. Glagau 1876: 148-149). Wilhelm Marr (1819-1904) griff in seinem 1879 publizierten Pamphlet Der Sieg des Judenthums über das Germanenthum das weitverbreitete antisemitische Stereotyp auf, wonach die Juden nicht zum Ackerbau befähigt seien, und dass es sich um eine bemerkenswerte kulturgeschichtliche Erscheinung handele, dass das Judentum in ganz Europa eine städtische Bevölkerungsgruppe bilde (vgl. Marr 1879: 10).

$\mathrm{Zu}$ einer starken Konvergenz antisemtischer und großstadtfeindlicher Ideologeme kam es jedoch erst in den Schriften der Sammlungsbewegung des völkischen Nationalismus, die sich um 1880 in Österreich und zehn Jahre später im Deutschen Kaiserreich herausbildete. Sowohl der Antisemitismus als auch die Großstadtfeindschaft wirkten auf verschiedene Weise innerhalb der völkischen Bewegung. Der Antisemitismus drückte sich einerseits auf einer formalen Ebene in sogenannten Arierparagraphen völkischer Verbände und Vereine aus und manifestierte sich andererseits in deren Programmen und umfassendem Schrifttum (vgl. Puschner 2001: 51). In vergleichbarer Weise, wie der Antisemitismus bei der Lektüre völkischer Literatur hervortritt, lassen sich in der Eigenliteratur der völkischen Bewegung auch mannigfache Belege für eine ausgeprägte Feindschaft gegenüber den modernen Großstädten finden. Die zentrale Bedeutung, die die Völkischen von einer Bewältigung der Großstadtentwicklung für die von ihnen angestrebte Wiedergeburt und Erneuerung des „Deutschtums“ ausgehen sahen, hob Max Robert Gerstenhauer (1873-1940) in seiner 1933 erschienen Rückschau auf die historische Entwicklung der völkischen Bewegung paradigmatisch hervor, wenn er schreibt, dass die Rettung oder der Untergang des deutschen Volkes davon abhänge, ob es gelingt, dem durch die Verstädterung heimatlos gewordenen

\footnotetext{
${ }^{1}$ In dieser Arbeit wurde auf eine durchgehende gegenderte Schreibweise verzichtet. Dies ist dadurch begründet, dass die zitierten antisemitischen und großstadtfeindlichen Texte, soweit bekannt, ausschließlich von Männern verfasst wurden. Eine gendersensible Sprache wäre vor diesem Hintergrund insofern irreführend, als sie suggerieren würde, dass Frauen in gleicher Weise an der völkischen Diskussion über Judentum und Großstadt beteiligt gewesen seien. Dies bedeutet im Umkehrschluss selbstverständlich nicht, dass Frauen weniger anfällig für antisemitische und großstadtfeindliche Ideen sind.
} 
und entwurzelten ,,proletarisierten Großstadtvolk wieder eine wirtschaftliche und geistige Heimat zu geben“"(Gerstenhauer 1933: 6).

Zur großstadtfeindlichen Publizistik der Völkischen traten praktische Unternehmungen hinzu, mit denen dem schädlichen Einfluss der Großstädte entgegengewirkt werden sollte. $\mathrm{Zu}$ den weitestgehenden Ansätzen und praktischen Umsetzungen, die nicht auf die völkische Bewegung begrenzt waren, gehörte die von Theodor Fritsch (1852-1933) entwickelte Gartenstadtidee und die ländliche Genossenschaftssiedlung. Die breite Rezeption dieser Ideen und Praktiken in der völkischen Bewegung verdankte sich der mehrheitlich geteilten Überzeugung, dass sowohl von den zum ultimativen Feindbild stilisierten Juden, die als eine großstädtische Bevölkerungsgruppe wahrgenommen wurden, als auch von den Großstädten eine existentielle Gefahr für die deutsche Nation bzw. das deutsche Volk ausgehen.

Die vorliegende Studie verfolgt vor diesem Hintergrund zwei Zielsetzungen: Sie untersucht die dominanten Argumentationsmuster und Stereotype über die der Antisemitismus und der Hass gegen die Großstädte im völkischen Denken miteinander verbunden sind. Sie untersucht, welche Charakteristika in der Wahrnehmung des völkischen Antisemitismus die Juden als ,großstädtisch“ und die modernen Großstädte als ,jüdisch“ prädestinieren. Hierfür werden völkische Schriften aus der Zeit zwischen dem beginnenden 20. Jahrhundert und dem Ausbruch des Zweiten Weltkrieges analysiert. Das zweite Erkenntnisinteresse der Studie besteht darin, einen substantiellen Beitrag zu einer sozialwissenschaftlichen Theorie der Großstadtfeindschaft zu leisten. In der Forschung mangelt es bisher an Versuchen, das Phänomen der Feindschaft gegenüber den modernen Großstädten zu definieren und theoretische Ansätze zu seiner Erklärung und Einordnung zu entwickeln. Im Mittelpunkt der Auseinandersetzung mit dem Phänomen der Großstadtfeindschaft wird dabei die Frage stehen, wie sich das großstadtfeindliche Lager im Allgemeinen und die völkische Großstadtfeindschaft im Besonderen zur modernen Industriegesellschaft positioniert haben und inwieweit eine Ablehnung der Großstadtentwicklung mit der Akzeptanz bzw. der Ablehnung anderer Aspekte der Modernisierung verbunden ist. Es geht dabei also um die Klärung der Frage, in welchem Verhältnis die modernen und antimodernen Elemente der Großstadtfeindschaft zueinander stehen. Daran schließt sich die Frage an, welche alternative Moderne die völkischen Großstadtfeinde zu verwirklichen suchen und welche Bedeutung den Städten als politische, ökonomische und kulturelle Zentren und Knotenpunkte für die Verwirklichung einer alternativen Moderne beigemessen wird. 
Die Studie versteht sich damit als Beitrag zur Erforschung der Haltung des völkischen Antisemitismus zur Moderne, die diese Diskussion um den Aspekt der antisemitischen Großstadtwahrnehmung erweitern möchte. Zugleich verortet sich diese Studie in der Stadtforschung und versteht sich im Besonderen als ein Beitrag zu deren Geschichtsschreibung. Bevor sich im 20. Jahrhundert mit der Stadtsoziologie eine akademische und empirische (Sub-)Disziplin herausbildete, die sich darum bemühte, einen ausgewogenen und differenzierten Blick auf die modernen Großstädte zu entwickeln, hatten negative Sichtweisen die theoretischen Reflexionen und empirischen Untersuchungen zu den Großstädten und den Entwicklungen in den Städten im späten 18. und im 19. Jahrhundert dominiert. Die Stadtforschung nahm ihren Anfang in Studien und Beobachtungen, die mit der Intention erstellt wurden, einen negativen Einfluss des modernen Stadtlebens auf die Bevölkerung und den Nationalstaat nachzuweisen. Die wichtigsten Verstädterungstheorien, die Ende des 19. Jahrhunderts in Deutschland formuliert wurden, stammen von Autoren, die in der Entwicklung der modernen Großstädte ein grundlegendes Problem sahen (vgl. Hansen 1889; Ammon 1895). Einige der in diesen Untersuchungen aufgestellten Thesen wurden zum Teil bis in die zweite Hälfte des 20. Jahrhunderts in Schriften zur Stadtforschung und Stadtplanung positiv rezipiert (vgl. Bahrdt 1998: 57-59). Eine Auseinandersetzung mit der historischen Entwicklung der Großstadtfeindschaft schließt daher eine Beschäftigung mit den historischen Ursprüngen der Stadtforschung notwendigerweise mit ein.

\subsection{Forschungsstand}

Der Forschungsstand zum Antisemitismus und zur Großstadtfeindschaft stellt sich sehr disparat dar: Während Literatur zum modernen Antisemitismus inzwischen ganze Teilbibliotheken füllt, ist die Anzahl an Studien zur Großstadtfeindschaft sehr begrenzt. Ähnlich wie in der Antisemitismusforschung dominieren empirische Arbeiten aus der Geschichtswissenschaft das Forschungsfeld zur Großstadtfeindschaft. In der deutschsprachigen Sozialwissenschaft hat das Thema bisher so gut wie keine Resonanz hervorgerufen. Eine Ausnahme stellt die kritische Beschäftigung mit der Großstadtfeindschaft durch Vertreter der Stadtsoziologie dar, die jedoch nicht über einleitende Erläuterungen hinausgeht (vgl. Bahrdt 1998: 57-80; Häußermann/Siebel 2004: 19-28). Eine Ursache für das Desinteresse der Sozialwissenschaften könnte in der von Louis Wirth bereits 1938 aufgestellten und viel diskutierten These einer weitgehenden Nivellierung der Stadt-Land- 
Gegensätze liegen (vgl. Wirth 1938). Ihm zufolge stellen die modernen Großstädte der Industriegesellschaft keine distinkten sozialen Orte dar, da sich der ,urbanism as a way of life“ weit über die Grenzen der Großstadt hinaus ausgebreitet habe. Mit Wirth ließe sich argumentieren, dass die gesamtgesellschaftliche Ausformung urbaner Lebensstile es mit sich bringt, dass negative Einstellungen gegenüber den modernen Großstädten keinen relevanten Untersuchungsgegenstand mehr abgeben. Exemplarisch hierzu heißt es im Oxford Dictionary of Sociology unter dem Stichwort „Anti-Urbanism“:

Contemporary sociology largely rejects anti-urbanism. It is now generally recognized that the growth of cities, and the varied forms of social association occurring within them, are both consequences of the emergence of modern industrial societies. (o. A. 2009: 25)

Dieser Einwand lässt sich im Hinblick auf die Geschichte der Großstadtfeindschaft in Deutschland entkräften: Großstadtfeindliches Denken radikalisierte sich gegen Ende der 1920er Jahre, als die Hochphase der Verstädterung (ca. 1870-1925) bereits abgeschlossen war. Wie noch nachzuweisen sein wird, wirkt die Tradition der Großstadtfeindschaft bis in die Gegenwart nach. Die Auffassung, die Großstadtfeindschaft sei ein Phänomen der Übergangszeit von der Agrar- zur Industriegesellschaft, lässt sich insofern empirisch widerlegen. Auch in theoretischer Hinsicht muss dem Argument seine Plausibilität abgesprochen werden: Als eine sozial konstruierte Interpretation der Welt und der eigenen und kollektiven Identität ist die Großstadtfeindschaft auf die soziale Wirklichkeit nicht angewiesen und bedient sich dieser nach ihrer eigenen Logik. Dennoch dürfte die in dem Zitat sich ausdrückende Sichtweise dazu beigetragen haben, dass die sozialwissenschaftliche Forschung zur Großstadtfeindschaft an ihrem Anfang steht und es bisher an Definitionen und theoretischen Ansätzen mangelt.

Eine erste größere sozialwissenschaftliche Veröffentlichung zu dem Thema stellt der von dem amerikanischen Soziologen Michael J. Thompson im Jahr 2009 herausgegebene Sammelband Fleeing the City. Studies in the Culture and Politics of Antiurbanism dar. Neben historischen und gegenwartsspezifischen Einzelfallstudien zur Stadtfeindschaft in verschiedenen Ländern enthält der Sammelband auch zwei Aufsätze, die sich dem Phänomen aus einer theoretischen Perspektive annähern (vgl. Thompson 2009a; Clapp 2009). Wie noch zu zeigen sein wird, liefert der Aufsatz des Herausgebers, der die Ursache für die Großstadtfeindschaft in einer ländlichen Sozialisation sieht, keine Erkenntnisse, die für die Entwicklung einer Theorie der Großstadtfeindschaft hilfreich sind. Es ist zudem bemerkenswert, dass in keinem der zehn Beiträge des Sammelbandes der Antisemitismus erwähnt wird; auch nicht in dem Beitrag, der 
sich mit dem Zusammenhang von Großstadtfeindschaft und Homophobie/alternative Geschlechterrollen in der Weimarer Republik beschäftigt (vgl. Mancini 2009).

Einen gegenwartsbezogenen und globalen Ausblick auf die Verbreitung und Virulenz der Großstadtfeindschaft geben Ian Buruma und Avishai Margalit in ihrem Buch Occidentalism. The West in the Eyes of its Enemies (vgl. 2004: 13-47). Großstadtfeindschaft begreifen sie als zentralen Bestandteil einer antiwestlichen Ideologie, die sie als Okkzidentalismus bezeichnen. Den Ursprung dieser Ideologie sehen die Autoren in dem Denken westlicher Autoren, die dann von Teilen der nichtwestlichen Welt übernommen wurde. Ihr Kapitel über die Großstadtfeindschaft enthält wichtige Erkenntnisse für diese Studie. So heben die Autoren hervor, dass die Verbindung der Großstädte und Metropolen mit dem Westen im Allgemeinen und Juden und Amerika im Besonderen über die Assoziation der Großstädte mit Geld/Handel, Individualismus und der sexuellen Selbstbestimmung der Frau geschieht. Zudem weisen sie auf eine Erkenntnis hin, die von mehreren Forscher und Forscherinnen geteilt wird: Stadtfeinde hassen und bewundern die Städte zugleich (vgl. auch Rose 1948; Beauregard 2009; Kahmann 2015).

Der empirisch am besten untersuchte Gegenstand ist die historische Entwicklung der Großstadtfeindschaft in Deutschland bis $1945 .^{2}$ Auf diesem Gebiet prägen die Arbeiten der Historiker Klaus Bergmann, Andrew Lees und Ulrich Linse die Forschung. Bergmann hat mit seiner 1970 erschienenen Dissertation Agrarromantik und Großstadtfeindschaft das deutschsprachige Standardwerk zu dem Thema vorgelegt, das für diese Studie unabdingbare Erkenntnisse und Hinweise enthält. Bergmann rekonstruiert die Entwicklung der Großstadtfeindschaft von den Schriften Wilhelm Heinrich Riehls in den 1850er Jahren bis zum Ende der NS-Herrschaft und des Zweiten Weltkrieges. Die Verbindungen zum Antisemitismus hebt Riehl schwerpunktmäßig in den Kapiteln zu der von dem völkischen Ideologen Bruno Tanzmann gegründeten Bauernhochschulbewegung, der von ihm mit initiierten Artamanenbewegung und dem Verhältnis des Nationalsozialismus zur Großstadt hervor. Er arbeitet sie jedoch nicht systematisch heraus.

Andrew Lees untersucht in seiner ersten Studie aus dem Jahr 1985 in einem vergleichenden Ansatz die Großstadtwahrnehmung in den USA, Großbritannien, Frankreich und Deutschland

\footnotetext{
${ }^{2}$ Es existieren Aufsätze zu unterschiedlichen Epochen und Akteuren der Großstadtfeindschaft in Deutschland. So beschäftigen sich die Aufsätze von Jeffrey Herf (1993) und Bernhard Dietz (2008) mit der Großstadtrezeption der Anhänger der Konservativen Revolution in der Weimarer Republik. Bernhard Marchand (1999) und Manfred Walz (1980) analysieren das Verhältnis von Großstadtfeindschaft und NS-Ideologie. Rolf Peter Sieferle und Peter Zimmermann untersuchen den Topos der „Stadt als Rassengrab“ in großstadtfeindlichen Texten des 19. und 20. Jahrhunderts (vgl. 1992).
} 
in der Zeit zwischen 1820 und 1940 (vgl. Lees 1985). Er arbeitet dabei die in allen Ländern dominanten Diskurse zu den Großstädten heraus, zu denen er die Debatten über Armut, einen angenommenen physischen und demographischen Zerfall und die Kulturkritik zählt. Im Unterschied zu Bergmann umschließen seine Untersuchungen neben ablehnenden und negativen Haltungen zur Großstadtentwicklung auch Reaktionen, die sich mehrheitlich positiv auf die modernen Großstädte und ihre politische, soziale und ökonomische Bedeutung beziehen (vgl. Lees 1985: 189-255; 2002). Dem Zusammenhang zwischen Antisemitismus und Großstadtfeindschaft schenkt Lees deutlich weniger Beachtung als Bergmann. Er wird in seinen Untersuchungen nur peripher thematisiert.

Ulrich Linse richtet den Fokus seiner Forschung hingegen auf die Geschichte großstadtfeindlicher Praktiken in Bewegungen, die eine ablehnende oder ambivalente Haltung zur Moderne einnahmen, wie die Lebensreform- und Jugendbewegung. In diversen Aufsätzen und in der Quellensammlung Zurück o Mensch zur Mutter Erde beschäftigt er sich mit der Geschichte der Landkommunen in Deutschland (vgl. Linse 1983, 1982/1983, 1993, 1996, 2014). Allen drei Autoren kommt das Verdienst zu, das Material erschlossen und strukturiert zu haben, das den großstadtfeindlichen Diskurs in Deutschland maßgeblich geprägt und dominiert hat. Ohne diese materialreichen Vorarbeiten wäre die vorliegende Studie nicht zu verwirklichen gewesen.

Einen größeren Raum für die Analyse des Zusammenhangs von Antisemitismus und Großstadtfeindschaft gewährt der Kulturhistoriker Joachim Schlör in seiner Habilitationsschrift Das Ich der Stadt. Debatten über Judentum und Urbanität, 1822-1938 (vgl. Schlör 2005). In seiner Studie begreift Schlör die von Antisemiten geführte Debatte über eine besondere Beziehung der Juden zum modernen Großstadtleben als ein dominantes, jedoch nicht als das einzige Narrativ, das von den Juden als Großstadtbewohner par excellence handelt. In einem eigenen Kapitel rekonstruiert er dieses antisemitische Narrativ unter der Heranziehung sehr unterschiedlicher Autoren. Erwähnung finden dabei auch Aussagen von völkischen und nationalsozialistischen Ideologen wie beispielweise Alfred Rosenberg oder Hans F.K. Günther. Schlör liefert - wie bereits zuvor in einem Aufsatz zu diesem Thema (vgl. Schlör 1995) - wichtige Erkenntnisse über Motive, Wirkungsweise und Verbreitung des antisemitischen Bildes der Juden als Großstädter. Eine systematisch angelegte Untersuchung des Zusammenhanges zwischen Antisemitismus und Großstadtfeindschaft stellt die Studie nicht dar - was sie auch nicht beansprucht zu sein. 
Die Forschung zur völkischen Bewegung hat sich bisher noch nicht eingehend mit der Großstadtwahrnehmung im völkischen Denken beschäftigt. Die Existenz eines Zusammenhanges zwischen völkischer Ideologie und Großstadtfeindschaft wurde im Laufe der Zeit von verschiedenen Forschern im Kontext einer Analyse völkischen Denkens thematisiert. Studien aus den 1960er Jahren führen die Großstadtfeindschaft und die Agrarromantik der Völkischen als Belege für den Antimodernismus der Bewegung an. Prominent wurde diese These in der Arbeit von George L. Mosse mit dem Titel The Crisis of German Ideology und in Fritz Sterns Studie The Politics of Cultural Despair vertreten (vgl. Mosse 1964; Stern 1961). Neuere Forschungen gehen von einer differenzierteren Haltung der völkischen Bewegung gegenüber der modernen Industriegesellschaft aus. Diese Studie kommt zu einem ähnlichen Schluss. Gleichwohl kommen auch neuere Untersuchungen zu dem Ergebnis, dass eine negative Haltung gegenüber den modernen Großstädten und der Verstädterung einen inhaltlichen Schwerpunkt des völkischen Schrifttums ausmachten (vgl. Tourlamain 2014: 34-40). So beschäftigt sich der Historiker Uwe Puschner in seiner Habilitationsschrift zur völkischen Bewegung im Kaiserreich mit den in der Bewegung dominanten Topoi der Großstadt als eines „Rassengrabs“ und als eines Ortes „,negativer Selektion“ (vgl. Puschner 2001: 115-119).

Wie bereits erwähnt, ist es in der Antisemitismusforschung unumstritten, dass ein Zusammenhang zwischen dem modernen Antisemitismus und der Ablehnung der modernen Großstädte besteht. In der Forschung existiert mittlerweile eine überschaubare Anzahl von Aufsätzen, die sich diesem Aspekt widmen. Zu erwähnen ist in diesem Zusammenhang neben dem bereits aufgeführten Aufsatz von Joachim Schlör der theoretische Essay des amerikanischen Soziologen Arnold M. Rose, der 1948 unter dem Titel Antisemitisms Root in City-Hatred erschienen ist. Hierbei handelt es sich um einen zentralen theoretischen Referenztext der vorliegenden Studie, auf dessen Überlegungen immer wieder zurückgegriffen wird. Einleitende Überlegungen zu Antisemitismus und Großstadtfeindschaft enthält der Aufsatz des Historikers Hillel J. Kieval, der für diese Untersuchung wichtig ist, da er einer korrespondenztheoretischen Sichtweise jeden Anspruch auf Plausibilität abspricht (vgl. Kieval 1999). Zwei weitere Beiträge zu dem Thema stammen von mir (vgl. Kahmann 2011, 2015). Während der erste Aufsatz grundlegende Gedanken über das Verhältnis von Antisemitismus und Großstadtfeindschaft enthält, basiert der zweite auf den empirischen Forschungen, die auch der vorliegenden Studie zugrunde liegen. Er präsentiert somit erste Erkenntnisse, die während der Untersuchung gewonnen wurden. Ich beschäftigte mich überdies mit dem Zusammenhang von Antisemitismus und Großstadtfeindschaft in meiner 
2012 am Institut für Politikwissenschaft an der Johannes Gutenberg-Universität Mainz eingereichten Magisterarbeit mit dem Titel: Antisemitismus und Großstadtfeindschaft. Über die Verknüpfung antisemitischer und antiurbaner Ideologeme in nationalsozialistischen Schriften.

Zusammenfassend lässt sich über den Stand der Forschung zur Großstadtfeindschaft sagen, dass kein ausdifferenziertes Forschungsfeld existiert und Theorie- und Definitionsangebote beinahe vollständig fehlen. Zudem existiert keine Studie, die sich schwerpunktmäßig mit dem Zusammenhang zwischen Antisemitismus und Großstadtfeindschaft beschäftigt.

\subsection{Aufbau der Arbeit}

Im ersten Kapitel wird ein theoretischer Zugang $\mathrm{zu}$ dem Zusammenhang zwischen Antisemitismus und Großstadtfeindschaft aus der Perspektive der Antisemitismusforschung entworfen. Hierfür werden ausgewählte theoretische Schriften diskutiert und einerseits in Beziehung zu empirischen Studien gesetzt, die eine entsprechende Verbindung eruiert haben, und andererseits mit eigenem empirischen Material in Beziehung gesetzt. Die Auswahl der Theorien ist daher an der Frage orientiert, welche Erkenntnisse sie für eine Erforschung des Zusammenhanges zwischen Antisemitismus und Großstadtfeindschaft liefern können. Es wird bewusst darauf verzichtet, die verschiedenen Theoriestränge, zwischen denen in der Antisemitismusforschung unterschieden wird, in den Mittelpunkt der Analyse zu stellen. Es scheint mir zielführender zu sein, ausgewählte theoretische Schriften gezielt nach ihrem heuristischen Erkenntniswert für das Thema der vorliegenden Studie zu untersuchen. Damit ist auch der Anspruch verbunden, größere Redundanzen gegenüber anderen Studien in der Antisemitismusforschung zu vermeiden. Gleichwohl bleiben die bisherigen Ansätze einer Systematisierung der Theorieangebote in der Antisemitismusforschung nicht unreflektiert. Kapitel 2 gibt sowohl einen kompakten Überblick über die historische Genese des modernen Antisemitismus als auch über die Entwicklung der wissenschaftlichen und theoretischen Auseinandersetzung mit dem modernen Antisemitismus.

Das zweite Kapitel beschäftigt sich mit der Großstadtfeindschaft als einem sozialen Phänomen sui generis. In Ermangelung von Theorien und Definitionen ist es für das Erkenntnisinteresse dieser Studie unabdingbar, die historische Genese und die zentralen Werke der Großstadtfeindschaft zu analysieren. Die Darstellung der Entwicklung der 
Großstadtfeindschaft konzentriert sich auf die wichtigsten Entwicklungslinien und die zentralen Bewegungen und Akteure der großstadtfeindlichen Bewegung. Der Bogen wird dabei von den Anfängen einer statistischen Beschäftigung mit negativen Umwelteinflüssen des Stadtlebens in der Mitte des 18. Jahrhunderts bis hin zu Manifestationen großstadtfeindlichen Denkens in der Gegenwart gespannt. Eine kompakte Darstellung bringt es mit sich, dass bestimmte Aspekte nur kursorisch angeschnitten werden können. Künstlerische Formen der Großstadtfeindschaft in Literatur, Dichtung, Film und den bildendenden Künsten wurden in die Analyse nicht mit aufgenommen. ${ }^{3}$ Die Darstellung der historischen Genese stützt sich primär auf die Sekundärliteratur, wird jedoch besonders in den Unterkapiteln zur völkischen Bewegung und zum Nationalsozialismus um eigenes empirisches Material ergänzt. Das 5. Kapitel beschäftigt sich mit den zentralen Schlüsselwerken der Großstadtfeindschaft in Deutschland. Die Forschung ist sich darin einig, dass die Schriften von Wilhelm Heinrich Riehl, Georg Hansen, Otto Ammon und Oswald Spengler die Entwicklung und Radikalisierung der Großstadtfeindschaft maßgeblich beeinflusst haben. Auf Grundlage der Analyse der historischen Genese und der zentralen Texte wird in Kapitel 6 ein Beitrag zu einer Theorie der Großstadtfeindschaft verfasst. Hierfür werden die existierenden theoretischen Überlegungen und Ansätze zur Großstadtfeindschaft zusammengeführt und danach befragt, welchen Erkenntnisgewinn sie liefern.

In Kapitel 7 werden zunächst die methodologischen Grundlagen der Studie und das Verständnis der qualitativen Inhaltsanalyse dargestellt. Im darauffolgenden Unterkapitel wird die Auswahl des empirischen Materials begründet und dieses in seinem historischen Kontext analysiert. Im letzten Unterkapitel wird das Kategoriensystem, das der empirischen Analyse zugrunde liegt, vorgestellt und erläutert. Im Kapitel 8 werden schließlich die empirischen Ergebnisse dargestellt und diskutiert. Dabei steht jedes der drei Unterkapitel für ein dominantes Argumentationsmuster, das im Material identifiziert wurde: Personifizierung der Verstädterung in den Juden; Unterschiedliche Anpassungsfähigkeit von Juden und Deutschen an die Großstadt; Sexualität, Judentum und Großstadt. Jedes der drei Unterkapitel des empirischen Kapitels wird durch eine kurze Zusammenfassung abgeschlossen. Am Ende des empirischen Kapitels erfolgt eine Gesamtzusammenfassung der dargestellten und diskutierten Topoi der völkischen Diskussion um Judentum und Großstadt. Abgeschlossen wird die Studie durch ein Fazit und den Ausblick auf Forschungsdesiderate und Fragen, die sich durch die Studie ergeben.

\footnotetext{
${ }^{3}$ Einen guten Überblick über Romane mit völkischem Inhalt aus der Zeit 1871 und 1945 liefert die Studie des Literaturwissenschaftlers Jost Hermand (vgl. 1988).
} 
2. Geschichte und Theorie(n) des modernen Antisemitismus

Der moderne Antisemitismus, der sich im letzten Drittel des 19. Jahrhunderts in Deutschland entwickelte, sowie die Versuche seiner theoretischen Durchdringung haben ihren Ursprung in der Emanzipationsepoche des deutschen Judentums, die um 1780 begann und mit der Gründung des Deutschen Reiches 1871 ihren Abschluss fand. In dieser fast hundertjährigen Entwicklung fand ein Formwandel der traditionellen, religiös-christlichen Judenfeindschaft hin zum säkularisierten Antisemitismus der bürgerlich-kapitalistischen Gesellschaft statt, so dass sich diese Epoche als die Frühphase des (modernen) Antisemitismus begreifen lässt. Dieser Formwechsel der in der europäischen Kultur tradierten Judenfeindschaft, die ihren Ursprung in Abgrenzungsversuchen des Christentums gegenüber dem Judentum in der Antike hat, hing maßgeblich mit zwei Entwicklungen zusammen: zum einen mit den in der Mitte des 18. Jahrhunderts einsetzenden sozialen und politischen Transformationsprozessen in deren Folge die feudale Ständegesellschaft durch den modernen Nationalstaat und eine vom Bürgertum getragene kapitalistische Ökonomie ersetzt wurde. Die Durchsetzung der bürgerlichen Gesellschaft verband sich dabei mit einem Wandel von unmittelbaren, persönlichen in vermittelte, versachlichte Herrschaftsverhältnisse einer kapitalistischen Tauschgesellschaft. Der moderne Antisemitismus ist ein Produkt dieses gesellschaftlichen und historischen Transformationsprozesses, so dass die Modernität und der Charakter des Antisemitismus unerkannt bleiben, sollte diese Entwicklung nicht reflektiert werden (vgl. Claussen 2005: 53).

Begleitet wurde dieser Prozess andererseits von einer sich schrittweise vollziehenden Integration der jüdischen Bevölkerung in die bürgerliche Gesellschaft. Im Unterschied zu Frankreich ging in den deutschen Teilstaaten die rechtliche Gleichstellung der Juden nicht aus einer bürgerlichen Revolution hervor, sondern wurde vom absolutistischen Staat und seinem aufgeklärten Beamtentum „gewährt“. Die zunehmende Aufhebung rechtlicher Beschränkungen ermöglichte der jüdischen Bevölkerung im 19. Jahrhundert einen sozialen Aufstieg und veränderte ihren sozialen Status von Grund auf. Lebte die Mehrheit der Juden und Jüdinnen zu Beginn der Emanzipationsepoche am Ende des 18. Jahrhunderts in Armut, war um 1870 eine jüdische Unterschicht in Deutschland kaum noch existent (vgl. Berding 1988: 38). Die zeitliche Koinzidenz des sozialen Aufstiegs der jüdischen Bevölkerung in Berufe, die für die bürgerliche Gesellschaft von zentraler Bedeutung sind einerseits und die Durchsetzung der industriellen Massengesellschaft andererseits erweckten bei weiten Teilen 
der nichtjüdischen Bevölkerung den Anschein, dass die Juden vom Modernisierungsprozess profitieren würden (vgl. Claussen 2005: 55). Da sich die Berufsstruktur der deutschen Juden im 19. Jahrhundert von der Mehrheit der Deutschen nach wie vor deutlich unterschied, führte die Eingliederung der jüdischen Bevölkerung in die kapitalistische Konkurrenzgesellschaft dazu, dass sie als Repräsentanten der sich ausformenden modernen Gesellschaft erschienen (vgl. Rürup 1987: 104-105).

Die heutige Forschung ist sich darin einig, dass in der sozialen Stellung der Juden nicht die Ursache für die Entstehung des modernen Antisemitismus gesehen werden kann; die wahrnehmbare Überrepräsentanz der jüdischen Bevölkerung in den freien bürgerlichen Berufen und im Handel war jedoch eine Voraussetzung dafür, dass der Hass, der Neid und die Projektionen der Antisemiten und Antisemitinnen die Juden und keine andere Bevölkerungsgruppe trafen und dass schließlich sie zur Personifikationen der modernen Gesellschaft erklärt wurden. Die in der ersten Hälfte des 19. Jahrhunderts auftretenden antijüdischen Reaktionen auf die gesellschaftliche Integration der Juden unterschieden sich vom modernen Antisemitismus darin, dass sie noch nicht mit einem allumfassenden Weltbild zusammenhingen. Sie bezogen sich in erster Linie auf die soziale Stellung der Juden und forderten eine Rücknahme bisher erlassener Gesetze zur rechtlichen Gleichstellung oder sprachen sich gegen eine vollständige Rechtsgleichheit der jüdischen Minderheit aus.

Zugleich bemühte sich die antijüdische Publizistik des 19. Jahrhunderts, religiöse Begründungszusammenhänge in den Hintergrund treten zu lassen und den Ausschluss der Juden mit nationalistischen und aus dem Volkstumsgedanken abgeleiteten Argumenten zu begründen. Die Tradition der christlichen Judenfeindschaft wurde dabei nicht abgelegt, vielmehr wurde ,an Befangenheiten und Animositäten des alten religiösen Gegensatzes“ angeknüpft (Greive 1983: 84). Die nationalen, völkischen und die gegen Ende des 19. Jahrhunderts auftretenden rassenbiologischen Begründungszusammenhänge der sich modernisierenden Judenfeindschaft lösten die religiösen und wirtschaftlichen Stereotype nicht ab, sondern überlagerten diese (vgl. Berding 1988: 8).

Am Ende des Prozesses der rechtlichen Gleichstellung der jüdischen Bevölkerung in Deutschland hatte sich das antisemitische Judenbild grundlegend gewandelt. In den vorangegangenen hundert Jahren säkularisierte sich die Judenfeindschaft nicht nur, sie löste sich auch zunehmend von dem Handeln und dem Dasein der im Deutschen Reich lebenden Juden ab und entwarf ein antisemitisches Judenbild, das ein genuines geistiges Produkt der Antisemiten war. Dieser Prozess markiert in der historiographischen 
Antisemitismusforschung den Übergang zum modernen Antisemitismus. Die Forschung ist sich darin einig, dass der moderne Antisemitismus ein postemanzipatorisches Phänomen ist, das den Charakter eines Weltbildes bzw. einer Welterklärung hat. Der Antisemitismus des Industriezeitalters ist, wie es Reinhard Rürup treffend formuliert hat, mehr als nur ein antijüdisches Programm oder eine antijüdische Bewegung, die sich gegen die Emanzipation der Juden richtet. Er muss vielmehr als ein „Erklärungsmodell für die nicht verstandenen Entwicklungstendenzen der bürgerlichen Gesellschaft“ begriffen werden, das „Lösungsmöglichkeiten für die wirtschaftliche, politische und kulturelle Krise der Gegenwart“ offeriert (Rürup 1987: 115). In diesem Sinne stellt der moderne Antisemitismus das Zerrbild einer Gesellschaftstheorie dar (Rürup 1987: 115).

Mit dem Anspruch des modernen Antisemitismus, die moderne Gesellschaft umfassend deuten und erklären zu können, ist ein grundlegender Wandel in der Beziehung von antisemitischem Subjekt und jüdischem Objekt verbunden: Das Handeln und die soziale Stellung der Juden haben für die Entstehung, Verbreitung und Wirkung des Antisemitismus nach 1870 keine Bedeutung mehr. Er gewinnt seine Dynamik aus dem psychologischen Drang der Antisemiten, die Krisenhaftigkeit und Ambivalenz moderner Vergesellschaftung von dem konstruierten Ideal einer homogenen Gemeinschaft abzuspalten und in einem ,jüdischen Prinzip“ zu verdinglichen.

Hinter unterschiedlichen und gegensätzlichen Erscheinungen der Moderne wird das Wirken „jüdischer Mächte“ vermutet. Der moderne Antisemitismus konstituiert sich als ein soziales Phänomen sui generis - trotz seines christlichen Erbens, das ihm inhärent ist - darüber, dass er im Gegensatz zur vorbürgerlichen Judenfeindschaft von der Existenz der jüdischen Bevölkerung abstrahiert. Detlev Claussen ist daher in seinem Befund zuzustimmen, dass die traditionelle Judenfeindschaft konkret, der moderne Antisemitismus abstrakt ist (vgl. Claussen 1988: 12). Dies bedeutet zugleich nicht, dass wahnhafte Vorstellungen von einer ,jüdischen Allmacht“ erst im letzten Drittel des 19. Jahrhunderts entstanden sind. Helmut Berding (1988: 18) betont, dass die „ins Mythenhafte gesteigerte Wahnidee vom verschwörerischen Machtstreben“ der Juden sich bereits im 17. Jahrhundert herausgebildet hat. Unstrittig ist zudem, dass zentrale Stereotype der Judenfeindschaft unter dem Vorzeichen kapitalistischer Vergesellschaftung aktualisiert und reformuliert wurden. Eine kohärente Ideologie im Sinne einer ablehnenden Reaktion und Deutung bestimmter Modi gesellschaftlicher Strukturentwicklungen stellen ältere Formen der Judenfeindschaft jedoch nicht dar. 
Der weltanschauliche Charakter des modernen Antisemitismus war im Besonderen unter den radikalen Antisemiten der wilhelminischen Gesellschaft stark ausgeprägt, an deren Spitze im letzten Jahrzehnt des 19. Jahrhunderts die völkische Bewegung trat (vgl. Massing 1959: 80). Jedoch wies auch der „gemäßigte“ Antisemitismus der Konservativen die Tendenz für eine allumfassende Welterklärung auf (vgl. Rürup 1987: 115). Im Unterschied zu der Frühphase des Antisemitismus, in der es keine politischen Gruppierungen gab, die sich unter der Maßgabe einer antisemitischen Programmatik bildeten, wurde der Antisemitismus im Kaiserreich zu einem politischen Faktor (vgl. Berding 1988: 43-44). Ihren stärksten Ausdruck fand diese Entwicklung in der Gründung von antisemitischen Parteien, politischen Splittergruppen und beruflichen Interessenvertretungen seit Ende der 1870er Jahre (vgl. Bergmann 1996: 450-453).

Um dem weltanschaulichen Charakter des modernen Antisemitismus in der Analyse gerecht zu werden, darf die Forschung nicht bei der deskriptiven Beschreibung des breiten Ensembles widersprüchlicher Vorurteile stehen bleiben (vgl. Rensmann 2004: 72). Dem trägt Thomas Haury Rechnung, indem er betont, dass der moderne Antisemitismus nach bestimmten Denkprinzipien aufgebaut ist und durch sie ein strukturiertes Bild von der Welt entwirft. Das antisemitische Weltbild ist ihm zufolge durch drei Grundstrukturen geprägt (vgl. Haury 2002: 105-114): zum ersten durch die Personifizierung nicht verstandener und daher abgelehnter Prozesse und Strukturen der Moderne in den Juden. Vielfältige Erscheinungen in Politik, Ökonomie und Kultur werden auf das verschwörerische und sinistre Handeln ,jüdischer Strippenzieher“" zurückgeführt. Der Wahn von einer jüdischen Verschwörung wird von den antisemitischen Subjekten dabei stets im Weltmaßstab gedacht, so dass Juden und Jüdinnen als eine universale, globale und abstrakte Macht erscheinen, die hinter sozialen und politischen Transformations- und Modernisierungsprozessen stünden.

Das zweite Element, durch das der moderne Antisemitismus charakterisiert ist, ist ein Manichäismus. Die Welt wird von Antisemiten und Antisemitinnen strikt binär codiert, wobei alles Böse und Verächtliche als ,jüdisch“ imaginiert, alles Gute und Schöne hingegen mit der eigenen Wir-Gruppe identifiziert wird. Da das Judentum das Böse schlechthin verkörpert, ist der Antisemitismus mit Erlösungsphantasien verbunden, so dass ihm seit seiner Entstehung eine Vernichtungsperspektive inhärent ist.

Das dritte Denkprinzip betrifft die Imagination der Juden als eine Antithese zu einer ersehnten, unter den Bedingungen moderner Vergesellschaftung aber nicht zu verwirklichenden nationalen Gemeinschaftsbildung. Juden und Jüdinnen gelten im modernen 
Antisemitismus nicht als Angehörige einer beliebig anderen Nation, zu der sie eigene freundschaftliche oder feindliche Beziehungen unterhält, sondern als der Feind aller Nationen. Sie erscheinen als eine existenzielle Gefahr für die Existenz einer imaginierten homogenen Gemeinschaft und verkörpern für die Antisemiten das Nicht-Identische (vgl. auch Holz 2010).

Der gewandelte Charakter des modernen Antisemitismus rief in jüdischen, aber auch in einigen nichtjüdischen Kreisen eine Gegenreaktion hervor, die auf die Zurückdrängung des Antisemitismus abzielte. Zu nennen wären hier zum einen die Abwehrvereine, die auf vielfältige Weise versuchten, dem Antisemitismus in der deutschen Gesellschaft entgegenzuwirken. $\mathrm{Zu}$ den bedeutendsten Vereinen des Abwehrkampfes gegen den Antisemitismus zählt der 1893 gegründete Centralverein deutscher Staatsbürger jüdischen Glaubens (CV) und der 1890 ins Leben gerufene Verein zur Abwehr des Antisemitismus. Dabei setzten sich ihre Protagnisten auch dezidiert mit den Argumenten der antisemitischen Gegenseite auseinander, so dass davon gesprochen werden kann, dass diese vor- und außerwissenschaftliche Beschäftigung mit dem Antisemitismus die spätere Theorieentwicklung in der Antisemitismusforschung beeinflusst hat (vgl. Botsch/Kopke 2012: 312; Wyrwa 2010: 31; Holz 2010a: 317). Im letzten Drittel des 19. Jahrhunderts setzten sich zudem sozialdemokratische und sozialistische Autoren mit den gesellschaftlichen Ursachen, den sozialen Trägergruppen und der politischen Funktion des modernen Antisemitismus auseinander und legten hierdurch die Grundlagen für eine sozialwissenschaftlich informierte Antisemitismusforschung (vgl. Rürup 2004: 118).

Wie eingangs bereits erwähnt, lassen sich die Anfänge des Versuches einer theoretischen Durchdringung der modernen Judenfeindschaft bereits hundert Jahre zuvor, zu Beginn der Debatte über die Emanzipation der deutschen Juden, verorten. Die Befürworter einer rechtlichen Gleichstellung der jüdischen Bevölkerung begründeten ihre Position damit, dass die negativen Eigenschaften, die den Juden zugeschrieben werden, zwar zutreffend sein, jedoch nicht mit dem Wesen der Juden begründet werden könnten, sondern das Produkt einer Diskriminierung der Juden durch ihre nichtjüdische Umwelt seien. Wenngleich hiermit, wie Jan Weyand hervorhebt, eine Theorie der christlichen Judenfeindschaft formuliert wurde, enthält diese Begründung eine zentrale Grundannahme moderner Theorien über den Antisemitismus: „Antisemitismus ist nicht aus dem Handeln der Juden, sondern aus dem der Judenfeinde zu erklären“ (Weyand 2015: 65).

Die Antisemitismusforschung steht indes erst am Beginn einer tiefergehenden Auseinandersetzung mit Theorien und Erklärungsansätzen, die vor der NS-Zeit bzw. vor dem 
Ende des Zweiten Weltkrieges entstanden sind. ${ }^{4}$ Untersuchungen zu der historischen Genese der Antisemitismusforschung waren und sind von der These geprägt, dass sich die wissenschaftliche Beschäftigung mit dem Antisemitismus durch die Erfahrung des Holocaust in quantitativer und qualitativer Hinsicht gewandelt hat (Rürup 1987b: 153; Holz 2010: 19 Bergmann 2004: 219, Fn 1). So unstrittig es ist, dass die nationalsozialistische Verfolgungsund Vernichtungspraxis und die draus resultierende Vernichtung des europäischen Judentums notwendigerweise eine Zäsur in der wissenschaftlichen Betrachtung der Judenfeindschaft markierten, stand diese These bisher auf tönernen Füßen und wurde nicht entlang einer empirischen Untersuchung des tatsächlichen Erkenntnispotentials der Frühschriften der Antisemitismusforschung entwickelt. Erste Untersuchungen zeigen hingegen, dass wichtige Erkenntnisse des gegenwärtigen Forschungstandes bereits im 18. und 19. Jahrhundert von zumeist jüdischen Autoren formuliert wurden (einen ersten Überblick geben Hahn/Kistenmacher 2015). Die ersten Theorien zum Antisemitismus, die in einen sozialwissenschaftlichen bzw. soziologischen Forschungszusammenhang gestellt wurden, entstanden in den 1920er Jahren, als es zu ersten Ansätzen einer Institutionalisierung der Soziologie an den deutschen Universitäten kam. ${ }^{5}$

Seit den Anfängen einer Auseinandersetzung mit dem Antisemitismus in den Sozialwissenschaften in den 1920er Jahren ist in der internationalen Forschung eine Fülle von theoretischen Ansätzen entstanden, die schwer überschaubar ist. In Forschungsarbeiten der

\footnotetext{
${ }^{4}$ Eine erste umfassende Studie zu Antisemitismus-Theorien aus der Zeit vor der NS-Herrschaft hat die Historikern Franziska Krah in ihrer Dissertation vorgelegt (vgl. Krah 2016).

${ }^{5}$ Hervorgehoben sei in diesem Zusammenhang der 1925 erschienene Text des Frankfurter Soziologieprofessors Franz Oppenheimer (1864-1943) Der Antisemitismus im Lichte der Soziologie. Der Text ist aus zweierlei Gründen einer näheren Betrachtung wert: Zum einen steht er paradigmatisch für die sozialwissenschaftlich informierte Auseinandersetzung mit dem Antisemitismus in der Weimarer Republik (vgl. Kahmann 2015a: 387392). Dies betrifft zum einen seine gruppen- und sozialpsychologische Argumentation sowie die Tatsache, dass der Text außerhalb des akademischen Feldes veröffentlich wurde. So wurde der Aufsatz nicht in einer Fachzeitschrift, sondern in der jüdischen Monatszeitschrift Der Morgen publiziert. Es ist für diese Studie zum anderen deshalb von Interesse, da er erste, jedoch unsystematisch gebliebene Überlegungen zum Zusammenhang zwischen Antisemitismus und Stadtfeindschaft enthält. Oppenheimer, der in dem Aufsatz eine positivistische und an der Naturwissenschaft orientierte Auffassung der Soziologie vertritt, begreift den Antisemitismus als einen Sonderfall des Phänomens der Gruppenfeindschaft, die sich gegen Juden richtet, da diese eine besonders fremde Minorität in den Gesellschaften bilden, in denen sie leben. Nach ihm entspricht es einem soziologischen Gesetz, dass die jüdische Bevölkerung aufgrund ihrer sozialen Stellung als Städter, Händler und zur Unterklasse herabgedrückte vormalige Obersicht die feudal-absolutistische Ordnung ablehnt. Ein anderes Gesetz besage ferner, dass der Agrar-Adel als herrschende Schicht die Kaufleute der Städte verachtet und dieser Hass sich in besonderer Schärfe gegen den jüdischen Städter, den jüdischen Kaufmann, den Mann des Tausches richtete (vgl. Oppenheimer 1925: 157-158). Wie noch zu zeigen sein wird, enthalten Oppenheimers Überlegungen, bis auf den angedeuteten Konnex zwischen Juden als Stadtbewohner und als Personifikationen des ökonomischen Tausches, keine Erklärungskraft für den Zusammenhang zwischen Antisemitismus und Großstadtfeindschaft. Oppenheimers Aufsatz blieb zudem ohne erkennbaren Einfluss auf spätere Theorien in der Antisemitismusforschung, was nicht zuletzt an seinem naturwissenschaftlichen Verständnis der Soziologie gelegen haben dürfte.
} 
letzten Jahre wurde dazu übergegangen, die verschiedenen Theorieangebote und Theoriestränge zu bündeln und eine kompakte Darstellung des Forschungstandes zu den Theorien der Antisemitismusforschung zu präsentieren. Ein Klassifikationsprinzip orientiert sich dabei an fachdisziplinären Grenzen und an einer historischen Schuldbildung.

So unterteilt Thomas Gräfe in seiner Darstellung des Forschungstandes die Theorien in die Kategorien: Marxismus, Psychoanalyse, sozialwissenschaftliche Vorurteilsforschung und Gruppensoziologie (vgl. Gräfe 2010). In der deutschsprachigen Antisemitismusforschung hat sich zuletzt ein anderes Kategorisierungssystem etabliert, in dessen Mittelpunkt stärker erkenntnistheoretische und methodologische Aspekte stehen. Diese Darstellungsform wurde von Klaus Holz in seiner 2001 erschienenen Habilitationsschrift Nationaler Antisemitismus in die Forschung eingeführt (vgl. Holz 2010: 49-111). Da andere Studien aus der sozialwissenschaftlichen Antisemitismusforschung sich am Konzept der Holz'schen Kategorisierung der Antisemitismustheorien orientieren und es in Teilen übernommen haben, wird seine Darstellung der Theoriestränge an dieser Stelle kurz erläutert (vgl. Rensmann 2004; Knothe 2009; Globisch 2013) ${ }^{6}$.

Holz unterteilt die Theorieangebote in der Antisemitismusforschung in funktionale, kausale, differenztheoretische und korrespondenztheoretische Ansätze: Funktionalistische Theorien, die in der sozialpsychologischen Vorurteilsforschung dominieren, gehen von einer komplementären Funktion von Vorurteilen für die vorurteilsbehaftete Wir-Gruppe aus. Die Konstruktion von „outgroups“ und die damit verbundene Abwertung dieser Personengruppe dienen einerseits der Aufwertung der eigenen Gruppe und ermöglichen zugleich die Projektion von Aggressionen und Wünschen nach außen.

Unter Kausaltheorien versteht Holz Ansätze, die die Ursachen für den Antisemitismus auf psychologische und/oder gesellschaftliche Faktoren zurückführen. Hierunter subsumiert er die

\footnotetext{
${ }^{6}$ Die umfassendste Weiterentwicklung findet sich in der Dissertation von Lars Rensmann (vgl. 2004: 95-123), in der im Unterschied zu Holz' Studie zudem politikwissenschaftliche Ansätze aus der politischen Kulturforschung, der Rechtsextremismusforschung und der politischen Psychologie diskutiert werden. Rensmanns Darstellung der Antisemitismustheorien unterschiedet sich von der von Holz am stärksten in der Einordnung der Arbeiten der Kritischen. Die von Holz vorgenommene Subsumtion der Antisemitismus-Theorie und der empirischen Studien der älteren Kritischen Theorie unter das Label der Kausaltheorie wird von Vertretern einer an den Arbeiten des Instituts für Sozialforschung orientieren Antisemitismusforschung kritisiert. Rensmann zufolge enthalten ihre Arbeiten sowohl funktionalistische, kausale als auch differenztheoretische Aspekte (vgl. Rensmann 2004: 106107). Nach Stephan Grigat (2007: 286, Fn 7) offenbart die Holz'sche Darstellung die Unmöglichkeit der Kritischen Theorie „mit Analyseelementen beizukommen, die einem traditionellen Theorieverständnis entsprungen sind“".
} 
Arbeiten zum Antisemitismus der älteren Kritischen Theorie und neuere Theorieversuche, wie die Ansätze von Moishe Postone und Detlev Claussen, die an die Überlegungen der Kritischen Theorie anschließen.

Differenztheorien zeichnen sich nach Holz durch die Rekonstruktion der Entstehung des antisemitischen Judenbildes aus, das Antisemiten in Differenz zum Selbstbild der eigenen Wir-Gruppe entwerfen. Es wird dabei davon ausgegangen, dass die von Antisemiten semantisch konstruierte Figur des Juden sich geläufigen Ordnungs- und Kategorisierungssystemen, wie dem der Freund-Feind-Dichotomie, entzieht. Aus differenztheoretischer Sicht wird erforscht, wie Juden zum Symbol von Ambivalenz und Ununterscheidbarkeit gemacht werden. Holz entwickelt im Anschluss an soziologische Differenztheorien, namentlich die Arbeiten von Zygmunt Baumann und Armin Nassehi, seine wissenssoziologische Semantikanalyse des Juden als die Figur eines Dritten, der die nationale Ordnung der Welt zu unterlaufen scheint und sie dadurch in Frage stellt.

Unter Korrespondenztheorien versteht Holz hingegen Ansätze, die den Antisemitismus auf einen tatsächlichen Konflikt zwischen jüdischer Minderheit und nichtjüdischer Mehrheit zurückführen und insofern die Ursache für antisemitische Vorurteile aus „der Interaktion zwischen ingroup und outgroup, Mehrheit und Minderheit oder aus angeblich tatsächlichen Besonderheiten der Juden, ihrer Berufsstruktur, Religion usw. ableiten“ (Holz 2010: 62). Es wird dabei von Kritikern und Kritikerinnen der Korrespondenztheorien nicht bestritten, dass ökonomische Krisen- oder Konkurrenzsituationen zur Mobilisierung antisemitischer Ressentiments beitragen können; aus korrespondenztheoretischer Sicht bleibt jedoch unverstanden, dass sich im modernen Antisemitismus eine Abstraktionsleistung vollzieht, die zur Folge hat, dass das Handeln oder Verhalten von Juden und Jüdinnen für die Entstehung antisemitischer Feindbilder gänzlich irrelevant ist. Da diese Erkenntnis für die gegenwärtige Forschung von zentraler Bedeutung ist, spielen korrespondenztheoretische Überlegungen nur am Rande der Forschung, bspw. in populärwissenschaftlichen Darstellungen, eine Rolle.

Im Kontext dieser Studie ist es wichtig hervorzuheben, dass eine Untersuchung des Zusammenhanges von Antisemitismus und Großstadtfeindschaft nicht mit einem vergleichsweise hohen Verstädterungsgrad der jüdischen Bevölkerung oder einem besonderen jüdischen Beitrag zur Großstadtkultur in Verbindung gebracht werden kann. Beide Ansätze werden als Ursache für die Entstehung einer antisemitischen Großstadtfeindschaft ausgeschlossen - zum einen, da die These von einer historisch tradierten Bindung der jüdischen Bevölkerung an das Stadtleben in Deutschland empirisch nicht zutreffend ist (vgl. 
Lowenstein 1980; Richarz 1990, 1999); zum anderen, weil diese Sichtweisen den Schwerpunkt der Analyse nicht auf die Großstadterfahrung und Großstadtwahrnehmung der Antisemiten und der sich aus ihnen ergebenden psychologischen Bedürfnisse legt, die für ein Verständnis des Zusammenhangs von Antisemitismus und Großstadtfeindschaft unabdingbar sind. Insofern grenzt sich diese Studie von jenen Überlegungen ab, die bereits der Historiker Hillel J. Kieval treffend kritisierte:

I introduce this story to provide a counterpoint to the view, often found in studies of modern antisemitism, that Jews have occupied a central role in the evolution of the modern city, that their presence and stake in urban culture has been so high as to render them the symbolic equivalent of the city itself. (Kieval 1999: 4)

Für die Entwicklung eines theoretischen Zugangs zum Zusammenhang von Antisemitismus und Großstadtfeindschaft wird im nachstehenden Kapitel auf ausgewählte theoretische Schriften zurückgegriffen. Überblickt man die Theorien der Antisemitismusforschung, so fällt auf, dass nur wenige Schriften explizite Überlegungen zum großstadtfeindlichen Gehalt des modernen Antisemitismus enthalten. Der einzige Text, in dem die gegen die Juden gerichtete Großstadtfeindschaft zum Ausgangspunkt der Überlegungen zum modernen Antisemitismus gemacht wird, ist der in der deutschsprachigen Forschung relativ unbekannte Essay des amerikanischen Soziologen Arnold Rose. Neben seinem Essay, der den Titel Antisemitism's Root in City-Hatred trägt, werden im Folgenden die theoretischen Arbeiten von Talcott Parsons, Moishe Postone und Shulamit Volkov diskutiert.

Es wird an dieser Stelle bewusst darauf verzichtet, alle Theoriestränge en detail zu beschreiben oder alle namhafteren und bekannteren Theorien $\mathrm{zu}$ diskutieren. In diesem Zusammenhang sei auf Samuel Salzborns Ansatz für eine integrative Theorie des Antisemitismus verwiesen, in der die Mikro- und Makroperspektiven der bisherigen Theorien zusammengeführt und mit Ergebnissen eigener empirischer Untersuchungen abgeglichen werden (vgl. Salzborn 2010, 2012). 
3. Theoretische Zugänge zum Zusammenhang von Antisemitismus und Großstadtfeindschaft

3.1. Talcott Parsons: The Sociology of Modern Anti-Semitism

Talcott Parsons (1902-1979) zählt zu den einflussreichsten und bedeutendsten Soziologen des 20. Jahrhunderts. Er leistete mit seinem 1937 erschienen Werk The Structure of Social Action und seiner 1951 publizierten Studie The Social System entscheidende Beiträge zur soziologischen Handlungs- und Systemtheorie (vgl. Parsons 1937, 1951). Parsons gehört nicht nur in den Kanon der soziologischen „Klassiker“, sondern begründete die Bildung eines solchen Kanons in der Soziologie, da auf ihn die bis heute gültige Einstufung der Arbeiten von Émile Durkheim (1858-1917) und Max Weber (1864-1920) als Grundlagenwerke der (westlichen) Soziologie zurückzuführen ist (vgl. Joas/Knöbl 2013: 39-40). Hans Joas und Wolfgang Knöbl zufolge kommt Parsons das Verdienst zu, die diffus gewordene theoretische Diskussion innerhalb der Soziologie gebündelt zu haben, indem er die Soziologien Durkheims und Werbers zum Ausgangspunkt seiner Überlegungen machte. Hierdurch wurde die Stellung der Soziologie innerhalb der Sozialwissenschaften wesentlich gestärkt.

Hinter der Bedeutung Parsons für die soziologische Theoriebildung im Allgemeinen und der Systemtheorie im Besonderen treten seine während des Zweiten Weltkrieges verfassten Analysen des Nationalsozialismus und des Antisemitismus deutlich zurück. Seine Studien zum Antisemitismus sind jedoch besonders aus wissenschaftsgeschichtlicher Sicht interessant, da sie Teil der umfassenden Feindaufklärung und Gegnerforschungen waren, die in den USA seit Ausbruch des Krieges unternommen wurden. Der US-Administration war daran gelegen, so viel Wissen wie möglich über das nationalsozialistisch regierte Deutschland zu gewinnen, um den Kriegsgegner besser einschätzen zu können. In diesem Zusammenhang stellten führende amerikanische Sozial- und Geisteswissenschaftler ihre Dienste und Expertise den US-Nachrichten- und Geheimdiensten zur Verfügung. Zu den bekanntesten Migranten aus Europa, die für die USA Feindaufklärung gegen Nazi-Deutschland betrieben, gehören Franz Neumann (1900-1954) und Herbert Marcuse (1898-1979), die über die Zeit des Zweiten Weltkrieges hinaus für US-Geheimdienste tätig waren (vgl. Müller 2010).

Zwischen 1938 und 1945, so Uta Gerhardt, bildete die Untersuchung des Nationalsozialismus und des Antisemitismus im Auftrag staatlicher Institutionen das Hauptforschungsfeld von Parsons. Er schrieb diesbezüglich zehn themenbezogene Aufsätze und verfasste mehrere 
Radiosendungen und Vorträge (vgl. Gerhardt 1993). Durch einen Studienaufenthalt in Heidelberg im Jahr 1925 war Parsons in besonderer Weise mit den Verhältnissen in Deutschland vertraut. Sein antifaschistisches Engagement begann indes bereits vor dem Kriegseintritt der USA: Parsons sprach sich nachdrücklich für einen Kriegseintritt an der Seite Großbritanniens und gegen den Isolationismus in den Vereinigten Staaten aus (vgl. Gerhardt 1993: 18). Parsons war zudem - jedoch nur peripher - an den Forschungsprojekten zum Antisemitismus beteiligt, die von den großen jüdischen Dachorganisationen in den USA in Auftrag gegeben wurden. Im Frühjahr 1944 begegnete er in New York bei einem Treffen von Vertretern jüdischer Organisationen und Vorurteilsforschern auf Max Horkheimer und Theodor W. Adorno. Zweck des Treffens war es, über das weitere Vorgehen des American Jewish Committee (AJC) in der Entwicklung von Forschungsarbeiten zum Antisemitismus zu beraten (vgl. Fleck 2007: 378-379). Dies ist wissenschaftsgeschichtlich insofern von größerer Bedeutung, als die Zusammenarbeit zwischen den großen jüdisch-amerikanischen Organisationen und amerikanischen und europäischen Sozialforschern in der empirischen Erforschung des Antisemitismus maßgeblich zur Etablierung der Antisemitismusforschung als eines neuen Forschungsfeldes beigetragen hat (vgl. Ziege 2011).

Parsons 1942 erschienener Text The Sociology of Modern Anti-Semitism ist für diese Studie relevant, da er die These vertritt, dass der Antisemitismus auf Desintegrationsprozesse zurückzuführen ist, die mit den sozialen Umbrüchen der Industrialisierung und der Verstädterung zusammenhängen, und dass Juden und Jüdinnen mit diesen Prozessen identifiziert werden. Die Rezeption seines Textes an dieser Stelle soll nicht darüber hinwegtäuschen, dass der Text problematische Implikationen und theoretische Defizite aufweist. Dies betrifft Aussagen, denen zufolge das angeblich schlechte Verhalten von Juden als ein Faktor in der Entstehung des Antisemitismus berücksichtigt werden müsste. So führt Parsons den wirtschaftlichen Erfolg der jüdischen Bevölkerung auf unfaire und aggressive Methoden der Juden zurück (vgl. Parsons 1969: 113).

Der Vorwurf, dass der Sammelband Jews in a Gentile World, in dem Parsons Text zuerst erschien, tendenziell antisemitisch und problemunangemessen sei, wurde 1942 in einer Rezension eines Schülers von Parsons erhoben (vgl. Gerhardt 1992: 258). Parsons wies in diesem Zusammenhang darauf hin, dass sein Manuskript von den Herausgebern eigenmächtig und ohne Absprache verändert und gekürzt wurde, so dass der Sinn entstellt worden sei. Parsons Unzufriedenheit mit dem Text drückte sich unmissverständlich auch darin aus, dass er seinen Aufsatz in spätere Aufsatzsammlungen nicht mit aufnahm (vgl. Gerhardt 1993: 21). 
Trotz dieses Sachverhalts kann sein Aufsatz relevante Erkenntnisse für meine Untersuchung liefern und wird daher im Folgenden näher analysiert.

Parsons Argumentation zergliedert sich in drei Abschnitte: in eine religionssoziologische Betrachtung des Judentums, eine Darstellung der Strukturprinzipien der modernen Gesellschaft und eine Analyse der sozialen Stellung der Juden in der Moderne.

Parsons sieht in den Juden eine besondere Minderheitengruppe, die sich in den Gesellschaften in denen sie lebt, nie ganz integriert und in ihrer zweitausend Jahre alten Geschichte eine eigene Identität bewahrt habe (vgl. Parsons 1969: 101). Die Abgrenzung gegenüber der sie umgebenden Umwelt verdankt sich nach Parsons der Stellung der Religion im Leben der Juden. Die alle Bereiche des Lebens umfassende Religion des Judentums weise die Besonderheit auf, dass sie als eine nationale Religion auf das Land Israel ausgerichtet sei. Nach der Vertreibung aus dem historischen Israel trat die Religion an die Stelle des Territoriums als vereinigendes Moment der in der Diaspora lebenden Juden und bildete die Grundlage dafür, dass Juden sich als eine Nation bzw. ein Volk verstehen. Die Besonderheit der jüdischen Religion macht Parsons an zwei Punkten fest: an der exklusiven Verbindung zwischen dem jüdischen Volk und ihrem Gott; der monotheistische Charakter des Judentums habe verhindert, dass Juden den Glauben anderer Gruppen annahmen. Ein weiteres Spezifikum stellt die Thora als ein Regelwerk für alle Lebensbereiche dar (vgl. Parsons 1969: 102-106). Aufgrund dieser Eigenheiten wurden die Juden nach Parsons bereits vor dem Aufkommen der modernen Industriegesellschaft mit bestimmten Charaktereigenschaften assoziiert: Die strenge Exegese der Thora begründete den Ruf der Juden als „Buch des Volkes“ und führte dazu, dass sie mit Rationalität und Intellektualität in Verbindung gebracht wurden. Das andere Charakteristikum, das Juden zugeschrieben wurde, ist ein besonderer Geschäftssinn, der von Parsons mit dem Umstand zusammengebracht wird, dass Juden aufgrund ihrer Bindung zur Stadt gezwungen waren im Handel zu arbeiten (vgl. Parsons 1969: 106-107).

Die soziale Stellung der Juden in der Moderne habe sich demgegenüber kaum verändert. Mit Blick auf die USA konstatiert Parsons, dass Juden und Jüdinnen in den Großstädten und in bestimmten Berufen überrepräsentiert seien: im Handel, dem Finanzwesen, der Filmindustrie, der Kleidungsindustrie und der Presse. Obwohl sich im Besonderen die jüdischen Mittel- und Oberschichten von einer orthodox ausgelegten Religionsausübung gelöst und einen Prozess der Akkulturation durchlaufen haben, sind sie nicht völlig integriert und bleiben eine fremde Minderheitengruppe (vgl. Parsons 1969: 112-113). Nach Parsons haben die Juden von den 
tiefgreifenden Strukturprozessen der Modernisierung einerseits profitiert, andererseits gehört die jüdische Bevölkerung zu jenen Minderheiten denen die Integration in die Gesellschaft besonders schwerfällt und die von sozialer Desintegration und Unsicherheit betroffen sind.

Parsons charakterisiert die modernen westlichen Gesellschaften durch ihren hohen Grad der Industrialisierung und Verstädterung und durch Errungenschaften „,in the technological and economic spehres, by a complex economic and social structure, and by heterogeneity and mobility of population“ (Parsons 1969: 108). In Anlehnung an die von Ferdinand Tönnies getroffene Unterscheidung zwischen Gemeinschaft und Gesellschaft konstatiert er eine zunehmende Schwächung familiärer Bindungen, wie sie für die Sozialbeziehungen der vorindustriellen Gemeinschaft noch charakteristisch waren. Dies führe zu einer sozialen Desintegration - einem Zustand, den Durkheim mit dem Begriff der Anomie kennzeichnete. Der durch diese Orientierungslosigkeit erzeugte Druck auf die Subjekte verursache die Bildung neuer emotionaler Beziehungen. Parsons sieht den Nationalismus als eine neue affektiv besetzte Form der Gemeinschaftsbildung, die in extremen Fällen - wie dem Nationalsozialismus - paranoide Züge annehmen kann. Der Prozess der Desintegration geht zudem einher mit einem weit verbreiteten Gefühl von Deprivation, das bei Schichten auftritt, die über ein geringes Einkommen, mangelnde Reputation und fehlende soziale Sicherheit verfügen. Hieraus resultiert nach Parsons Frustration, die jedoch aufgrund vorherrschender Normen nicht offen artikuliert werden kann. Die Frustration muss sich daher gegen ein Symbol richten (vgl. Parsons 1969: 111).

In der Moderne werden Parsons zufolge die Juden zu einem Symbol, an dem die durch den Strukturwandel der Moderne ausgelösten Frustrationen ausagiert werden. Er begreift den Antisemitismus hierbei als direkte Folge der sozialen Desintegration. Parsons vertritt die These, dass die aus dem Gefühl der Unsicherheit resultierende Aggression nicht nur gegen Juden, sondern auch gegen andere Gruppen gerichtet sein kann. Er spricht von einer „freefloating aggression“, für die zum Beispiel auch Kommunisten, Katholiken oder Banker zum Objekt des Hasses werden können (vgl. Parsons 1969: 118). Dass sich der moderne Antisemitismus trotz seiner grundsätzlich austauschbaren Feindbildkonstruktionen nicht zufällig gegen Juden und Jüdinnen richtet, führt Parsons auf Spannungen und Konflikte zwischen Juden und Nicht-Juden zurück. Diese Konflikte umfassen mehrere Ebenen und Dimensionen.

Als religiösen Faktor bestimmt er dabei die Spannungen, die sich aus der Nähe von Christentum und Judentum ergeben (vgl. Parsons 1969.: 115-116). Die Hauptursache sieht 
Parsons jedoch in ökonomischen Konkurrenzkämpfen und dem wirtschaftlichen Erfolg der jüdischen Bevölkerung, der auf Seiten der Mehrheitsgesellschaft Neid hervorrufe. Die jüdische Bevölkerung ist demnach in gesellschaftlichen Teil- und Funktionssystemen dominant und erfolgreich, die am stärksten mit den sozialen Umbrüchen der Moderne zusammenhängen:

Moreover, the success of the Jews has been attained on the whole in spheres which are the least closely integrated with the so-called Gemeinschaft patterns, as it is most conspicuous in trade and commerce, the professions, the arts, the theater, and in intellectual fields. (Parsons 1969: 113)

Einen weiteren Grund dafür, wieso Hass und Aggressionen auf Juden projiziert werden, sieht Parsons im aggressiven Verhalten der Juden selbst. Dieses resultiere aus der besonderen Unsicherheit der Juden als einer fremden Minderheitengruppe (vgl. Parsons 1969: 116). ${ }^{7}$. Den Umstand, dass Juden in besonderer Weise geeignet sind als „Sündenbock“ zu dienen, erklärt Parsons zudem mit der engen Verbindung, die zwischen Nationalismus und Antisemitismus besteht. Ihm zufolge ist eine Hauptfunktion des Nationalismus, eigenes Versagen durch die Partizipation an den Erfolgen und Errungenschaften des nationalen Kollektives zu kompensieren und zugleich die Erfolge einer anderen Nation zu schmälern. Die Juden erfüllen hierbei eine doppelte Funktion: Sie rufen zum einen das eigene Versagen ins Bewusstsein und symbolisieren zum anderen den Erfolg einer anderen Gruppe (vgl. Parsons 1969: 117-118). Abschließend kommt Parsons zu dem Schluss, dass in den Vereinigten Staaten die Erfolgsbedingungen für eine antisemitische Massenbewegung, vergleichbar mit der des Nationalsozialismus, nicht gegeben sind; gleichwohl betont er, dass die wesentlichen Elemente der NS-Ideologie auch in den USA existieren würden (vgl. Parsons 1969: 120).

Obwohl Parsons in seinem Aufsatz The Sociology of Modern Anti-Semitism an keiner Stelle, wie Salzborn (2010: 56-57) betont, seine korrespondenztheoretische Sichtweise auf die Ursachen des Antisemitismus relativiert, ist seine These, dass die durch die Verstädterung und Industrialisierung ausgelösten Desintegrationsprozesse eine antisemitische Projektionsorientierung entwickeln würden, einer genaueren Betrachtung wert. Der Bezug zum Thema dieser Studie ergibt sich aus der Tatsache, dass die von Parsons im Rückgriff auf Tönnies verwendete Unterscheidung zwischen Gemeinschaft und Gesellschaft auch als eine Differenz zwischen einer dörflich-kleinstädtischen und einer großstädtischen Lebensform

\footnotetext{
${ }^{7}$ Wie weiter oben dargelegt wurde, gehören diese Passagen zu den problematischen Implikationen des Textes, die nicht nur im Sinne korrespondenztheoretischer Überlegungen den Antisemitismus auf eine vermeintlich objektive Faktizität sozioökonomischer und kultureller Eigenheiten der jüdischen Bevölkerung zurückführen, sondern antisemitische Stereotype reproduzieren.
} 
begriffen wurde: „Die Großstadt ist typisch für die Gesellschaft schlechthin“, heißt es in seinem Werk Gemeinschaft und Gesellschaft (Tönnies 1912 [1887]: 298). ${ }^{8}$

Für die Entwicklung eines theoretischen Zugangs zum Zusammenhang von Antisemitismus und Großstadtfeindschaft ist daher von Bedeutung, dass die Identifizierung von Juden und Jüdinnen mit gesellschaftlichen Sphären, die am stärksten Vergesellschaftungs- und am wenigsten Gemeinschaftsmustern entsprechen, mit ihrer Wahrnehmung als Großstadtbewohner zusammenhängen kann. Die von Parsons beschriebene Desintegration infolge der Modernisierung meint zugleich die Wahrnehmung einer unvollständigen Integration und Anpassung an eine im hohen Maße verstädterte und urbanisierte Gesellschaft. In Anlehnung an die Antisemitismus-Theorie von Parsons lässt sich die These aufstellen, dass der Hass und der Neid, die auf Juden und Jüdinnen projiziert werden, mit der Vorstellung zusammenhängen, dass diesen eine bessere Integration in eine urbanisierte Gesellschaft geglückt ist. Somit lässt sich mit Parsons argumentieren, dass die durch die Verstädterung mit ausgelösten Frustrationen und Aggressionen infolge einer fortschreitenden sozialen Desintegration eine antisemitische Projektionsorientierung entwickeln, die auf einer Identifizierung von Juden und Jüdinnen mit dem sozialen Strukturwandel der Moderne basiert.

Die antisemitische Identifizierung der Juden mit dem Großstadtleben, die Parsons implizit thematisiert, jedoch nicht systematisch herausgearbeitet hat, stellte wenige Jahre später sein Kollege, der amerikanische Soziologie Arnold Rose, in den Mittelpunkt seiner Antisemitismus-Theorie.

\footnotetext{
${ }^{8}$ Wie es für die ersten soziologischen Betrachtungen des Großstadtlebens nicht ungewöhnlich ist, enthalten Tönnies‘ Überlegungen eine deutlich wahrnehmbare stadtkritische bzw. großstadtfeindliche Stoßrichtung. Eine weitverbreitete Vorstellung in der großstadtfeindlichen Publizistik, derer sich auch Tönnies bedient, stellt die These dar, dass das Streben nach Vergnügen und die Verfolgung partikularer Interessen in den Großstädten für den Verfall des Familienlebens verantwortlich zeichnen (vgl. Tönnies 1912 [1887]: 297-302). Tönnies“ Ausführungen $\mathrm{zu}$ den Weltstädten, die in seiner Vorstellung auf die Großstädte folgen und durch eine unbeschränkte Herrschaft von Kapital und Geld gekennzeichnet sind, in denen sich geld- und genusssüchtige Menschen massierten, wurde über 30 Jahre nach der Erstveröffentlichung seines Werkes von Oswald Spengler aufgegriffen und zum Allgemeingut des großstadtfeindlichen Lagers in Deutschland.
} 


\subsection{Arnold M. Rose: Anti-Semitism's Root in City-Hatred}

Der Aufsatz des US-amerikanischen Soziologen Arnold Marshall Rose (1918-1968) erschien erstmals 1948 in der politischen Monatszeitschrift Commentary, die drei Jahre zuvor vom American Jewish Committee ins Lebens gerufen worden war. Als Soziologieprofessor lehrte er an mehreren Universitäten in den USA, bis er schließlich 1968 zum Präsidenten der American Sociological Association gewählt wurde, deren Vorsitz er jedoch aufgrund einer tödlich verlaufenden Krebserkrankung nicht mehr antreten konnte.

Rose, dessen Forschungsschwerpunkte unter anderem auf der Minderheiten- und Vorurteilsforschung lagen (vgl. Ball 1971), lieferte mit seinem Essay den einzigen theoretischen Beitrag zum Zusammenhang von Antisemitismus und Großstadtfeindschaft. Beide Phänomene weisen ihm zufolge keine Gemeinsamkeiten auf, sondern stehen in einem direkten kausalen Verhältnis. Nach Rose hat der moderne Antisemitismus seine Ursache in einer negativen Wahrnehmung des Stadtlebens, das für Antisemiten und Antisemitinnen die Juden symbolisieren. So lautet die Hauptthese seines Aufsatzes: „The Jews are hated today, I would suggest, primarily because they serve as a symbol of city life“ (Rose 1948: 376).

Rose bezieht seine Ausführungen zum Antisemitismus auf allgemeine Überlegungen zu sozialpsychologischen Ursachen von Vorurteilen. Im Mittelpunkt steht dabei die Annahme, dass die inkriminierte Gruppe eine symbolische Bedeutung (,symbolic significane“) für die Gruppe der Vorurteilsbehafteten besitzt. Nach Rose symbolisiert die angefeindete Gruppe Bedürfnisse der vorurteilsbehafteten Subjekte, die nicht befriedigt oder nicht offen ausgesprochen werden können. Vorurteile repräsentieren demnach eine Ersatzbefriedigung (,substitute satisfaction“) für die ausbleibende Befriedigung zentraler Bedürfnisse und Begierden (vgl. Rose 1948: 374). Rose folgt hierbei einem sozialpsychologischen Ansatz zur Analyse von Vorurteilen, der inhaltliche Gemeinsamkeiten mit der Antisemitismus-Theorie der älteren Kritischen Theorie aufweist - speziell mit dem Konzept der pathischen Projektion aus Horkheimers und Adornos Dialektik der Aufklärung (vgl. 2010 [1944]). ${ }^{9}$ Rose geht davon

\footnotetext{
${ }^{9}$ Dass sich der Antisemitismus sowohl aus Neid als auch aus Hass speist, konstatierte Leo Löwenthal in einer ein Jahr nach Rose Text erschienenen Studie über antisemitische Agitation in den Vereinigten Staaten (vgl. Löwenthal 1990 [1949]). Die unter dem Titel Prophets of Deceit erschienene Untersuchung war Teil der vom American Jewisch Comittee geförderten Studies in Prejudice. Löwenthal arbeitet anhand antisemitischer Texte heraus, dass das dort gezeichnete Judenbild sowohl gefährlich als auch attraktiv auf das Publikum wirken soll. Demzufolge schreiben antisemitische Propagandisten Juden und Jüdinnen heimlich begehrte Charaktereigenschaften $\mathrm{zu}$, was dazu führe, dass die Rezipienten Neid gegenüber den Juden empfinden (Löwenthal 1990 [1949]: 87).
} 
aus, dass unterdrückte und verleugnete Bedürfnisse von den Subjekten abgespalten und auf eine fremde Gruppe projiziert werden. Vorurteile basieren insofern immer auf Emotionen, die sowohl Hass und Angst als auch Neid und Begehren umfassen (vgl. Rose 1948: 375).

Sozialen Minderheitengruppen kommen nach Rose unterschiedliche Funktionen für die Generierung von Vorurteilen zu. So sehen demzufolge Rassisten in den Vereinigten Staaten in der afroamerikanischen Bevölkerung freien und leidenschaftlichen Sex, sowie eine erhöhte sexuelle Anziehungskraft auf das jeweils andere Geschlecht innerhalb der eigenen Gruppe symbolisiert. Der auf die Afroamerikaner und Afroamerikanerinnen projizierte Drang nach sexueller Freizügigkeit kann aufgrund rigider Moralvorstellungen jedoch nicht ausgelebt werden und wird daher unterdrückt (vgl. Rose 1948: 375).

In Abgrenzung zum Rassismus analysiert Rose den Antisemitismus und das ihm entsprechende antisemitische Judenbild. Rassismus und Antisemitismus können ihm zufolge nicht als unterscheidungslose Formen einer gleichen Vorurteilsstruktur aufgefasst werden. Im Gegensatz zum Rassismus werden die Juden im Antisemitismus nicht zu einem Symbol für körperliche und geistlose Vitalität und Sexualität gemacht, sondern zu Symbolen des modernen Großstadtlebens. Für den Antisemitismus ist nach Rose konstitutiv, dass die Juden eine erfolgreiche Anpassung an die Anforderungen des Großstadtlebens symbolisieren. Antisemiten assoziieren Juden demnach mit Charaktereigenschaften und Merkmalen, die dem Großstadtleben zugeordnet werden müssen:

Rather, the Jews are associated with economic success, political radicalism, and quick adaptiveness to a rapidly changing world. Historically such traits are connected with life in cities, and so are the Jews. The Jews are the urban people par excellence. (Rose 1948: 375)

Die Juden symbolisieren demzufolge einerseits Eigenschaften, die für das Großstadtleben als charakteristisch angesehen und daher abgelehnt werden. Darunter fallen nach Rose folgende Eigenschaften: „the impersonality, the sharpness, the weakness, the cosmopolitanness, the narrow-mindedness, the pushiness, the cliquishness, the ,capitalism“ and the ,Communism" [...] (Rose 1948: 377). Andererseits existiert eine unbewusste Bewunderung für die Großstadt, was zur Folge hat, dass antisemitisch eingestellte Personen die Juden als Symbol für eine erfolgreiche Anpassung an die Großstadt beneiden. Die Feindschaft der Antisemiten gegenüber den Großstädten resultiert nach Rose daher entweder aus der mangelnden Fähigkeit der Antisemiten, sich ihr anzupassen, oder aus deren Empfindung dies auf Kosten der moralischen Integrität getan zu haben (vgl. Rose 1948: 377). 
Der Grund, wieso ausgerechnet Juden zu einem Symbol für das Großstadtleben gemacht werden, ist nach Rose in einer historisch bedingten Nähe der jüdischen Bevölkerung zum Stadtleben zu sehen. Diese Nähe interpretiert er als eine direkte Folge antijüdischer Gesetze, die Juden dazu zwangen in Berufen tätig zu sein, wie beispielsweise dem Handel, die sie an die Stadt banden. Diese historisch gewachsene und tradierte Bindung an das Stadtleben habe den Juden in der Entwicklung des Kapitalismus und der Verstädterung einen Vorteil verschafft, der den Neid der nichtjüdischen Bevölkerung geweckt habe (vgl. Rose 1948: 375376; vgl. auch Aly 2012: 281-282). ${ }^{10}$

Hierbei muss eingewendet werden, dass Rose Ausführungen nicht für die Geschichte des Judentums in Deutschland zutreffen. So lebte im deutschsprachigen Raum vom Spätmittelalter bis ins 19. Jahrhundert die Mehrheit der Juden auf dem Land und in kleinen Agrarstädten (vgl. Richarz 1999: 327). Städtisch geprägt war die jüdische Bevölkerung vor 1870 nur in Preußen, wo es im Unterschied $\mathrm{zu}$ den süddeutschen Staaten keine Niederlassungsbeschränkungen gab, die der jüdischen Bevölkerung die Ansiedlung in den Städten untersagte (vgl. Maurer 1992: 65; Rürup 1987a: 34). Der Bedeutungsverlust des ländlichen Judentums setzte Steven M. Lowenstein zufolge erst mit der Gründung des Deutschen Reiches 1871 ein, als ein umfassender Urbanisierungsprozess unter deutschen Juden seinen Anfang nahm, in dessen Folge sie von einer überwiegend ländlichen, zu einer mehrheitlich großstädtischen Bevölkerungsgruppe wurden (vgl. Lowenstein 1980: 233-234). Dass Juden und Jüdinnen von Antisemiten zu einem Symbol für das Stadtleben gemacht werden, kann daher nicht aus einer tatsächlich existierenden überhistorischen Bindung der jüdischen Bevölkerung an die Stadt abgeleitet werden.

\footnotetext{
${ }^{10}$ Das von Rose hervorgehobene Argument, dass die jüdische Bevölkerung aufgrund ihrer Lebensweise auf die Verstädterung besser vorbereitet gewesen sei, findet sich auch in der geschichtswissenschaftlichen Literatur zur Siedlungsgeschichte der deutschen Juden wieder. Die auf dem Land lebenden Juden waren demzufolge aufgrund ihrer Tätigkeit als Händler, die sie mit kapitalwirtschaftlichem Denken vertraut machte und ein hohes Maß an Mobilität verlangte, ein urbanes Element im Dorf (vgl. Richarz 1990, 1999) oder für die Abwanderung in die Großstädte prädestiniert (vgl. Lowenstein 1980). Joachim Schlör kritisiert an dieser Argumentation, dass sie von einer natürlichen Übertragung der Erfahrungswerte auf die nachkommende Generation ausgehe, so dass zumindest untergründig, ,der Eindruck einer auf gewisse Weise ,den Juden“ innenwohnenden (ererbten? angeborenen? genetisch verankerten?) Sicherheit im Umgang mit Geld [entstehe]“ (Schlör 2005: 173). Schlör führt das fiktive Beispiel eines jüdischen Händlersohnes an, der von einer Kleinstadt nach Berlin zieht, und stellt die Frage, ob dieser besser auf den Konkurrenzkampf vorbereitet sei, weil „seine Vorfahren im Mittelalter als Geldverleiher tätig waren“ (Schlör 2005: 173). Die im letzten Drittel des 19. Jahrhunderts entstandenen Großstädte schufen eine neue Lebenswelt, die sich mit dem Leben in den bisherigen Kleinstädten nicht vergleichen lässt. Vor diesem Hintergrund kann die These, dass die jüdische Bevölkerung in Deutschland auf das Großstadtleben wesentlich besser vorbereitet gewesen sei, nicht überzeugen.
} 
Hervorzuheben ist, dass Rose gerade nicht die Stellung der jüdischen Bevölkerung zum Stadtleben oder einen jüdischen Beitrag zur urbanen Kultur in den Mittelpunkt seiner Analyse stellt, sondern die psychologischen Bedürfnisse der antisemitischen Subjekte. Das Verhältnis der Antisemiten und Antisemitinnen zur Großstadt begreift Rose, wie bereits dargestellt wurde, als ambivalent. Auf der einen Seite hassen sie sie, auf der anderen Seite wissen sie, wenn auch unbewusst, dass die Großstädte ein unverzichtbarer Teil der modernen Welt sind: „They admire cities, at the same time as they fear and hate them“ (Rose 1948: 377). Dass die Großstadt gehasst werden kann, man zugleich aber an ihr festhält und ein Teil von ihr ist, erklärt Rose mit dem psychologischen Effekt, wonach die Projektion auf die Großstadt bezogener Affekte und Gefühle auf Juden und Jüdinnen den Antisemiten mit der Stadt als solcher versöhnt:

The symbolic projection of hatred of the city onto Jews allows the prejudiced person to destroy the city and to escape the city, and at the same time to keep it and live in it. (Rose 1948: 377)

Demzufolge kommt dem Antisemitismus die Funktion zu, dass Antisemiten nicht mehr die Großstädte als solche hassen, sondern die Juden, die ihre widersprüchlichen Gefühle gegenüber der Großstadt symbolisieren. Die Projektion negativer und positiver Gefühle gegenüber den Großstädten auf Juden und Jüdinnen macht diese nun zum Gegenstand der Stadtfeindschaft und nimmt zugleich die Großstädte aus dem Fokus der Stadtfeinde. Hierdurch bleibe, so Rose, die Großstadt unberührt.

Dieser psychologische Mechanismus ist nach Rose in der Logik des Vorurteils begründet. Der Gegenstand, der bei den vorurteilsbehafteten Personen einen psychologischen Konflikt auslöst, wird durch eine soziale Gruppe substituiert, wodurch der Gegenstand nicht mehr direkt bekämpft werden muss, da er an der inkriminierten Gruppe, die ihn nun symbolisiert, ausagiert werden kann. Vorurteile haben nach Rose demzufolge die Funktion, dass sie zur Lösung eines mentalen Konflikts beitragen. Damit eine Gruppe zum Symbol für etwas werden kann, das sowohl gehasst als auch geliebt wird, bedarf es nach Rose mehrerer Voraussetzungen: Der mentale Konflikt muss in den vorurteilsbehafteten Personen tief verankert sein, die inkriminierte Gruppe muss über einen langen Zeitraum mit dem Gegenstand oder der Sache identifiziert werden, an dem sich der Konflikt entzündet. Der Konflikt muss zudem von einer Mehrheit der Mitglieder einer Gesellschaft gefühlt werden und die symbolische Assoziation der Gruppe mit dem Gegenstand muss der Vorurteilsbildung vorausgehen (vgl. Rose 1948: 377). 
Der Umstand, dass Vorurteile zugleich auf einer negativen und positiven Affektbildung basieren, bedingt nach Rose zudem, dass die symbolische Identifikation einer Gruppe mit einer Sache - Großstadtleben in Bezug auf Juden, Sexualität in Bezug auf Afroamerikaner auch dann nicht gebrochen wird, wenn eine überwiegend oder ausschließlich positive Haltung gegenüber diesen Dingen eingenommen wird. Die Identifizierung von Juden und Jüdinnen mit dem Großstadtleben kann daher auch eine philosemitische Wendung bekommen oder schon immer philosemitisch begründet sein. Rose leistet mit seiner Theorie daher auch einen Beitrag zur kritischen Forschung zum Philosemitismus, für die die Erkenntnis zentral ist, dass der Philosemitismus nicht das Gegenteil, sondern die ideologische Kehrseite des Antisemitismus darstellt (vgl. Rose 1948: 377-378).

Die theoretischen Erkenntnisse, die aus der Theorie von Arnold Rose für den Zusammenhang von Antisemitismus und Großstadtfeindschaft gewonnen werden können, bestehen zum einen darin, dass die Haltung der Antisemiten und Antisemitinnen zur Großstadt von einer Gleichzeitigkeit von Hass und Bewunderung gekennzeichnet ist. Großstadtfeindschaft kann nicht als ein Vorurteilssyndrom begriffen werden, das von außen auf die Großstädte oder ihre Bewohnerschaft projiziert wird, sondern bezieht seine Dynamik aus einer spezifischen Großstadtwahrnehmung antisemitisch eingestellter Großstadtbewohner. Die Feindschaft gegenüber den Großstädten muss daher - mit Rose gedacht - als ein Phänomen begriffen werden, das der Großstadt und den urbanen Gesellschaften der westlichen Industriestaaten inhärent ist.

Eine weitere zentrale Erkenntnis seiner Theorie besteht darin, dass das Unbehagen gegenüber den Großstädten aus dem Gefühl einer mangelnden Anpassungsfähigkeit an das Großstadtleben resultiert, das angesichts einer grundsätzlichen Faszination für die Großstädte und einem Verlangen nach einer erfolgreichen Anpassung an sie hasserfüllte Affekte mobilisiert. Die Projektion ambivalenter Gefühle in Bezug auf das Großstadtleben auf Juden und Jüdinnen geht dabei einher mit der Konstruktion einer antisemitischen Sozialfigur, die Joachim Schlör im Hinblick auf den antisemitischen Diskurs über die Großstadt den „Urbantyp“, den Stadtbewohner par excellence, nennt (vgl. Schlör 1995). Diese Sozialfigur zeichnet sich aus Sicht der Antisemiten dadurch aus, dass sie „sich in der Stadt zurechtfindet, [...] sich ihren Bewegungen, ihren Geschwindigkeiten, ihren wechselnden Rhythmen anpassen kann. [...] Er [Stadtbewohner par excellence; B.K.] weiß, wie die Stadt funktioniert und ist bereit, seine Bewegungsabläufe, sein Zeitbudget, seine Stimmungslage denen der Stadt einzufügen“" (Schlör 1995: 233-234). 
Ausgehend von diesen Überlegungen ist es konstitutiv für die antisemitische Haltung zur Großstadt, dass den Juden eine Anpassungsfähigkeit an die komplexen Anforderungen des Großstadtlebens unterstellt wird und dass sie mit als spezifisch erachteten großstädtischen Phänomenen assoziiert werden. Im Anschluss daran kann die These aufgestellt werden, dass für den Zusammenhang von Antisemitismus und Großstadtfeindschaft auch der Identifizierung der Juden mit der sich zuerst in den Städten entwickelnden modernen Geldwirtschaft und dem Handel eine Bedeutung zukommt. Inwieweit es einen Zusammenhang zwischen der Personifizierung von Handel und Geld in den Juden und ihrer Wahrnehmung als Großstadtbewohner gibt, soll im nächsten Abschnitt anhand der Antisemitismus-Theorie von Moishe Postone diskutiert werden.

\subsection{Moishe Postone: Die Logik des Antisemitismus}

Der theoretische Ansatz des US-amerikanischen Soziologen Moishe Postone zum modernen Antisemitismus, der erstmals 1979 erschien ${ }^{11}$, gehört trotz seines fragmentarischen Charakters, der ihm die Kritik der Monokausalität (vgl. Rensmann 2004: 107) bzw. der Eindimensionalität einbrachte (vgl. Holz 2010: 89), zu den einflussreichsten Theorien der sozialwissenschaftlichen Antisemitismusforschung. Im Gegensatz zum Aufsatz von Arnold Rose steht die Feindschaft gegenüber der Großstadt jedoch nicht im Mittelpunkt der theoretischen Überlegungen von Postone. Gleichwohl eignet sich seine Theorie dazu, Erkenntnisse über den Zusammenhang zwischen Antisemitismus und Großstadtfeindschaft zu gewinnen. Dies ist in erster Linie nicht dem naheliegendem Umstand geschuldet, dass er an zwei Stellen seines Essays auf den großstadtfeindlichen Impetus des modernen Antisemitismus verweist (vgl. Postone 1982: 15, 16), sondern hat seinen Grund darin, dass empirische Studien aus der Antisemitismusforschung nachgewiesen haben, dass es einen Zusammenhang zwischen der Wahrnehmung der Juden als Personifikationen von Handel und Geld und ihrer Wahrnehmung als Repräsentanten der Urbanität gibt (vgl. Spülbeck 1997; Gornik 2007).

\footnotetext{
${ }^{11}$ Angesichts der Existenz verschiedener Fassungen dieses Aufsatzes, die unter verschiedenen Titeln veröffentlicht worden sind, stellt sich bei der Betrachtung der Rezeptionsgeschichte der Theorie von Postone eine gewisse Konfusion ein. Dabei ist es entscheidend hervorzuheben, dass die Fassung seines theoretischen Ansatzes, wie sie hier diskutiert wird, erstmals 1982 unter dem Titel Zur Logik des Antisemitismus in der deutschen Fachzeitschrift Merkur erschienen ist. Einen Überblick über die Chronologie der Veröffentlichungen der verschiedenen Fassungen kann in den editorischen Nachweisen des Buches Deutschland, die Linke und der Holocaust nachgelesen werden (vgl. Postone 2005: 214-215).
} 
Für ein Verständnis dieses Zusammenhangs ist die von Postone analysierte Wirkmächtigkeit des antisemitischen Gegensatzpaares von bodenverbunden und wurzellos von zentraler Bedeutung. Eine Erkenntnis seiner Theorie besteht darin, dass der moderne Antisemitismus eine Denkform ist, die so strukturiert ist, dass sie soziale Phänomene entlang des Gegensatzpaars verwurzelt/wurzellos als Antagonismen begreift und sie in den Deutschen bzw. den Juden personifiziert. Die Deutschen bzw. „Arier“ erscheinen demzufolge als mit dem Heimatboden verwachsenes Volk, während die Juden Wurzellosigkeit, Mobilität und Universalismus verkörpern. Diese Feststellung ist für mein Forschungsthema deshalb von großem Interesse, da die Unterscheidung einer bäuerlich/ländlich-bodenverbundenen und einer großstädtisch-wurzellosen Lebensweise konstitutiv für die antisemitische Großstadtfeindschaft ist. Um theoretische Einblicke in diese Differenz zu bekommen, ist es daher wichtig $\mathrm{zu}$ fragen, aus welchen theoretischen Überlegungen Postone diese Einsicht bezieht.

Postone unternimmt zuerst eine deskriptive Bestimmung des modernen Antisemitismus. Dieser weise im Unterschied zum Rassismus die qualitative Besonderheit auf, dass er in den Juden eine nicht greifbare, abstrakte Macht personifiziert, die für ökonomische Krisen gleichermaßen verantwortlich gemacht wird, wie für die gesellschaftlichen und kulturellen Umbrüche der Moderne. Im Gegensatz zu älteren Formen der Judenfeindschaft erscheinen die Juden demnach nicht einfach als Träger von Geld, sondern als Personifizierung des modernen Kapitalismus (vgl. Postone 1982: 15-16). Für eine Erklärung dieser Personifizierung bedarf es für Postone einer materialistischen Erkenntnistheorie, die zwischen dem Wesen und der Erscheinungsform des Kapitalismus unterscheidet. Dies ist insofern wichtig, als das Industriekapital im Gegensatz zum Finanzkapital nicht zum Objekt antisemitischer Angriffe gemacht wird (vgl. Postone 1982: 16-17). Für den modernen Antisemitismus ist es demnach charakteristisch, dass kapitalistische Prozesse entgegen ihrer tatsächlichen Beschaffenheit in zwei sich gegenüberstehenden Sphären wahrgenommen werden.

Die Ursache für das Auseinandertreten von Wahrnehmung und Wesen des Kapitalismus sieht Postone im Warenfetisch begründet. Dieser Fetisch hat nach Marx seinen Ursprung in der Warenform selbst und klebt somit den Arbeitsprodukten an, „sobald sie als Waren produziert werden“ (MEW 23: 87). Die Ware hat nach Marx einen Doppelcharakter. Sie besitzt sowohl einen Gebrauchswert, der sich aus der Nützlichkeit der Ware als eines einsetzbaren Gegenstandes ergibt, als auch einen Tauschwert, der durch die in der Gesellschaft durchschnittlich-notwendige Arbeitszeit bestimmt ist, die für die Herstellung der Ware 
benötigt wird. Der Ware kommt nach Marx damit tatsächlich ein gesellschaftlicher Charakter zu, da die Warenbesitzer erst über den Austausch ihrer Waren in Beziehung miteinander treten. Entscheidend ist hierbei jedoch, dass die Menschen ihre Waren nicht aufeinander beziehen und tauschen, weil „diese Sachen ihnen als bloß sachliche Hüllen gleichartig menschlicher Arbeit gelten“" (MEW 23: 88). Erst indem die Warenbesitzer ihre Arbeitsprodukte tauschen, setzen sie ihre verschiedenen Arbeiten als menschliche, abstrakte Arbeit miteinander gleich. Sie tun dies, ohne es zu wissen. Für die Warenbesitzer scheint es dabei so, als ob die Ware von sich aus, gewissermaßen von Natur aus, die Eigenschaft besäße, Wert in sich zu tragen. Es hat den Anschein, als ob der gesellschaftliche Charakter der Ware ihre natürliche Eigenschaft sei. Soziale Verhältnisse werden hierdurch vergegenständlicht und naturalisiert. So schreibt Postone:

Durch diese Form der Vergegenständlichung gewinnen die gesellschaftlichen Verhältnisse des Kapitalismus ein Eigenleben, sie bilden eine ,zweite Natur'- ein System von Herrschaft und Zwängen, das, obwohl gesellschaftlich, unpersönlich, sachlich und ,objektiv' ist und deshalb natürlich zu sein scheint. (Postone 1982: 17)

Die dem Warenfetisch inhärente Tendenz zur Naturalisierung sozialer Verhältnisse erlangt eine neue Dimension, wenn nicht Waren untereinander getauscht werden, sondern Ware gegen Geld. In der Bewegung G-W-G, die Marx die einfache Warenzirkulation nennt, wird aus dem der Ware immanentem Gegensatz von Gebrauchs- und Tauschwert ein äußerer, so dass, wie Marx schreibt, „die Waren als Gebrauchswerte dem Geld als Tauschwert gegenüber [treten]“ (MEW 23: 119). Postone schlussfolgert hieraus, dass aufgrund dieser Entäußerung die Ware als ein natürlicher, rein stofflicher Gegenstand erscheine, dem gegenüber das Geld als einziger Ort des Wertes erscheine, ,als Manifestation des ganz und gar Abstrakten anstatt als entäußerte Erscheinungsform der Wertseite der Ware selbst“" (Postone 1982: 18). Aus der Vergegenständlichung sozialer Beziehungen, wie sie für die bürgerliche Gesellschaft charakteristisch ist, resultiert demnach auf der Ebene der Warenanalyse ein Gegensatz zwischen Geld als Abstraktem einerseits und der Ware als stofflich konkreter Natur andererseits. Nach Postone ist dabei entscheidend, dass beide Seiten der Antinomie konkret/abstrakt vergegenständlicht sind und somit als natürlich erscheinen: Die abstrakte Seite tritt in Form von „objektiven“ Naturgesetzen auf, die konkrete Seite erscheint als rein stoffliche Natur (vgl. Postone 1982: 18).

Auf der Ebene der Kapitalverwertung verstärkt sich nach Postone die Naturalisierung der Antinomie von konkret/abstrakt. Das Kapital, verstanden als sich selbst verwertender Wert, weist demnach auch einen Doppelcharakter auf: Im Lauf seiner Verwertung durchläuft es 
sowohl den Produktions- als auch den Zirkulationsprozess, nimmt dabei also sowohl die Form der Ware als auch die des Geldes an. Da der Wert im Produktionsprozess die Form der Ware annimmt, erscheint dieser als ein rein stofflicher Vorgang, als ein, wie Postone schreibt, materiell schöpferischer Prozess, der losgelöst vom Kapital zu sein scheint (vgl. Postone 1982: 20). ${ }^{12}$ Das Industriekapital bildet demnach die konkrete Dimension der Antinomie auf der Ebene der Kapitalverwertung. Da es sich bei ihm nicht mehr um eine abgeschlossene Einheit handelt, wie bei der gebrauchswertbildenden, individuellen Arbeit, sondern um ein dynamisches System, das Mensch wie Maschine umfasst, kommt der manifesten Form des Konkreten, dem Produktionsprozess, ein quasi-organischer Charakter zu. Die abstrakte Seite, die Zirkulationssphäre, erscheint demgegenüber als unorganisch und künstlich. Hierin liegt für Postone die Unterscheidung zwischen der Wahrnehmung des Konkreten als verwurzelt und des Abstrakten als wurzellos/bodenlos begründet:

So kann das industrielle Kapital als direkter Nachfolger ,natürlicher' handwerklicher Arbeit auftreten und, im Gegensatz zum ,parasitären' Finanzkapital, als ,organisch verwurzelt‘. (Postone 1982: 20)

Nach Postone geht eine Verherrlichung der Natur, des Bodens, des Blutes, der konkreten Arbeit und der Gemeinschaft mit einer positiven Bezugnahme auf das industrielle Kapital und die Technik zusammen, da beide Dinge als konkrete Gegenprinzipien zum Abstrakten gesehen werden. Charakteristisch für den modernen Antisemitismus ist demnach die Personifizierung der abstrakten Seite des Kapitals (Geld, Handel, Zins, Finanzkapital) in den Juden. Der moderne Antisemitismus muss demnach als ein sich antikapitalistisch verstehender Angriff gegen das Abstrakte verstanden werden, als eine besonders gefährliche Form des Fetischs, die dazu führe, dass „der Gegensatz von stofflich Konkretem und Abstraktem zum rassischen Gegensatz von Arier und Jude [wird]“ (Postone 1982: 22).

Einer der häufigsten Kritikpunkte an Postones Essay lautet, dass dieser lediglich eine Analogie zwischen dem Fetischismus der warenproduzierenden Gesellschaft und dem modernen Antisemitismus aufgezeigt habe. Der Versuch die Marx ‘sche Kritik der politischen

\footnotetext{
${ }^{12}$ Postone schließt hierbei an Überlegungen von Max Horkheimer und Theodor W. Adorno aus den Elementen des Antisemitismus aus ihrem Hauptwerk Die Dialektik der Aufklärung an. In Anlehnung an die Marx'sche Mehrwerttheorie gehen sie davon aus, dass die Ursächlichkeit des Produktionsprozesses für die Entstehung des Mehrwerts im Gesamtprozess der Verwertung des Kapitals nicht erscheint. Da sich den Arbeitern erst beim Verkauf der Waren offenbare, dass sie der Ware mehr Wert zugeführt haben, als durch ihren Lohn abgedeckt ist, erscheine die Zirkulation als verantwortlich für die Ausbeutung. Dass der Mehrwert nur im Zusammenspiel von Produktions- und Zirkulationssphäre entstehen kann, bleibt verborgen. So schlussfolgern Horkheimer und Adorno, dass „die Verantwortlichkeit der Zirkulationssphäre für die Ausbeutung gesellschaftlich notwendiger Schein [ist]“" (Horkheimer/Adorno 2010 [1944]: 183). Der Hass gegen die Zirkulationssphäre lade sich antisemitisch auf, da die Juden allzu lange in diese „eingesperrt waren“(Horkheimer/Adorno 2010 [1944]: 183).
} 
Ökonomie direkt auf den Antisemitismus zu beziehen wird kritisiert und in Frage gestellt (u.a. Claussen 2005: 54; Heinrich 2005: 192). Stephan Grigat hält diesem Einwand entgegen, dass der Antisemitismus sowohl in theoretischer als auch in historischer Hinsicht mit dem Waren-, Geld- und Kapitalfetisch zusammenhängt, da dieser „,wesentlich eine Reaktion auf die fetischistische Gesellschaftsstruktur ist“" (Grigat 2007: 289).

Klaus Holz führt überdies den Kritikpunkt an, dass Postone die Personifizierung des Abstrakten in den Juden zwar beschrieben, aber nicht erklärt habe (vgl. Holz 2010: 89). Postones knapp gehaltener Versuch einige Schlaglichter auf historische Ursachen zu werfen wie die antijüdische Tradition der Assoziierung der Juden mit Geld - greift als Erklärung in der Tat zu kurz (vgl. Postone 1982: 23-24). Die Frage, wieso der Warenfetisch nur bei einer Minderheit der bürgerlichen Subjekte zur Bildung einer antisemitischen Wahrnehmungsstruktur und Projektionsorientierung führt, bleibt bei Postone ungeklärt. Er verweist dabei auf die Notwendigkeit sozialpsychologischer und psychoanalytischer Untersuchungen.

Trotz der theoretischen Leerstellen seines Ansatzes ist die empirische Plausibilität seiner Theorie unbestritten. Für das Anliegen meiner Studie, eine zentrale Sinndimension der antisemitischen Großstadtfeindschaft theoretisch $\mathrm{zu}$ fassen, nämlich die der Gegenüberstellung von einem „ländlich-bodenverbunden“ und „großstädtisch-wurzellosem“ Leben, hat seine Theorie einen hohen heuristischen Erkenntniswert: Obwohl sich die Großstadtfeindschaft historisch betrachtet immer wieder auch mit anti-industriellen Einstellungen verbunden hat, so meine These, kommt der Assoziation der Großstädte mit dem Handel und der Geldwirtschaft für eine antisemitisch ausgerichtete Großstadtfeindschaft eine weitaus wichtigere Bedeutung zu. Die von Postone untersuchte Identifikation der Juden mit dem Konnex Geld und Wurzellosigkeit wird in einem großstadtfeindlichen Kontext um den Aspekt des Großstadtlebens erweitert (vgl. Kahmann 2011: 111).

Die Ablehnung des Industriekapitals, so die These weiter, spielt für die antisemitische Großstadtfeindschaft hingegen eine untergeordnete Rolle. In Erweiterung von Postones Theorie kann angenommen werden, dass die im antisemitischen Denken existierende Wahrnehmung der Großstädte als wurzellose und anorganische Gebilde auf ihrer Identifizierung mit der modernen Geldwirtschaft und der ökonomischen Zirkulationssphäre beruht. Großstadtfeindschaft und eine sich in der Verherrlichung des Bauerntums ausdrückende Agrarromantik richten sich demnach nicht grundsätzlich gegen das Industriekapital und die industrielle Produktion. 
So gab es großstadtfeindliche Ideen und Versuche, die Industrie zu dezentralisieren und in ländliche Gegenden auszulagern um eine Entballung der Großstädte zu erreichen. Die großstadtfeindliche Gartenstadtbewegung sah beispielswiese eine Verlagerung der Industrie an den Standrand vor (vgl. Kapitel 4.3.). Dies macht deutlich, dass das Industriekapitel und die moderne Technik grundsätzlich in agrarromantische Denkmuster integrierbar sind.

Paradigmatisch hierfür ist die Schrift Die Verstädterung. Ihre Gefahren für Volk und Staat vom Standpunkte der Lebensforschung und der Gesellschaftswissenschaft des Rassetheoretikers Hans F.K. Günther, die Klaus Bergmann zufolge zu den Standardwerken der nationalsozialistischen Großstadtfeindschaft gehört (vgl. Bergmann 1970: 340). Günther hebt hierin hervor, dass für die Zukunft Deutschlands allein die Gestalt des Bauern richtungsweisend sein kann und dass sich im „Zeitalter der Technik und Industrie“ der technisch-wissenschaftliche Fortschritt der bäuerlichen Gesinnung anzupassen habe und nicht umgekehrt. Günther möchte dies jedoch nicht als ein Urteil gegen die „deutsche Industrie“ oder das „deutsche Arbeitertum“ verstanden wissen, sondern als Hinweis darauf, dass „eine Volkserneuerung als ein Vorgang der Auslese, der Heimgründungen, der Familienverwurzelungen, als eine Frage von ,Blut und Boden““ gedacht werden muss (Günther 1934: 47). Eine notwendige Maßnahme für das Programm einer „Entstädterung“ sieht er infolgedessen in der Verlagerung von Fabriken und deren Belegschaft auf das Land (vgl. Günther 1934: 48).

In der antisemitischen Logik lässt sich die ökonomische Zirkulationssphäre, die als wurzellos, mobil und universell wahrgenommen wird, nicht mit einer Verherrlichung der Natur und dem Ideal von der Unmittelbarkeit und Authentizität des Landlebens vereinbaren. Es ist die Identifizierung der Juden mit der Wertdimension, die sie für die Antisemiten zu einer abstrakten Macht werden lässt, die Unfassbarkeit, Universalität und Mobilität umschließt (vgl. Postone 1982: 18). Nur hierdurch können Juden, wie Postone in Hinsicht auf den großstadtfeindlichen Gehalt des modernen Antisemitismus schreibt, als das wahrgenommen werden, „was hinter dem ,Asphaltdschungel“ der wuchernden Metropolen, hinter der ,vulgären, materialistischen, modernen Kultur' und, generell, hinter allen Kräften, die zum Niedergang althergebrachter sozialer Zusammenhänge, Werte und Institutionen führen, steht“ (Postone 1982.: 15).

Die Ethnologin Susanne Spülbeck hat in einer empirischen Studie Erkenntnisse gewonnen, die einen engen Zusammenhang zwischen Antisemitismus und Großstadtfeindschaft belegen 
und zugleich Rose These plausibilisieren, wonach Juden mit Charaktereigenschaften assoziiert werden, die als städtisch wahrgenommen werden.

In einer ethnographisch angelegten Gemeindestudie untersuchte sie die Reaktionen der Bewohnerschaft einer ostdeutschen Gemeinde auf die Unterbringung von jüdischen Flüchtlingen aus der ehemaligen Sowjetunion. Diese wurden kurz nach der Wiedervereinigung in einer Asylunterkunft in der Nähe der Gemeinde untergebracht. Spülbeck weist in ihrer Studie nach, dass die jüdischen Migranten und Migrantinnen von den Bewohnern mit dem Handel und dem Geld assoziiert werden und dass diese Assoziation mit der Wahrnehmung der Juden als Stadtbewohner zusammenhängt. In ihrer Funktion als Stadtbewohner werden die Juden als egoistisch und bindungslos charakterisiert. Sie stellt darüber hinaus fest, dass eine zur gleichen Zeit eingetroffene Flüchtlingsgruppe, die aus sogenannten Wolgadeutschen besteht, von den Bewohnern der Gemeinde als bodenständige, ehrliche und arbeitsame Landbewohner beschrieben wird. So schreibt Spülbeck hinsichtlich der von den Bewohnern und Bewohnerinnen konstruierten Land-/Stadtbewohner-Dichotomie:

In Winterfeld [Name des Dorfes; B.K.] war der Diskurs über die Urbanität der Juden aus den Gebieten der ehemaligen Sowjetunion mit dem tradierten Stereotyp vom ,reichen Juden' und vom ,Juden als Händler' als Erklärungsmuster für den städtischen Lebensstil verbunden. Der diskursive Bezug zum Stadt-Land-Konflikt und seine Bedeutungskonstitution anhand antisemitischer Stereotype war umso deutlicher zu beobachten, weil hier eine andere Gruppe von Fremden zur gleichen Zeit auftauchte. Diese Gruppe, [„Wolgadeutsche“; B.K.] deren wahrgenommene Charakteristika in den vorgelegten Texten vor allem ihre nicht-jüdische und ländliche Herkunft ausmachten, wurde in Kontrast zu den Juden gestellt. (Spülbeck 1997: 134135)

Die sich im modernen Antisemitismus vollziehende Verbindung der Juden mit Geld, Wurzellosigkeit und dem Großstadtleben lässt sich nicht nur in antisemitischen Texten, sondern auch anhand von antisemitischen Karikaturen herausarbeiten. Dorota Gornik weist in ihrer Studie nach, dass die Skyline von New York City als Symbol für die Großstadt in den Karikaturen des NS-Blattes Der Stürmer in regelmäßigen Abständen zum Motiv erhoben wurde. Im Mittelpunkt dieser Karikaturen steht ein als „Wallstreet-Jud“ bezeichneter und dementsprechend antisemitisch dargestellter „Finanzkapitalist“", der über den Hochhäusern der US-amerikanischen Metropole thront (vgl. Gornik 2007: 84, 86, 94).

Einen weiteren Beleg dafür, dass die Personifizierung von Geld und Wurzellosigkeit in den Juden mit ihrer Identifikation als Großstadtbewohner zusammenhängt, kann der Studie Die Juden und das Wirtschaftsleben des Nationalökonomen und Soziologen Werner Sombart (1863-1941) entnommen werden (vgl. Sombart 1911). Sombart entwickelte seine Überlegungen zum Beitrag, den die jüdische Religion zur Entfaltung des Kapitalismus 
beigetragen habe, in Anlehnung an Max Webers berühmter Protestantische-Ethik-These (vgl. Rehberg 1988: 158). Wenngleich sich Sombart in seiner Studie gegen den Rassenantisemitismus wendet und im Sinne eines positivistischen Wissenschaftsverständnisses beansprucht, sich eines Werturteils zu enthalten, zeichnet er ein Judenbild, das antisemitische Stereotype in sich vereint. Eine seiner Hauptthesen ist, dass der Kapitalismus das Produkt der Vereinigung zweier gänzlich unterschiedlicher Völker sei: auf der einen Seite die bodenständigen nordischen Völker, vornehmlich Germanen, die eine wissenschaftlich-technische Begabung hätten, auf der anderen Seite das „abstrakt“ und „rational“ veranlagte jüdische Volk, „mit ausgeprägtem Sinn für begrifflich-diskursive Erfassung der Dinge“ (Sombart 1911: 421). Die Eigenschaften der Juden führt Sombart darauf zurück, dass die Juden seit jeher ein Wüsten- und Wandervolk gewesen sind, das nie mit der Scholle verwachsen gewesen ist. Der Umstand, dass Juden schon immer Stadtbewohner gewesen sind, hängt Sombart zufolge damit zusammen, dass die Großstadt „die unmittelbare Fortsetzung der Wüste [ist] - sie steht der dampfenden Scholle ebenso fern wie diese und zwingt ihren Bewohnern ein nomadisierendes Leben auf wie diese" (Sombart 1911: 415). Die Elemente „Wüste“ und „Wanderung“, die nach Sombart das ,jüdische Wesen“ charakterisieren, vereinigen sich im Geld, das nicht im Boden verwurzelt sei (Sombart 1911: 426). Er schlussfolgert, dass die Juden „Herren des Geldes und durch das Geld, das sie sich untertan machten, die Herren der Welt [wurden]“ (Sombart 1911: 427).

In Anlehnung an die Theorie von Postone und unter Verweis auf die hier angeführten empirischen Beispiele kann für die Studie die These formuliert werden, dass es einen Zusammenhang zwischen der Personifizierung der ökonomischen Zirkulationssphäre in den Juden und ihrer Wahrnehmung als Großstadtbewohner gibt. Dies kann sich darin äußern, dass die Juden als Personifizierungen negativ wahrgenommener urbaner Charaktereigenschaften erscheinen und hierdurch im antisemitischen Diskurs zu „Städtern im Dorf“ (Spülbeck) werden, oder im Fall der Stürmer-Karikaturen, in denen die Juden als diejenige Macht dargestellt werden, die sich hinter der Hochhausfassade der modernen (amerikanischen) Metropole verbirgt. Juden und Jüdinnen erscheinen insofern als Stadtbewohner par excellence und die Großstädte als ,jüdisch“ dominiert.

Die zweite These, die aus Postones Theorie gewonnen werden kann, ist, dass das Industriekapital und die moderne Technik in die Agrarromantik und die Blut-und-BodenIdeologie des modernen Antisemitismus integrierbar sind. Eine antisemitisch begründete 
Großstadtfeindschaft korrespondiert somit nicht mit einer grundsätzlichen Ablehnung von Technik und Industrie.

\subsection{Shulamit Volkov: Antisemitismus als kultureller Code}

Der Aufsatz der israelischen Historikerin Shulamit Volkov Antisemitism as a Cultural Code ist erstmals 1978 erschienen. Wenngleich es sich bei ihrer Analyse in erster Linie um eine geschichtswissenschaftliche Studie handelt, ist sie für die sozialwissenschaftliche Antisemitismusforschung aus mindestens zwei Gründen von Interesse: zum einen, da ihr das historische Material als Grundlage für eine sozialwissenschaftliche Interpretation des Antisemitismus dient; und zum anderen, da sie sich in ihrer kultursoziologisch geprägten Analyse bereits zu einem Zeitpunkt für semantische bzw. soziolinguistische Aspekte interessierte, als der lingustic turn den Kultur-, Geistes- und Sozialwissenschaften noch bevorstand (vgl. Salzborn 2010: 147).

Während bei Arnold Rose die Großstadtfeindschaft im Mittelpunkt seiner Betrachtungen zum Antisemitismus steht und sich bei Parsons und Postone immerhin dezidierte Verweise auf den Zusammenhang zwischen Antisemitismus und Großstadtfeindschaft finden lassen, entbehrt Volkvos Theorie einer direkten Bezugnahme auf dieses Thema. Für mein Forschungsvorhaben ist ihre Theorie von Interesse, da sie sich mit der Frage auseinandersetzt, wieso der Antisemitismus im Kaiserreich zu einem Symbol, zu einem Code für die Zugehörigkeit $\mathrm{zu}$ einem kulturellen Lager werden konnte, in dem sich verschiedene antimoderne Ideen amalgamierten. Ihr Ansatz analysiert den kultursoziologischen Prozess einer gesellschaftlichen Homogenisierung und Segmentierung im Kaiserreich, der zu einer symbolischen und realen Polarisierung durch den Antisemitismus führte und antisemitische Weltbilder nachhaltig prägte (vgl. Salzborn 2012: 197).

Zu Beginn ihres Aufsatzes steht für Volkov zunächst die Frage im Mittelpunkt, ob es eine Kontinuität, eine direkte Verbindungslinie zwischen dem Antisemitismus des Kaiserreiches und dem Vernichtungsantisemitismus der Nationalsozialisten gibt. Interessant ist für sie in diesem Zusammenhang die Frage, welche Bedeutung man dem Niedergang der antisemitischen Parteien im Kaiserreich zumessen muss. Volkov rezipiert hierfür zwei einander entgegenstehende Interpretationen: Während Richard S. Levy aus dem Verfall der antisemitischen Parteien auf eine Schwächung des Antisemitismus im Allgemeinen schließt, 
sieht Werner Jochmann gerade in der Bedeutungslosigkeit dieser Parteien einen möglichen Grund dafür, wieso der Antisemitismus in die Gesellschaft diffundieren konnte (vgl. Volkov 2000: 15-16). Volkov teilt die Auffassungen Jochmanns und schussfolgert, dass der nachweisbare Niedergang der antisemitischen Parteien „,nicht als ein Anzeichen für ein generelles Nachlassen des deutschen Antisemitismus gewertet werden [kann], sondern signalisiert lediglich einen Wandel der Form“(Volkov 2000: 16).

Diesen Formwandel begreift Volkov als einen Prozess, in dessen Folge der Antisemitismus von einer manifesten politischen Idee, die mit großem Nachdruck vertreten wurde, zu einem kulturellen Muster gerinnt, das sich bei einem Teil der wilhelminischen Gesellschaft um die Jahrhundertwende zu entwickeln beginnt. Dieses Muster entspricht ihr zufolge dem Syndrom der Authoritarian Personality (vgl. Adorno et al. 1950), da es die komplette Persönlichkeit affiziere und sowohl auf der Ebene der Rationalität als auch auf der Ebene impliziter Werte, Normen, Lebens- und Denkweisen und Emotionen wirkt (vgl. Volkov 2000: 19). Der Begriff der Weltanschauung eigne sich daher nicht zur Beschreibung des Antisemitismus, da dieser zu eng gefasst ist. Volkov schlägt hingegen den Begriff der Kultur vor, verstanden als „Gesamtgeflecht aller Arten des Denkens, Fühlens und Handelns“ (Volkov 2000: 19). Charakteristisch für diese Kultur ist demnach nicht nur eine antimoderne Mentalität, die sich gegen Liberalismus, Kapitalismus und Sozialismus wendet, sondern auch die Latenz, mit der diese Anschauungen zum Ausdruck gebracht werden. Volkov zufolge vertreten nur wenige Menschen diese Kultur im vollen Bewusstsein ihrer Bedeutung. Die deutliche Mehrheit der Mitglieder passe sich ihr passiv an (vgl. Volkov 2000: 20).

Neben dieser modernitätsfeindlichen Kultur etablierte sich nach Volkov ein weiteres kulturelles Lager in der wilhelminischen Gesellschaft, das sie mit dem Begriff der Emanzipation kennzeichnet. Somit existierten um die Jahrhundertwende zwei sich gegenüberstehende Kulturen in Deutschland. Da der Antisemitismus in der Regel auf einer verbalen Ebene verblieb und für die Tagespolitik keine praktische Bedeutung hatte, konnte er zu einem kulturellen Code werden (vgl. Volkov 2000: 23). Der Antisemitismus wurde demnach $\mathrm{zu}$ einem zentralen Element, das die Integration in das kulturelle Lager der Modernitätsfeinde erleichterte. Aus dieser Funktionsbestimmung des modernen Antisemitismus folgt für Volkov, dass der Antisemitismus weder identisch mit der modernitätsfeindlichen Kultur noch ein einfaches Element dieser war. Der symbolische Gehalt des Antisemitismus drückte sich darin aus, dass er für die Mitglieder der eigenen Kultur nicht nur die Feindschaft gegenüber Juden ausdrückte, sondern die Bereitschaft 
signalisierte, ein ganzes Bündel von politischen Ideen und moralischen Normen zu übernehmen. Der Antisemitismus wurde somit zu einem politisch-kulturellem Symbol, dessen Bedeutung man zu entschlüsseln lernte.

Nach Volkov konnte der Antisemitismus zu solch einem kulturellen Symbol bzw. Code werden, da er in seiner Sprache von einzelnen Juden bewusst abstrahierte. Volkov spricht in diesem Zusammenhang von einer ,kognitiven Abstraktion“, die in der Wortneuschöpfung des Begriffes Antisemitismus angelegt ist (vgl. Volkov 2000: 27). Der Begriff, der im letzten Drittel des 19. Jahrhunderts im Umfeld von Wilhelm Marr (1819-1904) geprägt wurde, stellt für Volkov eine zweifache Abstraktion dar: Die erste bestehe darin, dass der Begriff nicht Juden, sondern das Judentum in den Mittelpunkt der Aufmerksamkeit rückt; die zweite darin, dass mit dem Begriff „Semitismus“ ein unmittelbarer Bezug auf lebende Juden umgangen wurde und damit jene Unschärfe und Bedeutungsoffenheit geschaffen worden ist, die dem symbolischen Prozess gerecht wurde, der ,judenfeindliche Einstellungen zur Analogie für eine ganze Serie anderer Auffassungen machte“ (Volkov 2000: 28). Nach Volkov transzendierte der Begriff Antisemitismus den Judenhass und wurde zugleich mit ihm identisch. Mit der Etablierung des Begriffs schuf Marr entgegen seiner ursprünglichen Intention - einen erneuten Angriff gegen die Juden zu lancieren - ein neues Phänomen (vgl. Volkov 2000: 27).

Die Entwicklung des Antisemitismus zu einem Symbol setzte sich für Volkov durch die spezifische Semantik der antisemitischen Parolen fort. Paradigmatisch hierfür ist für sie das Schlagwort des Journalisten Otto Glagau (1834-1892), der in seiner Streitschrift Deutsches Handwerk und historisches Bürgerthum (1879) erklärte: „Die soziale Frage ist die Judenfrage“. Hierdurch gelang ihm die assoziative Verbindung zwischen zwei Themenkomplexen, die bis zu diesem Zeitpunkt in Deutschland nicht identisch waren. Aufgrund der Kolportage dieser Parole wurde ein Bindeglied zwischen einer mittelständischen Sozialkritik und dem Antisemitismus geschaffen (vgl. Volkov 2000: 30). Nach Volkov ist es jedoch erst Heinrich von Treitschke (1834-1896) gelungen, eine Parole zu entwerfen, in der nicht nur von einzelnen Juden abstrahiert wird und sich der Antisemitismus mit anderen Themen verbindet, sondern die zum Ausdruck einer geschlossenen Weltanschauung wird. Die Anforderungen an solch eine Parole erfüllte sein bekanntes antisemitisches Diktum: „Die Juden sind unser Unglück“. Die sogenannte Judenfrage wurde hierdurch nicht mehr als ein Problem gesehen, das neben anderen existierte, sondern stellte den Kern aller Probleme der Welt dar (vgl. Volkov 2000: 32) 
Für eine Beantwortung der Frage, ob es eine Kontinuität judenfeindlicher Einstellungen vom Kaiserreich bis zum Nationalsozialismus gab, ist für Volkov die Analyse der kulturellen Funktion des Antisemitismus entscheidend. Für sie beruht die Fortexistenz des Antisemitismus nicht primär auf dem Vorhandensein von antisemitischen Parteien oder Verbänden, sondern „auf dem Fortdauern der Kultur und ihres einheitlichen Vokabulars“ (Volkov 2000: 36). Im Unterschied zur bisherigen antisemitischen Kultur verbanden die Nationalsozialisten mit dem verbal geäußerten Antisemitismus unmittelbare Implikationen für ihr Handeln sowie ein Programm der Einschüchterung und Vernichtung. So charakterisiert Volkov den Nazismus als eine Kultur, in der „,verbale Aggression nicht ein Ersatz für Handeln war, sondern seine Vorbereitung“ (Volkov 2000a: 74). Die Tatsache, dass viele Menschen in Deutschland die Gefahren des Aufstiegs der NSDAP unterschätzt haben, hat nach Volkov ihren Grund darin, dass viele Beobachter die gewandelte Sprache des NSAntisemitismus nicht mehr entschlüsseln konnten (vgl. Volkov 2000: 36).

Der Bezug von Volkovs Theorie zu dem Thema dieser Studie ergibt sich dadurch, dass der völkische Antisemitismus mit seiner kaum überschaubaren Anzahl an Schriften und Periodika über den eigenen Rezipientenkreis hinaus wirkte und maßgeblich zur Entstehung der von ihr analysierten modernitätsfeindlichen und anti-liberalen Kultur in der wilhelminischen Gesellschaft beitrug. In Anlehnung an Volkov kann gesagt werden, dass die Feindschaft gegenüber den Großstädten und Metropolen zu einem festen ideologischen Bestandteil der antisemitischen Kultur des Kaiserreichs avancierte und über ein spezifisches Vokabular kommuniziert wurde.

Eine besondere Wirkmächtigkeit kommt hierbei dem Begriff des „Asphalts“ zu, der in antisemitischen Texten zum pejorativ verwendeten Synonym für die Großstadt und den Juden als Großstadtbewohner avancierte. Der Begriff wird im Zusammenhang mit Phänomenen genannt, die für antisemitische Autoren das Großstadtleben charakterisieren: „Asphaltdemokratie“, „Asphaltpresse“, „Asphaltgeistigkeit“ oder „Asphaltliteratentum“ sind Neologismen, die in antisemitischen Schriften der Kaiserzeit und in der Weimarer Republik eine weite Verbreitung fanden. Es ist kein Zufall, dass es sich bei den genannten Phänomenen um vermittelnde soziale und politische Instanzen handelt. Geld, Intellekt Presse und demokratischer Parlamentarismus gelten der antisemitischen Logik zufolge als zwischengeschaltete und abstrakte Instanzen, die eine direkte Volksherrschaft unterdrücken würden. Die zentrale Bedeutung für die antiliberale und modernitätsfeindliche 
Weltanschauung bzw. Kultur ergibt sich dabei aus den facettenreichen Bedeutungsinhalten des Asphalt-Begriffes.

Diez Bering hat in seiner Studie über die Geschichte des Antiintellektualismus herausgearbeitet, dass das Schlagwort „Asphalt“ im Kontext der „Blut-und-Boden“-Ideologie $\mathrm{zu}$ sehen ist und eine antiintellektuelle, großstadtfeindliche und antisemitische Konnotation aufweist (vgl. Bering 1978: 129-133). Zu dem gleichen Ergebnis kommt Klaus Bergmann. Ihm zufolge fungierte der Asphalt-Begriff als negativer Gegenbegriff zu „Blut-und-Boden“ „und wurde metaphorisch für die ,Wurzellosigkeit‘ des Großstädters und des jüdischen Großstädters verwendet“" (Bergmann 1970: 326). Bergmann weist darauf hin, dass diese Metapher in unterschiedlichen Variationen von Joseph Goebbels (1897-1945) verwendet wurde und in seinen Schriften identisch mit den Wörtern „Jude“, ,jüdisch“ und ,Judentum“ war (vgl. Bergmann 1970: 326). So schrieb Goebbles in einem Artikel, der mit Weltfeind überschrieben ist:

Auf dem Asphalt der modernen Großstädte errichtet der Weltjude die imperialistische Diktatur des roten Goldes; ihre Säulen sind Presse, Arbeiterbewegung, Parlament und Freiheit der bürgerlichen Parteien. (Goebbels 1935 [1928]: 334)

Damit der antisemitische Sinngehalt des Asphalt-Begriffs von den Rezipienten des Textes verstanden werden kann, ist ein expliziter Verweis auf „Juden“ oder das „Judentum“ nicht unbedingt notwendig. Hierin liegt der Grund, wieso Goebbels in einem Text von der ,jüdischen Asphaltpresse“ (1935 [1927]: 24) und in einem anderen von der „Berliner Asphaltpresse“ (1935 [1927]a: 22) sprechen kann, ohne dass sich der antisemitische Bedeutungsinhalt geändert hätte.

Ein paradigmatisches Beispiel für die Verwendung des Asphaltbegriffs in der völkischantisemitischen Literatur kann aus der von dem Artamanen Georg August Kenstler herausgegebenen Zeitschrift Blut und Boden. Monatsschrift für wurzelstarkes Bauerntum, deutsche Wesensart und nationale Freiheit entnommen werden. Ein dort veröffentlichter Appell, sich gegen die zunehmende ,geistige Verstädterung“ zu erheben, klingt wie folgt:

Denn Religion, Volk und Land haben heute ihren gemeinsamen Feind in dem Geist des Asphalts, in der seelenlosen Zivilisation der großen Stadt und dem seelenlosen Getriebe des zur Maschine gewordenen Staates. Gegen diese volksverderbenden Mächte rufen wir Euch zum Kampf heraus! Bauern heraus zur deutschen Revolution! Heraus zur Revolution von Blut und Boden! (Looff et al. 1931: 152)

Das Zitat enthält die etablierte und dem völkischen Lesepublikum wohlvertraute Antinomie von Großstadt/Zivilisation/Asphalt einerseits, Blut/Boden/Bauernstand andererseits. Der 
Autor dieser Zeilen kann sich zugleich sicher sein, dass die in völkischen Kreisen vorhandene assoziative Verbindung von „Juden“ und „Großstadt" ihre Wirkung nicht verfehlt und dadurch sein Text von den Lesern entsprechend verstanden und gedeutet wird.

In Erweiterung der Theorie Volkvos kann die Erkenntnis gewonnen werden, dass der Zusammenhang zwischen Antisemitismus und Großstadtfeindschaft durch die Semantik mit konstituiert wird. Volkovs sozio-linguistischer Ansatz basiert jedoch nicht darauf, wie Samuel Salzborn betont, dass Sprache und soziale Wirklichkeit miteinander gleichgesetzt werden. Ihre Theorie des Antisemitismus ist im Unterschied zu postmodernen Ansätzen nicht von der materiellen Basis der Wirklichkeit abgekoppelt (vgl. Salzborn 2010: 147-148). Es existiert jedoch ein bestimmtes Vokabular, auf dessen Grundlage sich eine assoziative Verbindung der Themenkomplexe „Juden“ und „Großstadt“ vollzieht. Diese Schlagwörter und Begriffe weisen nicht nur eine antisemitische und großstadtfeindliche Konnotation auf, sondern signalisieren die Akzeptanz der Übernahme einer umfassenden modernitätsfeindlichen Weltanschauung.

Die Begriffe drücken daher nicht nur eine Ablehnung der Großstadt und einen Hass auf Juden aus, sondern sind Ausdruck einer grundsätzlichen Ablehnung bestimmter kultureller und politischer Umbrüche der Moderne. Über die kommunizierte Großstadt- und Judenfeindschaft werden daher zugleich auch weitere Ideologiefragmente transportiert. Hierzu zählen eine ausgeprägte Intellektuellenfeindschaft, die Verherrlichung von „Blut-und-Boden“, sowie eine Agrarromantik, die mit der Verklärung des Bauernstandes einhergeht. Die Agitation antisemitischer Ideologien beruht dabei auf einem Wissenskanon, der das Verständnis zwischen Autoren und Rezipienten sicherstellt. Der Antisemitismus fungiert als eine Basisideologie, über die andere Ideologiefragmente miteinander verbunden sind. 
Zusammenfassung

Mit Parsons kann im Hinblick auf die völkische Bewegung darauf hingewiesen werden, dass deren Protagonisten im Kaiserreich von den Auswirkungen des Verstädterungsprozesses betroffen waren und dass diese Erfahrungen der Affektbildung Vorschub leisteten, die sich gegen Juden und Jüdinnen als Symbole einer urbanen Gesellschaft richteten. Die Wortführer der völkischen Bewegung waren mit den Großstädten aus eigener Anschauung vertraut, hielten zu ihnen Distanz, ohne sich jedoch von ihnen ganz abzuwenden. Wie im empirischen Kapitel dieser Studie gezeigt werden kann, entwickelte das Unbehagen, das die völkischen Ideologen angesichts der Großstadtentwicklung verspürten, eine antisemitische Projektionsorientierung.

Mit Rose gedacht, führt die für die Moderne wichtige Fähigkeit, sich dem modernen Großstadtleben anzupassen zu können bei Antisemiten zu einem mentalen Konflikt, da sie die Großstädte zugleich hassen und bewundern und sich ihre ambivalenten Gefühle ihnen gegenüber nicht eingestehen können. Dies hat zur Folge, dass Juden zu einem Symbol für das Großstadtleben gemacht werden, auf die diese widersprüchlichen Gefühle projiziert werden. Die affektgeladene Großstadtwahrnehmung der Völkischen müsste insofern von einem Judenbild geprägt sein, das die Juden als eine Personengruppe ausweist, die sich den Großstädten anpassen kann.

Mit und in Anlehnung an Postone kann die These formuliert werden, dass der Verstädterungsprozess als solcher in den Juden personifiziert wird und dass es einen Zusammenhang zwischen der Identifizierung der Juden mit Geld und Handel und ihrer Darstellung als Großstadtbewohner gibt. Im empirischen Material müssten sich demnach Ausführungen finden lassen, die die Verstädterung als einen von Juden imitierten Prozess beschreiben und die von dem Konnex Judentum, Geld und Großstadt handeln.

In Anlehnung an Volkov kann die Großstadtfeindschaft als Teil der modernitätsfeindlichen Kultur im wilhelminischen Kaiserreich begriffen werden, die durch den modernen Antisemitismus kulturell geformt wurde. Antisemitische Begriffe können innerhalb dieses Lagers auf einen großstadtfeindlichen Inhalt verweisen und umgekehrt. Die Bereitschaft, antisemitische Denkfiguren $\mathrm{zu}$ übernehmen korrespondiert mit der Bereitschaft, großstadtfeindliche Ideologeme zu akzeptieren. Die Interreferenz antisemitischer und 
großstadtfeindlicher Argumentationsmuster muss sich in völkischen Schriften nachweisen lassen. 
4. Historische Genese der Großstadtfeindschaft in Deutschland

Die Stadtkritik und die Idealisierung des Landlebens sind so alt wie die städtischen Hochkulturen selbst. Bereits Platon und Aristoteles hoben die Bedeutung des Bauernstandes hervor und hingen dem Ideal einer von der Agrarwirtschaft dominierten Kleinstadt an (vgl. Clapp 2009: 53). Negativ konnotierte Stadtbilder und Stadtmythen, die von einer sündhaften und dekadenten Lebensweise in einer von der göttlichen und natürlichen Ordnung losgelösten Stadt handeln, sind ein fester Bestandteil der christlich geprägten Ideengeschichte Europas. Wenngleich historisch tradierte Stereotype die Wahrnehmung der modernen Großstädte beeinflussen und mitgeprägt haben, existiert keine ungebrochene Kontinuität stadtfeindlichen Denkens von der Antike bis in die Gegenwart. Die mit der Verstädterung und Urbanisierung einhergehenden sozialen, kulturellen und politischen Umbrüche des Industriezeitalters sind ein genuines Phänomen des 19. Jahrhunderts und nicht vergleichbar mit früheren sozialen Transformationsprozessen.

Eine negative Sichtweise auf das moderne Stadtleben entwickelte sich in Deutschland jedoch nicht erst seit dem um 1870 einsetzenden Prozess der rapiden Verstädterung, sondern hat ihren historischen Ursprung im Wandel des traditionellen, im Mittelalter entstandenen Städtewesens, der in den meisten westeuropäischen Staaten um 1750 (vgl. Lees/Lees 2007) und in Deutschland um 1800 einsetzte. Zu dieser Zeit begannen sich die politischen, sozialen und ökonomischen Grundlagen des modernen Städtewesens in Deutschland herauszubilden (vgl. Krabbe 1989: 177). Zur Triebfeder der Transformation der Städte wurde das sich wandelnde Verhältnis zwischen Stadt und Nationalstaat. Im Zuge der Ausformung des modernen Nationalstaates unter der Herrschaft des Absolutismus verloren die Städte in Deutschland und in weiten Teilen Europas ihre im Mittelalter gewonnene Autonomie und wurden dem Machtanspruch des Nationalstaats untergeordnet: „By the eighteenth century, territorial balances of power had shifted decisively away from the cities toward the states that surrounded them“ (Lees/Lees 2007: 39). Begleitet wurde dieser Prozess von einer Öffnung der Städte gegenüber ihrem Umland, die in dem Abbau von Stadtmauern und anderen Begrenzungsanlagen ihren Ausdruck fand, so dass nicht mehr die physische Abgeschlossenheit, sondern die Offenheit zu einem zentralen Charakteristikum der Städte des 19. Jahrhunderts wurde. Die Nationalisierung der Städte und die mit der Industrialisierung zunehmende Verflechtung zwischen Stadt und Land waren zugleich die Voraussetzung für die Formulierung einer Stadtfeindschaft und schließlich einer Großstadtfeindschaft, die in gesamtgesellschaftlichen Zusammenhängen gedacht wurde und in deren Mittelpunkt der 
Gedanke rückte, dass die Städte bzw. die Großstädte eine Gefahr für die Bevölkerung und den Nationalstaat insgesamt darstellen.

Zentrale Thesen des Stadtdiskurses, der sich in der zweiten Hälfte des 18. Jahrhunderts zu entwickeln begann, wie beispielsweise die Behauptung, die Stadt stelle eine ungesunde Lebensumwelt dar, prägten die Großstadtfeindschaft des ausgehenden 19. Jahrhunderts. Die Darstellung der historischen Genese der Großstadtfeindschaft setzt in dieser Studie daher in der Mitte des 18. Jahrhunderts an, als sich die politischen, sozialen und ökonomischen Grundlagen für eine Modernisierung der Gesellschaft und der Städte begannen herauszubilden. Von der Existenz einer Großstadtfeindschaft in dem Zeitraum zwischen 1750 und 1850 kann indes nicht die Rede sein, existierten im Unterschied zu England und Frankreich im noch nicht vereinigten Deutschland zu dieser Zeit noch keine Metropolen, die sich ihrer Bedeutung und Größe nach von anderen Städten signifikant unterschieden. Mit Berlin überschritt erst in der Mitte des 18. Jahrhunderts die erste deutsche Stadt die Marke von 100000 Einwohnern, womit die Bevölkerungsentwicklung Berlins deutlich hinter der von Paris und London zurückblieb.

\subsection{Der hygienisch-medizinische Stadtdiskurs im 18. und 19. Jahrhundert}

Mit dem Funktionswandel des Städtewesens setzte ab der Mitte des 18. Jahrhunderts eine neue Betrachtungsweise des Stadtlebens in Europa und in Deutschland ein, die sich von vorhergehenden Reflexionen darin unterschied, dass sie mit dem Anspruch verbunden war, die Lebensverhältnisse in den Städten erfahrungs- und materialgestützt zu untersuchen. Damit wurde einerseits der Grundstein für eine empirisch ausgerichtete Stadtforschung gelegt und andererseits der Beginn einer das moderne Stadtleben problematisierenden Sichtweise markiert (vgl. Pfeil 1972: 27-38). ${ }^{13}$ Die Medizingeschichte hat herausgearbeitet, dass seit der Mitte des 18. Jahrhunderts die Annahme eines schädlichen und gesundheitsgefährdenden Einflusses der Städte auf die Gesundheit ihrer Bewohner eine weitverbreitete Lehrmeinung in der deutschen Medizin war (vgl. Bleker 1983, Krämer 2013). Geprägt war die Stadtkritik der Ärzte durch eine mit den Schriften Jean-Jacques Rousseaus und der Romantik in Verbindung stehenden Verklärung des Landlebens und der Natur (vgl. Bleker 1983: 121). Ulrich Linse hat

\footnotetext{
${ }^{13}$ Erste Ansätze einer statistischen Untersuchung der Geburten- und Sterberate in den Großstädten entwickelten sich bereits in der zweiten Hälfte des 17. Jahrhunderts in England. London hatte bereits um 1700 eine Einwohnerzahl von fast 700000 Bewohnern erreicht (vgl. Pfeil 1972: 27-28).
} 
hierzu angemerkt, dass das Bürgertum des 18. Jahrhunderts zunächst die Utopie eines moralischen, sozialen und politischen Fortschritts auf das Landleben und seine Bewohner projizierte, bevor diese Romantisierung im Laufe des 19. Jahrhunderts in eine modernitätsfeindliche Großstadtfeindschaft umschlug (vgl. Linse 1993: 314).

Die Medizinalstatistik des 18. und 19. Jahrhunderts versuchte die negativen Einflüsse des Stadtlebens statistisch zu erfassen und zielte darauf ab, Gesetzmäßigkeiten der städtischen Bevölkerungsentwicklung zu ermitteln (vgl. Pfeil 1972: 29). Diese Bemühungen standen zunehmend im Kontext sozialreformerischer Bestrebungen für eine Verbesserung der (groß)städtischen Lebensverhältnisse. Der dahinterstehende Grundgedanke war von der soziallamarckistischen Gesellschafts- und Bevölkerungstheorie geprägt, der zufolge Umwelteinflüsse einen direkten Einfluss auf das Erbgut eines Menschen und damit auch auf seine Nachkommenschaft haben. Es wurde angenommen, dass die gesundheitsgefährdenden Folgeerscheinungen des Stadtlebens mit einer Verbesserung des hygienischen Lebensstandards verschwänden. Im Zuge der Ausformung sozialmedizinischer Reformansätze in der zweiten Hälfte des 19. Jahrhunderts avancierte der Soziallamarckismus zur paradigmatischen Grundlage der stadthygienischen Debatte (vgl. Sieferle/Zimmermann 1992: 57).

Die während des 19. Jahrhunderts wiederholt auftretenden Choleraepidemien in den deutschen Städten sowie die schlechten Wohnverhältnisse des stetig wachsenden großstädtischen Proletariats schienen die stadtkritischen Annahmen der Mediziner zu bestätigen. Die Medizinhistorikerin Johanna Bleker kommt in ihrer Untersuchung zum medizinischen Diskurs zur Stadt im 18. und 19. Jahrhundert jedoch zu dem Schluss, dass die These von der Stadt als einer ungesunden Lebensumwelt, die eine deutlich höhere Mortalitätsrate verursache als das Land, nicht auf empirisch belastbarem Material, sondern auf Vorurteilen und normativen Setzungen beruhte, die dazu führten, dass an dieser Theorie in weiten Teilen der Medizin bis ins 20. Jahrhundert hinein festgehalten wurde (vgl. Bleker 1983; Gebhardt 1988). Es wäre daher ein Fehlschluss, sähe man hinter dem Gesundheitsdiskurs über das Stadtleben des späten 18. und des 19. Jahrhunderts nur pragmatische und problemorientierte Erwägungen.

Die zunehmende Fokussierung der staatlichen Bürokratie auf die Gesundheit der Bevölkerung steht in einem Zusammenhang mit dem sich ausformenden modernen Nationalstaat in Europa und ist Ausdruck und Folge dessen, was Michel Foucault als Bio-Macht bzw. Bio-Politik beschreibt: Hierunter versteht Foucault eine Macht zum Leben, deren höchste Funktion nicht 
mehr das Töten, sondern die Durchsetzung des Lebens ist. Die beiden Pole dieser im 17. Jahrhundert entstandenen Macht bilden die Disziplinierung des Körpers und die Regulierung der Bevölkerung. Foucault hebt dabei hervor, dass seit der Mitte des 18. Jahrhunderts Maßnahmen zur regulierenden Kontrolle der Gesundheit der Bevölkerung ergriffen wurden, die auf die Fortpflanzung, die Geburten- und Sterblichkeitsrate, das Gesundheitsniveau und die Lebensdauer der Bevölkerung abzielten (vgl. Foucault 2014: 129-153).

Aufgrund der wachsenden Bedeutung der Städte rückten die städtischen Lebensverhältnisse verstärkt in den Fokus der gesundheitswahrenden Politik des Staates. Die Diskussion über Hygiene und Gesundheit konzentrierte sich zunehmend auf das Stadtleben und fand allmählich Eingang in die Stadt- und Bevölkerungspolitik des absolutistischen Staates. Diese statistischen Erhebungen konzentrierten sich nicht nur auf vergleichsweise leicht quantifizierbare Indikatoren, wie die Geburten- und Sterblichkeitsrate, sondern versuchten einen negativen Einfluss des Stadtlebens auf die geistige und sittliche Veranlagung der Stadtbevölkerung nachzuweisen: „Early observers [of the cities; B.K.] assembled an impressive array of statistics on morality, infanticid, suicide, madness, prostitution, epidemics, and other social pathologies of great concern to municipal authorieties." (Nye 1985: 660). Stadtkritik und Stadtforschung waren in dieser Debatte zwei Seiten der gleichen Medaille, an der ersichtlich wird, dass die Stadtforschung von Beginn an eine observierende, inspizierende und kontrollierende Funktion übernahm (vgl. Lindner 2004: 13).

Die Soziologin Marianne Rodenstein hat in ihrer Studie zudem nachgewiesen, dass die mit der Ausformung der bürgerlichen Gesellschaft verbundene Vorstellung von Gesundheit den Städtebau in Theorie und Praxis seit 1750 zunehmend beeinflusste (vgl. Rodenstein 1988). Die ab der zweiten Hälfte des 18. Jahrhunderts erschienen medizinischen Polizeien zielten darauf ab, die Gesundheit zu einem Gegenstand staatlichen Handels zu machen und wurden von Ärzten und Medizinalstatistikern als ein Mittel begriffen, mit dem Einfluss auf die gesundheitswahrenden Aspekte des absolutistischen Städtebaus ausgeübt werden sollte (vgl. Rodenstein 1988: 46).

Bis Mitte des 19. Jahrhunderts war der Einfluss von Gesundheitsvorstellungen auf den Städtebau jedoch gering. Erst in der zweiten Hälfte des 19. Jahrhunderts entwickelte sich Rodenstein zufolge ,in Theorie und Praxis eine Richtung des Städtebaus, in der die Gesundheit der Bevölkerung als ein bei der Planung wesentlicher Gesichtspunkt plötzlich eine bedeutende Rolle spielt" (Rodenstein 1988: 67). Der entscheidende Grund, wieso Gesundheitskonzepte erst zu diesem Zeitpunkt für den Städtebau wichtig wurden, ist nach 
Rodenstein darin zu sehen, dass das Bürgertum die Themenfelder Hygiene und Moral in einen Kausalzusammenhang stellte. Die Wohnverhältnisse des stetig anwachsenden Proletariats bildeten aus Sicht bürgerlicher Stadt- und Wohnungsreformer einen Ansatzpunkt, um über Reformen Einfluss auf die Moral der Arbeiterschichten auszuüben. Das Interesse des Bürgertums an Reformen der Wohnungsversorge verdankte sich insofern der thematischen Verbindung der Wohnungsfrage mit den Themen Gesundheit und Moral (siehe für den intereuropäischen Vergleich Bullock/Read 1985).

Die Wohnungsfrage avancierte im wilhelminischen Kaiserreich $\mathrm{zu}$ dem innenpolitisch dominierenden Thema (vgl. Häußermann/Siebel 2000: 85). Dies verdankte sich dem Umstand, dass die Wohnsituation in den proletarischen Stadtvierteln zu einem immer drängenderen Problem wurde: seit dem ersten großen Verstädterungsschub im Jahr 1840 trat in den deutschen Großstädten, im Besonderen in Berlin, ein periodischer Mangel an bezahlbarem Wohnraum auf. Aufgrund der hohen Mietkosten, die nicht selten mehr als die Hälfte des Einkommens einer Arbeiterfamilie beanspruchten, wurden Schlafplätze und Zimmer an Fremde untervermietet, was zu einer Überbelegung vieler Wohnungen führte. Die Existenz von familienfremden Personen in den Wohnungen kennzeichnete das Familienleben vieler Arbeiterhaushalte.

Eine Wohnung wurde von der Statistik als überbelegt registriert, wenn auf ein heizbares Zimmer sechs oder mehr Personen kamen (vgl. Häußermann/Siebel 2000: 64). Im Berlin des Jahres 1875 traf dies auf jede fünfte Wohnung zu. Zudem waren die Wohnverhältnisse in den großstädtischen Arbeiterquartieren bis zur Jahrhundertwende oftmals durch eine unzureichende Trinkwasserversorgung, einen fehlenden Anschluss an das Kanalisationssystem und eine mangelnde Müllentsorgung geprägt. In der Überfüllung der Wohnungen, der Untervermietung von feuchten Kellern und schlecht isolierten Dachböden sowie in der dichten Überbauung der Grundstücke wurde von zeitgenössischen Beobachtern eine ernstzunehmende Gesundheitsgefährdung gesehen.

Im Mittelpunkt der bürgerlichen Wohnungsreformbewegung stand dabei die Annahme, dass sich eine Verbesserung der hygienischen Wohnverhältnisse auf die Moral und die Sittlichkeitsvorstellungen der Arbeiterschaft auswirkt. In diesem Zusammenhang wurde die sozialintegrative Funktion der Wohnungsversorgung hervorgehoben, mit deren Hilfe man sich eine Anpassung der proletarischen Schichten an die bürgerliche Kultur mit ihren Normen und Werten versprach. Nach Rodenstein konnte durch die Herstellung eines Zusammenhanges zwischen Wohnungsfrage und Gesundheit die Wohnungsnot an das zentrale Problem der 
bürgerlichen Gesellschaft des 19. Jahrhunderts gekoppelt werden: die Überwindung der Klassengegensätze (vgl. Rodenstein 1988: 121). Die Wohnungsnot in den Großstädten wurde von der Reformbewegung daher, wie Michael Honhart (1990: 5) hervorhebt, als eine grundsätzliche Gefahr für das Familienleben, die Religion, die Moral und den Patriotismus gesehen.

Ein wichtiges Anliegen der Reformer war es, die Wohnungen in Mehrfamilienhäusern mit einer besseren Luftzufuhr und einem stärkeren Lichteinfall auszustatten. „Mehr Licht, mehr Luft“ wurde zu einer ihrer zentralen Forderungen. In Bauplänen für die Errichtung neuer Mietshäuser wurde versucht, diesen Ansprüchen gerecht zu werden. Die Aktivitäten der Reformbewegung wirkten sich überdies maßgeblich darauf aus, dass sich in vielen deutschen Großstädten ab 1890 eine kommunale Wohnungspolitik zu entwickeln begann, die durch einen sozialen Wohnungsbau in den Wohnungsmarkt eingriff (vgl. Krabbe 1985: 428-429).

Die Ideen und Ansätze für eine Verbesserung der Wohnverhältnisse wurden dabei jedoch stets von einem Ideal aus gedacht, dem agrarromantische und großstadtfeindliche Motive zugrunde lagen: als ideale Lebens- und Wohnumgebung galt der Wohnungsreformbewegung das alleinstehende Einfamilienhaus mit Garten, das in die Tradition einer germanischen Siedlungsweise gestellt wurde (vgl. Bullock/Read 1985: 75). Dahinter stand die Vorstellung, dass die wurzellos gewordenen Arbeiterfamilien wieder zu bodenverwachsenen Menschen gemacht werden müssten. Die Einfamilienhäuser sollten in dem Verständnis der Reformer die Familien vor den negativen Einflüssen der Großstädte schützen (vgl. Bullock/Read 1985: 73). Als Negativfolie diente das mehrgeschossige Mehrfamilienhaus („Mietkasernen“), das auch dem Spiritus Rector der Großstadtfeindschaft, Wilhelm Heinrich Riehl, als Sinnbild der Verderbnis der modernen Großstädte galt (vgl. Riehl 1861: 238-246).

Der Historiker Wolfgang Krabbe konstatiert in diesem Zusammenhang, dass die Wohnungsreformbewegung von falschen ideologischen Prämissen ausgegangen sei und der Realität romantisch verklärte Vorbilder gegenübergestellt habe (vgl. Krabbe 1989: 91). Er weist darauf hin, dass weder die vorindustriellen Wohnbedingungen in den Städten, noch das Landleben komfortabler und hygienischer waren, ,,als der einfachste städtische Wohnstandard um die Jahrhundertwende“ (Krabbe 1989: 91; vgl. auch Wischermann 1986: 102-103). Andrew Lees hat in seinen Studien zur Großstadtfeindschaft in Deutschland hervorgehoben, dass es vielfältige Gemeinsamkeiten in der Argumentation von Stadtreformern und Großstadtfeinden gegeben hat. Erstere waren ihm zufolge mit den Lebensbedingungen in den 
Großstädten unzufrieden und wollten diese, im Unterschied $\mathrm{zu}$ den Großstadtfeinden, innerhalb der bestehenden Ordnung verbessern (vgl. Lees 1979: 75, 2002: 38).

Die Stadtkritik der Mediziner und der damit verbundene Hygiene- und Gesundheitsdiskurs, die als Vorgeschichte der Großstadtfeindschaft begriffen werden können, nahmen zentrale Aspekte der sich in der zweiten Hälfte des 19. Jahrhunderts in Deutschland herausbildenden Großstadtfeindschaft vorweg. Eine grundsätzlich negative Haltung gegenüber den Städten war damit jedoch nicht verbunden, fühlten sich die Ärzte und die Anhänger der Wohnungsreformbewegung einer überwiegend optimistischen Einschätzung der Großstadtentwicklung verpflichtet und waren der Überzeugung, dass die Großstädte eine lebenswerte und gesunde Umwelt darstellen können. Die Auseinandersetzung der Medizinalstatistiker und der Wohnungsreformer mit den städtischen und großstädtischen Lebensverhältnissen basierte jedoch nicht nur auf einer pragmatischen und erfahrungsgestützten Herangehensweise, sondern war in erheblichem Maße von Vorurteilen, Stereotypenbildung und konservativen Wertüberzeugungen geprägt.

Der Topos von der ungesunden und krankmachenden Stadt begleitete die Wahrnehmung der Großstadtentwicklung im 19. Jahrhundert und wurde $\mathrm{zu}$ einem der wirkmächtigsten Argumente, die gegen die modernen Großstädte hervorgebracht wurden. Der sich ab 1750 herausbildende Konnex von Stadtleben und Gesundheit respektive Krankheit lieferte mannigfaltige Anknüpfungspunkte für zivilisations- und modernisierungskritische Heimat-, Erneuerungs- und Reformbewegungen, die in der wilhelminischen Gesellschaft in Erscheinung traten.

\subsection{Großstadtfeindschaft im Kaiserreich und in der völkischen Bewegung}

Die im Kaiserreich weitverbreitete Ansicht, dass die moderne Großstadt sowohl Symptom als auch Ursache für die sozialen Fehlentwickelungen der Zeit ist, führte der Volkskundler und Kulturhistoriker Wilhelm Heinrich Riehl (1823-1897) in seinem vierbändigen Werk Die Naturgeschichte des Volkes als Grundlage einer deutschen Social-Politik in den 1850er Jahren erstmals zu einer kohärenten Ideologie zusammen (vgl. Lees 1979: 62; Bergmann 1970: 38). Riehl legte mit seinen Schriften die thematische Stoßrichtung und den Duktus der sich von da an entwickelnden Großstadtfeindschaft fest. Nach Klaus Bergmann handelt es sich bei den nachfolgenden Ideologieproduktionen stets um Variationen der Riehl'schen 
Argumentation, die zwar neue Akzente gesetzt und nach neuen Formulierungen gesucht, der Großstadtfeindschaft jedoch nur selten neue Aspekte hinzugefügt haben (vgl. Bergmann 1970: 38; Bahrdt 1998: 59).

Riehl kam zu seinen Einsichten nicht über die unmittelbare Erfahrung des Großstadtlebens; er schrieb seine Naturgeschichte zu einer Zeit, in der es mit Hamburg, Berlin und München nur drei Städte mit über 100000 Einwohnern gab und die von der Industrialisierung begleitete Verstädterung noch an ihrem Anfang stand. Sein Großstadtbild war daher von den Entwicklungen in Frankreich und im Besonderen von England geprägt, wo die Verstädterung und Industrialisierung zu einem deutlich früheren Zeitpunkt einsetzten. Einen persönlichen Eindruck von London, das bereits Anfang des 18. Jahrhunderts 700000 Einwohner zählte, konnte sich Riehl als Besucher der Weltausstellung verschaffen, die 1851 in der Stadt gastierte (vgl. Pfeil 1972: 39).

Die breitenwirksame Rezeption und Popularisierung seiner Gedanken zur Großstadtentwicklung im wilhelminischen Kaiserreich erfolgte hingegen bereits unter dem Eindruck eines gesellschaftlichen Transformationsprozesses, dessen unverkennbares Zeichen eine in der deutschen Geschichte noch nie dagewesene Binnenwanderung in die Städte war. Es wird geschätzt, dass zwischen 1860 und 1925 etwa 22 bis 25 Millionen Menschen ihre Ursprungsgemeinde verließen (vgl. Häußermann/Siebel 2004: 21). In der Folge sank der Anteil der Landbewohnerschaft an der Gesamtbevölkerung drastisch: Zwar blieb die absolute Zahl der ländlichen Bevölkerung zwischen 1871 und 1910 aufgrund eines Bevölkerungswachstums konstant, ihr relativer Anteil an der Bevölkerung sank jedoch in dieser Zeit von 63,9\% auf 39,9\%. Zugleich erhöhte sich der Anteil der großstädtischen Bewohnerschaft von 4,8\% auf 21,3\% (vgl. Köllmann 1992: 201). Die Anzahl der Großstädte erhöhte sich im selben Zeitraum von 8 auf 48, die absolute Zahl der Großstadtbewohner von 2 auf 14 Millionen (vgl. Bergmann 1970: 18).

Vor dem Hintergrund dieser Entwicklungen fungierte die Großstadtfeindschaft im Kaiserreich, wie Bergmann hervorhebt, als Ausdruck einer konservativ-vaterländischen Gesinnung, in deren Mittelpunkt sowohl das politische Primat der nationalen Einheit als auch ein romantisches und in Teilen irrationales Ideal von Gemeinschaft standen. In der Wahrnehmung der Großstadtfeinde untergrub die Entwicklung eines partikularen Klasseninteresses der organisierten großstädtischen Arbeiterschaft die gerade erst gewonnene Einheit Deutschlands. Zudem weckte die Unübersichtlichkeit der großstädtischen 
Massengesellschaft die Sehnsucht nach einer abgeschiedenen Idylle (vgl. Bergmann 1970: 70-85; Lees 1985: 172).

Die Abwanderung aus den ländlichen Gebieten in die städtischen Ballungszentren erregte gegen Ende des 19. Jahrhunderts verstärkt die Aufmerksamkeit großstadtfeindlicher Autoren. In den 1890er Jahren setzte eine publizistische Hochphase der Großstadtfeindschaft in Deutschland ein (vgl. Lees 1979: 65; Bergmann 1970: 70). Einen nachhaltigen und entscheidenden Einfluss auf die ideologische Ausformung der Großstadtfeindschaft übten Schriften sozialbiologistisch, sozialdarwinistisch und rassenhygienisch argumentierender Verstädterungstheoretiker aus, die auf der Grundlage statistischen Materials den Nachweis erbringen wollten, dass die Großstädte ohne Zuwanderung nicht überlebensfähig seien und dass Menschen mit einer überdurchschnittlichen erblichen Veranlagung infolge ihres sozialen Aufstiegs und aufgrund der ,widernatürlichen“ Lebensverhältnisse in den Großstädten immer weniger Kinder bekommen und infolgedessen in kurzer Generationenfolge aussterben würden.

Im Vergleich zu den vom Soziallamarckismus geprägten Betrachtungen über den Zusammenhang von großstädtischer Umwelt und Gesundheit stellten die sozialdarwinistischen und rassenhygienischen Verstädterungstheorien eine signifikante Radikalisierung dar. Während die Anhänger des Soziallamarckismus davon ausgingen, dass eine Modernisierung der großstädtischen Lebensverhältnisse die Voraussetzung für die Lösung der Probleme sei, die mit den Großstädten identifiziert wurden, sah der Sozialdarwinismus in einer Verfeinerung urbaner Lebensweisen die Ursache für den von ihm konstatierten Prozess einer „Gegenauslese“ in den Großstädten (vgl. Sieferle/Zimmermann 1992). Sozialdarwinistische und rassenhygienische Analysen zur Stadt-Land-Wanderung führten insofern unweigerlich $\mathrm{zu}$ zivilisationskritischen, kulturpessimistischen und degenerationstheoretischen Schlussfolgerungen.

Eine einflussreiche sozialbiologistische Untersuchung über die Auswirkungen der Verstädterung auf die Demografie stellt die Arbeit des Münchner Statistikers Georg Hansen dar, die 1889 unter dem Titel Die drei Bevölkerungsstufen erschien (vgl. Kapitel 5.2.). Seine Behauptung, wonach die Großstädte ohne den Zuzug aus ländlichen Gegenden innerhalb weniger Generationen aussterben würden, ,become one of the most pervasive and compelling lines of attack against the city among German anti-urbanists of all sorts“ wie Lees zutreffend feststellt (Lees 1985: 143). Seine Studie avancierte schnell zu einem Standardwerk der Großstadtfeindschaft, und seine These wurde von zahlreichen Ideologen aufgegriffen und 
radikalisiert (vgl. Lees 1979: 66). Die wichtigste Weiterentwicklung legte der alldeutsche Sozialdarwinist und Rassenhygieniker Otto Ammon (1842-1916) vor (vgl. Kapitel 5.3.).

Ihren Einfluss machten diese Schriften im Besonderen auf Bestrebungen geltend, die die Binnenwanderung umkehren wollten. Um die Menschen von einer Abwanderung in die Großstädte abzuhalten, sollten sowohl die Lebensbedingungen auf dem Land verbessert als auch ein besonderes Ethos des ländlichen Lebens kultiviert werden. Angeführt wurde diese Stadtfluchtbewegung von dem vormaligen Landschullehrer Heinrich Sohnrey (1859-1948), der ab 1893 die Zeitschrift Das Land. Zeitschrift für die sozialen und volkstümlichen Angelegenheiten auf dem Lande herausgab, die ein Zentralorgan des Kampfes gegen Binnenwanderung und Verstädterung war (vgl. Bergmann 1970: 63-64).

Inhalt und Duktus der in der Zeitschrift erschienen Artikel spiegelten den Grundtenor des großstadtfeindlichen Lagers im Kaiserreich wider: Das Landleben wurde von den Autoren der Zeitschrift als „Lebensquell“ und „Jungbrunnen“ der Nation und des Volkstums gepriesen, und es wurde wie selbstverständlich davon ausgegangen, dass - wie es in einem Artikel exemplarisch formuliert wurde - die Bewohnerschaft der Großstädte physisch und moralisch „entarten“ werde, „wenn nicht das Ackerbau und Viehzucht treibende übrige Land einen großen Teil seines Nachwuchses um des besseren Verdientes willen trotzdem dorthin sendete und so das Blut einer der naturgemäßen Lebensweise überwiegend entfremdeten großstädtischen Bevölkerung immer von neuem durch Zuführung gesunder Säfte aufrichte“ (o.A. 1896: 26).

In konservativen und nationalistischen Kreisen der wilhelminischen Gesellschaft avancierten die modernen Großstädte zu einem Feindbild, dem die Auflösung familiärer Beziehungen und Werte sowie eine Schwächung nationaler Stärke zur Last gelegt wurden. Die Bandbreite großstadtfeindlicher Stereotype reichte von der Behauptung, dass das Großstadtleben ein hohes Maß an Devianz in Form von Kriminalität, Materialismus und Egoismus fördere, bis hin zur der weitverbreiteten Furcht, dass männliche Großstadtbewohner den körperlichen Anforderungen des Militärdienstes nicht mehr gerecht würden (vgl. z.B. Sohnrey 1896: 4; o. A. 1902: 149).

Die rassenhygienischen Studien der Verstädterungstheoretiker beeinflussten im hohen Maße die gegen Ende des 19. Jahrhunderts entstehende völkische Bewegung und lieferten wichtige Impulse für die von den Völkischen angestrebte körperliche und geistige Erneuerung und „Gesundung“ des deutschen Volkes. In der Forschung hat sich in den letzten Jahren ein 
engeres Begriffsverständnis der völkischen Bewegung durchgesetzt (vgl. Botsch 2012: 10). ${ }^{14}$ Mit Puschner gesprochen handelt es sich bei den Völkischen um eine Sammlungsbewegung, die sich schwerpunktmäßig aus antisemitischen, alldeutsch/pangermanischen, lebensreformerischen, eugenischen, kulturell und bzw. oder religiös ausgerichteten Teilbewegungen zusammensetzte, die mitunter auch gegenläufige Standpunkte einnahmen und einander bekämpften (vgl. Puschner 2003: 446). Die Völkischen organisierten sich im Kaiserreich und in der Weimarer Republik in Vereinen, Verbänden, Gemeinden, Bünden, Orden und auch in Parteien, wobei der Verein die wichtigste Organisationsform der Bewegung bildete (vgl. Breuer 2008: 48).

Wenngleich es seit dem letzten Jahrzehnt des 19. Jahrhunderts einen Einigungswillen in den unterschiedlichen Segmenten der Bewegung gab, scheiterten bis zum Ersten Weltkrieg alle Versuche eine völkische Dachorganisation ins Leben zu rufen (vgl. Puschner 2001: 280). Nach Puschner geht die nach der Jahrhundertwende zunehmende Verbreitung völkischer Gedanken auf ein dichtes personelles Beziehungsgeflecht unzähligen organisatorischen Querverbindungen und einen fließenden ideologischen Übergang „zwischen völkischer Bewegung, nationalem Lager und den zivilisationskritischen (bildungs)bürgerlichen Protest-, Such- und Alternativbewegungen“ zurück (Puschner 2001: 280).

Der heterogenen inhaltlichen Ausrichtung der völkischen Bewegung stand eine große Homogenität der sozialen Trägerschicht gegenüber. Der überwiegende Teil der Völkischen stammte aus den protestantisch geprägten Gebieten des Deutschen Reiches, schwerpunktmäßig aus Sachen und Hessen, und rekurrierte sich aus dem unteren Mittelstand (selbst- und unselbstständige Kaufleute, Handwerker, kleine Beamte) (Breuer 2008: 48; zur völkischen Bewegung in Sachsen vgl. Piefel 2004).

Die völkische Bewegung agierte im Verlauf ihrer Wirkungsgeschichte im Spannungsfeld eines Volkstumsgedankens, der als eine geistig-kulturelle Einheit begriffen werden konnte, aber auch streng biologistisch im Sinne einer „Rasseneinheit“" interpretiert wurde. Die biologistische Auffassung dessen, was als völkisch und deutsch definiert wurde, gewann bis zum Ersten Weltkrieg immer mehr an Gewicht (vgl. Bergmann 1996: 456). Den dominanten

\footnotetext{
14 Hiermit verbunden ist die Bemühung die Völkischen typologisch zu erfassen und von anderen rechtsgerichteten Gruppen und Strömungen zu unterscheiden (vgl. hierfür die Arbeiten von Stefan Breuer). Ungeachtet dessen wird der Begriff völkisch in Teilen der Sozial- und Geisteswissenschaft und speziell in populärwissenschaftlichen Darstellungen synonym für eine rechtsextreme Weltanschauung oder einen auf dem Ideal ethnischer Homogenität beruhenden Nationalismus verwendet.
} 
Bezugspunkt der völkischen Ideologie bildete ein ethnisch-kulturell begründetes Konstrukt von Volk und Nation, das einem republikanischen und als „westlich“ apostrophierten Nationalstaatsverständnis entgegengesetzt wurde. Die Völkischen räumten der Idee der Volksgemeinschaft, verstanden als eine Gemeinschaft, die alle Teile eines als holistisch aufgefassten Volkes umfasst (vgl. Breuer 2008: 19), die Priorität gegenüber einer ständisch gegliederten Ordnung ein und definierten die Zugehörigkeit zur deutschen Nation explizit nicht über die Staatsangehörigkeit, sondern über die Zugehörigkeit zu einem fiktiven Volkstum. Der völkische Verleger, Publizist und Politiker Theodor Fritsch, der als einer der wenigen Völkischen die Bewegung sowohl im Kaiserreich als auch in der Weimarer Republik prägte, brachte in einem Artikel aus dem Jahr 1924 die gemeinsame Zielsetzung der völkischen Bewegung prägnant auf den Punkt, wenn er schreibt, dass die Völkischen danach strebten, alle der deutschen Nation „blutmäßig“ angehörenden Menschen zu einer Gemeinschaft zusammenzufassen (vgl. Fritsch 1924: 405).

Neben dem Nationalismus übten die zeitgenössischen Rassentheorien einen starken Einfluss auf die völkische Bewegung aus. Die große Mehrheit der Völkischen bezog sich positiv auf rassistische Kategorien und die wissenschaftlichen Ergebnisse der Rassenanthropologie und war daher der Überzeugung, dass das deutsche Volk überwiegend aus „Rassenmischlingen“ und nur zu einem geringen Teil aus „reinrassigen“ Ariern/Germanen bestehe. Das in der völkischen Bewegung mehrheitsfähige Verständnis von „Rasse“ stellte auf die Idee einer „Volksrasse“ ab und lief darauf hinaus, die Deutschen in ihrer Gesamtheit zu einem germanisch/arisch geprägten Volk zu erklären, das vor „fremdrassigen“, in erster Linie jüdischen Einflüssen, zu schützen sei. In völkischen Kreisen überwogen jedoch zugleich die Bedenken, dass das Ideal einer „Rassenreinheit“ eine exkludierende Wirkung entfalte und die Gesamtheit des deutschen Volkes nicht abbilde. Exemplarisch für diese Überlegungen steht die Folge Passage aus dem auf Text Die Rassenlehre und die Völkischen von Otto SchmidtGibichenfells:

Es ist also ganz ausgeschlossen, etwa die Forderungen zu erheben, das Blutsbekenntnis auf sämtliche Merkmale der nordischen bzw. germanischen Rasse auszudehnen. Das Äußerste in dieser Beziehung wäre das Überwiegen der germanischen bzw. nordischen Merkmale. Aber selbst diese Forderung würde schon viele ausschließen, die im völkischen Sinne als gut, ja als sehr gut deutsch zu bezeichnen sind. Wir dürfen eben niemals vergessen, daß unser Volk zwar noch in natürlicher und kultureller Beziehung germanisch bestimmt ist, daß aber bei ihm von einer auch nur annähernden Rassenreinheit nicht mehr die Rede sein kann. ,Rasse“ im strengen Sinne ist ein naturwissenschaftlicher, anthropologischer, hingegen ,Volk ${ }^{6}$ ein geschichtlicher und geographischer Begriff. (Schmidt-Gibichenfels 1922: 7) 
Die breite Rezeption der Rassenlehren stellte daher nicht das völkische Primat von Volk und Nation in Frage, sondern muss als Ausdruck einer Biologisierung des Nations- und Volksbegriffes im radikalen Nationalismus des späten 19. Jahrhunderts begriffen werden. Peter Walkenhorst zufolge verlor der radikale Nationalismus im Kaiserreich zunehmend an Geltung gegenüber einem etatistisch verstandenen Nationsverständnis. Radikale Nationalisten suchten daher nach einer Möglichkeit, das bisherige ethnisch-kulturelle Nationsverständnis zu ergänzen und wissenschaftlich abzusichern. Der mit akademischen Weihen versehene Rassebegriff erfüllte diese Funktion in Form eines semantischen Codes (vgl. Walkenhost 2007: 86). Das Verhältnis zwischen Nationalismus und Rassismus, wie es Walkenhost für den radikalen Nationalismus im Kaiserreich im Allgemeinen hervorhebt, trifft auch auf die völkische Bewegung zu:

Den semantischen Kern des radikalnationalistischen Rassenbegriffs bildete das emphatische Bekenntnis zur biologischen Determiniertheit der nationalen Gemeinschaft. Aufgrund seiner inhaltlichen Unbestimmtheit und Reichweite, die nicht nur die Grenzen des Nationalstaates, sondern auch diejenigen der 'Volksgemeinschaft' transzendierte, war der Rassenbegriff als politisch-soziale Ordnungskategorie für die radikalen Nationalisten jedoch unbrauchbar. Es besaß für sie deshalb auch nicht den Stellenwert eines neuen Deutungsmusters, das an die Stelle des Volksbegriffs treten konnte, sondern fungierte als ein semantischer Code, der auf die vermeintlich herausragende Bedeutung biologischer Faktoren für die Zukunft des deutschen Volkes verwies. (Walkenhorst 2007: 103-104)

Eine den Nationalismus und den Volkstumsgedanken transzendierende Rassenlehre war nicht mehrheitsfähig und entwickelte sich daher nur an den Rändern der völkischen Bewegung. Hierzu zählt der nach dem Ersten Weltkrieg entstehende Flügel der nordischen Bewegung, der sich grundsätzlich gegen eine Gleichsetzung von Volk und „Rasse“ aussprach und seine Hauptaufgabe darin sah, „nordische Rassenelemente“, die in ihrer ,reinsten“ Form mehrheitlich in der norddeutschen Bevölkerung, in Skandinavien und in Teilen Großbritanniens ausgemacht wurden, in der deutschen Bevölkerung durch einen rassenzüchterischen Prozess der „Aufnordung“ zu erhöhen. Der ideologische Disput, der im Hinblick auf die unterschiedliche Einschätzung des Verhältnisses zwischen Rasse und Nation im völkischen Lager existierte, lässt sich an zwei Referenzautoren des völkischen Rassismus aufzeigen: Houston Stewart Chamberlain (1855-1927) vertritt in seinem Werk Die Grundlagen des neunzehnten Jahrhunderts die in der völkischen Bewegung dominante Idee von der Existenz von „Volksrassen“. Er spricht von einem „organischen Verhältnis“, das zwischen Rasse und Nation bestünde und weist dem Nationalstaat der Neuzeit eine rassenbildende Funktion zu (Chamerlain 1901: 290-294). Als einer der führenden Vertreter der nordischen Bewegung, wendete sich Hans F.K. Günther (1891-1968) zwanzig Jahre später vehement gegen diese Annahme. So schreibt er in seiner Rassenkunde des deutschen 
Volkes: „Rasse und Volkstum decken sich nicht [...]. Es gibt keine italienische, spanische, griechische oder englische Rasse“ (Günther 1922: 7). Die transnationale und in Teilen auch antinationale Stoßrichtung des nordischen Denkens löste ideologische Konflikte in der völkischen Bewegung aus und traf mitunter auf heftigen Widerstand von Seiten völkischer Nationalisten (vgl. Lutzhöft 1971: 137-157; Essner 1994; Breuer 2009, 2010).

Die Heterogenität der völkischen Bewegung zeigt sich auch darin, dass sie ganz verschiedene Denkrichtungen und Geistesströmungen der Jahrhundertwende, wie Szientismus, Ästhetizismus, Subjektivismus, Naturalismus, Sozialismus und Idealismus, übernahm (vgl. Geisen et al. 1994: 368). Im Hinblick auf Fragen, die die Religion oder eben die ideologische Bestimmung des Rassekonzeptes betrafen, ergaben sich hierdurch unterschiedliche und sich zum Teil widersprechende weltanschauliche Begründungen innerhalb der völkischen Bewegung (vgl. Breuer 2004: 996-997). Das einheitsstiftende Moment der völkischen Bewegung ist nach Breuer daher nicht in der Weltanschauung zu suchen, sondern in der Gesinnung und Ideologie. Nach ihm unterscheidet sich die völkische Bewegung von anderen rechten Strömungen der Kaiserzeit durch eine Präferenz für Ungleichheit, eine Orientierung an der Nation und eine soziale Mittelstandideologie. Völkisch versteht er demgemäß als eine „rechtsnationalistische Gesinnung, die sich mit mittelständischen Ideologemen verbindet eine Kombination, an die dann wiederum weltanschauliche Optionen anlagern können, die so ausgeprägt sein können (aber nicht müssen), dass die durch Gesinnung und Ideologie gestiftete Einheit gesprengt wird“" (Breuer 2004: 1000).

Ein zentrales Element des völkischen Nationalismus ist der Antisemitismus, der in den einzelnen Strömungen und Segmenten der Bewegung unterschiedlich stark ausgeprägt war (vgl. Puschner 2003: 448). Breuer zufolge handelt es sich bei den Völkischen um diejenige Variante der politischen Rechten im Kaiserreich, die die engste Verbindung mit dem Antisemitismus eingegangen ist (vgl. Breuer 2005: 505).

Werner Bergmann zufolge entstanden die völkische und die antisemitische Bewegung unabhängig voneinander, verliefen dann eine Zeit lang parallel und nährten sich seit den späten 1890er Jahren einander an (vgl. Bergmann 1996: 449). Breuer nimmt in dieser Frage einen anderen Standpunkt ein und legt überzeugend dar, dass beide Bewegungen in ihrer jeweiligen Entstehung eng miteinander verbunden sind (vgl. Breuer 2004). Die völkische und antisemitische Bewegung können ihm zufolge analytisch auseinandergehalten werden; auf einer historisch-empirischen Ebene zeige sich jedoch, dass die Entstehung beider Bewegungen zeitlich miteinander zusammenhängt und dass sich zentrale Elemente des 
völkischen Diskurses in der antisemitischen Bewegung herausgebildet haben (vgl. Breuer 2008: 26-28). Nach ihm ist die völkische Bewegung das Produkt einer Harmonisierung- und Synthestisierungssstrategie innerhalb der antisemitischen Bewegung, mit der ein Mittelweg zwischen den modernen und anti-modernen Polen der Bewegung gefunden werden sollte (Breuer 2005).

Der völkische Antisemitismus war darum bemüht, die Judenfeindschaft als ein wesentliches Element und als Voraussetzung für eine Erneuerung des „Deutschtums“ darzustellen. Exemplarisch hierfür erklärte Hermann Jäger in einem im Hammer unter der Überschrift Der innere Zusammenhang der völkischen Forderungen erschienenen Text, „daß der deutsche Antisemitismus nicht etwas bloß Verneinendes ist, sondern daß er sich darstellt als ein Glied der gesamten völkischen Politik, deren durchaus positives Ziel die Gesunderhaltung und Gesundmachung des deutschen Volkes ist“ (Jäger 1920: 323).

Wie weiter oben bereits erwähnt, übte die großstadtfeindliche Ausrichtung der Rassenhygiene einen starken und nachhaltigen Einfluss auf die völkische Bewegung aus und trug dazu bei, dass die Großstadtfeindschaft zu einem konstitutiven Merkmal völkischen Denkens wurde. Die Rassenhygiene entwickelte sich als eine wissenschaftliche Spezialdisziplin im Anschluss an die Schriften des britischen Naturforschers und Cousins Charles Darwin, Francis Galton (1822-1911), gegen Ende des 19. Jahrhunderts in Deutschland. Sie verstand sich als eine anwendungsorientierte Wissenschaft, die, wie es Fitz Lenz in dem zweiten Band vom Grundriß der menschlichen Erblichkeitslehre und Rassenhygiene beschreibt, positiv auf die erbliche Veranlagung der Bevölkerung einwirken wolle und sich demgemäß als eine Hygiene der erblichen Veranlagung begreift (vgl. Lenz 1921: 111). Der Grundri $\beta$ erschien erstmals 1921 im Verlag des völkischen Verlegers Julius Friedrich Lehmann und wurde zum Standardwerk der Rassenhygiene in Deutschland, das aufgrund seiner Popularität nach den Namen der Autoren - Erwin Baur, Eugen Fischer und Fritz Lenz - benannt wurde („BaurFischer-Lenz"c) (vgl. Baur 1921 et al.).

In dem zweiten Band, für den Lenz alleine verantwortlich zeichnete, wird der Beweis versucht zu führen, dass die Unterschiede in der Fortpflanzung zwischen Stadt und Land von größter rassenbiologischer Bedeutung sind, ,da die durchschnittliche Erbbeschaffenheit der Stadt- und der Landbevölkerung infolge sozialer Auslese recht verschieden ist" (Lenz 1921: 98). Gemeint ist damit die bereits von Georg Hansen und Otto Ammon getroffene Feststellung, dass besonders begabte Menschen von dem Großstadtleben angezogen werden, während Menschen mit einer „schlechteren“ erblichen Veranlagung dazu tendierten, auf dem 
Land zurückzubleiben. In den Großstädten, so Lenz weiter, durchlaufen die rassisch hochwertigen Nachkommen der ländlichen Zuwanderer einen sozialen Aufstieg, der sich jedoch auf Kosten eines starken Geburtenrückgangs vollzieht. Die in den Großstädten unter den Bedingungen moderner Lebensverhältnisse stattfindende soziale Auslese sei daher die Ursache für eine biologische „Gegenauslese“, die zu einem schnellen Rückgang in der Begabung der Bevölkerung führt (vgl. Lenz 1921: 69-84).

In der völkischen Publizistik fungierten unter Bezugnahme auf die rassenhygienische Forschung und die einschlägige großstadtfeindliche Literatur, das Bauerntum und das Landleben als positive Gegenbilder zu den modernen Großstädten. Von ihnen sollte die körperliche und geistige Erneuerung und Wiedergeburt des „Deutschtums“ ausgehen. Im Landvolk und im Bauerntum sahen die Völkischen den unverfälschten Kern des Volkstums verkörpert und machten in ihnen die „Quelle der völkischen Gesundheit“ aus (Hering 1915: 70), die frei von ,jüdischen“ und „undeutschen“ respektive großstädtischen Einflüssen gewähnt wurden und daher durch die völkische Arbeit in ihrem Bestand gestärkt werden sollten. Die „modischen Großstadtpfuhle“, „die ins Ungemessene wachsen und das Land entvölkern“, wie es Adolf Reincke, der Herausgeber der völkischen Zeitschrift Heimdall, formulierte (1907: 15), wurden hingegen als eine dem deutschen Volk nicht zuträgliche und ungesunde Lebensumwelt beschrieben, die über kurz oder lang zu einer Zersetzung völkischer Identität und zu einem Geburtenrückgang unmittelbar beitrage.

Vor dem Hintergrund der Überzeugung, dass die Großstädte an der Volkskraft „,zehren“ und diese nur unter den Bedingungen des Landlebens vital gehalten werden könne, entwickelten sich in völkischen Kreisen Ansätze, die um die Idee einer ländlichen Menschenzucht, fernab großstädtischer Ballungszentren, kreisten. Zu den bekanntesten Siedlungsversuchen zählt die nahe Rheinsberg gelegene Siedlung Heimland, die aus dem Umfeld der Zeitschrift Hammer und der ihr angeschlossenen Hammerbünde hervorgegangen ist. Linse zufolge handelt es sich bei ihr um die einzig dauerhaft existierende völkische Genossenschaftssiedlung vor dem Ersten Weltkrieg. Nach dem Krieg setzte ein rapider Niedergang ein, der in der Inflationszeit zum Ende der Siedlung führte. Eine „rassische Erneuerung“ blieb nach Linse jedoch eine nicht umgesetzte Utopie der Heimland-Siedler (vgl. Linse 1996: 403-406). Zu einer in der völkischen Bewegung kontrovers diskutierten rassenzüchterischen Siedlungsidee zählte der Vorschlag von Willibald Hentschel (1858-1947), in sogenannten Mittgart-Siedlungen die Polygamie zu praktizieren. Die Umsetzung dieser Idee scheiterte nicht zuletzt an der zu geringen Bereitschaft von Frauen, daran mitzuwirken. 
In Studien zur völkischen Ideologie aus den 1960er Jahren werden die Großstadtfeindschaft und die Verherrlichung von Landschaft und Natur als ein Beleg für die antimoderne und irrationale Grundhaltung der völkischen Bewegung angeführt (vgl. Mosse 1964: 13-30; Stern 1961). Die These, dass die völkische Bewegung die Position einer radikalen Ablehnung gegenüber der modernen Industriegesellschaft eingenommen habe, wird von der neueren Forschung mehrheitlich nicht mehr geteilt (vgl. Puschner 2001: 155-165; Breuer 2008, 2010a). Breuer sieht das Verhältnis der Völkischen zur Moderne darin gekennzeichnet, dass sie die erste oder einfache Modernisierung - Leistungsprinzip, wissenschaftlich-technische Rationalität, funktionale Differenzierung - anerkannten, jedoch nicht die zweite, reflexive Modernisierung (vgl. Beck et al. 2001), die eine Modernisierung der Prämissen der Industriegesellschaft bzw. eine Modernisierung der Moderne meint, in deren Folge sich die Lebens- und Arbeitsformen der Kleinfamilie und die patriarchale Geschlechterordnung ändern (vgl. Breuer 2005, 2008, 2010a). Breuer zufolge begrüßten die Völkischen die Industrialisierung unter der Bedingung, dass die Rechte der Landwirtschaft und ein hoher Anteil der Landbevölkerung an der Gesamtbevölkerung gewahrt bleiben würden.

Im Hinblick auf die Großstadtwahrnehmung der völkischen Bewegung muss diesem Befund zugestimmt werden. Unter dem Eindruck einer sich rapide vollziehenden Verstädterung und Industrialisierung ging es der völkischen Bewegung des Kaiserreichs darum, einen von ihr konstatierten ländlichen und bäuerlichen Charakter des deutschen Volkes zu bewahren. Gemäß ihrer Forderung nach einer körperlichen und seelischen Erneuerung des Volkes sollte eine zunehmende Verstädterung des deutschen Volkes abgewendet werden. Dies schloss die Forderung mit ein, das Landleben als ein Gegengewicht zu den Großstädten zu erhalten und das Bauerntum von der kapitalistischen Verwertungslogik auszunehmen.

Städte wurden zwar als ein notwendiges Element „,nationalen Lebens“ anerkannt - einige Ideologen strebten eine Symbiose aus Stadt - und Bauernkultur an ${ }^{15}$ - dies schloss jedoch grundsätzlich jene Aspekte und Komponenten aus, die dem Leben in den Großstädten und Metropolen seit der Wende zum 20. Jahrhundert ihr unverkennbares Gepräge gaben: Vergnügungs- und Amüsierbetriebe, die Konsumwelt der Warenhäuser und die mit der Anonymität, Größe und Dichte der Großstädte verbundene Möglichkeit für ein deviantes Sozial- und Sexualverhalten waren mit völkischen Überzeugungen nicht vereinbar. Völkische Vorstellungen von städtischem Leben bezogen sich in ihrer überwiegenden Mehrheit auf das Ideal einer ländlich geprägten Kleinstadt von nicht mehr als 30000 Einwohnern, die Teil

\footnotetext{
${ }^{15}$ Vgl. z.B. Meurer 1903: 362; o. A. 1913: 99; Jäger 1920: 322.
} 
einer industrialisierten Wirtschaftsordnung sein sollte. Ein paradigmatisches Zeugnis für die völkische Stadtrezeption legte Theodor Fritsch 1914 in der von ihm herausgegebenen Zeitschrift Hammer ab:

Die Städte sollen ja auch in Zukunft bestehen, denn auch sie sind notwendig für gewisse kulturelle Aufgaben. Nur ist es ein krankhafter Zustand, wenn diese Städte wie Wasserköpfe anschwellen und darüber das Land verkümmert. Mich dünkt, daß ein Volk noch gut gedeihen kann, wenn ein Drittel desselben in gelehrten, künstlerischen, industriellen, kaufmännischen und beamtlichen Berufen tätig ist, während zwei Drittel durch Land- und Gartenbau sich nähern. (Fritsch 1914: 286)

Wenngleich also die Völkischen keine Rückkehr in eine vorindustrielle Agrarordnung anstrebten, wurde die Meinung strömungsübergreifend geteilt, dass die Großstädte eine lebensfeindliche Umwelt für das deutsche Volk darstellen würden. In der völkischen Literatur wurden daher unterschiedliche Ideen und Vorschläge diskutiert, wie dem negativen und „verzehrenden“ Einfluss der Großstädte entgegengewirkt werden könne: sie reichten von der Errichtung von Gartenstädten, über kostenlose Landaufenthalte für Kinder und Jugendliche aus den Städten, Landschulen, einen freiwilligen Landarbeitsdienst, die Schaffung von Einfamilienhäusern mit Garten, den Obst- und Gemüseanbau in den Großstädten bis hin zu den bereits erwähnten Konzepten einer rassischen Menschenzucht auf Bauernhöfen und in ländlichen Siedlungen.

Während andere gegen die Großstädte gerichteten Schriften im Kaiserreich nicht notwendigerweise antisemitisch waren oder - wie im Fall von Riehl - einen unsystematisch gebliebenen antisemitischen Impetus aufwiesen, verbanden eine Vielzahl der völkischen Autoren ihre ablehnende Betrachtung der Verstädterung und des modernen Großstadtlebens mit ihrem Antisemitismus. Ein anschauliches Beispiel hierfür liefert ein Zitat aus Julius Langbehns (1851-1997) Rembrandt als Erzieher, das einen maßgebenden Einfluss auf die Ausformung völkischen Denkens ausübte. Das Zitat kann insofern als paradigmatisch für die Grundausrichtung der antisemitischen Großstadtfeindschaft der Völkischen angesehen werden, da in ihm der Gedanke ausgedrückt wird, dass das Großstadtleben ,jüdische“ und daher ,undeutsche“ Charakterzüge aufweise. Langbehn spricht davon, dass

der rohe Geldkultus ein nordamerikanischer und zugleich jüdischer Zug [ist], welcher in dem jetzigen Berlin mehr und mehr überhand nimmt; eine deutsche und ehrenfeste Gesinnung sollte Dem gegenüber ganz entschieden Stellung nehmen. ${ }^{16}$ (Langbehn 1890: 308)

\footnotetext{
${ }^{16}$ An diesem Zitat lässt sich exemplarisch aufzeigen, dass die Großstadtfeindschaft ein verbindendes Element zwischen dem modernen Antisemitismus und dem Antiamerikanismus darstellt. Die assoziative Verbindung der amerikanischen Bevölkerung mit dem Großstadtleben vollzieht sich - analog zum Antisemitismus - über die Identifizierung der USA mit dem Geld und dem Finanzkapital. Exemplarisch hierfür erklärt Oswald Spengler in
} 
Wie im empirischen Kapitel dieser Studie gezeigt wird, symbolisierten die modernen Großstädte für die Völkischen Materialismus, Geldwirtschaft und Genusssucht, die von vielen Autoren der Bewegung auf ein ,jüdisches Prinzip“ zurückgeführt wurden. Hieraus ergab sich die Wahrnehmung der Großstädte als ,jüdisch“ und die Wahrnehmung der jüdischen Bevölkerung als eine großstädtische Bevölkerungsgruppe.

Die völkische Bewegung war diejenige Reform- und Erneuerungsbewegung des wilhelminischen Kaiserreichs, die in der Frage der Positionierung gegenüber den modernen Großstädten eine vergleichsweise negative und radikale Haltung einnahm. Sie war jedoch bei weitem nicht die einzige Bewegung, die sich von einer Stärkung des Landlebens eine Veränderung und Reform der Industriegesellschaft versprach. Die großstadtfeindlichen Schriften von Riehl, Hansen, Ammon und Sohnrey lieferten die ideelle Vorbereitung für Bewegungen, die in der Fin-de-Siècle-Stimmung der Jahrhundertwende einem praktischen Programm des Schutzes des Landvolkes und des Landlebens folgten (für einen Überblick vgl. Bergmann 1970: 85-174). Einen solchen Ansatz verfolgte etwa die Heimat- bzw. Heimatschutzbewegung, die den Naturschutz, die Denkmal- und die Volkstumspflege zu einem praktischen Programm zusammenführte und die, wie Andreas Knaut hervorhebt, dem ländlichen Leben eine besondere Aufmerksamkeit widmete und dessen Schutz und Erhaltung als besonders wichtig erachtete (vgl. Knaut 1991: 28).

Ansätze für eine Reform sozialer Verhältnisse durch eine Stärkung des Landlebens war dabei jedoch keine ausschließliche Domäne konservativer oder offen antidemokratischer Kräfte, wenngleich diese in den Erneuerungs- und Heimatbewegungen dominierten. Dass großstadtfeindliche Ideen und Praktiken auch auf sozialreformerische Bestrebungen einen Einfluss ausübten, die in ihrer Mehrheit nicht konservativ und völkisch ausgerichtet waren, zeigt das Beispiel der Lebensreformbewegung, bei der es sich um die einflussreichste Reformbewegung bzw. Reformbewegungen des Kaiserreichs handelt. ${ }^{17}$ Nach Linse ging von

seinem 1933 erschienenen letzten Buch, Jahre der Entscheidung, dass es sich bei den USA und den Amerikanern um ,ein unermeßliches Gebiet und um eine von Stadt zu Stadt schweifende Bevölkerung von Trappern [handelt], die in ihm auf die Dollarjagd gehen, rücksichtlos und ungebunden, denn das Gesetz ist nur für den da, der nicht schlau oder mächtig genug ist, es zu verachten“ (Spengler 1933: 48). Die Identifizierung der USA mit dem Geld hängt somit mit der Wahrnehmung der Amerikaner als einer wurzellosen, mobilen und daher großstädtisch geprägten Bevölkerung zusammen. Eine Untersuchung des Zusammenhangs zwischen Antiamerikanismus und Großstadtfeindschaft steht noch aus.

${ }^{17}$ Jürgen Reulecke zufolge provozierte die Großstadtfeindschaft der Lebensreformbewegung eine seriöse wissenschaftliche Auseinandersetzung mit den modernen Großstädten. Gegen Ende des 19. Jahrhunderts entstanden zum Teil in bewusster Abwehr gegen großstadtfeindliche Ideen wissenschaftliche Ansätze und Studien, die „die Entwicklungs- und Gestaltungsmöglichkeiten der modernen Großstadt optimistischer 
ihr die erste Phase eines ,praktischen Antiurbanismus“ in Deutschland aus. Für die Großstadtfeindschaft in Deutschland ist es ihm zufolge insgesamt charakteristisch, dass sie ihre Wirkung nicht nur auf der Einstellungsebene entfaltete, sondern sich phasenweise auch in praktischen Unternehmungen Bahn brach (vgl. Linse 1993: 315).

\subsection{Großstadtfeindschaft in der Lebensreformbewegung}

Die Anfänge der Lebensreformbewegung gehen auf das erste Drittel des 19. Jahrhunderts zurück, wenngleich der Begriff der Lebensreform erst gegen Ende des Jahrhunderts geprägt wurde. Ihre Hochphase erlebte sie im Kaiserreich (vgl. Frecot 1976: 138). Sie verstand sich als eine Gegenbewegung zur aufkommenden Industriegesellschaft, deren Folgen und Entstehungsbedingungen sie in den Mittelpunkt ihrer Kritik an den ungesunden Lebensverhältnissen stellte. So richtete sie sich in ihrem Kulturpessimismus nicht nur gegen die Industrialisierung und Verstädterung, sondern in einem spezifischeren Sinn gegen eine allumfassende Verwissenschaftlichung und Rationalisierung der Gesellschaft, die als schädlich für die individuelle Existenz gesehen wurden (vgl. Krabbe 1974: 14; Sprondel 1986: 316). Für die Lebensreformbewegung war es charakteristisch, dass sie ihre sozialreformerischen Bestrebungen nicht auf eine gesamtgesellschaftliche Veränderung ausrichtete, sondern einem ganzheitlichen Ansatz folgte, der im Individuum und in seiner Lebensweise den Ausgangspunkt für eine Gesellschaftsveränderung sah. Die Lebensreform wurde in erster Linie als eine Selbstreform aufgefasst.

Der Historiker Wolfgang Krabbe unterscheidet zwischen peripheren und spezifischen lebensreformerischen Bestrebungen. Zum äußeren Kreis der Lebensreformbewegung zählt er die Siedlungs- und Gartenstadtbewegung sowie die Boden- und Wohnungsreformbewegung. Den engeren Kreis bilden der Vegetarismus, die Nacktkultur und die Naturheilkunde sowie die Impfgegner, Feuerbestatter und Vivisektionsgegner. Zwischen diesen beiden Kreisen sieht er die Antialkoholbewegung. Außerhalb der Lebensreform stehend, jedoch mit ihr verbunden, verortet er die Jugendbewegung, die Reformpädagogik, die Volks- und Heimatschutzbewegung sowie die Anthroposophie (vgl. Krabbe 1974: 13). Eine besondere Bedeutung nimmt dabei der Vegetarismus ein, den Krabbe als Wurzel und ideologischen 
Motor der Lebensreformbewegung ansieht (vgl. Krabbe 1974: 49; Sprondel 1986). Er weist darauf hin, dass die Begriffe Lebensreform und Vegetarismus weitgehend deckungsgleich sind und dass der Vegetarismus alle anderen lebensreformerischen Bewegungen rezipiert und in eine globale Ideologie integriert hat (vgl. Krabbe 1974: 48).

Linse sieht im alten Bildungsbürgertum den Hauptträger der Lebensreformbewegung. Er begreift die Bewegung als eine Revolte eines Teils des Bildungsbürgertums gegen die sozialen und kulturellen Umbrüche der Moderne (vgl. Linse 1983: 30-33; Frecot 1976: 138). Nach ihm reagierte das alte Bildungsbürgertum auf seinen Statusverlust mit einem Rückfall in welttranszendierende, apokalyptische Denk- und sektiererische Organisationsmuster (vgl. Linse 1983: 31). In diesem Zusammenhang wendeten sich die der Lebensreform zugeneigten Bildungsbürger von den liberalen und sozialdemokratischen Parteien ab und entdeckten in der Lebensreform einen dritten Weg jenseits von Liberalismus und Kommunismus.

Der Behauptung, dass die Lebensreformbewegung überwiegend vom alten Bildungsbürgertum getragen wurde, widerspricht Eva Barlösius in ihrer Studie (vgl. Barlösius 1997: 129-171, 224-228). Nach ihr beruht diese Schlussfolgerung darauf, dass von den Ideen und der Selbstdarstellung der Bewegung auf die soziale Herkunft ihrer Mitglieder geschlossen werde. Sie dreht diesen Begründungszusammenhang um, indem sie einen Zusammenhang zwischen der Übernahme von lebensreformerischen bzw. vegetarischen Idealen mit einer spezifischen Interessenlage konstatiert. Sie weist in ihrer Studie nach, dass im Vegetarismus die mittlere technische Beamtenschaft des öffentlichen Dienstes und der Privatwirtschaft sowie Volksschullehrer und Künstler deutlich überrepräsentiert waren. Diese Berufsgruppen lassen sich ihr zufolge einem neuen Mittelstand zurechnen, dessen sozialer Aufstieg sich im Zuge der Industrialisierung und der gesellschaftlichen Modernisierung vollzog. Ökonomisch stünden die Mitglieder dieser Schicht der qualifizierten Arbeiterschicht nahe, in der Lebensführung orientierten sie sich jedoch am Bürgertum. Die durch den Vegetarismus repräsentierte systematische Lebensführung trug demzufolge $\mathrm{zu}$ ihrer kulturellen Verbürgerlichung bei, indem sie als Distinktionsmerkmal gegenüber proletarischen Schichten wirkten sollte (vgl. Barlösisus 1997: 170-171). Zugleich bot die vegetarische Lebensweise eine Möglichkeit, sich gegenüber den arrivierten bürgerlichen Schichten abzugrenzen. Insofern stellte die Lebensreformbewegung keine rebellierende, sondern vielmehr eine sozial angepasste Lebensweise dar, die zur sozialen und beruflichen Integration beitragen sollte (vgl. Barlösius 1997: 165-166). 
Obwohl sich in der Lebensreformbewegung nur eine sehr kleine Minderheit der deutschen Bevölkerung organisierte, konnte sie mit ihren Publikationen über Vegetarismus und Naturheilkunde bisweilen ein Massenpublikum erreichen. Sie übte damit einen nachhaltigen Einfluss auf das Gesundheitsbewusstsein und die Ernährungsweise breiter Bevölkerungsschichten aus (vgl. Krabbe 1974: 161-165; Sprondel 1986: 325). Der Organisationsgrad der Lebensreformbewegung verteilte sich sehr ungleich über das Deutsche Reich. Besonders stark vertreten war sie in protestantisch geprägten Großstädten in Norddeutschland und in Sachsen (vgl. Barlösius 1997: 115-125). Da sie mehrheitlich von bürgerlichen und protestantischen Schichten getragen wurde, war ihre Bedeutung in den Industriestädten des Ruhrgebiets, in denen es kein vergleichbares städtisches Bürgertum gab, relativ gering. Wenig Anklang fand sie überdies in den katholisch geprägten Gebieten Süddeutschlands, im Besonderen in Bayern, wo nur 1\% der Lebensreformer lebte. Der starke Einfluss der konfessionellen Bindung auf die Bereitschaft, lebensreformerische Ideale zu übernehmen, kann auf einen protestantischen Säkularisierungsprozess zurückgeführt werden, in dessen Folge es zu einer Trennung von kirchlichen Dogma und subjektiver Glaubensaneignung kam. Die Lebensreformbewegung kann demgemäß als eine ethischreligiös aufgeladene Bewegung verstanden werden, in deren Mittelpunkt eine diesseitig ausgerichtete Lebensführung stand (vgl. Sprondel 1986: 318-320; Barlösius 1997: 126-129). Die Entwicklung hin zu einem verweltlichten oder säkularisierten Glaubensbekenntnis blieb im Katholizismus, im Unterschied zum Protestantismus, weitgehend aus.

Die Frage, wie die Bewegung politisch einzustufen ist, wird von der Forschung unterschiedlich eingeschätzt. Wolfgang Krabbe hat darauf hingewiesen, dass sich die großen Dachverbände parteipolitisch und konfessionell neutral verhielten. Politische Äußerungen bezogen sich demzufolge auf die Sozialpolitik, wobei Spielarten des Sozialismus dominierten. Krabbe kommt zu dem Schluss, dass die Mehrheit der Mitglieder zumindest der Tendenz nach demokratisch eingestellt war (vgl. Krabbe 1974: 158-159). Ulrich Linse betont hingegen stärker den ambivalenten Charakter der Lebensreformbewegung: Sie sei einerseits aufgrund ihrer Großstadtfeindschaft, Rückwärtsgewandtheit und Realitätsferne präfaschistisch gewesen. Auf der anderen Seite lieferte sie jedoch einen positiven Beitrag zur Lösung „der durch Industrialisierung und Urbanisierung aufgeworfenen ökologischen, hygienischen und sozialpsychologischen Fragen“(vgl. Linse 1983: 33-34).

Linses Einschätzung macht darauf aufmerksam, dass die Lebensreformbewegung trotz oder gerade wegen ihrer kulturpessimistischen Grundintention zu einem Katalysator für die 
gesellschaftliche Modernisierung in Deutschland wurde. Walter Sprondel bestimmt in Hinsicht auf den Vegetarismus drei verstärkende Effekte, die die Lebensreformbewegung auf den Modernisierungsprozess ausübte: Die auf ein „Heilschicksal“ bezogenen Richtlinien zur Lebensführung gewannen ihre Geltung nur im Binnenbereich der Gruppe. Hierdurch wurden die gesellschaftlichen Subsysteme von jeder Heils- und Identitätsrelevanz entlastet, was zur Stärkung ihrer Autonomie führte. Dies trug zur Entwicklung einer gesellschaftlichen Differenzierung bei. Ein weiterer Aspekt betrifft die von der Bewegung forcierte Ausgestaltung einer Privatsphäre unter ihren Mitgliedern. Indem sie Essen, Kleidung und Freizeitaktivitäten als identitätsrelevant sakralisierte, förderte sie maßgeblich die Entwicklung von Identitätsentwürfen. Hierdurch leistete sie zugleich einen Beitrag zur Pluralisierung des Anbietermarktes für Identitätsentwürfe, was mit einer Schwächung kirchlich bestimmter Lebensentwürfe einherging. Somit trug die Bewegung zur Institutionalisierung einer heterogenen und offenen Kultur bei, wie sie für die moderne Gesellschaft charakteristisch ist (vgl. Sprondel 1986: 328). Von der Forschung wurde überzeugend herausgearbeitet, dass das Körperbild und die Körperpraktiken der Lebensreformbewegung ein Produkt der Moderne sind. Die Entdeckung des menschlichen Körpers als etwas Formbares setzte erst mit der beginnenden Individualisierung um die Mitte des 19. Jahrhunderts ein (vgl. Fritzen 2006: 235). Mit ihrem Körperideal, das die Werte Gesundheit, Leistungsbereitschaft, Selbstkontrolle, Attraktivität, Erfolg und Individualität umfasste, nahm die Lebensreformbewegung aktiv am Modernisierungsprozess teil (vgl. Wedemeyer-Kolwe 2004: 281).

Die Bedeutung und die Relevanz der Großstadtfeindschaft für die Lebensreformbewegung lassen sich an der ideologischen Ausrichtung des Vegetarismus exemplarisch aufzeigen. Der Vegetarismus sah in der Aufnahme gesunder, natürlicher Nahrung die Grundlage für einen Gleichklang von Körper und Geist. Die Harmonie des Körpers wurde als Voraussetzung für eine harmonische Lebensweise gesehen. Das Leitideal der völligen Harmonie war in der Wahrnehmung der Vegetarier jedoch nur fernab der modernen, urbanen Welt zu verwirklichen. Das soziale Zusammenleben in den Großstädten, das deutlich stärker als das Landleben von Anonymität, Arbeitsteilung und Konkurrenzdruck geprägt ist, zerstöre den von Natur aus harmonisch aufeinander abgestimmten Funktionszusammenhang von Leib und Seele (vgl. Sprondel 1986: 321). Überdies wurde es als unvermeidlich erachtet, dass die Menschen in der großstädtischen Industriegesellschaft unreine Nahrungsstoffe zu sich nähmen (vgl. Sprondel 1986: 321). Das Natürlichkeitsideal des Vegetarismus, demzufolge eine gesunde Ernährung und Lebensweise nur jenseits der Großstädte möglich sei, verband 
sich mit dem in den 1890er Jahren sich verstärkenden sozialbiologischen Diskurs über eine sich in den Großstädten vollziehende körperliche und geistige Degeneration. Die Großstädte erfüllten für die Lebensreformer geradezu eine Symbolfunktion für die These eines Zusammenhanges zwischen körperlicher Entartung und einer wachsenden Sittenlosigkeit und Lasterhaftigkeit (vgl. Krabbe 1974: 14). Die Überzeugung der Lebensreformer, dass die Großstädte eine krankmachende Umwelt darstellten, schloss an den sozialhygienischen und biomedizinischen Diskurs an, der die Großstadtentwicklung seit dem Ende des 18. Jahrhunderts begleitete.

Wie der Vegetarismus ging auch die Nacktkulturbewegung davon aus, dass sich in den Großstädten ein körperlicher und geistig-sittlicher Verfall vollziehe. So betrachteten ihre Anhänger gebräunte Haut nicht nur als ein soziales Distinktionsmerkmal gegenüber adligen Kreisen, sondern auch als ein Unterscheidungsmerkmal hinsichtlich des als verderblich angesehenen Großstadtlebens. Die Blässe wurde $\mathrm{zu}$ einem Kennzeichen des Großstadtmenschen erklärt, wohingegen die Bräune als Ausdruck einer körperlichen und geistigen Gesundung gesehen wurde (vgl. Wedemeyer-Kolwe 2004: 264). Die Großstadtfeindschaft der Anhänger der Freikörperkultur enthielt dabei das Moment einer Verteidigungsstrategie. Als Reaktion auf den an sie gerichteten Vorwurf, dem Sittenverfall Vorschub zu leisten, führte die FKK-Bewegung das Argument ins Feld, dass die Industriezivilisation und die modernen Großstädte mit ihren unzumutbaren hygienischen und unsittlichen Verhältnissen „Brutstätten der Unzucht“ seien (vgl. Wedemeyer-Kolwe 2004: 266). Aus Sicht der FKKler neutralisiere das Nacktsein in der Natur den Geschlechtstrieb, während der körperbetonte Kleidungsstil der großstädtischen Frauen als Ursache für die Entstehung eines unnatürlichen Sexualtriebs ausgemacht wurde.

Eine negative Fokussierung auf die moderne Großstadt kann als ideologischer Bezugspunkt der verschiedenen lebensreformerischen Bestrebungen gesehen werden. Eine Überhöhung der Natur und eine Idealisierung des Landlebens, welche vom Ideal der Bodenverbundenheit her gedacht wurden, einte die Reformansätze:

Alle diese Reformkonzeptionen gingen aus von einer Prämisse der verlorenen Bodenständigkeit und der Wurzellosigkeit der städtischen Massen, die durch verschiedene Maßnahmen mit der ihnen entfremdeten Natur erneut in Berührung gebracht werden sollten. (Krabbe 1974: 28)

Vor diesem Hintergrund ist es folgerichtig, dass die Lebensreformbewegung bestrebt war, eine lebensweltliche Alternative zu den Großstädten zu entwickeln. Als geeigneten Ansatz, um ihrem Ziel einer Erneuerung des Individuums jenseits der schädlichen Einflüsse der 
urbanen Industriezivilisation näher zu kommen, erschien der Bewegung die Errichtung von ländlichen Siedlungskommunen (vgl. Feld 1979: 16; Sprondel 1986: 322). Die genossenschaftliche Siedlung stand dabei im Mittelpunkt der lebensreformerischen Großstadtfeindschaft. Das Ziel dieser Siedlungen wurde mehrheitlich jedoch nicht in einer Abkehr von der modernen Gesellschaft gesehen. Die angestrebte alternative Lebensführung, die als ein Distinktionsmittel eingesetzt werden sollte, vertrug sich nicht mit einem radikalen Eskapismus. Viele Siedlungen der Lebensreformbewegung suchten daher die Nähe zu den Großstädten und setzten moderne Techniken zu deren Bewirtschaftung ein vgl. (Rohkrämer 1999: 125).

An den Rändern der Bewegung etablierten sich weitere, zum Teil umfassendere Konzepte einer praktischen Großstadtflucht. Von besonderer Bedeutung ist hierbei der Gedanke, den Gegensatz von Stadt und Land durch die Errichtung von Gartenstädten aufzulösen. Nach Linse führte die Gartenstadtidee die beiden Hauptstränge der Großstadtfeindschaft zusammen: die Idealisierung einer ländlichen Lebensweise und die Entwicklung einer Utopie der neuen Stadt (vgl. Linse 1993: 339). Die 1902 gegründete Deutsche Gartenstadtgesellschaft wurde maßgeblich durch das 1898 erschienene Buch To-Morrow. A Peaceful Path to Real Reform des Briten Ebenezer Howard (1850-1928) inspiriert. Zwei Jahre zuvor hatte bereits Theodor Fritsch in seinem Buch Die Stadt der Zukunft seine völkischen Vorstellungen von einer Gartenstadt publiziert. Noch Jahrzehnte später bezichtigte Fritsch Howard des geistigen Diebstahls und stellte diesbezüglich Mutmaßungen über eine angebliche jüdische Abstammung Howards an (vgl. Fritsch 1926a: 203). Der Plagiatsvorwurf entbehrt jeder Grundlage und dürfte aus dem Verdruss darüber erwachsen sein, dass seine Schrift, obwohl es starke inhaltliche Überschneidungen mit Howard gibt, einen geringeren Einfluss auf die Gartenstadtbewegung in Deutschland ausübte, wenngleich nicht davon gesprochen werden kann, dass sie von der Bewegung überhaupt nicht rezipiert wurde (vgl. Schubert 2004).

Sowohl Howard als auch Fritsch sahen es als eine Notwendigkeit an, dass in den Gartenstädten der Bodenspekulation ein Ende bereitet werden sollte, indem Grund und Boden ausschließlich von der Gemeinde verpachtet werde. Beide verbanden mit ihren Konzepten die Idee einer neu zugründenden Stadt, die nicht mehr als 30000 Einwohner haben sollte. Der Grundriss der Gartenstadt war kreisförmig angelegt, wobei jeder Zone bzw. jedem Ring eine andere Funktion zugedacht wurde: Im Zentrum der Stadt sollten öffentliche Gebäude (Rathaus, Bibliothek, Krankenhaus usw.) errichtet werden, die durch einen Stadtgarten mit 
dem ersten Stadtring verbunden sind, in dem sich Geschäftsläden befinden. Der anschließende kreisförmige Boulevard war der Errichtung von alleinstehenden Wohnhäusern mit angeschlossenem Garten vorbehalten. Der innere Bereich der spiralförmig angelegten Gartenstadt sollte in der Vorstellung Howards durch einen breit angelegten Gartenstreifen, gedacht als „grüner Gürtel“, von den Außenbezirken getrennt werden. Den äußeren Rändern der Stadt, die bereits eine deutliche Unterscheidung zwischen Stadt und Land vermissen lassen sollten, war die Ansiedlung von Fabriken und Lagerhallen zugedacht.

Mit den lebensreformerischen Siedlungsaktivitäten, die gegen Ende des 19. Jahrhunderts einsetzten und bereits nach der Jahrhundertwende an Schwung verloren, begann die erste Phase sozialreformerischer Siedlungsversuche in Deutschland (vgl. Linse 1983: 20). Wie es dem politisch heterogenen Charakter der Lebensreformbewegung entsprach, entwickelten sich Siedlungsaktivitäten über die politischen Lager hinweg. Die Bandbreite reichte dabei von sozialistisch/anarchistisch/pazifistisch, über spiritistisch-okkultistisch bis hin zu völkischantisemitisch orientieren Siedlungen (vgl. Frecot 1976: 139). Trotz der differierenden politischen Grundausrichtungen lagen den Siedlungsaktivitäten gemeinsam geteilte Motive zugrunde. Nach Linse waren die Siedlungen insofern „romantisch“, als sie gelebte Utopien sein wollten, die ,augenblicksgebundene ökonomische, politische und soziale Zwecksetzungen einer diese transzendierenden Zielsetzung unterwerfen“ (Linse 1983: 8). Nach Krabbe einte die Siedlungen vier Grundintentionen (1974: 36): erstens die Ablehnung des kapitalistischen Wirtschaftssystems, dem mit der Einführung einer Güterwirtschaft entgegengewirkt werden sollte; zweitens das Streben nach einem utopischen Zustand der „Natürlichkeit, Wahrhaftigkeit und Echtheit“; drittens die Schaffungen von Gemeinschaften, die sich Selbstzweck waren; und viertens das Streben nach einem naturverbundenen Leben jenseits der Großstadtzivilisation und einer wahrgenommenen Gemeinschaftsfremdheit.

Obwohl die meisten Lebensreformer einen positiven Begriff von „Volk“ und oftmals auch von „Volksgemeinschaft“ hatten, bildeten völkische Anschauungen eine Minderheitenmeinung im lebensreformerischen Spektrum (vgl. Krabbe 1984: 157). Nach Florentine Fritzen strebten die Lebensreformer eine gesündere Gesellschaft durch eine Reform aller ihrer Mitglieder an (vgl. Fritzen 2006: 249). Eine rege Siedlungsaktivität entfaltete die völkische Bewegung erst nach dem Ersten Weltkrieg (vgl. Linse 1996: 407409). Ideale und Ideen der Lebensreformbewegung, wie die Körpererziehung, die Alkoholabstinenz oder der Vegetarismus, übten jedoch einen nicht zu unterschätzenden Einfluss auf die völkische Bewegung im Allgemeinen und auf die völkische Rezeption der 
Rassenhygiene im Besonderen aus (vgl. Puschner 2001: 165-173). Die Lebensreform war für die völkische Bewegung attraktiv, zugleich suchten Lebensreformer die Nähe zu völkischen Kreisen. Es existierten vielfältige personelle Verflechtungen zwischen der Lebensreform- und der völkischen Bewegung (vgl. Puschner 2001: 167; Breuer 2008: 98-111).

$\mathrm{Zu}$ den bekanntesten Persönlichkeiten gehört der antisemitische Publizist Heinrich Pudor (1865-1943), der ein Vordenker der Nacktkulturbewegung war. Seine Großstadtfeindschaft war von rassistischen und nationalistischen Gedanken durchdrungen. So führte er in einer seiner Schriften aus, dass „die erste Forderung, die das deutsche Menschentum an die Städte zu stellen hat“, dahin gehe, „daß sie weitläufiger werden müssen“. In seiner Vorstellung sollten die Städte aus frei stehenden Häusern mit Garten bestehen und nicht aus mehrgeschossigen Mehrfamilienhäusern, da ,in diesem undeutschen Häuserhaufen und Massen-Quartieren ein wirklich deutsches Geschlecht nicht gedeihen [kann]“ (Pudor 1906: $13)$.

Die Verbindung zwischen der Lebensreform- und der völkischen Bewegung lässt sich zudem an der 1893 in der Nähe von Berlin gegründeten Vegetarischen Obstbau-Kolonie Eden veranschaulichen, die als eine der wenigen lebensreformerischen Siedlungsprojekte die nationalsozialistische Herrschaft überdauerte. Die Siedlung, die sich nach kurzer Zeit auch für Nichtvegetarier öffnete, stand von Beginn an völkischen Ideen nahe (vgl. Linse 1983: 40), warb für ihre Produkte in völkischen Zeitschriften (so etwa im Hammer. Blätter für deutschen Sinn) und zählte zu ihren Bewohnern einflussreiche Vordenker der völkischen Bewegung (vgl. Puschner 2001: 199).

Die Siedlungsaktivitäten der Lebensreformbewegung waren jedoch weitgehend erfolglos und endeten in der Regel mit der Auflösung der Siedlungskommunen. Nach der Jahrhundertwende gingen die Siedlungsaktivitäten stark zurück. Die zweite Phase einer praktisch ausgerichteten Großstadtfeindschaft setzte mit Ende des Ersten Weltkrieges ein. Diesen bis 1923 anhaltenden Schub bezeichnet Linse als die freideutsch-jugendbewegte Phase (vgl. Linse 1983: 20).

\subsection{Großstadtfeindschaft in der Jugendbewegung und der Weimarer Republik}

Die Anfänge der Jugendbewegung gehen über die Konstituierung einer sich als Freideutsch bezeichnenden Jugendbewegung im Jahre 1913 hinaus. Die Freideutsche Jugendbewegung 
hat ihre Wurzeln in Gemeinschaften und Bünden, in denen sich um die Jahrhundertwende höhere Schüler und Studenten zusammentaten. Die in quantitativer Hinsicht bedeutendste Gruppe bildeten dabei die Wandervögel. Im Mittelpunkt ihrer Aktivitäten stand das Jugendwandern und das damit verbundene Ziel „Volk“ und „Heimat“ kennenzulernen (vgl. Schenk 1991: 53-54). Die ideengeschichtlichen Ursprünge des Wandervogels reichen zurück bis zur romantischen Philosophie des 18. Jahrhunderts, die einen starken Einfluss auf die Jugendbewegung ausübte. Walter Laqueur begreift die Romantik als die Form der Gesellschaftskritik, wie sie in den Wandervogelverbänden artikuliert und gelebt wurde und in dem Streben nach einer Rückkehr zur Natur, der Abwendung von einer materialistischen Zivilisation, der Sehnsucht nach einem einfachen Leben, der Wiederentdeckung alter Volkslieder und Folklore sowie der Übernahme mittelalterlicher Namen und Sitten ihren Ausdruck fand (vgl. Laqueur 1962: 16-17).

$\mathrm{Zu}$ einem organisatorischen Zusammenschluss innerhalb der Jugendbewegung kam es auf dem Meißnerfest, das zwischen dem 11. und 13. Oktober 1913 in der Nähe von Kassel stattfand. Die mehr als zweitausend Besucher des Festes entstammten einem heterogenen Spektrum. Zu den eingeladenen Verbänden gehörten Wandervogelbünde, Abstinenzvereine, Reformschulen und Studentenverbindungen aus Deutschland und Österreich (vgl. Schenk 1991: 58). Die Zusammensetzung der teilnehmenden Verbände verrät eine ideologische und personelle Verbindung zur Lebensreformbewegung. In Analogie zu den Lebensreformern setzte die Freideutsche Jugendbewegung auf eine Sozialreform durch alltagskulturelle Abgrenzung gegenüber der Gesellschaft. Bei ihr trat im Unterschied zur Lebensreform das Moment einer Abgrenzung gegenüber der Erwachsenenwelt hinzu. Die Jugendbewegung vertrat einen Anspruch auf Eigenerziehung und Eigenverantwortlichkeit als Konzepte eines neuen jugendlichen Bewusstseins und einer jugendlichen Eigenwertigkeit (vgl. Knoll 1988: 11). Zugleich übte die zivilisationskritische und kulturpessimistische Grundhaltung des Bildungsbürgertums des wilhelminischen Kaiserreichs einen Einfluss auf die bürgerlichen Jugendbewegten aus. Nach Linse partizipierten die Jugendlichen an einem Verhaltensmodus der bildungsbürgerlichen Vatergeneration und sind somit als ein Teilaspekt der GebildetenRevolte dieser Zeit zu sehen (vgl. Linse 1976: 119). In die gleiche Richtung argumentiert Dietmar Schenk, wenn er hervorhebt, dass sich die Freideutsche Jugend in ihrer Kritik an der wilhelminischen Gesellschaft spezifisch bürgerlicher Denkmuster romantisch-idealistischer Provenienz bediente (vgl. Schenk 1991: 148). 
Schenk sieht die Weltanschauung der Freideutschen durch die beiden Leitbegriffe Idealismus und Romantik charakterisiert (vgl. Schenk 1991: 143): Als idealistisch sind demnach ihr Programm der Gewissensfreiheit und Selbsterziehung, ihre Hoffnung auf die Jugend als eine verändernde Kraft sowie die Radikalität ihres Veränderungswillens zu sehen, die Affinitäten zum Sozialismus aufwies. Als romantisch gelten ihm ihre Idee von Gemeinschaft, die einer romantisierenden Vorstellung von „Volk“ entspringt, sowie die partielle Nähe der Jugendbewegung $\mathrm{zu}$ politischen Konzepten der nationalen Integration unter völkischen Vorzeichen. Nach Schenk besaß ihr Nationalismus eine deutlich wahrnehmbare romantischutopische Komponente. Der unumstrittene Leitbegriff der Jugendbewegung war das „Volk“. Für die Freideutschen Jugendbewegten verbanden sich mit ihm auch agrarromantische und großstadtfeindliche Inhalte. In der Vorstellungswelt der Bewegung existierte das „Volk“ einerseits nur fernab der Großstädte in ländlichen und kleinstädtischen Gegenden, andererseits wurde unter dem Begriff „Volk“ ein noch zu verwirklichender Zustand verstanden, der gemeinhin als „Volksgemeinschaft“ bezeichnet wurde (vgl. Schenk 1991: 146).

Vor diesem Hintergrund wird verständlich, dass die Jugendbewegung der lebensreformerischen Siedlungsidee positiv gegenüberstand. Erste Debatten über die Errichtung von ländlichen Siedlungskommunen wurden von einem radikalen Teil der Jugendbewegung bereits vor dem Ersten Weltkrieg geführt (vgl. Linse 1983: 89). Die Erfahrung des Ersten Weltkrieges führte zu einer politischen Radikalisierung und zu einem neuen Aktivismus innerhalb der Freideutschen Jugendbewegung. Im Besonderen unter den Kriegsteilnehmern der Jugendbewegung wuchs durch die Kriegserfahrung der Wunsch nach einer aktiven Hinwendung zu einem Gemeinschaftsleben in der Natur. Linse zufolge stärkte die Kriegserfahrung sowohl die jugendbewegte Sehnsucht nach der Natur als auch ihren Glauben an eine den Klassenantagonismus überwindende Volksgemeinschaft (vgl. Linse 1983: 90-91): Inmitten der kriegsbedingten Landschaftsverwüstungen und Gräuel beschworen die Soldaten der Jugendbewegung in ihren Briefen die Schönheit der Natur und die heilende Kraft des Bodens. Zugleich führte der Kontakt mit Angehörigen des Proletariats in den Reihen der dem Bildungsbürgertum entstammenden Jugendbewegten zu der Überzeugung, dass sich die Fronterfahrung in die Nachkriegsordnung im Sinne einer die Klassenunterschiede überwindende Volksgemeinschaft übertragen lassen könne. ${ }^{18}$ Diese

\footnotetext{
${ }^{18}$ Die bürgerliche Jugendbewegung übte zugleich einen Einfluss auf sozialdemokratisch organisierte Verbände der Jungsozialisten aus. Nach dem Ersten Weltkrieg adaptierten Jungsozialisten auf der Suche nach einer „sozialistischen Persönlichkeit“, die das Primat der Lehre vom Sozialismus als das Produkt einer objektiven
} 
Entwicklung trug maßgeblich dazu bei, dass die ländliche Siedlungsarbeit nach dem Krieg zu einer Obsession der Jugendbewegung wurde (vgl. Linse 1993: 322).

Die Siedlungen, die der Freideutschen Jugendbewegung zugeordnet werden können, unterschieden sich in ihrer politischen Zielsetzung und ideologischen Begründung. Nach dem Ersten Weltkrieg setzte eine Spaltung der Bewegung ein, die zu einem endgültigen Verfall der Freideutschen Jugend als Organisationszusammenhang um 1923 führte (vgl. Preuß 1991: 227). Nach dem Krieg war die Bewegung durch eine zunehmende Polarisierung zwischen einem freideutsch-sozialistischen und einem völkischen Flügel gekennzeichnet. Schenk sieht den wesentlichen Unterschied zwischen beiden Positionen darin, dass sich im mehrheitlich „linken“ Lager eine pazifistische Grundhaltung durchgesetzt habe, die von dem völkischen Teil der Freideutschen nicht geteilt wurde (vgl. Schenk 1991: 176). Schenk weist zugleich darauf hin, dass diese aus der historischen Retroperspektive dargestellte Gegensätzlichkeit der beiden Positionen nicht dem in der Freideutschen Bewegung zu dieser Zeit existierenden Einigungswillen entsprach. Trotz inhaltlicher Auseinandersetzungen wurde von Vertretern beider Lager Wert darauf gelegt, die strömungsübergreifenden Gemeinsamkeiten hervorzuheben. Dass das völkische Lager von der Mehrheit der Freideutschen nicht als eine Gegenströmung wahrgenommen wurde, hängt mit der Bedeutungsoffenheit des Begriffs völkisch innerhalb der Jugendbewegung zusammen. In ihren Integrationsbemühungen definierten die Freideutschen den Begriff im Sinne einer Öffnung hin zum Volkstumsgedanken, der innerhalb der Bewegung konsensfähig war. Puschner weist in diesem Zusammenhang darauf hin, dass viele Jugendbewegten den Begriff völkisch undogmatisch und nicht im Sinne einer Rassenideologie verwendeten (vgl. Puschner 2010: $68)$.

Die ideologischen Schnittmengen, die die Zeit der relativen Einigkeit der Bewegung überdauerten (vgl. Schenk 1991: 176), lassen sich anhand der Ausrichtung der Siedlungen herausarbeiten. In der Siedlungsphase von 1918 bis 1923 dominierten Siedlungen, die sich als sozialistisch verstanden. Unabhängig von der politischen Positionierung benennt Linse drei Charakteristika, die sozialistische, völkische und religiöse Siedlungen miteinander verbanden (vgl. Linse 1983: 91-96): zum einen die schon angesprochene Idee einer die sozialen

Entwicklung ökonomischer Verhältnisse in Frage stellte, Verhaltensmodi und ästhetische Ausdrucksformen der bürgerlichen Lebensreform- und Wandervogelbewegung: „Lebensreform, Naturverbundenheit und Sozialismus waren vielen Jungsozialisten in der unmittelbaren Nachkriegszeit verwandte, wenn nicht gar synonyme Momente im Ringen um den ,neuen Menschen“ “(Walter 1986: 18). 
Gegensätze in sich aufhebende Volksgemeinschaft. Der Unterschied zwischen „,sozialistisch“ und „,ölkisch“ bestand Linse zufolge darin, dass die sozialistische Konzeption potentiell alle Menschen umfasste. In der Jugendbewegung bestand Uneinigkeit in der Frage der Aufnahme von Juden und Jüdinnen. Wenngleich es in der gesamten Freideutschen Jugendbewegung einen latenten Antisemitismus gab, behielten die Gegner einer Ausschlusspraxis zumindest verbal die Oberhand (vgl. Schenk 1991: 180-184). Mehrere Wandervogelverbände schlossen jedoch bereits vor 1914 Juden grundsätzlich von einer Mitgliedschaft aus, und führende Köpfe der Bewegung verbreiteten in ihren Schriften antisemitisches Gedankengut (vgl. Winnecken 1991; Greiert 2011: 899; Niemeyer 2013: 143-160).

Der zweite Gesichtspunkt betrifft den bildungsbürgerlichen Führungsanspruch, den die Jugendbewegung mit den Siedlungen verband. Von ihnen sollte eine gegen den Materialismus gerichtete geistige Erneuerung ausgehen. Das dritte Kennzeichen der Siedlungen bezieht sich auf die antikapitalistische Produktions- und Lebensweise, die mit den Siedlungen versucht wurde zu etablieren. Die Siedlungen sollten nicht auf zweck- und wirtschaftsrationalen Prinzipien basieren, sondern im Kontrast zum kapitalistischen Profitstreben der Bildung einer egalitären Gemeinschaft dienen. Nach Linse verweisen diese Charakteristika darauf, dass es bei der von der Jugendbewegung vertretenen Politik des „Dritten Weges“ keine deutlichen Grenzen zwischen linken und rechten Positionen gab. Vielmehr bewegte sich die lebensreformerische und jugendbewegte Gebildetenrevolte zwischen reaktionären und revolutionären Zielsetzungen (vgl. Linse 1983: 95). Die Hochphase der Siedlungsaktivitäten innerhalb der Jugendbewegung fällt auf die ersten Jahre der Weimarer Republik. Mit deren Konsolidierung verloren auch die Siedlungen an Bedeutung (vgl. Linse 1982/83: 16). Zu einer erneuten Hinwendung zur Siedlungsidee in der Jugendbewegung kam es im Zuge der Weltwirtschaftskrise Ende der 1920er Jahre.

Diesen Zeitabschnitt beschreibt Linse als die bündisch-jugendbewegte Phase (vgl. Linse 1983: 21). In dieser bis zur Machtübergabe an die Nationalsozialisten anhaltenden Phase des jugendbewegten Siedlungsaufbaus verschwanden linke respektive nicht-völkische Siedlungsideen fast vollständig (vgl. Linse 1993: 330-331). Getragen wurden die Siedlungen in erster Linie vom völkischen Flügel der Bündischen Jugend.

Die Jugendbewegten betrachteten die Bünde als ein Gegenmodell zum künstlich geschaffenen Staat der Weimarer Republik. Die Bünde sollten ihrem Selbstverständnis nach als eine natürlich gewachsene und organische Gemeinschaft dem „Wesen des Volkes“ entsprechen (vgl. Barth 2006: 62). Das Nationalempfinden der Bündischen Jugend richtete sich demnach 
nicht auf den Staat, sondern auf ein imaginäres Volk (vgl. Jovy 1984: 89). Rüdiger Ahrens kommt in seiner Untersuchung zur bündischen Jugend zu dem Schluss, dass sich eine völkische Orientierung bereits Anfang der 1920er Jahre, in der Phase der Formierung der bündischen Jugend, durchsetzte (vgl. Ahrens 2015: 383). Er verortet die Bewegung in dem historischen Zusammenhang der politischen Rechten und sieht sie ideologisch darüber gekennzeichnet, dass sie das Volk im Sinne eines historisch-genetischen Abstammungsverbands ,gegen den Individualismus der Liberalen und den Klassenkollektivismus der Linken zum Subjekt der Geschichte erklärte“ (Ahrens 2015: 10).

Der Beginn eines verstärkten Aktivismus innerhalb völkisch-jugendbewegter Kreise, der sich mit dem Ausbruch der Weltwirtschaftskrise in einer erneuten Hinwendung zu ländlichen Siedlungen ausdrückte, setzte um die Mitte der 1920er Jahre ein. Die Radikalisierung der Großstadtfeindschaft in diesen Kreisen kann in zweifacher Hinsicht als eine Folge des durchschlagenden Erfolges von Oswald Spenglers Der Untergang des Abendlandes gesehen werden. Der kurz nach Ende des Ersten Weltkrieges publizierte erste Band des Buches erfüllte das im Bürgertum vorherrschende Bedürfnis nach einer ideengeschichtlichen Einordnung und Bewertung der vorrangegangenen und noch anhaltenden sozioökonomischen und kulturellen Transformationsprozesse. Der Titel des Buches hatte dabei das Potential die kulturpessimistische und zivilisationskritische Grundhaltung weiter Teile des Bürgertums auf den Begriff zu bringen. Die große Aufmerksamkeit, die dem Buch zuteilwurde, verdankte sich auch dem Umstand, dass die Großstadtfeindschaft das zentrale Moment seiner geschichtsphilosophischen Betrachtungen bildete. Die Herausbildung der Groß- und Weltstädte rückte Spengler in den Mittelpunkt seiner umfassenden Interpretation der Entwicklung und schließlich des Niedergangs der abendländischen Gesellschaften. Mit dem Untergang des Abendlandes trug Spengler maßgeblich dazu bei, großstadtfeindliches und agrarromantisches Denken im städtischen Bürgertum zu popularisieren und zu etablieren. Nach Bergmann war er „der Ideologe eines kulturpessimistischen Bürgertums, der dessen Unbehagen in vermeintlich wissenschaftlicher Form bestätigte“ (Bergmann 1970: 179). Die geschichtsphilosophische bzw. -deterministische Ausrichtung seiner Großstadtfeindschaft ließ Spengler zu dem populärsten und radikalsten Interpreten der Feindschaft gegenüber der Großstadt in Deutschland werden (vgl. Reulecke 1985: 40).

Unter denjenigen rechts-intellektuellen Autoren und Schriftstellern der Weimarer Republik, die von der Forschung unterschiedlich konturiert unter dem Sammelbegriff der Konservativen Revolution, des neuen Nationalismus (vgl. Breuer 1995, 2010a) oder des Neokonservatismus 
(vgl. Dupeux 2005) gefasst werden, ist Spengler derjenige Ideologe gewesen, dessen Feindschaft gegenüber der modernen Großstadt am stärksten ausgeprägt war. Seine Thesen zu den Großstädten und dem Bauerntum, wenngleich sie nicht antisemitisch begründet waren, lieferten für die völkische und schließlich die nationalsozialistische Bewegung genug Anhaltspunkte, um in Teilen übernommen werden zu können. Die Haltung anderer rechter Intellektueller gegenüber den Großstädten unterschied sich von der Großstadtfeindschaft Spenglers darin, dass sie in deutlich geringerem Maße mit einer Idealisierung des Landlebens und des Bauernstandes korrespondierte (vgl. Dietz 2008). Die antiliberalen und antidemokratischen Ideen des neuen Nationalismus bzw. der neuen Nationalismen (vgl. Mommsen 2005) hoben sich durch eine stark ausgeprägte Affirmation der modernen Technik (vgl. Rohkrämer 1999), der Präferenz für eine Inklusion der Arbeiterklasse in die Nation und eine antibürgerliche und in Teilen nationalbolschewistische Grundhaltung von nationalistischen und konservativen Strömungen des Kaiserreichs ab (vgl. Breuer 2010a: 176203).

Im Hinblick auf die Großstadtrezeption nahm Ernst Jünger (1895-1998) die Gegenposition zu Spengler ein. In dem 1926 veröffentlichten Aufsatz, der mit dem programmatischen Titel Gross-Stadt und Land überschrieben ist, erteilte Jünger der Bauerntumsideologie und der Agrarromantik eine deutliche Absage und kritisierte die völkisch grundierte Großstadtfeindschaft scharf. Der völkischen Bewegung warf er eine unzeitgemäße Verklärung des Landlebens vor und plädierte wider diese „verfehlte Romantik“ dafür, die Kräfte für eine nationale Erhebung in den Großstädten zu suchen, da ihnen die Zukunft gehöre. ${ }^{19}$ Sein Credo lautete daher: „Wir müssen eindringen in die Kräfte der Großstadt, in die Kräfte unserer Zeit, die Maschine, die Massen, den Arbeiter“(Jünger 2001 [1926]: 233).

Jüngers Ausführungen können jedoch nicht als Beleg für eine grundsätzlich positive Haltung jener rechten Intellektueller herangezogen werden, die unter dem Sammelbegriff der Konservativen Revolution gefasst werden. Die Forschung ist sich darin einig, dass die Großstadtfeindschaft ein verbindendes Element jener nationalistischen Kreise war. Klaus von Beyme konstatiert diesbezüglich, dass mit der Ausnahme Jüngers, alle Protagonisten der Konservativen Revolution Vorurteile gegen die Großstadt hegten (vgl. von Beyme 2013:

\footnotetext{
${ }^{19}$ Jüngers Kritik provozierte eine Gegenreaktion aus den Reihen der Völkischen. Gerstenhauer attestierte Jünger in seiner Darstellung der Geschichte der völkischen Bewegung, dass dieser die Grundfrage allen Daseins, die Frage von „Blut und Boden“ negiere und damit unter Beweis gestellt habe, „da $ß$ er im Liberalismus zutiefst und wohl unrettbar befangen ist" (Gerstenhauser 1933: 3).
} 
236). Bernhard Dietz macht in der Großstadtfeindschaft ein zentrales Element einer von der Konservativen Revolution favorisierten Politik des dritten Weges jenseits von Liberalismus und Marxismus aus und sieht in ihr ein Mittel, mit dem gegen die politische Linke, den Westen und die Weimarer Demokratie mobilisiert wurde (vgl. Dietz 2008: 803). Jeffrey Herf stellt in den Schriften der Konservativen Revolution eine unterschiedliche Technik- und Großstadtrezeption fest: Während die moderne Technik auf eine große Zustimmung traf, wurden die Großstädte und im Besonderen Berlin als Symbole des Liberalismus und des Kosmopolitismus abgelehnt (vgl. Herf 1993).

Praktische Schlussfolgerungen, wie mit den Großstädten zu verfahren sei, enthielt die Publizistik rechtsintellektueller Zirkel in der Regel nicht. Die zeitgenössische Rezeption dieser Werke war daher auch von dem Vorwurf einer ausschließlich theoretischen Großstadtkritik geprägt, die nicht selten als Ausdruck eines städtischen und „wurzellosen Intellektualismus“ verstanden wurde. So wurde Spengler einerseits sein Fatalismus als eine Willensschwäche ausgelegt, andererseits bestärkte er den radikal-völkischen Flügel der bündischen Jugendbewegung in ihren Bemühungen für eine zur Praxis drängenden Großstadtfeindschaft. Der völkische Gedanke einer Ansiedlung von Großstadtbewohnern auf dem Land entwickelte sich sowohl im Anschluss an als auch im Widerspruch zu Spengler. Die Völkischen übernahmen seine großstadtfeindlichen, antidemokratischen und kulturpessimistischen Ressentiments, ohne jedoch sein geschichtsphilosophisches Konzept zu akzeptieren (vgl. Bergmann 1970: 217).

In ideologischer und organisatorischer Hinsicht spielte Bruno Tanzmann (1878-1939) eine entscheidende Rolle für die Herausbildung einer radikalen und praxisorientierten Großstadtfeindschaft innerhalb des völkischen Flügels der Jugendbewegung in der Weimarer Republik. Tanzmann gehört zu den Begründern der Deutschen Bauernhochschulbewegung (vgl. Bergmann 1970: 219-246). Nachdem bereits ab 1919 die als Zentralorgan der Bewegung fungierende Zeitschrift Die Deutsche Bauernhochschule herausgegeben wurde, entstanden bis 1923 sechs sogenannte Bauernhochschulen. In diesen internatähnlichen Einrichtungen sollten Schüler und Lehrer nach Lehrplänen arbeiten, die von Tanzmann maßgeblich beeinflusst waren. Sie dienten vorrangig dem Zweck, die ländliche Bevölkerung im völkischen Sinne zu beeinflussen und $\mathrm{zu}$ einem ,germanischen Bauerngeschlecht“ umzuerziehen. In der Vorstellung Tanzmanns bildete das naturverbundene Bauerntum den Kern des deutschen Volkes, von dem aus die Bildung einer ,neue[n], wahrhaftige[n] Volksgemeinschaft“ ausgehen sollte (Tanzmann 1923: 5). Nachdem Tanzmann 1925 den Vorsitz der 
Schirmherrschaft der Deutschen Bauernhochschule niederlegt hatte, wendete er sich der Jugendbewegung zu, die er für seinen völkischen Aktivismus zu gewinnen suchte. 1923 wendete er sich erstmalig an die deutsche Jugend mit der Aufforderung, an einer Inneren Kolonisation der deutschen Ostgebiete mitzuwirken. Als sogenannte Siedlungsbauern sollten junge Deutsche einen „kraftvollen Volkskern“ bilden und die Voraussetzungen für eine Expansion über die deutschen Staatsgrenzen nach Osteuropa schaffen (vgl. Piefel 2005: 269270). Hiermit gab Tanzmann der Gründung der Artamanenbewegung den entscheidenden Anstoß.

Die Artamanen gehörten dem rechten, vom nordischen Denken beeinflussten Flügel der Bündischen Jugend an und nahmen in der Frage zu den Großstädten und der Verstädterung eine exponierte Stellung ein. Nach Bergmann handelt es sich bei ihnen um die einzige Gruppe innerhalb der Jugendbewegung deren Denken und Praxis sich ausschließlich auf die Bekämpfung der Landflucht und der Verstädterung konzentrierten (vgl. Bergmann 1970: 247). Die Gründung der Artamanen geht auf einen durch Tanzmann inspirierten Text von Willibald Hentschel zurück, der 1923 in der Deutschen Bauernhochschule erschien. Ausgehend von einer Kritik an dem Werk Der Untergang des Abendlandes, das Hentschel als eine Irrlehre bezeichnet, richtete er einen Appell an die deutsche Jugend sich unter dem Fantasiebegriff Artam zu einer ,ritterlichen Kampfgenossenschaft auf deutschem Boden“ zusammenzuschließen, um unter der Leitung eines erfahrenen Obmannes auf ostelbischen Rittergütern alle landwirtschaftlichen und technischen Arbeiten zu verrichten. In dem Aufsatz gibt Hentschel als Ziel der Artamanen die Vertreibung polnischer Landarbeiter aus den Ostgebieten Deutschlands und den Kampf gegen „Raff- und Genußgier, Mammonismus und gemeines Behagen“" aus (Hentschel 1923: 44).

Der Text zog ein Jahr später einem Aufruf zur Gründung von Artamanenschaften nach sich, der von dem Gutspächter Georg Obendorfer, Bruno Tanzmann und Wilhelm Kotzde unterzeichnet wurde. Bereits im Frühjahr 1924 trat die erste Artamenschaft unter der Führung von Georg August Kenstler ihren Dienst in der Landwirtschaft auf einem Rittergut in Sachsen an (vgl. Kater 1971: 577). Ihr Konzept der freiwilligen Landarbeit verfolgte neben einer antislawischen, auch eine imperialistische Zielsetzung (vgl. Bergmann 1970: 266-267; Kater 1971: 604-607; Linse 1983: 330-331). Die Ansiedlung von deutschen Siedlern in den östlichen Gebieten des Reiches sollte polnische Land- und Wanderarbeiter vertreiben und damit einen imaginierten „slawischen Vorstoß“ stoppen. Nachdem die Innere Kolonisation abgeschlossen ist, bedurfte es in der Vorstellung der Atamanen Lebens- und Siedlungsraum 
im Osten, um die den Großstädten entrissenen Menschen mit ausreichend Land zu versorgen. Der bäuerliche Eroberungszug jenseits der deutschen Ostgrenzen war das letzte Ziel der Artamanen (vgl. Bergmann 1970: 274-275).

In der zweiten Hälfte der 1920er Jahre erlebte die Bewegung einen regen Zulauf. Es wird geschätzt, dass 1929 ungefähr 2300 Mitglieder der Bewegung auf 260 Gütern lebten und arbeiteten. Eigenes Land für die Errichtung von Siedlungen konnte aufgrund mangelnder finanzieller Mittel nur in sehr begrenztem Umfang erworben werden. Das langfristige Ziel der Artamanen, selbstbestimmt auf eigenem Boden zu siedeln, verwirklichte sich nur für eine kleine Minderheit der Bewegung (vgl. Kater 1971: 592-593). Bis zur Auflösung der Bewegung Mitte der dreißiger Jahre konnten schätzungsweise zwischen 100 bis 150 Mitglieder eigenes Land erwerben (Kater 1971: 595; Linse 1983: 328).

Entgegen der Einschätzung Bergmanns (1970: 266-267), dass die Artamanen die Bildung eines Agar- und Bauernstaats angestrebt und damit ein dezidiert irrationales und antimodernes Programm verfolgt hätten, erkennt Stefan Breuer in den Bestrebungen der Bewegung keine Abkehr von der modernen Industriegesellschaft. Die Siedlungsarbeit stellte ihm zufolge den Versuch dar, eine ausreichende landwirtschaftliche Basis sicherzustellen, um Ernährungsengpässe, wie sie nach dem Ersten Weltkrieg aufgetreten waren, zu vermeiden (vgl. Breuer 2008: 220). Breuer überbewertet in diesem Zusammenhang jedoch die zweckrationalen Gründe für die völkische Forderung der Artamanen nach einer Stärkung des Landlebens. Die Einsicht in die Notwendigkeit der Sicherstellung einer ausreichenden Lebensmittelversorgung durch die Erfahrung des Krieges spielte unzweifelhaft eine wichtige Rolle für die völkische Idealisierung des Landlebens. Es ist jedoch ein Charakteristikum der völkischen Agrar- und Bauernideologie, dass diese sich nicht nur auf ernährungspolitische Erwägungen und Notwendigkeiten fokussierte, sondern maßgeblich auf bevölkerungspolitischen und demographischen Überlegungen basierte, die mit rassenhygienischen Zielsetzungen verknüpft waren. Völkische Autoren legten daher besonderen Wert darauf, dass die doppelte Bedeutung der Landwirtschaft für das Wohlergehen des Volkes nicht übersehen werde. So führte beispielsweise Hermann Jäger im Hammer aus, dass die Landwirtschaft nicht nur der Erzeugung von Lebensmitteln diene, sondern ihren weiteren Wert vielmehr darin habe, „daß sie den Menschen in Lebensbedingungen bringt, die in hohem Grade seine leibliche und auch seine geistige Gesundheit zu fördern geeignet sind; sie ist der Jungborn der Volkskraft, vorausgesetzt, daß sie in der Form der kleinen und mittleren Bauernwirtschaft betrieben wird“ (Jäger 1920: 321). 
Die Artamanen verfolgten insofern kein modernitätsfeindliches Programm, als sie der modernen Technik gegenüber sehr aufgeschlossen waren. Wie es für den nordischen Gedanken insgesamt charakteristisch ist, wurde die Technik als Ausdruck der schöpferischen Leistungsfähigkeit der „,nordischen Rasse“ gesehen. Ihre positive Haltung gegenüber der modernen Technik lässt sich jedoch nicht auf ihre Sichtweise zu den Großstädten übertragen. Für die Artamanenbewegung lässt sich eine unterschiedliche Großstadt- und Technikrezeption aufzeigen, die der Artamanenführer des Rittergut Limbach, Alwiß Rosenberg, wie folgt ausdrückte: „Es ist uns lange klar, daß es nicht die Technik ist, die uns zugrunde richtet, sondern vor allem die Stadt. Die Technik hat uns ein ganzes Stück vorwärts gebracht. Ist ihre Grundlage gesund, so wird sie sich durchsetzen. Verderbender ist der Einfluß der Städte“ (Rosenberg 1927: 364). Fritz Hugo Hoffmann, Bundesführer der Artamanen, forderte die großstädtische Jugend explizit auf, sich als Ingenieure der Bewegung anzuschießen und an einer Technisierung und Maschinisierung der Landwirtschaft mitzuwirken. Verkehrswege und sogar Flugzeuge sollten künftige Artamanen in seiner Vorstellung bauen können, aber immer, wie Hoffmann betonte, ,in der Verbundenheit als Bauer“ (Hoffmann 1928: 34). Die ländliche Siedlungsarbeit sollte eine möglichst hohe Zahl der großstädtischen, ,erbgesunden“ Jugend wieder zu einem Bauerngeschlecht machen, was als Voraussetzung für eine Versöhnung von Land und (Klein-)Stadt auf industrieller Grundlage angesehen wurde. So heißt es diesbezüglich in dem ersten Heft des in der Deutschen Bauernhochschule veröffentlichten „Artamanenrufs an Deutschlands Jugend“:

Schon heute kann gesagt werden, daß die Artamanenschaft Beweis geliefert hat, daß stadtgeborene, kulturfähige und erbtüchtige Jugend unbäuerlicher Herkunft, die dem Lande und dem Bauerntum so zahlreich verloren gegangen war, entgegen einem herrschenden Aberglauben sehr wohl ins Bauerntum zurückgeführt werden kann. (Wahle 1927: 372)

Die Artamanen verband eine enge Beziehung zur NSDAP. Einflussreiche Nationalsozialisten waren einerseits aktive Mitglieder oder standen der Bewegung und ihren Nebenorganisationen, wie dem Bundschuh, anderweitig nahe. Einflussreiche Nationalsozialisten mit einer Verbindung zu den Artamanen waren Heinrich Himmler und Richard Walther Darré, die jedoch keine aktive Siedlungsarbeit leisteten sowie der spätere Kommandant von Auschwitz, Rudolf Höß. Andererseits war die Mehrheit der ArtamanenFührung in der Partei aktiv (vgl. Bergmann 1970: 276; Linse 1983: 327; Niemeyer 2013: 5253), was jedoch nicht für die Mehrheit der einfachen Mitglieder vor 1933 zutrifft (vgl. Brauckmann 2005: 189-191). Als Referenten traten überdies Baldur von Schirach und Alfred Rosenberg auf; Joseph Goebbels wird die Teilnahme an einem Lehrgang der Artamanen im Jahre 1928/1929 nachgesagt (vgl. Niemeyer 2013: 53). An der internen Uneinigkeit über die 
Nähe zur NSDAP zerbrach 1929 schließlich die Bewegung und spaltete sich. Ein Teil der Artamanen, der sich in der Tradition der Vorkriegsjugendbewegung sah und darauf bestand, überparteilich zu sein, gründete eine neue Organisation mit dem Namen Die Artamanen, bündische Gemeinden für Landarbeit und Siedlung (vgl. Bergmann 1970: 281-285). Der verbliebene Bund Artam e.V. ging 1931 in Konkurs. Die Artamanen, die sich ab Oktober 1933 wieder Bund Artam nannten, wurden im September 1934 in den Reichsnährstand eingegliedert und im Dezember 1935 per Anordnung aufgelöst (vgl. Brauckmann 2005: 182183).

\subsection{Großstadtfeindschaft und Nationalsozialismus}

Die Nähe einiger führender Nationalsozialisten zu den Artamanen macht deutlich, dass Ideologen der völkischen Großstadtfeindschaft in hohe Ämter und an wichtige Schaltstellen des NS-Staates gelangten. In der geschichtswissenschaftlichen Forschung ist es unstrittig, dass einflussreiche Nationalsozialisten großstadtfeindliche Positionen bezogen und dass die NS-Propaganda sich großstadtfeindlicher Ressentiments bediente. Die Frage, welche Bedeutung die Großstadtfeindschaft für die NS-Ideologie im Allgemeinen und für die NSPolitik im Besonderen hatte, wurde von der Forschung bisher jedoch äußert unterschiedlich beantwortet. Die Positionen reichen von der These, dass eine radikale Großstadtfeindschaft zu den zentralen Elementen der nationalsozialistischen Weltanschauung gehöre und dass die Nationalsozialisten die Großstädte als solche abgelehnt und eine ländliche Siedlungsform nach vorindustriellem Muster favorisiert hätten (vgl. Lees 1985: 269-288; Heuser 1991); bis zur Gegenthese, die Nationalsozialisten hätten die Großstadtfeindschaft nur zu Wahlkampfzwecken eingesetzt, ohne jedoch nach 1933 eine großstadtfeindliche Agenda umgesetzt zu haben (vgl. Dietz 2008: 810). ${ }^{20}$ In diesem Kapitel soll gezeigt werden, dass beide Ansätze zu einseitig sind und dass trotz des polymorphen und eklektischen Charakters der NS-Ideologie von einem engen Zusammenhang zwischen Großstadtfeindschaft und Nationalsozialismus gesprochen werden kann.

\footnotetext{
${ }^{20}$ Die in diesen Thesen zum Ausdruck kommende Polarität spiegelt die unterschiedlichen Positionen in der NSForschung zur Frage des Verhältnisses zwischen Nationalsozialismus und Moderne wider. Die Darstellung der unterschiedlichen Sichtweisen in diesem Forschungsfeld würde den Rahmen dieses Kapitels sprengen. Einen guten Überblick über den Forschungsstand bis in die Mitte der 1990er Jahre gibt Axel Schildt (vgl. 1994).
} 
Der Einfluss einer völkischen Großstadtfeindschaft auf die NS-Programmatik manifestierte sich spätestens mit dem Eintritt Richard Walther Darrés (1895-1953) in die NSDAP im Jahr 1930. Darré, der dem nordischen Flügel der völkischen Bewegung angehörte, wurde von Hitler im selben Jahr mit dem Aufbau des agrarpolitischen Apparates der Partei beauftragt. ${ }^{21}$ Hiermit war eine zweifache Zielsetzung verbunden: eine stärkere Verankerung der Partei in das ländliche Milieu und eine gezielte Unterwanderung landwirtschaftlicher Interessenvertretungen (vgl. Münkel 1996: 68-74). Um diese Ziele zu erreichen ergänzte die Partei bereits vor dem Parteieintritt Darrés im März 1930 ihr Parteiprogramm aus dem Jahr 1920 durch die Parteiamtliche Kundgebung über die Stellung der N.S.D.A.P. zum Landvolk und zur Landwirtschaft, in der Forderungen der traditionellen Agrarverbände aufgenommen wurden (vgl. Münkel 1996: 69). Ansätze zur Integration ländlicher und bäuerlicher Wählerschichten gab es bereits in den Anfangsjahren der NSDAP. Entsprechende Bemühungen wurden von lokalen Initiativen getragen, die von namhaften NS-Politikern wie Heinrich Himmler und Otto und Gregor Strasser unterstützt wurden (vgl. Grill 1982).

Darré leitete jedoch nicht nur eine stärkere Öffnung der NSDAP zur Landbevölkerung ein, sondern forcierte die Biologisierung der Agrarpolitik und machte diese zu einem zentralen Element der NS-Rassenpolitik (vgl. Mai 2002: 48). In seinen 1929 und 1930 erschienenen Büchern Das Bauerntum als Blutquell der nordischen Rasse und Neuadel aus Blut und Boden legte Darré dar, dass das von ihm angestrebte „rassische Zuchtprogramm“ nur fernab des Einflusses der Großstadt verwirklicht werden kann. ${ }^{22}$ Darré, der wenig Fachkompetenz in ernährungspolitischen Fragen besaß, sah daher in der Lebensmittelerzeugung nicht die zentrale Aufgabe der nationalsozialistischen Agrarpolitik. In einer Rede im Jahr 1935 führte

\footnotetext{
${ }^{21}$ In dieser Funktion übernahm Darré die Rolle eines völkischen Interessenpolitikers der deutschen Landwirtschaft und stellte in seinen an die ländliche Bevölkerung gerichteten Schriften die Großstadtfeindschaft und im Besonderen den Antisemitismus hinten an. Deutlich wird dies bei der von Darré anlässlich der Reichstagswahlen 1932 herausgegeben Broschüre Landvolk in Not und seine Rettung durch Adolf Hitler, die keinen Antisemitismus und eine nur am Rande auftauchende Großstadtfeindschaft enthält. Es wäre daher falsch davon auszugehen, dass Darré seine antisemitische Großstadtfeindschaft gezielt an eine ländliche und bäuerliche Wählerschicht adressierte. Die radikalsten antisemitischen Auslassungen über die Großstädte finden sich in denjenigen seiner Texten, die an ein völkisches und damit städtisches Publikum gerichtet waren.

${ }^{22}$ Darré ging in seiner großstadtfeindlichen Interpretation über die Voraussetzungen für eine „Rassenzucht“ soweit, dass ihm auch die Gartenstädte als nicht geeignete Orte erschienen, um einen „Neuadel“ heranzuzüchten, da bezweifelt werden müsse, ,daß die Stadt - auch die Gartenstadt - das Seelenleben der heranwachsenden Jugend so günstig zu beeinflussen vermag, daß daraus ein Führergeschlecht mit wirklich ausgereiftem Seelenleben entstehen kann. [...] Wer der deutschen Seele die naturgewachsene Landschaft nimmt, der tötet sie. Auch die bestangelegte Gartenstadt ist keine Landschaft in diesem Sinne. Schon die Ruhelosigkeit des Großstädters, der selten eine feste Stätte in dem steinernen Meer findet, mit der er seelisch verwachsen kann, sowie die durch die Stadt bewirkte allzu frühe Selbstständigkeit der Jugendlichen lassen das Seelenleben verkümmern und leisten einem auf Äußerlichkeiten gerichteten Denken recht unerwünschten Vorschub“ (Darré 1930: 86-87).
} 
er in seiner Funktion als Reichsminister für Ernährung und Landwirtschaft und als Reichsbauernführer diesbezüglich und mit deutlich erkennbarer antisemitischer Stoßrichtung aus:

In der nationalsozialistischen Agrarpolitik geht es nicht nur um die Ernährungswirtschaft, sondern zugleich um die Erhaltung des Bauerntums als Blutquelle des Volkes. Und dieser letzte Umstand ist doch sehr entscheidend und grundlegend. Denn es ist damit erstmalig die Folgerung aus der Tatsache gezogen worden, daß in einem Staate germanischer Natur das Blut nur auf dem Lande Generationen sich erhält und vermehrt, die Abkehr vom ländlichen Leben aber einen starken Verschleiß der Geschlechter bewirkt. Wenn man das Vergleichsbild bringen darf, so kann man sagen, daß das Blut des Volkes auf seinen Bauernhöfen sozusagen quellenartig emporsprudelt, um in der Stadt über kurz oder lang zu versiegen. Für Völker, deren Grundcharakter nomadischer Art ist, zum Beispiel für das jüdische Volk, gilt dieses Gesetz nicht, dagegen gilt es für germanisches Blut unbedingt und kann geradezu das eiserne Schicksalsgesetz des germanischen Menschentums genannt werden. (Darré 1941 [1935]: 301)

Darré strebte jedoch nicht die Rückkehr zu einer vorindustriellen Agrarordnung an, wie es solche Zitate nahelegen können. Er wendete sich in mehreren Schriften vehement gegen eine Bauernromantik, die er als Symptom eines „städtischen Intellektualismus“ verurteilte, da diese nicht zu einer grundlegenden Veränderung der politischen und sozialen Verhältnisse im völkischen Sinne führe. Spöttisch merkte er an, dass es dem Kapitalismus, worunter der Antisemit Darré die Herrschaft des Judentums über Handel und Finanzkapital verstand, „nur recht sei, wenn man sich in einem System mit Schrebergärten und Eigenheimen, mit Gartenstädten und Kleinsiedlungen möglichst gesund und häuslich einrichtet" (Darré 1931). Seine Blut-und-Boden-Ideologie zielte nicht auf die Konservierung bzw. Wiederherstellung einer einfachen bäuerlichen Lebensweise, sondern auf den Aufbau eines rassisch „hochwertigen“ Genpools. Agrarpolitik fasste Darré primär als angewandte Rassenpolitik auf (vgl. Corni/Gies 1994: 17), die sich auch neuester wissenschaftlicher Erkenntnisse und Methoden bediente. ${ }^{23}$ Seine auf ein fiktives Bauerntum zugeschnittene Rassenlehre schloss weder den Einsatz moderner Maschinen in der Landwirtschaft aus, noch stand sie im Widerspruch zur seiner grundsätzlichen Bejahung und Anerkennung der Leistungen der Industrie.

Darrés großstadtfeindliche Überzeugungen wirkten zudem in starkem Maße auf die Ideologie der SS. Darré leitete das zum 1. Januar 1932 als „Rasseamt der SS“ gegründete und 1935

\footnotetext{
${ }^{23}$ Eva-Maria Ziege hat zu Recht darauf hingewiesen, dass es ein ehrbarer, jedoch wenig überzeugender Versuch war und ist, die in verschiedenen wissenschaftlichen Disziplinen verankerte Rassenhygiene als „pseudowissenschaftlich“ abzutun. An ihr wirkten angesehene und mit einem internationalen Ruf versehene Wissenschaftler mit, die ,legitime Sprecher eines Autoritätsdiskurses waren, institutionell und akademisch eingebunden, abgesichert und besoldet" (Ziege 2002: 67; vgl. auch Walkenhorst 2007: 117-118). Es handelte sich bei der Rassenhygiene nicht nur dem Selbstverständnis ihrer Protagonisten nach um eine moderne Wissenschaft. Gleichwohl ist zu betonen, dass Darré mit seinem Zuchtideal, das der Tierzucht entnommen war, hinter den zeitgenössischen Forschungsstand zurückfiel (vgl. Weingart et al. 1988: 34-36).
} 
umbenannte „Rasse- und Siedlungshauptamt der SS“ (RuSHA), in das er zentrale Aspekte seiner Ideen von einer rassischen Auslese und einer auf rassischen Prinzipien basierenden ländlich-bäuerlichen Siedlungsarbeit einbringen konnte. Dem Amt kam zunächst die Funktion $\mathrm{zu}$, rassenbiologische Kriterien für die Aufnahme in die SS festzulegen, die rassische Tauglichkeit der Verlobten von SS-Männern zu überprüfen, wovon die Genehmigung zur Heirat abhängig gemacht wurde, und SS-Angehörige in landwirtschaftlichen Betrieben an den deutschen (Ost-)Grenzen anzusiedeln. Mit der Annexion des Sudentenlandes und der Eroberung der CSR und speziell nach dem Überfall auf Polen zeichnete sich in der Arbeit des RuSHA eine Schwerpunktverlagerung zugunsten einer volkstumspolitischen Praxis ab. Die Rassen- und Siedlungsexperten der SS stellten ihr Wissen und ihre Erfahrungen in den Dienst einer Neugestaltung der besetzten Ostgebiete und wendeten ihre Expertise nun an der in diesen Gebieten lebenden Bevölkerung an. Hierdurch wurde das RuSHA zu einer tragenden Säule einer auf ethnischen Säuberungen und einer genozidalen Praxis basierenden Volkstumsund Germanisierungspolitik in Osteuropa (vgl. Heinemann 2003: 11-14). Mit der Ernennung Heinrich Himmlers zum „Reichskommissar für die Festigung des Deutschen Volkstums“, die per geheimen „Führererlass“ erfolgte, fiel die gesamte Raum- und Siedlungsplanung für die besetzten Ostgebiete in den Verantwortungsbereich der SS. Die Pläne zur Besiedlung und Kolonisation der polnischen und russischen Gebiete basierten auf einer rassenbiologischen Bauerntumsideologie. Der Ende 1941 entwickelte Generalplan Ost sah die Aneignung der besetzten russischen Gebiete durch die Ansiedlung von rassisch ausgelesenen „Volksdeutschen“ durch die Errichtung eines breiten Gürtels von sogenannten Wehrbauersiedlungen vor, die der militärischen und rassenbiologischen Absicherung des Gebetes dienen sollten (vgl. Münk 1993: 428-438).

Mit der Übernahme der Leitung des RuSHA durch Darré, der 1938 von dem Amt zurücktrat und auf die spätere Raum- und Siedlungspolitik der SS in Osteuropa keinen Einfluss mehr hatte, formulierten mit ihm und Himmler zwei führende Nationalsozialisten mit engen Kontakten zu den Artamanen, „Anfang der dreißiger Jahre die weltanschaulichen Grundlagen des ,neuen Ordens“ und sorgten für ihre Festigung“ (Heinemann 2003: 24; zum Einfluss Darrés auf die weltanschauliche Schulung in der SS vgl. Harten 2014: 17-39). Der von den Artamanen vertretene Gedanke einer Besiedlung des Ostens diesseits und jenseits der deutschen Staatsgrenzen sowie die mit der Großstadtfeindschaft stark zusammenhängende Vorstellung einer bäuerlichen Rassenzucht übten einen starken und nachhaltigen Einfluss auf die Weltanschauung der SS aus. Die in der Ideologie der Artamanen fest verankerte Kombination aus rassenhygienischen, degenerationstheoretischen und sozialdarwinistischen 
Ansätzen „,bereitete das Terrain für die Politisierung der Utopie des ,Neuen Menschen“ im Nationalsozialismus und insbesondere innerhalb der SS“ vor (Diehl 2005: 59). Ideen der Artamanenbewegung fanden somit über die Rassenideologie der SS und die Agrarpolitik von Darré Eingang in die NS-Ideologie und schließlich in die Politik des NS-Staates und seiner Vernichtungspraxis (vgl. Becker 1988: 253-259).

Ein für die NS-Ideologie einflussreiches Buch, das das großstadtfeindliche Denken eines führenden Nationalsozialisten mit völkischem Hintergrund dokumentiert und die Großstadtwahrnehmung des Nationalsozialismus mitgeprägt hat, stellt Alfred Rosenbergs (1893-1946) 1930 erschienenes Hauptwerk Der Mythus des 20. Jahrhunderts dar. Rosenberg, der dem nordischen Flügel der völkischen Bewegung zuzurechnen ist (vgl. Akngren et al. 2008), wurde mit seinem Hauptwerk bis zur Ernennung Hitlers zum Reichskanzler nur in völkischen und christlichen Kreisen rezipiert, die sich mit seinem Buch aus gänzlich unterschiedlichen Beweggründen befassten. Stießen seine Thesen in völkischen Kreisen auf breite Zustimmung, provozierte der gegen das Christentum gerichtete Grundton des Buches den Protest der Kirchen. Während der NS-Herrschaft erhielt das Buch schließlich den Status einer halbamtlichen Literatur, was zu rapide steigenden Verkaufszahlen führte. Bis 1938 verkauften sich eine halbe Million Exemplare, 1942 betrug die Verkaufszahl schließlich eine Million (vgl. Piper 2005: 184). In seiner offiziellen Funktion als von Hitler persönlich „Beauftragter für die Überwachung der gesamten geistigen und weltanschaulichen Schulung und Erziehung der NSDAP“ begriff Rosenberg sich als Chefideologe des Nationalsozialismus, dessen Gestaltungspielräume jedoch aufgrund von Kompetenzüberschneidungen mit Ministerien und anderen staatlichen Stellen und durch das Fehlen exekutiver Vollmachten enge Grenzen gesetzt waren. Ernst Piper (2005: 328) zufolge stand Rosenberg im Spannungsfeld zwischen einer „grundsätzlichen Bedeutung auf der einen und nicht erkennbarer Wirksamkeit bei der Bewältigung drängender tagesaktueller Probleme auf der anderen Seite“. Im Hinblick auf die im Mythus des 20. Jahrhunderts enthaltenen Aussagen über die modernen Großstädte kann hingegen davon gesprochen werden, dass sie zentrale Motive der im Nationalsozialismus dominanten Sichtweise auf die modernen Großstädte enthalten.

So hebt Rosenberg die Bedeutung der Großstädte als kulturelle, ökonomische und politische Knotenpunkte hervor, sieht in den modernen Großstädten jedoch zugleich das Produkt einer Fehlentwicklung des Liberalismus, die durch den nationalsozialistischen Staat korrigiert werde müsse. Seinen Darstellungen ist zu entnehmen, dass er seine großstadtfeindlichen 
Thesen sowohl in Anlehnung als auch in Abgrenzung $\mathrm{zu}$ Spenglers Untergang des Abendlandes entwickelte. Im Fokus von Rosenbergs Ausführungen steht die Entwicklung der Weltstädte, deren Anwachsen er darauf zurückführt, dass ,im Zeichen der Freizügigkeit [...] bestes Blut ungehindert in die blutverseuchende Weltstadt [strömt] [...]“ (Rosenberg 1932: 544). Vor dem Hintergrund dieser Entwicklung sieht er nur die Möglichkeit ,auf dem Asphalt ,freiwillig‘ jämmerlich zu verenden, oder auf dem Land und in der mittleren Stadt ,gezwungen“ [werden] zu gesunden“ (Rosenberg 1932: 543). Um ein weiteres Anwachsen der Großstädte abwenden zu können, war für ihn eine Abkehr von der Lehre der liberalen Freizügigkeit erforderlich, worunter er in diesem Kontext eine Begrenzung der Einwohnerzahl deutscher Großstädten verstand. Rosenberg unterbreitet in seinem Buch den Vorschlag, die Einwanderung in Städte mit mehr als 100000 Einwohnern genehmigungspflichtig $\mathrm{zu}$ machen. In seiner Vorstellung sollte in einem nationalsozialistischen und völkischen Staat nur eine kleine Zahl von großstädtischen Zentren existieren, die höchstens 500000 Einwohner umfassen. Der Entstehung größerer Ballungsgebiete sollte ihm zufolge mit einer Dezentralisierung der Industrie begegnet werden.

Die Formel von „Blut-und-Boden“ wurde von der NS-Propaganda jedoch nicht nur in Bezug auf eine rassenbiologische Bauerntums- und Agrarideologie verwendet, wie sie von Darré, Rosenberg und der SS interpretiert wurde. Gesine Gerhard hat darauf hingewiesen, dass das Blut-und-Boden-Ideal der Nationalsozialisten nicht mir der Agrarideologie von Darré identisch war und auch unabhängig von dieser existiere (vgl. Gerhard 2005: 140). Der Ausdruck avancierte in der nationalsozialistischen Propaganda zu einem großstadtfeindlichen Schlagwort, das in einem umfassenderen Sinn einen organisch gewachsenen Staat und eine homogene Volksgemeinschaft bezeichnete (vgl. Bergmann 1970: 332-333). „Blut“ bezeichnete dabei die Gesamtheit des deutschen Volkes und mit „Boden“ war der Lebensraum der „Rasse“ gemeint, so dass sowohl Stadt- als auch Landbewohner Teil des völkischen Mythos waren. Auf der Grundlage dieses Begriffspaares, so Sieferle, ,konnte eine Volksgemeinschaft beschworen werden, die Bauern, Arbeiter, Beamte, Ingenieure usw. umfaßte“ (Sieferle 1984: 203). Nach Bergmann machten sich die Nationalsozialisten mit dieser Formel kulturpessimistische Affekte in der Bevölkerung zu Nutze und trugen damit zur Festigung von großstadtfeindlichen und agrarromantischen Denkmustern in einer verstädterten Industriegesellschaft bei (vgl. Bergmann 1970: 338).

Die Großstadtfeindschaft ging innerhalb der Führungsspitze des Nationalsozialismus daher auch über den Kreis derjenigen Ideologen hinaus, die der völkischen Bewegung der Weimarer 
Republik zugeordnet werden können. Dies betrifft auch und gerade Äußerungen Hitlers zu den Großstädten. In seinem zweiten, unveröffentlichten Buch zur Außenpolitik aus dem Jahr 1928 konstatierte er eine „Entdeutschung, Vernegerung und Verjudung unseres Volkes in den Großstädten“ (Hitler 1961 [1928]: 201). In ihnen sah er „Brutstätten der Blutsvermischung“ und der „Bastardisierung“ und bezeichnete sie als „eitrige Herde, in denen der internationale jüdische Völkermade gedeiht und die weitere Zersetzung endgültig besorgt“ (Hitler 1961 [1928]: 62). Breuer schlussfolgert hieraus, dass die Großstadtfeindschaft Hitlers nicht auf einer Ablehnung der Industrie basierte, sondern rassenbiologisch begründet war (vgl. Breuer 2010a: 279). Bernhard Marchand geht einen Schritt weiter und stellt die These auf, dass die NS-Großstadtfeindschaft nicht den Großstädten als solchen gegolten habe, sondern dem Ideal der „Blutreinheit“. Nachdem die jüdische Bevölkerung aus den deutschen Großstädten deportiert war, gab es ihm zufolge für die Nationalsozialisten keine Rechtfertigung mehr für ihre Großstadtfeindschaft (vgl. Marchand 1999: 49). An Marchands These ist besonders problematisch, dass sie den Zusammenhang von Antisemitismus und Großstadtfeindschaft im Sinne korrespondenztheoretischer Ansätze monokausal mit der jüdischen Existenz in den Großstädten erklärt. Breuer ist hingegen grundsätzlich darin zuzustimmen, dass Hitlers Großstadtfeindschaft nicht auf einer Industriefeindschaft beruhte.

Beide Ansätze verkennen jedoch, dass die Großstadtfeindschaft im Nationalsozialismus sich auf die soziale und politische Organisationsform der modernen Großstädte bezog und nicht allein auf die physische Verdrängung und Vernichtung „rassenfremder“ Bevölkerungselemente in den Großstädten reduziert werden kann. In einer nationalsozialistischen Sammlung literarischer und journalistischer Texte über die Großstadt aus dem Jahr 1933 wurde in einer die weitere Entwicklung antizipierenden Weise insofern von einem „heroischen Ringen um die Sinngebung der Stadt“" gesprochen und hervorgehoben, dass der Nationalsozialismus ,auch das Gesicht der Großstädte verändern“ werde (zit. nach Schlör 2005: 243). Weil die Feindschaft den modernen Großstädten direkt galt, fanden großstadtfeindliche Prämissen Eingang in verschiedene Politikfelder des NS-Staates. Der Einfluss großstadtfeindlicher Ansätze und Konzepte machte sich einerseits in den ersten drei Jahren der NS-Herrschaft in der Agrar-, Siedlungs-, Wohnungs- und Stadtpolitik bemerkbar. Andererseits manifestierten sich eine ablehnende Haltung gegenüber den modernen Großstädten in dem am 4. Oktober 1937 erlassenen Gesetz über die Neugestaltung deutscher Städte und den mit diesem Gesetz in Verbindung stehenden Plänen und Ansätzen einer städtebaulichen Erneuerung deutscher Großstädte, die der NS-Ideologie und den Vorstellungen Hitlers angepasst werden sollten. 
Nachdem Richard Walther Darré das Amt des Reichsministers für Ernährung und Landwirtschaft am 30. Juni 1933 übernommen hatte, konnte er einige seiner zentralen Ideen in einer rassenorientieren Bauernpolitik umsetzen (vgl. Mai 2002: 49-58; Böse 2008). Von entscheidender Bedeutung waren hierfür zwei Gesetze: das am 14. Juli erlassene Reichsgesetz über die Neubildung deutschen Bauerntums und das Reichserbhofgesetz (REG), das am 30. September im Reichsgesetzblatt veröffentlicht wurde und am 1. Oktober 1933 durch seine Verkündung auf dem Reichserntedankfest in Kraft trat. Das Gesetz bezüglich der Neubildung des deutschen Bauerntums machte die Schaffung bäuerlicher Siedlungen zur Staatsaufgabe; das Reichserbhofgesetz betraf die Einführung eines Anerbenrechts, das die Vererbung eines als Erbhof definierten landwirtschaftlichen Betriebes in männlicher Linie festschrieb, womit das Ziel verfolgt wurde, die Bauernhöfe vor einer Überschuldung und Zersplitterung zu schützen, damit, wie es in der Präambel des Gesetzestextes hieß, „sie dauernd als Erbe der Sippe in der Hand freier Bauern verbleiben“ (REG 1944 [1933]: 1). Das Reichserbhofgesetz stellte die materielle Grundlage der von Darré schon vor der NS-Herrschaft getroffenen ideologischen Unterscheidung zwischen Bauern und Landwirten dar (vgl. Darré 1941 [1932]) und fungierte als rechtlicher Ausdruck der von ihm vertretenen Blut-und-Boden-Ideologie (vgl. Böse 2008: 46). Böse zufolge kam dem Gesetz die Funktion eines Leitgesetzes zu, das „eine Vorreiterrolle bei der Schaffung einer völkischen Rechtsordnung im nationalsozialistischen Ungeist" spielte (Böse 2008: 19).

Die Funktion des Bauern bzw. des Erbhofbauern wurde von Darré nicht vorrangig in der Lebensmittelerzeugung gesehen, sondern in der Bereitstellung „guten“ Genmaterials für eine rassische Erneuerung des deutschen Volkes. In der Präambel des Reichserbhofgesetzes war diesbezüglich davon die Rede, dass die Reichsregierung „unter Sicherung alter deutscher Erbsitte das Bauerntum als Blutquelle des deutschen Volkes erhalten“ möge (REG 1944 [1933]: 1). Als „bauernfähig“ wurden vor diesem Hintergrund nur Menschen eingestuft, die die deutsche Staatsangehörigkeit nach den gesetzlichen Bestimmungen der NSRassenideologie besaßen, „deutschen oder stammesgleichen Blutes“ waren, worunter das Gesetz ex negativo alle Bevölkerungsteile bestimmte, deren Vorfahren väterlicher- oder mütterlicherseits kein ,jüdisches“ oder „farbiges“ Blut aufwiesen (REG 1944 [1933]: 3). Sogenannte Neubauernscheine wurden zudem grundsätzlich nicht an Menschen vergeben, die von der NS-Bürokratie als „erbkrank“ eingestuft wurden. Es wird geschätzt, dass ein Drittel bis über die Hälfte der Bewerber abgelehnt wurde (vgl. Mai 2002: 66). Das Reichserbhofgesetz fand in der Bauernschaft hingegen wenig Akzeptanz und wurde bis 1943 mehrfach abgeändert. Die Änderungen an dem Gesetz waren auch dem Umstand geschuldet, 
dass es in einen immer stärker werdenden Widerspruch zu den kriegsvorbereitenden Anforderungen an die Landwirtschaft geriet. Daniele Münkel zufolge traten ideologische Komponenten in der Agrarpolitik mit der zunehmenden Kriegsvorbereitung in den Hintergrund. Ihren Endpunkt erreichte diese Entwicklung mit der Eingliederung der Landwirtschaft in die Kriegswirtschaft (vgl. Münkel 1996: 93-94).

Elemente der Großstadtfeindschaft und der Blut-und-Boden-Ideologie bestimmten auch die Stadt- und Raumplanung der Nationalsozialisten. Bemühungen und Pläne für eine räumliche Reagrarisierung und Dezentralisierung der Großindustrie lassen sich nach Dieter Münk im Besonderen in den Anfangsjahren der NS-Herrschaft in der Stadt-, Wohnungs- und Siedlungspolitik nachweisen (vgl. Münk 1993: 405-413; Harlander 1995: 39-86). Nach Manfred Walz versuchten die NS-Stadtplaner in den ersten drei Jahren eine Auflockerung der Großstädte über die Errichtung von Stadtrandsiedlungen und über eine Sanierung der Altstädte zu erreichen (vgl. Walz 1980: 475). Mit dem Konzept der Kleinsiedlung, deren Standort an der Peripherie der Großstädte, in Mittel- und Kleinstädten, oder in ländlichen Gemeinden vorgesehen war, verfolgten die Nationalsozialisten mehrere Zielsetzungen (vgl. Münk 1993: 190-194; Harlander 1995: 53-66 u. 71):

Neben der Auflockerung der Großstädte sollten sie in erster Linie die großstädtischen Arbeiterschichten zurück in ländliche oder zumindest halbländliche Lebensverhältnisse führen. Hierdurch sollten sie zu einer „bodenverbundenen Schicht“ gemacht werden. Die Rückführung der Großstadtbewohner zur heimatlichen Scholle sollte über die Bereitstellung eines Eigenheims mit Garten gelingen, was zugleich $\mathrm{zu}$ einer höheren Autarkie in der Lebensmittelversorgung führen sollte. Mit dem Siedlungskonzept verbanden sich in erster Linie rassen- und bevölkerungshygienische Zielvorgaben: Die Siedlungen waren für Menschen vorgesehen, die dem Ideal der NS-Rassenideologie entsprachen. Gemäß dem großstadtfeindlichen Topos der ,ungesunden Großstadt“ ging die NS-Stadtplanung davon aus, dass die außerhalb der Kernstadt liegenden Siedlungen bessere Rahmenbedingungen für ein Bevölkerungswachstum garantieren würden. Ein weiterer Vorteil, den man sich von der Errichtung der Kleinsiedlungen versprach, betrifft die Wirkung, die die Stadtplanung von der Eigentumsbild ausgehen sah: Das Streben nach Eigentum galt nicht nur als ein „rassisches Merkmal“" (vgl. Walz 1980: 476), sondern auch als ein Mittel zur Befriedung der Arbeiterklasse. Schließlich spielten Aspekte des militärischen Luftschutzes eine Rolle bei den Plänen für die Dezentralisierung der Industrie. 
Obwohl der Kleinsiedlungsbau in den Anfangsjahren in den Mittelpunkt der Propaganda gerückt wurde, blieben die praktischen Ergebnisse weit hinter den erwarteten Zahlen zurück. Je weiter der nationalsozialistische Staat sich aus der kostenintensiven Finanzierung des Kleinsiedungsbaus zurückzog, desto radikaler wurde die ideologische Bedeutung der Siedlungen propagiert (vgl. Harlander 1995: 81). Zentrale Gedanken für eine nationalsozialistische Stadt- und Siedlungspolitik, die den bevölkerungspolitischen Gefahren der Großstädte Rechnung tragen sollte und die Vorteile von Großstadt und Dorf miteinander zu verbinden gedachte, hielt der NS-Hochschullehrer und Politiker Gottfried Feder (18831941) 1939 in einer Studie mit dem Titel Die neue Stadt fest. Hierin plädiert er für die Schaffung neuer städtischer Großsiedlungen mit einer Einwohnerzahl von bis zu 20000 Bewohnern. Seine Stadt- und Siedlungspolitik war in erster Linie für die Zeit nach dem „Endsieg“ konzipiert. Wie er selbst hervorhob, erschien sein Werk 1939 zu einem Zeitpunkt, als die Siedlungsarbeit vorrübergehend hinter die militärische Aufrüstung zurücktreten musste (vgl. Feder 1939: III).

Zur gleichen Zeit verloren die Nationalsozialisten die Innenstädte nicht aus dem Blick. Die von ihnen betriebene Sanierung der Altstädte war ebenfalls von großstadtfeindlichen Motiven angeleitet. Die Sanierung der Alt- und Innenstädte der deutschen Großstädte wurde von den Nationalsozialisten in den Kontext eines Kampfes gegen den „Moloch Großstadt“ gestellt. Da mit diesen Maßnahmen eine bevölkerungs- und rassenhygienische Politik umgesetzt werden sollte, war in der Diktion der NS-Stadtplanung nicht von einer Sanierung, sondern von einer Gesundung der Altstädte die Rede. Das erklärte Ziel war es, „rassisch minderwertige“ und politisch unerwünschte Elemente aus den Innenstädten zu eliminieren (vgl. Münk 1993: 293). Die am Leitbild der überschaubaren mittelalterlichen Kleinstadt orientierte Umwandlung der Innenstädte erfolgte über die Schaffung größerer Wohnungen, deren Wiederbelegung nach einer sorgfältigen Prüfung der Bewerber erfolgte. Nach Walz wurde damit eine ,geringfügige Auflockerung im Sinne einer Herabzonung und geringeren Belegung“ erreicht (Walz 1980: 475).

Im Einklang mit den großstadtfeindlichen Ansätzen in der Siedlungs-, Raum- und Agrarpolitik stilisierte die nationalsozialistische Geschichtspolitik die mittelalterliche (Klein)Stadt zum Symbol eines goldenen Zeitalters des deutschen Städtewesens. Die mittelfränkische Stadt Rothenburg ob der Tauber wurde von der Propaganda zu einem Sinnbild für eine gesunde deutsche Stadt und zum Ideal einer nationalsozialistischen Gemeinschaft erklärt (vgl. Hagen 2004, 2006). Als Symbol für die mittelalterliche 
Vergangenheit Deutschlands repräsentierte die Stadt für die Nationalsozialisten die Verbindung zwischen nationaler Identität und einem romantisch geprägten Landschaftsbild. Nach Hagen fungierte Rothenburg bereits seit der Gründung des Deutschen Reiches im romantischen Denken als ein „symbol of rootedness, community, and continuity with this perceived golden age of national greatness (Hagen 2004: 208). Die antijüdische Politik der Stadt im Mittelalter wurde als ein Beleg für den deutschen Charakter Rothenburgs besonders hervorgehoben. Als wenige Wochen vor der Reichspogromnacht die letzten jüdischen Bewohner aus Rothenburg vertrieben worden waren, rühmten sich Stadtvertreter damit, dass die Stadt nun wieder ,judenfrei“ sei. Um die Inszenierung der Stadt institutionalisierte die NS-Organisation Kraft durch Freude (KdF) einen politisierten Massentourismus, der es den „Volksgenossen“ ermöglichte, Rothenburg zu besichtigen. Es wird geschätzt, dass 1937, auf dem Höhepunkt des organisierten Tourismus, allein 72000 KdF-Touristen in die Stadt kamen (vgl. Hagen 2004: 211).

Mit der Verkündung des Vierjahresplanes im Jahre 1936 setzte eine Wende in der Siedlungspolitik ein, die zur Folge hatte, dass die Siedlungsplanung und die Schaffung neuen Wohnraums dem Primat der „Wehrhaftmachung der Wirtschaft“ untergeordnet wurden. Die Finanzierung der Stadtrandsiedlungen ging insgesamt zurück sowie auch ihr Anteil an dem Bauvolumen für neuen Wohnraum. Der Kleinsiedlungsbau wurde ab 1936 in erster Linie unter volkswirtschaftlichen und rüstungspolitischen Gesichtspunkten als ideale Wohnungsform für die industrielle Arbeiterschaft weitergeführt. Das ideologische Ziel einer Entballung der großstädtischen Industriezentren und einer Umsiedlung der Massen in weniger dicht besiedelte Gebiete des Reiches trat hinter diesen Erfordernissen deutlich zurück (vgl. Münk 1993: 194-197). Der Bedarf der Rüstungswirtschaft nach Arbeitskräften führte dazu, dass die öffentliche Hand und die kommunalen Wohnungsbaugesellschaften wieder verstärkt in den städtischen sowie in den großstädtischen Wohnungsbau investierten. Im Mittelpunkt des staatlich geförderten Wohnungsbaus stand fortan die Schaffung günstiger Mietwohnungen, „die sich vor allen Dingen durch ihre spartanische Minimalausstattung und eine extreme Beschränkung des Wohnraumes auszeichnete“ (Münk 1993: 232). Die Rüstungspolitik konterkarierte schlussendlich die in den ersten drei Jahren der NS-Herrschaft dominierende Politik einer räumlichen Reagrarisierung dadurch, dass sie eine verstärkte Abwanderung vom Land in die großstädtischen Ballungsräume bewirkte. Die militärische Aufrüstung beschleunigte die von der NS-Propaganda bekämpfte „Landflucht“ in Deutschland (vgl. Mai 2002: 65-66). 
Das geringe Ausstattungsniveau der neugeschaffenen Wohnungen hing unter anderem damit zusammen, dass finanzielle und personelle Ressourcen durch die Errichtung von Monumentalbauten und städtebauliche Großprojekte gebunden waren, die den Großstädten in Deutschland eine neue Gestalt geben sollten (vgl. Münk 1993: 243-247). Die auf Größe ausgelegten städtebaulichen und architektonischen Pläne für eine Umgestaltung ausgewählter Großstädte sollten den universellen Machtanspruch Hitlers und der NSDAP symbolisieren. Die hiermit verbundene Notwendigkeit, die Großstadt sowie ein Stadtwachstum ideologisch legitimieren $\mathrm{zu}$ müssen, steht jedoch nur scheinbar im Widerspruch $\mathrm{zu}$ den von den Nationalsozialisten verfolgten Ansätzen für eine Auflockerung und Entballung der Großstädte (einen Widerspruch konstatiert Lane 1986: 204) Münk hebt in diesem Zusammenhang hervor, dass dem quantitativ orientierten Leitbild der NS-Stadtplanung die Qualität städtisch-urbanen Lebens fehlte:

Die soziale und innerstädtische Differenzierung, das kulturelle Leben, die vielfältigen sozialräumlichen Prozesse, die der modernen Großstadt erst ihren spezifischen Charakter als soziale Organisationsform vermitteln, waren in diesen auf die reine Wirkung der Monumentalität gerichteten Konzepten nicht vorgesehen. (Münk 1993: 334)

Die auf der Errichtung von Monumentalbauten basierende Stadt- und Architekturpolitik der Nationalsozialisten stellt demzufolge keinen Widerspruch $\mathrm{zu}$ den großstadtfeindlichen Ansätzen in der Stadt-, Raum-, Wohnungs- und Agrarpolitik der Anfangsjahre dar. Sie kann vielmehr als die Kehrseite der gleichen Medaille begriffen werden. Beiden Ansätzen liegt das Feindbild der modernen Großstadt zugrunde, die aus den sozialen, kulturellen und politischen Umbrüchen des Industriezeitalters hervorging. Münk und Bergmann sprechen im Zusammenhang mit den NS-Plänen zur Umgestaltung der deutschen Großstädte von einer Enturbanisierung der Großstädte bzw. einem Antiurbanismus (vgl. Bergmann 1970: 354-360; Münk 1993: 334). Bergmann versteht hierunter, dass die NS-Stadtplanung das Ziel verfolgte die Gestalt und den Charakter der modernen Großstadt zu zerstören, die der NS-Ideologie als Symbol und Motor der Moderne galt. Durch eine politische Demonstrations-, Einschüchterungs- und Ordnungsarchitektur sollten die Großstädte zum Zeugnis „einer steingewordenen Ideologie“ gemacht werden, die nicht mehr „Zentren einer urbanen, und das heißt einer freien, konfliktreichen, mit dem Konflikt und von dem Konflikt lebenden Gesellschaft“" sind (Bergmann 1970: 360). Die Pläne für die Umgestaltung Berlins, so urteilen Bergmann und Taylor übereinstimmend, sahen die Errichtung einer überdimensionierten Gartenstadt vor (vgl. Bergmann 1970: 357; Taylor 1974: 260). In diesem Zusammenhang hebt Jeffrey Herf hervor, dass es den Nationalsozialisten gelungen sei, den internationalen und liberalen Charakter Berlins der 1920er Jahre zu zerstören. Er betont, dass im Unterschied 
zur modernen Technik die modernen Großstädte und Metropolen als Symbole für Kosmopolitismus und Liberalismus nicht in die NS-Ideologie integrierbar gewesen seien (vgl. Herf 1993).

Die Unterscheidung zwischen einem großstadtfeindlichen und einem der Großstadt positiv gegenüberstehenden Lager innerhalb des Nationalsozialismus ist vor diesem Hintergrund nicht aufrechtzuerhalten. Die Großstadtentwicklung der vorangegangenen 50 Jahre diente den Nationalsozialisten als eine Negativfolie, vor deren Hintergrund die politische, kulturelle und demographische Entwicklung der Moderne negativ beurteilt wurde. Der gemeinsame Bezugspunkt und die ideologische Klammer der negativen Wahrnehmung der modernen Großstädte im Nationalsozialismus war der Antisemitismus: Die verschiedenen ideologischen Lager - sofern sie sich zu den Großstädten äußerten - stimmten in der Ansicht weitgehend darin überein, dass die Großstädte des „liberalistischen Zeitalters“ als jüdisch identifizierte Strukturmerkmale und Phänomene der Moderne symbolisierten: Materialismus, Parlamentarismus, Liberalismus, Marxismus, Intellektualität, moderne Geldwirtschaft und Finanzkapital, moderne Architektur, Kosmopolitismus, urbanes Nachtleben. Vor diesem Hintergrund wird verständlich, wieso sich auch in Schriften und Aussagen von NS-Größen wie beispielweise bei Hitler und Goebbels - gegen die Großstädte gerichtete Invektiven finden lassen, die nicht der völkischen Bewegung angehörten.

Die Nationalsozialisten standen vor der ideologischen Herausforderung, unter der von ihnen mehrheitlich geteilten Prämisse, dass die Großstadt eine für Volk und „Rasse“ nicht zuträgliche Lebensumwelt darstelle, die totale Macht in einem Staat zu übernehmen, dessen ökonomische und kulturelle Ressourcen in den Großstädten konzentriert waren. Die Einbeziehung der Großstädte in ein positiv konnotiertes Narrativ machten die Nationalsozialisten daher von zwei Bedingungen abhängig: von einer Veränderung der räumlichen Struktur, der Gestalt und der Funktion der Großstädte und von propagandistisch aufbereiteten Maßnahmen, die den schädlichen Einflüssen des Großstadtlebens entgegenwirken sollten.

\subsection{Großstadtfeindschaft in Deutschland nach 1945}

Mit dem Ende der NS-Herrschaft hörte die Großstadtfeindschaft in Deutschland nicht auf zu existieren. George Mosse vertritt in seiner Studie zur völkischen Ideologie hingegen die 
These, dass die Erfahrung der Zerstörung der deutschen Großstädte im Zweiten Weltkrieg dazu geführte habe, dass das völkische Lager seine Feindschaft gegenüber den Großstädten revidierte und ihnen nun die gleiche ideologische Bedeutung beimaß wie dem Landleben (vgl. Mosse 1964: 23). Wenngleich sich diese These empirisch nicht erhärten lässt, so kann davon gesprochen werden, dass es nach $1945 \mathrm{zu}$ einer Zäsur in der Entwicklung zivilisationskritischen und großstadtfeindlichen Denkens insgesamt kam. Die Verschiebung der politischen Gelegenheitsstrukturen für eine auf eine breitere Masse abzielende Ideologieproduktion war in der Bundesrepublik zwei Ursachen geschuldet (vgl. Sieferle 1984: 225-234): Die konservative Zivilisations- und Kulturkritik, mitsamt ihren agrarromantischen und großstadtfeindlichen Implikationen, war durch den Nationalsozialismus, wenngleich sich dieser ihrer nur in Versatzstücken bediente und nicht mit ihr identisch war, politisch und moralisch diskreditiert. Eine weitere zentrale Ursache für die Marginalisierung zivilisationskritischer Strömungen bestand in der Integration der Bevölkerung in die prosperierende Industriegesellschaft der neu gegründeten Bundesrepublik. Nach den Mangelund Hungererfahrungen der unmittelbaren Nachkriegszeit führte die rapide und kontinuierliche Erhöhung des Lebensstandards im Verlauf der 1950er Jahre dazu, dass negative Stimmen zur Industrie- und Konsumgesellschaft inopportun erschienen und daher am Bedarf vorbei formuliert wurden. Nach Sieferle war die Zivilisationskritik zu dieser Zeit weit davon entfernt, größere Bevölkerungsgruppen anzusprechen und stand außerhalb des Grundkonsenses der sich als unpolitisch verstehenden post-nazistischen Nachkriegsgesellschaft (vgl. Sieferle 1984: 228).

Während die zunehmende demokratische Konsolidierung der politischen Kultur dazu führte, dass antidemokratische und zivilisationskritische Ideologieangebote - im Unterschied zur Weimarer Republik - keine breite Resonanz im Bürgertum hervorriefen, gab es in der nationalen Rechten eine personelle und ideengeschichtliche Kontinuität großstadtfeindlichen Denkens. Bereits kurz nach der Gründung der Bundesrepublik gründeten sich nationalistische Jugendverbände, die in Teilen an die Tradition des völkischen Flügels der bündischen Jugendbewegung der Weimarer Republik anschlossen. Ahrens hat hierzu angemerkt, dass diese nationalistischen Strömungen jedoch keine dominante Stellung innerhalb der Nachkriegsjugendbewegung einnehmen konnten (vgl. Ahrens 2015: 367). Der größte Dachverband zu dieser Zeit war der bis Ende der 60er Jahre bestehende Kameradschaftsring Nationaler Jugendverbände (KNJ), aus dem der bis heute bestehende Bund Heimattreuer Jugend und die 1994 vom Bundesinnenministerium verbotene Wiking-Jugend (WJ) hervorgingen. 
Im Umfeld bündischer Zusammenschlüsse verortete sich auch der von 1965/1966 bis 2001 bestehende Freundeskreis der Artamanen, der einen Zusammenschluss ehemaliger Mitglieder und Sympathisanten der Bewegung darstellte und vornehmlich der Pflege alter Kontakte, der Erinnerungsarbeit, des Austausches über Erfahrungen mit der Siedlungsarbeit nach 1945 und dem Aufbau eines Archives diente (vgl. Baumgärtner/Wrede 2009: 115-122; Brauckmann 2005: 177, 2012: 55; Kater 1971: 638). In den 1990er Jahren traten sogenannte NeoArtamanen mit konkreten Siedlungsplänen an den weitestgehend vergreisten Freundeskreis heran und begannen die Tradition der ländlichen Siedlungsarbeit fortzusetzen. Diese von mehreren Großfamilien getragenen Siedlungsprojekte im (Un-)Geist der historischen Artamanenbeweung existieren bis in die Gegenwart fort und erregten in den letzten Jahren eine hohe Aufmerksamkeit in Wissenschaft und Politik (vgl. Speit 2012: 70-71). Obwohl eine aktive Siedlungsarbeit bisher ein marginales Phänomen in der extremen Rechten geblieben ist, kommt dem ländlichen Siedlungsgedanken und der ländlichen Brauchtumspflege ein hoher ideologischer Stellenwert in der extremen Rechten im Allgemeinen und in den nationalistischen Jugendbünden im Besonderen zu.

Die Haltung zur Großstadt ist in extrem rechten Kreisen stets eingebettet in eine grundsätzliche Diskussion, wie man es mit der kapitalistischen Moderne halten soll. In diesem Zusammenhang wurde und wird in rechtsextremen Kreisen die ideologische Bedeutung des Stadt-Land-Gegensatzes für die Ermöglichungsbedingungen einer nationalistischen und antiliberalen Staats- und Gesellschaftsordnung diskutiert. Großstadtfeindliche Motive und Topoi lassen sich dabei seit Beginn der rechtsextremen Publizistik in der Bundesrepublik finden und fungier(t)en für einen Teil des Spektrums als ein verbindendes Element, mit dem versucht wurde einen ideologischen Einfluss auf Bewegungen geltend zu machen, die in ihrer Mehrheit nicht rechtsextrem sind.

Ein besonderes Augenmerk muss in diesem Zusammenhang auf die in den 1970er Jahren entstehende Ökologiebewegung gelegt werden, in der großstadtfeindliche Ressentiments in Teilen der Bewegung auf Akzeptanz stießen und mit einem dort vorherrschenden modernitäts- und zivilisationskritischen Grundton kompatibel waren. Exemplarisch zeigt sich dies an dem Wirken des ehemaligen SA-Mitglieds und selbsternannten Bio-Bauern Baldur Springmann (1912-2003), der ein wichtiger Ideologe und Funktionär der bundesdeutschen Ökologiebewegung war. Eine größere Bekanntheit erlangte er durch seine Mitwirkung an der Gründung der Partei Die Grünen, die er bereits 1980 wegen des Einflusses linkradikaler Gruppen wieder verließ. Nachdem er sich von den Grünen abgewendet hatte, gehörte er zu 
den Gründungsmitgliedern der Ökologisch-Demokratischen Partei (ÖDP), deren stellvertretender Vorsitzender er wurde. Die ÖDP wurde als eine konservative Alternative zu den Grünen gegründet und war in ihren Anfangsjahren eine Anlaufstelle für nationalistische und rechte Ökologen. Aus zwei Arbeitskreisen innerhalb und im Umfeld der ÖDP gingen 1991 die Unabhängigen Ökologen Deutschlands (UÖD) hervor, an deren Gründung Springmann maßgeblichen Anteil hatte (vgl. o. A. 1996: 315). Bei der bis 2001 existierenden Gruppe handelt es sich Oliver Geden zufolge um die bedeutendste rechts-ökologische Organisation der Bundesrepublik (vgl. Geden 1999: 99). Neben einem unter dem Deckmantel ökologischer Evidenzen nur schlecht kaschierten Rassismus gehörte die Großstadtfeindschaft zu den ideologischen Grundüberzeugungen der UÖD. Gegen die Großstädte gerichtete Gedichte, Bildmontagen und Illustrationen durchziehen die Verbandzeitschrift der UÖD, die unter dem Titel Ökologie. Zeitschrift für Natur und Heimatschutz herausgegeben wurde.

Die Quintessenz einer sich als ökologisch verstehenden rechtsextremen Großstadtfeindschaft legte Springmann wenige Jahre vor seinem Tod in seiner autobiographischen Schrift Bauer mit Leib und Seele dar (vgl. Darstellung 1). Insofern ist Jutta Ditfurths Befund zuzustimmen, dass zu ökorechten Positionen fast immer die Stadtfeindschaft hinzutritt (vgl. Ditfurth 1996: 114). Dabei muss jedoch beachtet werden, dass für die von Springmann artikulierte Großstadtfeindschaft und Agrarromantik ein wie auch immer definierter ökologischer Begründungszusammenhang nicht entscheidend ist. Justus H. Ulbricht hat zu Recht darauf hingewiesen, dass im rechtsextremen Denken mit Umwelt und Umweltschutz weder naturwissenschaftlich-technische noch gesellschaftswissenschaftliche Kategorien benannt sind sondern, dass es sich hierbei um Metaphern für eine als „natürlich“ apostrophierte Gesellschaftsordnung handelt, ,in der ,Volk‘, ,Heimat‘ und ,Natur ${ }^{`}$ zu einem organischen Ganzen verbunden zu sein scheinen“ (Ulbricht 1995: 225). Springmanns dichotome Gegenüberstellung einer bäuerlichen und einer urbanen-großstädtischen Lebensweise fasst die zentralen Denkfiguren der großstadtfeindlichen Literatur seit den Schriften Riehls zusammen und schließt an die völkische Großstadtrezeption vor 1933 an. Vor diesem Hintergrund wird auch verständlich, wieso Springmann und die NPD kurz vor seinem Tod noch zusammenfinden konnten. 2003 trat dieser auf dem Pressefest des parteieigenen Verlags, der Deutschen Stimme, auf, der dessen Autobiographie zweitweise vertrieb. Springmanns These von einem besonders ausgeprägten Volks- und Heimatbewusstsein im bäuerlich-ländlichen Milieu gehört zu den Grundüberzeugungen der extremen Rechten in der Bundesrepublik und stellt kein Alleinstellungsmerkmal einer ökologischen Rechten dar. So erklärte die NPD 1967 in ihrer Wochenzeitung Deutsche Nachrichten, dass ,einst die bäuerliche Lebensart Urgrund 
und Nährboden für die deutsche Kultur schlechthin“ gewesen sei und sich im bäuerlichen Brauchtum die deutsche Seele offenbare (zit. n. Speit 2012: 66).

Dass es sich hierbei nicht um Reminiszenzen ehemaliger Mitglieder der völkischen Bewegung handelt, wird daran deutlich, dass sich diese Argumente auch in rechtsextremen Texten der Gegenwart finden lassen. Ein besonders ausgeprägtes Beispiel stellt der Text Der Globalisierungs-Angriff auf den ländlichen Raum des NPD-Politikers und Neonazis Jürgen Gansel dar. In diesem entwickelt Gansel die These, dass die von der „Ostküste der USA“ gelenkte Globalisierung eine „Ausblutung“ des ländlichen Raumes in Deutschland bezwecke, so dass die Widerstandsfähigkeit der Bevölkerung gegen die Globalisierung abnehme, da „die Globalisten [sic!] keinen identitätsstarken, ortsverwurzelten und solidaritätsfähigen Menschen [wollen], wie es ihn in ländlichen und halbländlichen Gebieten noch gibt, sondern sein Gegenbild: den identitätskastrierten, wurzellosen und gemeinschaftsunfähigen Konsumbürger, wie er gerade in anonymen und multiethnischen Großstädten gedeiht" (vgl. Gansel 2007). In Dörfern und Kleinstädten erkennt Gansel infolgedessen den Kristallisationspunkt eines „,erd- und bluthaften Widerstandes gegen die Globalisierung“ und sieht die Aufgabe der „,nationalen Opposition“ darin, diese Entwicklung organisatorisch und intellektuell zu unterstützen.

\begin{tabular}{|ll|}
\hline Bäuerliche Lebensart & Industrielle Massengesellschaft \\
Ländliche Lebensform & Verstädtung, innerlich u. äußerlich \\
Ökologie des Menschen: & Isolation des Menschen: \\
Bewußtes Sicheinordnen & Streben nach Unabhängigkeit von \\
in Naturzusammenhänge & Naturzusammenhänge. Existenz in \\
und kosmische Rhythmen & Surrogaten und künstlicher Umwelt \\
& \\
Seßhaftigkeit. & Freizügigkeit, Mobilität \\
Grundbesitz, Heimat, Familie & Geldbesitz, modernes Nomadentum \\
Vorsorge auf lange Sicht & Auflösung der Familie. Geldbesitz, \\
Pflege der Umwelt (Mitwelt) & Ausbeutung der Umwelt (Rohstofflager) \\
& \\
Arbeit als Lebensunterhalt & Job zum Geldmachen. Das „Leben“ \\
und, im Rhythmus mit Muße, & fängt erst nach Feierabend oder auf \\
als Lebensinhalt. Leistungs- & Mallorca an. Leiden unter Leistungs- \\
freude, Pflichtbewußtsein & druck. „Arbeitskampf“ \\
& \\
Lebensgemeinschaften in & Wohlstandsgesellschaft einerseits, \\
überschaubarem Rahmen & Slums andererseits. Überall zwischen- \\
Unmittelbare Teilnahme an & geschaltete Verwaltungsapparate. \\
\hline
\end{tabular}




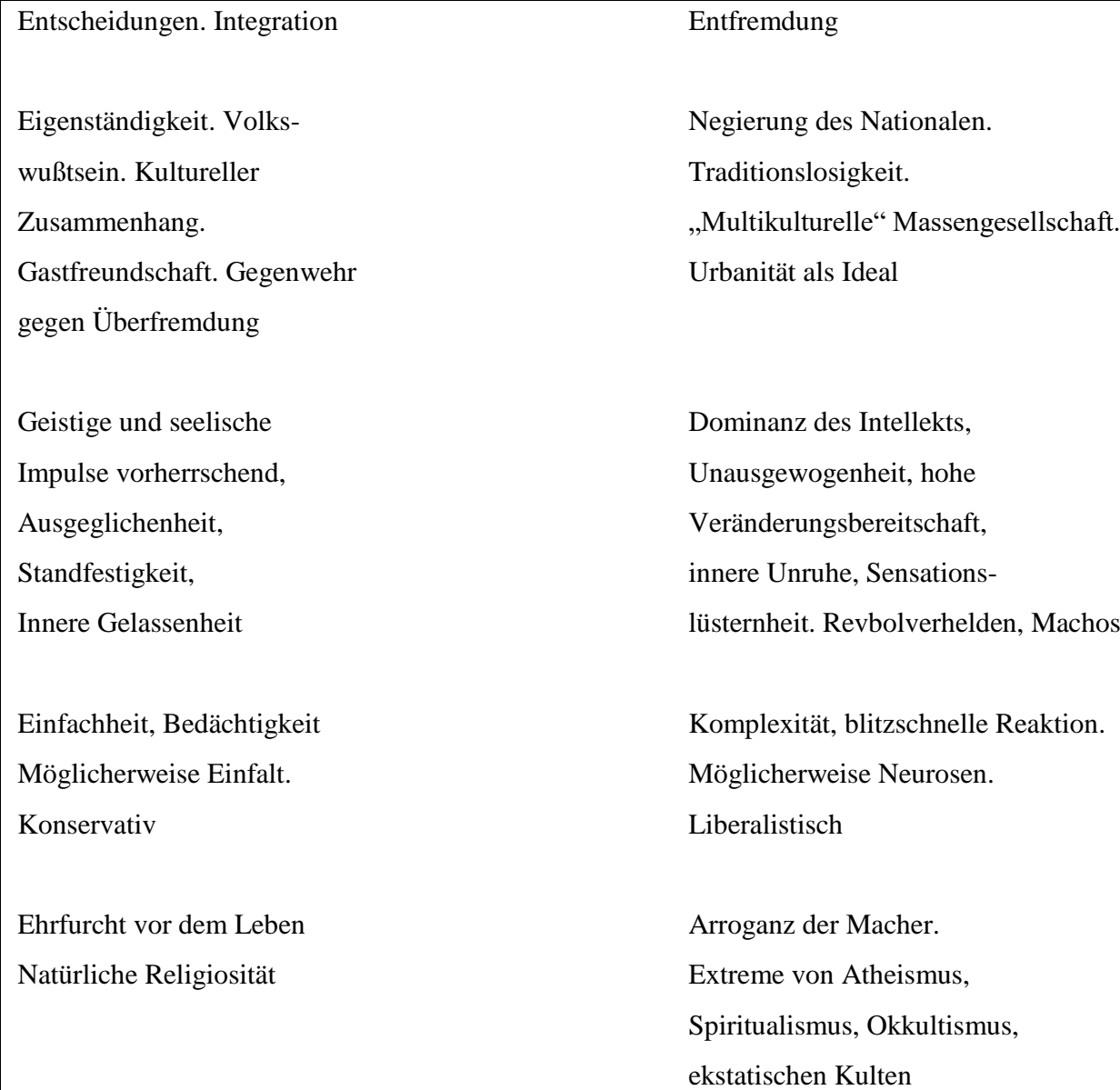

ekstatischen Kulten

Komplexität, blitzschnelle Reaktion.

Möglicherweise Neurosen.

Liberalistisch

Darstellung 1: Springmann 1995: 73; Rechtschreibfehler im Original

Die Idee einer Stärkung des Landlebens und einer damit einhergehenden Bekämpfung des zunehmenden Bevölkerungsrückgangs in ländlichen Regionen Ostdeutschlands ist Gegenstand gegenwärtiger strategischer Überlegungen in der extremen Rechten. In der Diskussion wird bewusst auf die großstadtfeindlich motivierten Siedlungsaktivitäten der völkischen Bewegung rekurriert und im Besonderen die Geschichte der Artamanen in Erinnerung gerufen. So würdigt ein Artikel in der der Jugendorganisation der NPD, den Jungen Nationaldemokraten, nahestehenden Zeitschrift hier \& jetzt. radikal rechte Zeitung die Artamanenbewegung als Beispiel für eine alternative Lebensgestaltung und ruft dazu auf, Bauernhöfe in „Mitteldeutschland“ zu erwerben, um auf ihnen nach völkischem Vorbild zu siedeln (vgl. Jurisch 2010).

Nicht nur im Hinblick auf die Geschichte der Artamanen gibt es im gegenwärtigen Rechtsextremismus Anknüpfungsversuche an eine großstadtfeindliche Praxis der völkischen Bewegung und des Nationalsozialismus. Jürgen Rieger bemühte sich um die Etablierung einer ländlichen Menschen- und Rassenzucht. Rieger stand bis zu seinem Tod im Jahre 2009 der neu-heidnischen Artgemeinschaft - Germanische-Glaubens-Gemeinschaft e.V vor, die sich in 
die Tradition des nordischen Flügels der völkischen Bewegung stellt und eine radikale Großstadtfeindschaft propagiert. Auch hier lässt sich ein Querverweis zu Springmann herstellen: Nach Springmanns Tod schaltete die Artgemeinschaft eine Traueranzeige, in der sein Beitrag zur „Gesundung unseres Volkes“ hervorgehoben wurde. In ihrer Agitation bezieht sich die Gruppe direkt auf das großstadtfeindliche Schrifttum der völkischen Bewegung. So vertreibt der Bücherdienst der Artgemeinschaft mit dem Einverständnis der Nachkommen eine Neuauflage des Buches Die Verstädterung von Hans F.K. Günther. Das Buch wird von Rieger auf der Internetseite des Verlages mit den Worten angepriesen, dass eine Schrift über Verstädterung gut in eine religiöse Schriftreihe passe, da „,nordisch-fälische Menschen in der Stadt nicht zu gedeihen vermögen, und ohne nordisch-fälische Menschen es keinen Artglauben geben kann“. Es müsse darum gehen, so Rieger weiter, „unsere Menschart aus für sie schädlichen Umweltbedingungen herauszulösen, ihr die kinder- und lebensfeindliche Umwelt der Stadt als Gefahr bewußt zu machen““. ${ }^{24}$

Eine ablehnende Haltung gegenüber den Großstädten existiert in der Gegenwart nicht zuletzt auch deshalb fort, weil ihr ein gewisser Grad an Wandlungsfähigkeit zu Eigen ist. So lässt sich etwa in den Reden des AfD-Politikers Björn Höcke beobachten, dass nicht der Gegensatz von Großstadt und Landleben, sondern die Differenz zwischen westdeutschen Metropolen und Ballungszentren einerseits und ostdeutschen Großstädten kleiner und mittlerer Größe andererseits, den Bezugspunkt seines antiurbanen Ressentiments bildet. Höcke bezeichnete auf einer gegen die Flüchtlingspolitik der Bundesregierung gerichteten AfD-Kundgebung im September 2015 die Stadt Erfurt als „,schön deutsch“ und teilte seinem Publikum mit, dass die wenigen verbliebenen deutschen Kinder in Berlin „Kanacksprach“ sprächen (vgl. Höcke 2015). Auch sonst findet sich in seinen öffentlichen Reden die Warnung davor, dass die Verhältnisse in den westdeutschen Großstädten nach Ostdeutschland ausgreifen könnten. Die völkische Aufladung dieser Bilder ist evident: Den von Amerikanisierung und Einwanderung heimgesuchten Metropolen der alten Bundesrepublik wird sinngemäß die Funktion eines die Volkskraft aufzehrenden Rassengrabes zugewiesen, die Städte Ostdeutschlands werden als Sinnbilder autochthoner Gemeinschaftsvorstellungen glorifiziert.

Die aufgeführten Beispiele verdeutlichen, dass von einer Kontinuität großstadtfeindlichen Denkens in völkischen und rechtsextremen Kreisen bis in die Gegenwart gesprochen werden kann. Der großstadtfeindliche Impetus des bundesrepublikanischen Rechtsextremismus besitzt dabei jedoch nicht die Evidenz der Großstadtfeindschaft der völkischen Bewegung des

\footnotetext{
${ }^{24}$ http://asatru.de/versand/main_bigware_34.php?bigPfad=22\&items_id=86 (01.06.2015)
} 
Kaiserreichs und der Weimarer Republik, deren publizistischer Umfang deutlich größer war. Stereotype über das Großstadtleben und eine Idealisierung des Landlebens existieren als Teil eines kulturellen Gedächtnisses in der deutschen Bevölkerung insgesamt fort - jedoch weniger auf einer manifest-bewussten Ebene, wie es für die 1920er Jahre zutrifft, als Spengler mit seiner Verstädterungstheorie maßgeblich zur Festigung einer antidemokratischen und totalitären Grundhaltung in weiten Teilen des Bildungsbürgertums beitrug. Eine vergleichbare Ideologieproduktion, die Einzug in politische und gesellschaftliche Diskussionen gefunden hat, gab es in der Geschichte der Bundesrepublik nicht. Die Tradition großstadtfeindlichen Denkens manifestiert sich in der Gegenwart vor allem über Redensarten, die einen Verweis auf eine großstadtfeindliche Bildersprache belegen, z.B. wenn von einer „Verwurzelung in der Heimatregion“ die Rede ist oder in einer kulturindustriell dargebotenen Inszenierung des Landlebens als einem way of life, wie es mittlerweile mehrere Magazine im Angebot haben, die ihre vor allem großstädtische Leserschaft mit Informationen über „ländliche Küche“ oder „ländliches Wohnen“ versorgen. 
5. Schlüsselwerke der Großstadtfeindschaft

\subsection{Wilhelm Heinrich Riehl}

In seiner vier Bände umfassenden Reihe Die Naturgeschichte des Volkes als Grundlage einer deutschen Social-Politik legte Wilhelm Heinrich Riehl (1823-1897) in der Mitte des 19. Jahrhunderts die ersten Schriften vor, in der die Behauptung eines negativen Einflusses von Verstädterung und Großstadtleben auf das deutsche Volk systematisch abgehandelt wird. Seine mit der Großstadtfeindschaft unmittelbar zusammenhängende Sicht auf die Bedeutung des Bauerntums für den Erhalt der feudalen Ordnung war stark geprägt von den Schriften Ernst Moritz Arndts (1769-1860), dessen Student und Schüler Riehl war. Arndt hob bereits zu Beginn des 19. Jahrhunderts hervor, dass das Bauerntum der eigentliche Träger und Bewahrer des Staates sei und dass ihm „mehr als in anderen Klasse des Volkes die ursprüngliche und gediegene Naturkraft, die Reinheit der Sitten, die Treue und Redlichkeit der Gesinnung [inne wohnt]“ (Arndt 1938 [1814]: 278, 1938 [1815]: 294;). Sein Credo lautete, dass ein Staat und ein Volk umso stärker und gefestigter seien, desto kräftiger der Bauernstand sei. Diese Überlegungen markierten für Riehl den Ausgangspunkt, um sich mit der Bedeutung der verschiedenen Stände im deutschen Volk zu beschäftigen. Seine Äußerungen über den Bauernstand und über die Großstädte sind Teil einer Darstellung der Kulturgeschichte des deutschen Volkes, die er im Vorwort zum ersten Band als eine soziale Volkskunde Deutschlands, als eine „allgemeine Systematik der Gesellschaft dieses Landes“ verstanden wissen wollte (vgl. Riehl 1861a).

Der studierte Theologe näherte sich seinem Programm einer sozialen Wissenschaft bzw. einer sozialen Ethnographie zuerst als Journalist an. Der Durchbruch gelang ihm 1850, als er anfing, für den Stuttgarter Verlag Cotta zu arbeiten. Aus seinen Aufsätzen für die Deutsche Vierteljahresschrift, in denen er sich bereits mit der Analyse einer sozial-ständischen Typologie von Bevölkerungsgruppen beschäftigte, ging sein Buch Die bürgerliche Gesellschaft hervor, das den zweiten Band seiner Naturgeschichte bildet (vgl. Altenbockum 1994: 35). Seine Untersuchungen über die gesellschaftlichen Zustände in Deutschland dienten Riehl eigenen Angaben zufolge zur Rechtfertigung einer konservativen Sozialpolitik (vgl. Riehl 1858: 38). Die Geschehnisse der gescheiterten März-Revolution von 1848 stärkten seine konservative Überzeugung und veranlassten ihn, sich der Materialsammlung für seine soziale Ethnographie zuzuwenden (vgl. Altenbockum 1994: 26-27). Sein Übertritt in die 
akademische Welt gelang mit der Ernennung zum Honorarprofessor an der staatswissenschaftlichen Fakultät in München durch den bayerischen König Maximilian II. (1811-1864) zu Beginn der 1850er Jahre. In den folgenden Jahren wurde Riehl mehrere Male zum Rektor der Münchner Universität ernannt (vgl. Altenbockum 1994: 64).

Die Bedeutung des Riehl'schen Werks für die Wissenschaftsgeschichte ist bis heute umstritten und wurde in der über 150-jährigen Rezeptionsgeschichte unterschiedlich beurteilt (vgl. Kalazny 2005: 49). In den 1850er Jahren rief seine Naturgeschichte des Volkes harsche Kritik in der Fachwelt hervor. Riehl, der sich als wissenschaftlicher Schriftsteller verstand, wurde im Besonderen sein literarischer Schreibstil zu Lasten gelegt. Es wurde ihm vorgehalten, seinen Gegenstand nur feuilletonistisch, jedoch nicht wissenschaftlich abgehandelt zu haben (vgl. Altenbockum 1994: 64). Die fehlende Anerkennung und ausbleibende Reputation durch die Fachwelt verdankten sich nicht zuletzt der Kritik des einflussreichen Historikers Henning von Treitschke. Lövenich hebt hervor, dass Treitschke sich in seiner Habilitationsschrift aus der Perspektive der Staatswissenschaft gegen Autonomiebestrebungen wendete, die die Etablierung einer eigenständigen Wissenschaft von der Gesellschaft zum Ziel gehabt haben (vgl. Lövenich 1992: 52). Dieses Ansinnen sah er durch Riehl verkörpert, der sein Programm einer sozialen Ethnographie als die Grundlage der Staats- und Gesellschaftswissenschaften verstand (vgl. Riehl 1858: 30-31). Altenbockum (1994: 37) nennt Riehl in diesem Zusammenhang einen sozialwissenschaftlichen Autodidakten. Ein breites Lesepublikum fanden seine Schriften hingegen in nichtakademischen Kreisen. Seine Naturgeschichte war ein großer Publikumserfolg, der mehrmals aufgelegt wurde. Auf ausgedehnten Lese- und Vortragreisen sprach Riehl vor weit über hunderttausend Menschen.

Die Rezeption seiner Schriften änderte sich Kalazny zufolge mit dem Tod Riehls. Die Aufwertung seines Werkes in den 1890er Jahren bereitete die nach dem Ersten Weltkrieg einsetzende breite Rezeption seiner Schriften vor (vgl. Kalazny 2005: 55). In den 1920er und 30er Jahren wurden Riehls Arbeiten zur Begründung einer „Soziologie des deutschen Volkstums" herangezogen, die an der Errichtung eines völkischen Staats mitwirken sollte (vgl. Kalazny 2005: 56). Im Nationalsozialismus wurde Riehl als Begründer der Blut-undBoden-Ideologie und als Entdecker der Bedeutung des Bauernstandes für den Erhalt des deutschen Volkes gewürdigt (vgl. Bergmann 1970: 39). 1935 wurde der „Wilhelm-HeinrichRiehl-Preis der Deutschen Volkskunde“ gestiftet. Die positive Bezugnahme der Nationalsozialisten auf Riehl beinhaltete einerseits eine gezielte Instrumentalisierung, die 
auch mit den Mitteln der Verfälschung arbeitete. So wurden manipulierte Editionen seiner Schriften herausgegeben. Andererseits fanden die nationalsozialistischen Blut-und-BodenIdeologen in den Schriften Riehls ein, wie es Kalazny (2005: 57) ausdrückt, sozialkulturelles Begriffsnetz, auf das sie ihre Weltanschauung beziehen und stützen konnten. Dies betrifft im Besonderen auch die in seiner Naturgeschichte artikulierte Judenfeindschaft, die bereits Elemente des modernen Antisemitismus in sich trug.

Riehl differenziert in seiner Naturgeschichte des Volkes zwischen vier Bevölkerungsgruppen bzw. Ständen in Deutschland. Der erste Stand bildet das Bauerntum, der zweite den Adel, der dritte das Bürgertum, und unter dem vierten Stand fasst Riehl all jene Gruppen zusammen, die sich entweder losgelöst haben oder aus dem bisherigen Gruppen- und Schichtsystem der Gesellschaft ausgeschlossen wurden und auf eine Auflösung der organischen Gliederung der Stände drängten. Die Hauptgruppe dieses vierten Standes bilde neben den Fabrikarbeitern das Geistesproletariat, das sich nach Riehl in ein Beamten-, Privatdozenten-, Journalisten-, Künstler- und Literartenproletariat untergliedert (vgl. Riehl 1858: 305, 343). Im Unterschied zu den anderen Ständen sei dieser Stand kosmopolitisch und vaterlandslos und stehe im Gegensatz zum Bauerntum (vgl. Riehl 1858: 281) Nach Riehl lassen sich die vier Stände in zwei sich gegenüberstehende Gruppen unterteilen: Bauerntum und Adel bilden demnach die Mächte des Beharrens, Bürgertum und vierter Stand die Mächte der sozialen Bewegung. Nach Riehl spiegelt sich diese Unterscheidung im Gegenüber von Land und Stadt wider: „Der große Gegensatz von Mächten des socialen Beharrens und der socialen Bewegung stellt sich zugleich dar als Gegensatz von Land und Stadt““ (Riehl 1858: 197).

Dem Bauernstand kommt für Riehl eine herausgehobene Bedeutung für den Erhalt der ständischen Gesellschaftsordnung zu. Nach ihm stellen die Bauern den Kern einer „unüberwindlichen conservativen Macht in der deutschen Nation dar“ (Riehl 1858: 41). Ihre konservative Überzeugung sei nicht theoretischer Natur, sondern entspreche ihrer Sitte (vgl. Riehl 1858: 41). Riehls Bewunderung des Bauernstandes drückt sich auch darin aus, dass er eigenen Angaben zufolge ursprünglich nur den Bauernstand erforschen wollte (vgl. Riehl 1861a). Den deutschen Bauern sei es zu verdanken, dass die Ideen der Französischen Revolution nicht bis zu den untersten Schichten des deutschen Volkes durchgedrungen seien und dass die ständische Ordnung 1848 erhalten geblieben sei (vgl. Riehl 1858: 41). Für Riehl unterscheidet sich der Bauernstand von den anderen Ständen darin, dass er überhistorisch ist und als einziger einen organisch selbständigen und unberührten Stand darstellt, der die Geschichte alten deutschen Volkstums in sich trage (vgl. Riehl 1858: 42-43). Insofern sei der 
Bauer der „rohe, aber ungefälschte Kern deutschen Wesens“ (Riehl 1858: 42). Riehl gelangt hierdurch zu dem Schluss, dass ,die innere Erfrischung und Verjüngung unseres Volkslebens nur noch von dem Bauernstande ausgehen [kann]“(Riehl 1858: 41).

Das Wesen des Bauern leitet Riehl aus dessen nicht-städtischem Charakter ab: So unterscheide sich die Körper- und Geisteshaltung des Bauern von der des Städters. Der Stadtbewohner sei eine Einzelpersönlichkeit, der Bauer existiere hingegen nur in der Gruppe (vgl. Riehl 1858: 43-44). Die größte Gefahr für das Bauerntum sieht Riehl in seiner Proletarisierung, die aus einer zunehmenden Abhängigkeit von der städtischen Geld- und Marktwirtschaft resultiere. Die Selbständigkeit des Bauern beruht nach Riehl auf seiner Unabhängigkeit vom Geld, woraus er schlussfolgert, dass durch das „kaufmännische Spekulieren der soziale Charakter des Bauern zerstört“"werde (Riehl 1858: 69).

Riehl entwickelt hierbei in Grundzügen eine fetischisierte Betrachtungsweise des Geldes, das er als abstrakt, künstlich und daher als wurzellos wahrnimmt. Den Juden als Personifikationen der Zirkulationssphäre misst Riehl eine entscheidende Rolle für den Niedergang des Bauerntums zu. Nach ihm geht die steigende Abhängigkeit der Bauern vom Geld einher mit ihrer Abhängigkeit von den Juden. Dies sei insofern fatal, als durch die Herrschaft des Geldes die Eigenart der Bauern zerstört werde (vgl. Riehl 1858: 71). Sollte sich dieser Prozess fortsetzen, so Riehl, dann werde aus dem Bauern ein „abstrakter Kulturmensch“ (Riehl 1858: 76). In der modernen Geldwirtschaft sieht Riehl hingegen den Grund dafür, dass es in den Großstädten kein Zusammenleben der Generationen gebe, wie es das bäuerliche Leben charakterisiere. Ihm zufolge stellt das Geld das wirtschaftliche Interesse des Einzelnen über das wirtschaftliche Interesse der Familie (vgl. Riehl 1861: 195). Die Juden werden als Personifikationen des Geldes in seiner Naturgeschichte dem deutschen Bauerntum in einer manichäischen und dichotomischen Weise gegenübergestellt. In diesem Zusammenhang spricht er von einem Gegensatz zwischen den ,heimatlosen Dorfjuden“ und dem Bauernstand (vgl. Riehl 1858: 74).

An diesem Beispiel wird deutlich, dass Riehls negative Auslassungen über die Juden Elemente des modernen Antisemitismus aufweisen, ohne dass seine Judenfeindschaft bereits $\mathrm{zu}$ einer allumfassenden Weltanschauung geronnen ist. Die Personifizierung der Zirkulationssphäre in den Juden bedingt bei Riehl antisemitische Zuschreibungen, wonach die Juden nicht nur heimat- und wurzellos seien, sondern auch eine Scheu gegenüber harter Arbeit und körperlicher Anstrengung besäßen (vgl. Riehl 1858: 366). An anderer Stelle schreibt Riehl, dass die Juden den Gelderwerb zum Selbstzweck erkoren und einen Kultus des 
Reichtums begründet hätten (vgl. Riehl 1858: 378). Insofern kann der Einschätzung Klaus Bergmanns, wonach es sich bei den judenfeindlichen Auslassungen in der Riehl'schen Naturgeschichte des Volkes um einen „milden Antisemitismus“ handelt, nicht zugestimmt werden (vgl. Bergmann 1970: 45). Riehl muss vor diesem Hintergrund als ein Vordenker der antisemitischen Großstadtfeindschaft gelesen werden.

Riehls These, dass die Haltung der von ihm skizzierten Bevölkerungsgruppen zur gesellschaftlichen Ordnung mit räumlichen Faktoren erklärbar sei, sie sich also auf einen Stadt-Land-Unterschied zurückführen lasse, führt ihn $\mathrm{zu}$ einer grundsätzlich negativen Bewertung des Verstädterungsprozesses und der Großstadtentwicklung. Hierbei handelt es sich um eine antizipative Feinderklärung, da ihr Objekt, die moderne, industrielle Großstadt, in den 1850er Jahren in Deutschland noch im Entstehen begriffen war. In der Mitte des 19. Jahrhunderts begann sich der Verstädterungs- und Urbanisierungsprozess erst langsam anzubahnen. Die Hochphase dieses Prozesses, der das bisherige Städtewesen grundlegend veränderte, begann erst in den 1870er Jahren (vgl. Reulecke 1985). Riehl versteht seine Ausführungen zur Großstadt daher sowohl als eine Bestandsaufnahme als auch als den Versuch die künftige Entwicklung der Großstadtentwicklung in Deutschland vorherzusagen.

So fordert er einerseits eine Emanzipation von der „Großstädterei“ (Riehl 1861: 330), andererseits spricht er davon, dass die Herrschaft der großen Städte „,das dunkle Gespenst der deutschen socialen Zukunft [ist]“ (Riehl 1861a: 67). Die Entwicklungen in England und Frankreich dienen Riehl dabei als Anschauungsmaterial. Im Hinblick auf London und Paris konstatiert er, dass Europa an der Größe seiner Großstädte krank werde: „Die gesunde Eigenart Altenglands wird in London gegraben, Paris ist das ewig eiternde Geschwür Frankreichs“ (Riehl 1861a: 95). Die deutschen Großstädte strebten danach, sich London und Paris anzugleichen. Riehl zufolge gibt es die allgemeine Tendenz, dass Städte in den Rang einer Weltstadt aufsteigen möchten und dadurch ihr nationales Gepräge verlören (vgl. Riehl 1861a: 97-98).

Einen weiteren zentralen Topos der Großstadtfeindschaft stellen seine Überlegungen zum Einfluss der Großstädte auf die Bevölkerung dar. Die Anziehungskraft, die die Großstädte auf die Menschen ausübt, sieht er in der dargebotenen Möglichkeit in den Großstädten, ,ernten zu können, ohne gesät zu haben“ (Riehl 1861a: 95). Die den Großstadtbewohnern und der Großstadt unterstellte Unproduktivität und Unselbständigkeit zeigt sich für Riehl noch in anderer Weise: Die Großstädte seien abhängig von der Zuwanderung der Landbevölkerung, ohne die die Großstädte auf lange Sicht nicht überlebensfähig wären: 
Das fabelhaft rasche Anwachsen unserer größeren Städte geschieht nicht durch einen Überschuß an Geburten, sondern durch einen Überschuß der Einwanderung. Das Land und die kleine Stadt wandert aus nach der Großstadt. (Riehl 1861a: 95)

Zudem behauptet Riehl, dass das Großstadtleben zu einer künstlerischen Unproduktivität führe. Er stellt die These auf, dass alle bedeutenden Künstler und Wissenschaftler Deutschlands aus ländlichen Gegenden stammten und dass das Talent mit dem Zuzug in die Großstädte erlösche (vgl. Riehl 1861a: 99-100).

Die entscheidende Gefahr, die Riehl von der Verstädterung ausgehen sieht, betrifft jedoch die Annahme einer Verschiebung des politischen Kräfteverhältnisses zugunsten des Proletariats. Die Herrschaft der Großstädte über das Land ist für ihn gleichbedeutend mit der Herrschaft des Proletariats (vgl. Riehl 1861a: 96). Im Unterschied zum Handwerker sei der großstädtische Fabrikarbeiter heimat- und familienlos. Nach Riehl hat er insofern keine Familie, als ihm ein natürliches Familienbewusstsein fehle (vgl. Riehl 1858: 350). Nicht die Besitzlosigkeit oder der Gegensatz von Kapital und Arbeit lege die Zugehörigkeit zum Proletariat fest, sondern die von ihm konstatierte Familien- und Heimatlosigkeit (vgl. Riehl 1858: 355). In den Arbeitervierteln der Großstädte sieht Riehl daher das Volksleben absterben, während er im Bauerntum nicht nur die Zukunft Deutschlands sieht, sondern zugleich in abgelegenen, ländlichen Gegenden den wahren Kern des Volkes ausmacht (vgl. Riehl 1861a: 256). Eine zunehmende Verstädterung müsse daher auch den Untergang der Nation nach sich ziehen: „Jede Nation, die nicht mehr eine gewisse Masse rohen Naturvolkes in ihren Gesamtkreis einschließt, ist ihrem Untergang nahe“ (Riehl 1861a: 256).

Riehls Untergangsprophezeiung sowie seine zusammengetragenen Thesen über die Großstadt umfassen die wirkmächtigsten Topoi und Argumentationsmuster der Großstadtfeindschaft und Agrarromantik, wie sie sich ausgehend von seinen Werken in Deutschland entwickelten haben. Die manichäische Unterscheidung zwischen volksbewahrenden und volkszerstörenden Kräften entlang eines konstruierten Stadt-Land-Gegensatzes hatte einen nachhaltigen Einfluss auf die völkische und nationalsozialistische Großstadtfeindschaft. Einen entscheidenden Bezugs- und Referenzpunkt für die Rezeption Riehls in völkischen und nationalsozialistischen Kreisen stellt seine Judenfeindschaft dar, deren Bedeutung sich aus der Idealisierung des Bauernstandes und der Identifizierung der jüdischen Bevölkerung mit der Zirkulationssphäre und damit als ein nichtbäuerliches, städtisches Element, ergibt.

Der zeitliche Kontext der Entstehung und Veröffentlichung seiner Naturgeschichte des Volkes macht deutlich, dass seine Großstadtfeindschaft nicht als Reaktion auf soziale oder 
ökologische Probleme der Verstädterung gelesen werden kann. An Riehls Werk wird deutlich, dass die Großstadtfeindschaft in Deutschland ihren Ursprung in einer weitegehenden Abstraktion der tatsächlichen Lebensverhältnisse in den Großstädten hat. Bei Riehl deutet sich ein den Modernisierungsprozess in Deutschland begleitender zivilisationskritischer Diskurs an, in dem das Landleben und der Bauernstand eine Projektionsfläche für Vorstellungen von „organischer Verwurzelung“, Authentizität und einer Unmittelbar- und Naturwüchsigkeit abgeben.

\subsection{Georg Hansen}

Georg Hansens Buch Die Drei Bevölkerungsstufen. Ein Versuch, die Ursachen für das Blühen und Altern der Völker nachzuweisen erschien 1889 zu einem Zeitpunkt, als eine neue Welle großstadtfeindlicher Publikationen einsetzte. Hansen, über dessen Biographie so gut wie nichts bekannt ist, legte mit seiner als statistischer Studie angelegten Schrift eine sozialanthropologische und -biologistische Betrachtung der Binnenwanderung vom Land zur Stadt vor, die die Wahrnehmung der Großstädte in Deutschland bis weit in das 20. Jahrhundert hinein prägen sollte (vgl. Pfeil 1972: 48). Andrew Lees zufolge gehört sein Buch zu den Standardwerken der Großstadtfeindschaft in Deutschland und seine demographischen Analysen zur Land-Stadt-Wanderung und zum Geburtenrückgang in den Städten „developed what was to become one of the most pervasive and compelling lines of attack among dedicated city haters" (Lees 1979: 65). Zusammen mit Otto Ammon, der Gedanken von Hansen in seinen Schriften kurze Zeit später aufgriff und weiterentwickelte, habe Hansen „the main lines of the demographic case against the city“ herausgearbeitet (Lees 1979: 66).

Seine These von der Abhängigkeit der Städte von der Zuwanderung aus ländlichen Gegenden und die Glorifizierung des Bauernstandes als eines Garanten für ein starkes und gesundes Volk wurden von Riehl als Topoi in den großstadtfeindlichen Diskurs eingeführt. Der Einfluss von Hansens Studie verdankt sich Bergmann zufolge daher dem Umstand, dass seine Theorie „bestimmte Aspekte der Ausführungen Riehls scheinbar bestätigte und wissenschaftlich verifizierte“ (Bergmann 1970: 50). Im Gegensatz zu den Schriften von Riehl, den Hansen in seiner Studie kein einziges Mal zitiert oder namentlich nennt, beinhaltet sein Buch jedoch keine systematisch ausgearbeitete Großstadtfeindschaft. Sein Werk kann zudem nur bedingt als großstadtfeindlich bezeichnet werden, da im Mittelpunkt seiner 
Betrachtungen nicht die modernen Großstädte stehen. Die Groß- und Industriestädte finden nur am Rande Erwähnung. Insofern ist Bergmann zuzustimmen, wenn er schreibt, dass Hansen „zum Mißbrauch reizendes Material für eine gegen die Großstadt und die Binnenwanderung gerichtete politisch-ideologische und romantisch Haltung geliefert [hat]“ (Bergmann 1970: 56).

Hansen unterscheidet in seinem Buch zwischen drei Bevölkerungsgruppen, die er nach ihrem Einkommen unterscheidet: Die Existenz des Bauernstandes und des Adels, so seine These, basiert auf dem Grundbesitz. Der städtische Mittelstand bezieht sein Einkommen aus der geistigen, das Proletariat aus der körperlichen Arbeit. Hansen zufolge existieren diese drei Bevölkerungsgruppen jedoch nicht nebeneinander, sondern stehen in einem organischen Verhältnis zueinander. Für Hansen stellen sie verschiedene Entwicklungsstufen innerhalb der Gesellschaft dar (vgl. Hansen 1889: 30-31). Die Entwicklung der Bevölkerungsstufen geht dabei vom Stand der Grundbesitzer aus, in erster Linie vom Bauernstand, der als einziger der drei Bevölkerungsstufen von Dauer sei. Aus den Überschüssen an Menschen, den dieser produziert, entsteht ein Bevölkerungsstrom, der sich vom Land in die Städte ergießt und dort den absterbenden Mittelstand ersetzt. Der unterlegene, nicht mehr konkurrenzfähige Teil des Mittelstandes steigt in die dritte Bevölkerungsstufe, in das Proletariat ab. Der Teil des Mittelstandes, dem der soziale Aufstieg in den Städten gelingt, sterbe hingegen aufgrund eines Geburtenrückganges aus. Die Schnelligkeit und Intensität dieses Bevölkerungsstroms bestimmt das geistige Niveau des Mittelstandes und deshalb auch die Höhe der Kultur des ganzen Volkes, da es sich beim Mittelstand um den Träger der Kultur handelt (vgl. Hansen 1889: 173). Je stärker und gesünder der Bauernstand ist, desto höher sei das geistige Niveau des städtischen Mittelstandes (vgl. Hansen 1889: 405). Im Vorwort des Buches gibt Hansen als Ziel seiner Studie aus, Mittel zu entwickeln, mit denen der als Organismus verstandene Bevölkerungsstrom ,gesund“ erhalten werden kann (Hansen 1889: III-IV).

Hansen begreift den von ihm skizzierten Bevölkerungsstrom und das Absterben der städtischen Bevölkerung als ein überhistorisches Naturgesetz. Seine Schrift steht in der Tradition eines Verständnisses von Sozial- und Gesellschaftswissenschaft, das von der Grundannahme ausgeht, dass sich in der sozialen Welt unumstößliche Gesetzmäßigkeiten feststellen lassen können. Hansen deduziert aus seinem Zahlenmaterial, an dessen objektiver Beweiskraft er keine Zweifel aufkommen lässt, dass die städtische Bevölkerung ,in je zwei Menschenaltern durch den Zuzug von auswärts vollständig ersetzt wird“ (Hansen 1889: 27). 
Die städtische Mittelschicht ist Hansen zufolge eine Übergangsstufe von der ersten zur dritten Bevölkerungsstufe. Der Mittelstand kenne „keine bleibenden Geschlechter. Niemand, der in ihn eintritt, hat Anspruch oder auch nur Aussicht, daß seine Nachkommen sich durch Generationen erhalten“ (Hansen 1889: 191). Die Groß- und Industriestädte nimmt er dabei explizit aus, da sich das Proletariat im Unterschied zum Mittelstand aus eigenen Kräften vermehren würde. Dies ändere ihm zufolge jedoch nichts an der Tatsache, dass die städtische Bevölkerung auf den Zustrom vom Land angewiesen sei, da das Absterben des Mittelstandes den Geburtenüberschuss der Arbeiterklasse übersteige. Vor dem Hintergrund dieser Behauptungen nennt Hansen den Bauernstand „den eigentlichen Kern des Volkes“ und macht in ihm den „Urquell“ seiner Kraft aus (vgl. Hansen 1889: 102, 264). Ihm zufolge führen die stetige Abgabe von Menschen an die Stadt und der mit dem Mittelstand bestehende Konkurrenzkampf dazu, dass das Bauerntum in seiner Existenz gefährdet sei. Der Mittelstand tendiere dazu, den Bauernstand zu zerstören (vgl. Hansen 1889: 325). Hansen plädiert dafür, alle politischen Bemühungen darauf zu richten, ein freies und kräftiges Bauerntum zu erhalten - anderenfalls drohe dem Volk seiner Meinung nach der Untergang.

Die Erbmonarchie ist ihm zufolge die ideale Staatsform, in der sich der Schutz des Bauerntums am besten verwirklichen lasse, da in ihr die Interessen des herrschenden Geschlechts, der Grundbesitzer, und der der Staates identisch seien (vgl. Hansen 1889: 324). Die parlamentarische Demokratie lehnt Hansen hingegen ab. Als geeignete Maßnahme für den Erhalt des Bauernstandes erscheint ihm im Besonderen die Einführung eines germanischen Anerbenrechts, das die Vererbung des Hofes auf einen Sohn festschreibt. Von besonderer Bedeutung ist für ihn dabei, dass der Bauer der kapitalistischen Konkurrenz entzogen und seine Existenz nicht nach Kriterien der Rentabilität bewertet werde (vgl. Hansen 1889: 339). Am Ende der Studie hebt Hansen die Bedeutung, die er dem Bauernstand für den Erhalt des Volkes zumisst, unmissverständlich hervor:

Ein Volk, das sich einen gesunden Bauernstand bewahrt hat, kann wohl besiegt, kann wohl niedergeworfen werden, aber dem Antäus gleich erhebt es sich immer wieder frisch gestärkt von der Erde. [...] so ist auch ein Volk dem Verderben geweiht, wenn es durch Vernichtung des Bauernstandes das Band zerrissen hat, welches die Menschen mit der allnährenden Mutter Erde verknüpft. (Hansen 1889: 407)

Die Bedeutung von Hansens Schrift über Die drei Bevölkerungsstufen für die Radikalisierung der Großstadtfeindschaft um die Jahrhundertwende liegt nicht in einer systematischen und umfassenden Betrachtung der Entwicklung der Großstädte begründet, wie sie Riehl Jahrzehnte zuvor vorgelegt hatte. Um der Großstadtfeindschaft eine neue Dynamik zu geben, musste Hansen das moderne Großstadtleben und die Großstadtentwicklung nicht 
thematisieren: Der von ihm gesetzte Schwerpunkt auf eine statistische Verifizierung der These einer volkserhaltenden Funktion des Bauernstandes und eine sich dazu komplementär verhaltende ,verzehrende“ Funktion des Stadtlebens sprach die Wissenschaftsgläubigkeit der wilhelminischen Gesellschaft an und verlieh der sich um die Jahrhundertwende radikalisierenden Großstadtfeindschaft eine wissenschaftliche Legitimation nach außen. Neben der Behauptung, dass die Stadtbevölkerung ihrem unausweichlichen Niedergang entgegengehe, sollte der Zuzug aus dem Land ausbleiben, übte seine Forderung, den Bauernstand aus der kapitalistischen Wertschöpfung herauszunehmen, einen nachhaltigen Einfluss auf die ideologische Ausformung der Großstadtfeindschaft aus und wurde im Besonderen in völkischen Kreisen rezipiert. Insofern ist es auch erklärbar, wieso eine Schrift zu den Standardwerken der Großstadtfeindschaft in Deutschland gezählt werden kann, obwohl die modernen Großstädte nicht im Mittelpunkt ihrer Betrachtungen stehen.

\subsection{Otto Ammon}

Die soziobiologistische Auseinandersetzung mit der Binnenwanderung in die Großstädte und der demographischen Entwicklung in den Großstädten wurde einige Jahre nach Hansens Schrift von Otto Ammon (1842-1916) fortgeführt, der den Topos von der Unfruchtbarkeit der Großstadtbevölkerung in sozialdarwinistischen und rassenhygienischen Kreisen popularisierte. Sein 1893 erschienenes Buch Über die natürliche Auslese beim Menschen (vgl. Ammon 1893) sowie die 1895 publizierte Studie Die Gesellschaftsordnung und ihre natürlichen Grundlagen stellen einflussreiche Werke der Rassenanthropologie in Deutschland dar. Das letzte Buch avancierte in den 1890er Jahren zu einem Besteller und brachte es innerhalb von fünf Jahren auf drei Auflagen (vgl. Weikart 1993: 482). Das Buch wurde auch in akademischen Kreisen außerhalb von Deutschland zur Kenntnis genommen: In den Jahren 1896 bis 1900 wurden Teile seines Buches ins Englische übersetzt und in wirtschaftswissenschaftlichen Fachzeitschriften veröffentlicht (vgl. Maccabelli 2008). Die zeitweilige akademische Würdigung seiner Schriften muss angesichts der Tatsache überraschen, dass Ammon keine akademischen Positionen bekleidete. Eine akademische Würdigung durch eine Universität erfuhr Ammon erst im Jahr 1904, als die medizinische Fakultät der Universität Freiburg ihm einen Ehrendoktortitel verlieh (vgl. Lichtsinn 1987: 10). 
Der studierte Ingenieur Ammon, der seit 1868 als Journalist tätig war und Besitzer der Konstanzer Zeitung sowie Miteigentümer der Badischen Landeszeitung war, kann zu einem der einflussreichsten Sozialdarwinisten und Rassentheoretikern seiner Zeit gezählt werden und gilt als Begründer der Sozialanthropologie in Deutschland. Ammon, der Mitglied des radikalnationalistischen Alldeutschen Verbandes war und sich im Umfeld des Eugenikers und Rassisten Ludwig Woltmann (1871-1907) und der von ihm herausgegeben Politischanthropologischen Revue bewegte (vgl. Weikart 2003: 279-280), bekannte sich in seinen Schriften zu einem rassistischen und nationalistischen Weltbild. Die Germanen bildeten für ihn eine überlegende „Rasse“, die vor dem Einfluss als minderwertig erachteter „Rassen“, wie den Polen und Russen, geschützt werden müsse (vgl. Ammon 1895: 208). Als schädlich erachtete er zudem jede

Abschwächung der Vaterlandsliebe, schädlich [ist] alles, was die kräftige Bethätigung einer nationalen Politik herabsetzt, schädlich darum insbesondere die Fremdtümelei, das Wahngebilde des Weltbürgertums, die Idee internationaler Verbrüderung einzelner Klassen, der Hang nach ewigem Frieden unter der Preisgabe nationaler Interessen. (Ammon 1895: 191192)

Die Tatsache, dass Ammon rassistisch und nationalistisch argumentierte, kann nicht auf eine rassistische Grundausrichtung des Sozialdarwinismus im Kaiserreich zurückgeführt werden. Richard Weikart weist darauf hin, dass der Sozialdarwinismus ursprünglich nicht vom Konservatismus, sondern von liberalen und sozialistischen Autoren getragen wurde (vgl. Weikart 1993). Ihm zufolge betonte die Mehrheit der Sozialdarwinisten in der zweiten Hälfte des 19. Jahrhunderts sowohl den individuellen als auch den kollektivistischen Konkurrenzkampf. In den 1890er Jahren kam es zu einer Rechtswende unter den Sozialdarwinisten, welche den Liberalismus insgesamt charakterisierte. Für ihn steht Otto Ammon paradigmatisch für diese Entwicklung, da dieser den Darwinismus nicht zur Begründung einer demokratischen, sondern einer aristokratischen Ordnung benutze (vgl. Weikart 1993: 483). In seinem Hauptwerk Die Gesellschaftsordnung und ihre natürlichen Grundlagen begreift Ammon den Ausleseprozess explizit als einen Vorgang, der sich sowohl zwischen Individuen als auch zwischen Völkern und „Rassen“ vollziehe. Er richtet sich zudem explizit gegen die Demokratie und fordert, dass Politiker nicht aus einer Wahl, sondern aus dem Prozess der natürlichen Auslese hervorzugehen hätten (vgl. Ammon 1895: 45-46). 
Ammon war nicht nur innerhalb Deutschlands mit Gleichgesinnten verbunden, sondern unterhielt über die Grenzen Deutschlands hinaus enge Kontakte. Eine besondere Beziehung unterhielt er zu dem französischen Rasseanthropologen Georges Vacher de Lapouge (18541936), dessen Schriften unter anderem einen großen Einfluss auf die Rassentheorien von Hans F.K. Günther ausübten (vgl. Hecht 2000). Terrenzo Maccabelli (2008: 485) zufolge unternahmen Ammon und Vacher de Lapouge den Versuch den Rassismus auf eine wissenschaftliche Grundlage $\mathrm{zu}$ stellen. Zwischen beiden entstand trotz zum Teil abweichenden Einschätzungen eine enge und von Freundschaft geprägte Zusammenarbeit, die darin zum Ausdruck kam, dass beide die Schriften des jeweils anderen in ihren Ländern bewarben (vgl. Hecht 2000: 294). Robert A. Nye hebt hervor, dass bei allen inhaltlichen Differenzen die negative Fokussierung auf die Großstadt ein verbindendes Element unter den zeitgenössischen Sozialdarwinisten und Eugenikern darstellte:

Social biologists often disagreed vigorously on the ,positive“ and ,negative ' effects of war, religion, occupation and race-mixing, but they universally agreed on the generally pathological influence of one social artifact: the city. (Nye 1985: 666)

Die für Ammons Werk wichtige Idealisierung des Bauernstandes und die Großstadtfeindschaft legte dieser neben den bereits genannten Arbeiten in einer 1894 veröffentlichten Kurzschrift mit dem programmatischen Titel Über die Bedeutung des Bauernstandes für den Staat und die Gesellschaft dar (vgl. Ammon 1894). In dieser Schrift spricht Ammon in einer universalgeschichtlichen Perspektive davon, dass mit der Gründung der Städte die „Leidensgeschichte der Menschheit“ begonnen habe (Ammon 1894: 19). In Anlehnung an Hansen, auf dessen Werk sich Ammon in seinen Schriften durchweg positiv bezieht, behauptet er, dass der Bauernstand alle anderen Berufsstände mit Menschen zu versorgen habe, da nur dieser einen menschlichen Überschuss produziere:

Von der größten Wichtigkeit ist ein Bauernstand, der unter naturgemäßen Bedingungen seine Aufgabe erfüllt, allen übrigen Berufsständen nicht nur Brot, sondern auch den Menschenersatz zu schaffen, der, wie wir sehen werden, darum notwendig ist, weil die dem Zusammenhang mit der Mutter Erde entzogenen Stände dem Aussterben verfallen, während das Land durch unbegrenzte Zeiträume hindurch an Leib und Seele gesunde Menschen zu erzeugen vermag. (Ammon 1895: 43-44)

Im Mittelpunkt seiner Analyse, die er im Vorwort seiner Studie über die Gesellschaftsordnung und ihre natürlichen Grundlagen als eine „,naturwissenschaftliche Grundlegung der Gesellschaftsordnung“ begreift, stehen die Vererbungs- und Evolutionstheorie Charles Darwins und die aus ihnen abgeleiteten Prinzipien der Fortpflanzung, der Vererbung, des „Kampfes ums Dasein“ und der natürlichen Auslese. Diese Naturgesetze bestimmen Ammon zufolge die Gesellschaft, die er sich als eine 
Gesellschaftsmaschine denkt, und stellen die Triebfedern für die Bildung einer in Stände gegliederten Ordnung dar, über deren individuelle Zugehörigkeit primär die Leistung und die Veranlagung des Individuums entscheiden. Die Funktionalität dieser Gesellschaftsmaschine hängt, wie es in dem Zitat zum Ausdruck kommt, von einem Bevölkerungsstrom ab, der sich von den ländlichen Gegenden in die Großstädte ergießt und dessen biologischen Träger der Bauernstand bildet. Die Binnenwanderung ist Ammon zufolge dadurch gekennzeichnet, dass höher begabte Menschen stärker dazu tendierten in die Großstädte abzuwandern als Menschen mit weniger guten erblichen Veranlagungen. Für Ammon hat die geistig-seelische Veranlagung und Begabung eines Menschen eine physiognomische, rassenbiologische Komponente: Höher begabte Menschen weisen ihm zufolge eine längliche Kopfform auf, weniger begabte neigten hingegen zu einer rundlichen Kopfform. Unter den aus dem Land abwandernden Menschen seien die Langköpfigen deutlich stärker vertreten als die rundköpfigen, die dazu tendierten, auf dem Land zu bleiben (vgl. Ammon 1893: 83). Die längliche Kopfform bezeichnet Ammon dabei als eine „germanische Kopfform“, einen rundlichen Kopf begreift er hingegen als das Produkt einer Einwanderung aus Asien nach Europa (vgl. Ammon 1893: 313).

Die Abwanderung in die Städte bildet Ammon zufolge deshalb die erste Stufe eines Prozesses der natürlichen Auslese. Dieser setze sich in den Städten fort: Einem Teil der nachkommenden Generationen der Einwanderer gelinge ein sukzessiver Aufstieg in die mittleren und höheren Bevölkerungsstände. Der soziale Aufstieg der Nachkommen der ländlichen Einwanderer in die oberen Stände ist nach ihm nur deshalb möglich, da die Angehörigen der höheren Stände in den Städten mit der Zeit aussterben und somit ein Nachrücken ermöglichen: „Die Macht, welche in den höheren Ständen Raum schafft für die Nachschübe von unten ist der Tod“"(Ammon 1895: 146). Von dem Aussterben sind demnach rassisch höherwertige Bevölkerungsgruppen betroffen, die in den höheren Schichten überrepräsentiert sind.

Die Hauptursache für das Aussterben der gehobenen Stände in den Städten sieht Ammon in einer unnatürlichen und überzivilisierten Lebensweise begründet, die den Lebensnerv des Städters unterbinde und ihm seiner Verbindung mit der „stärkenden Erde“ beraubt (vgl. Ammon 1894: 5): "Die höheren Stände verfallen ganz zweifellos dem Aussterben infolge der auf sie einwirkenden gesundheitswidrigen und sozialen Faktoren" (Ammon 1895: 149). Als entscheidenden Faktor bestimmt er dabei eine sich im städtischen Bürgertum einseitig 
vollziehende Entwicklung der geistigen Fähigkeiten, denen er eine negative Wirkung auf die körperliche Entwicklung und auf die Fähigkeit zur Fortpflanzung zuschreibt.

Der zunehmende Bildungsgrad und die damit einhergehenden besseren Verdienstmöglichkeiten führen ihm zufolge dazu, dass sich die Mitglieder der oberen Stände gegen eine hohe Kinderzahl entscheiden (vgl. Ammon 1893: 297, 1894: 16-17). Nach Ammon sind die Gelehrten- und Mittelstände am stärksten von einem Rückgang der Geburtenzahlen betroffen. Hohe Geburtenraten konstatiert Ammon lediglich für das großstädtische Proletariat, was dieser auf eine hohe Fruchtbarkeit unter den ländlichen Zuwanderern zurückführt, die nach ihrer Ankunft in den Städten in ihrer großen Mehrheit zu Mitgliedern des Proletariats werden. Er prophezeit jedoch zugleich einen Rückgang der Geburtenzahl unter den Nachkommen des großstädtischen Proletariats, der im Unterschied zu den höheren Ständen nichts mit der Bildung zu tun habe, sondern auf eine unnatürliche Lebensweise und eine „Entartung der Familientriebe“ zurückführt werden könne (vgl. Ammon 1895: 146-147). Wie bereits Riehl und Hansen, kommt Ammon zu der Schlussfolgerung, dass die Großstädte nicht durch eine Vermehrung ihrer Bevölkerung, sondern ausschließlich aufgrund des Zuzugs aus dem Land wüchsen und überlebensfähig sind (vgl. Ammon 1895: 147). Er schließt sich der Schlussfolgerung Hansens an, wonach die Stadtbevölkerung innerhalb „zweier Menschenalter“ durch neue Bewohner aus dem Land ersetzt werden müsse (vgl. Ammon 1895: 146).

Die von Ammon beschriebene natürliche Auslese funktioniert ihm zufolge bis zu dem Grad, wie sich die Sterblichkeitsrate der höheren Stände und die Fruchtbarkeit des Bauernstandes die Waage halten. Sollte es hingegen zu einem erheblichen Geburtenrückgang in einem Volk kommen, so hätte dies zur Folge, dass der Ausleseprozess in einer Gesellschaft qualitativ und qualitativ beschränkt wäre (vgl. Ammon 1895: 154). Die ungesunden und widernatürlichen Lebensverhältnisse in den Großstädten stellen demzufolge eine permanente Gefahr für den Ausleseprozess dar, da sie zu einem Geburtenrückgang führen könnten, sollte das Bauerntum nicht mehr in der Lage sein den Großstädten neues Menschenmaterial zu liefern. Ammon spricht in diesem Zusammenhang davon, dass es einen ,ungesunden Drang nach den Städten [gibt], der das Land an geistig befähigten Elementen zu veröden droht““(Ammon 1895: 385).

In einer zu den Schriften von Riehl und Hansen vergleichbaren Diktion hebt Ammon daher die Bedeutung des Bauerntums für den Erhalt eines Volkes hervor. Den Bauernstand bezeichnet er als „Urmaterial der Menschheit“, das sich nicht wieder aufbauen lasse, falls es aufhören sollte zu existieren (vgl. Ammon 1895: 328). Unter Verweis auf Riehl spricht er 
davon, dass nur vom Bauerntum eine politische und soziale Erneuerung des Volkslebens ausgehen könne (vgl. Ammon 1895: 335). Ammon sieht den Staat und die höheren Stände in der Pflicht, dafür Sorge zu tragen, dass der Bauernstand seiner Hauptaufgabe, der „Zeugung an Leib und Seele gesunder Nachkommen“, uneingeschränkt nachkommen könne. Er schlägt hierfür vor, dass die Bauern von allen modernen und städtischen Einflüssen abgeschirmt und somit von dem Prozess der natürlichen Auslese ausgenommen werden sollten: „Bessere Ernährung, höhere Bildung, städtische Interessen und nervöse Hast auf das Land verpflanzen, das hieße den Bauernstand an seiner Wurzel anzugreifen“ (Ammon 1895: 329).

Wie Ammon selbst hervorhob, fügte er der negativen Betrachtung des Verstädterungsprozesses und der Binnenwanderung keine wesentlich neuen Aspekte hinzu. In seinem Werk über die Gesellschaftsordnung und ihre natürlichen Grundlagen reformulierte er bereits bekannte Stereotype und Theoreme zu diesen Themen. Ammons Bedeutung für die Entwicklung und Festigung großstadtfeindlichen Denkens liegt darin begründet, dass das Buch an Spezialdiskurse der politischen Rechten des Kaiserreichs anschlussfähig war und dadurch die rassenhygienische und sozialdarwinistische Analyse des gut vernetzten Vielschreibers gerade in völkischen und rassistischen Kreisen auf großen Zuspruch stieß. Im Unterschied zur völkischen Großstadtfeindschaft begriff Ammon die Abwanderung in die Großstädte als einen natürlichen Vorgang, der sich nur geringfügig ändern lasse. Insofern liegt der Schwerpunkt seiner Ausführungen auch weniger auf der Großstadtfeindschaft, als auf der Idealisierung des Bauernstandes. Anschließend an Hansens Überlegungen konstruiert Ammon den Bauernstand als eine überhistorische, den gesellschaftlichen Verkehrsformen entrückte Gegengröße zur Moderne und zu den Großstädten. Hierdurch übte er einen nachhaltigen Einfluss auf die völkische Wahrnehmung und Idealisierung des Bauernstandes aus.

\subsection{Oswald Spengler}

Eine systematisch ausgearbeitete Großstadtfeindschaft legte der konservative Geschichtsphilosoph Oswald Spengler (1880-1936) in seinem zweibändigen Hauptwerk Der Untergang des Abendlandes vor, dessen erster Band kurz vor Ende des Ersten Weltkrieges erschien. Nach Bergmann trug das Buch zu einer Radikalisierung und Festigung großstadtfeindlichen und agrarromantischen Denkens in breiten Bevölkerungsschichten bei (vgl. Bergmann 1970: 179-193). Spengler schloss an bereits existierende Deutungs- und 
Argumentationsmuster zum Verstädterungsprozess an, bündelte diese und stellte sie in einen geschichtsphilosophischen Zusammenhang des Untergangs und Zerfalls der westeuropäischamerikanischen Zivilisation. In seiner geschichtsphilosophischen Darstellung einer, wie es im Untertitel seines Buches heißt, Morphologie der Weltgeschichte, maß Spengler der Analyse der Verstädterung und des Großstadtlebens eine zentrale Bedeutung für sein Verständnis von geschichtlicher Entwicklung bei.

Der große publizistische Erfolg seines Buches, der $\mathrm{zu}$ seiner Zeit über die Grenzen Deutschland weiter hinausreichte (vgl. Gasimov et al. 2013), verdankte sich einem durch die militärische Niederlage ausgelösten Bedürfnis nach einer pessimistischen Gegenwartsanalyse und Sinnstiftung. Rolf Peter Sieferle weist darauf hin, dass Spengler sein Buch als eine Rechtfertigung für den militärischen Sieg Deutschlands schrieb, es schließlich jedoch zu einem Erfolg wurde, ,weil sich das Publikum von ihm eine Deutung der Welt nach der deutschen Niederlage erhoffte" (Sieferle 1995: 106). Lenk et al. schreiben in diesem Zusammenhang, dass Spengler das existierende Bedürfnis nach einer Deutung der deutschen Niederlage als eines Vorzeichens des anstehenden Endes der bürgerlichen Gesellschaften befriedigte (vgl. Lenk et al. 1997: 40). Zu der Wahrnehmung seines Buches als publizistischer Antwort auf den Ausgang des Ersten Weltkriegs dürfte die zeitlich Koinzidenz der Erscheinung maßgeblich beigetragen haben: Der erste Band erschien zuerst im April 1918 in einem Wiener Verlag. Kriegsbedingt kam es mit einigen Monaten Verzögerung just zu dem Zeitpunkt in die deutschen Buchläden, als die militärische Niederlage Deutschlands besiegelt war (vgl. Conte 2004: 20).

In der Geschichtswissenschaft ist die prägende Wirkung, die Spenglers Werk auf die Weimarer Gesellschaft ausübte, unbestritten. Der Untergang des Abendlandes machte den vormaligen Oberlehrer, der aufgrund eines Erbes seit 1910 als Privatgelehrter tätig war, über Nacht berühmt. Als der zweite Band 1922 erschien, war Spengler, so Michael Biddiss, bereits eine „Kultfigur“ (Biddiss 1993: 279). Die Rezeption seiner Gedanken verlief quer zu den politischen Lagern und reichte vom konservativen Bildungsbürgertum über die linksradikale Avantgarde bis hinein in den Kreis marxistischer Intellektueller (vgl. Gasimov et al. 2013: 7).

An seiner Ablehnung der parlamentarischen Demokratie und des Weimarer Systems ließ Spengler nie einen Zweifel aufkommen. Biddiss ist zuzustimmen, wenn er schreibt, dass der Untergang des Abendlandes wie eine sich selbst erfüllende Prophezeiung ,zur Aushöhlung der zerbrechlichen Weimarer Republik“ beigetragen habe (Biddiss 1993: 292). Sein Werk 
wurde von den Fraktionen der radikalen Rechten in der Weimarer Republik dennoch ambivalent rezipiert. Stefan Breuer hat herausgearbeitet, dass Der Untergang des Abendlandes neben positiven Würdigungen in unterschiedlichen Lagern der extremen Rechten scharf kritisiert wurde und dass es dabei auch zu antisemitischen Verunglimpfungen seiner Person kam, obwohl Spengler nicht jüdisch war. Der Hauptkritikpunkt bezog sich auf seine Behauptung eines vorgezeichneten und nicht aufzuhaltenden Geschichtsverlaufs (vgl. Breuer 2004a).

So heißt es beispielweise in einem unter einem Pseudonym veröffentlichten Aufsatz von Theodor Fritsch aus dem Jahre 1924, dass Spenglers Schriften „ein Gemisch von richtigen Bemerkungen und überklugen Spitzfindigkeiten mit völlig lebensfremden und verfehlten Schlußfolgerungen [sind]“ (Stoltheim [Fritsch] 1924: 188). Spengler wurde im Besonderen im völkischen Lager dafür kritisiert, dass er die Bedeutung der Rassenfrage und die Gefährlichkeit des Judentums nicht erkannt habe. Wie bereits weiter oben dargelegt wurde, rief Spenglers Geschichtsdeterminismus in völkischen Kreisen heftigen Widerstand hervor und provozierte die Hinwendung zu Programmen einer aktiven Großstadtflucht (vgl. Bergmann 1970: 217).

Spenglers Beziehung zum Nationalsozialismus kann bis zur Machtübergabe 1933 als ambivalent, für die Zeit bis zu seinem Tod 1936 als spannungsreich beschrieben werden. Er begrüßte den Machtzuwachs der NSDAP seit 1930, zugleich kritisierte er in privaten Unterredungen die Partei und im Besonderen Adolf Hitler (vgl. Felken 1988: 186). Nach der Machtübergabe an die Nationalsozialisten schlug er Vereinnahmungsversuche aus und ging auf Distanz zu den neuen Machthabern. In seinem letzten Buch Jahre der Entscheidung (vgl. Spengler 1933), welches im Frühjahr 1933 erschien, übte er zum Teil scharfe Kritik an der NS-Bewegung. Nachdem sich die NS-Führung gegen ein Verbot des Buches entschieden hatte, lancierte die Partei eine Pressekampagne gegen Spengler, und das Propagandaministerium verfügte, dass die Berichterstattung über Spengler eingestellt werden solle (vgl. Felken 1988: 220). Bis zu seinem Tod im Jahr 1936 war Spengler im NS-Staat eine geduldete, jedoch keine erwünschte Persönlichkeit. Die Verwerfungen mit den NSMachthabern können jedoch nicht darüber hinwegtäuschen, dass Spenglers Der Untergang des Abendlandes einen nicht $\mathrm{zu}$ unterschätzenden Einfluss auf die völkische und nationalsozialistische Großstadtfeindschaft hatte.

Im Unterschied zu früheren Autoren der Großstadtfeindschaft begreift Spengler die Groß- und Weltstädte des 19. und 20. Jahrhunderts nicht als neue soziale Phänomene. Eine solche 
Behauptung widerspräche seinem Geschichtsverständnis, das er von dem der Fachhistoriker versucht abzugrenzen. Für Spengler vollzieht sich die Geschichte nicht in aufeinanderfolgenden, linear zueinander verlaufenden historischen Epochen, die in der Geschichtswissenschaft zu der Einteilung in Altertum, Mittelalter und Neuzeit geführt hat. Für Spengler handelt es sich bei diesem Muster um ein Produkt abendländischer Historiographie, das für andere Kulturkreise keine Bedeutung habe und diese daher vernachlässige. Ihm zufolge haben alle Kulturen eine gleich große Bedeutung für das Gesamtbild der Geschichte (vgl. Spengler 1997: 21-24).

Spengler unterscheidet zwischen folgenden bereits untergegangenen und noch bestehenden Kulturen: babylonische, ägyptische, antike, chinesische, indische, arabische, mexikanische und die abendländische, von ihm auch „faustische“ genannt. Kulturen begreift Spengler als „Einzelwelten des Werdens“, die nicht miteinander kommunizieren und sich nicht verstehen können. Obwohl die Kulturen für sich abgeschlossene Welten bilden, geht Spengler davon aus, dass ihre Entwicklung einem gleichen Muster folgt, eine gleiche Formsprache aufweist. Eine Kultur begreift er dabei als einen Organismus, der - vergleichbar mit der Entwicklung eines Menschen - die Phasen der Geburt, der Jugend, des Alterns und des Sterbens durchläuft. Am Ende einer jeden Kultur steht die Zivilisation, als „die äußersten und künstlichsten Zustände, deren eine höhere Art von Menschen fähig ist. Sie sind ein Abschluß; sie folgen dem Werden als das Gewordene“ (Spengler 1997: 43). Der Übergang einer Kultur in die Zivilisation ist für Spengler unausweichlich, er spricht von einem notwendig organischen Nacheinander (vgl. Spengler 1997: 43). ${ }^{25}$

In seiner Untersuchung möchte Spengler durch eine Analogiebildung das gemeinsame Muster herausarbeiten, das der Entwicklung aller Kulturen - von ihrer Geburt bis zum ihrem Verfall - zugrunde liegt. Hierbei spricht er von einer „organischen Struktur (Spengler 1997: 6) bzw. von einer „organischen Logik“ (Spengler 1997: 35) der Entwicklung einer Kultur. Nur vor

\footnotetext{
${ }^{25}$ Spenglers Unterscheidung zwischen Kultur und Zivilisation schließt an die in der deutschen Geistesgeschichte fest verankerte Gegenüberstellung der beiden Begriffe an, wenngleich er sie nicht in einem Gegensatz sondern in einer zeitlichen Abfolge zueinander sieht. Nach Norbert Elias geht diese Unterscheidung mindestens ins 18. Jahrhundert zurück und hat ihren Ursprung in dem sozialen Gegensatz zwischen der höfischen, adligen Gesellschaft und der mittelständischen Intelligenz. Unter zivilisiertem Verhalten verstand die Polemik der mittelständischen Intelligenz die geistige Gesittung des Adels, dessen Selbstverständnis nicht auf Leistung, sondern auf der Formung eines distinguierten und distinguierenden Verhaltens beruhte. Elias zufolge drückt der Begriff Zivilisation im Deutschen - im Unterschied zur englischen und französischen Sprache - daher einen Wert zweiten Ranges aus, der nur die Oberfläche des menschlichen Daseins umfasse. Der Gegensatz von Zivilisation und Kultur habe sich im Lauf der Zeit von einem sozialen in einen nationalen Gegensatz gewandelt. Elias verweist darauf, dass dieser Gegensatz mit der deutschen Niederlage im Ersten Weltkrieg eine Revitalisierung in Deutschland erlebte, als im Namen der Zivilisation gegen Deutschland gekämpft wurde (vgl. Elias 1997 [1939]: 89-131).
} 
diesem Hintergrund wird erklärbar, dass Spengler den Anspruch erheben kann, Geschichte vorherbestimmen zu können (vgl. Spengler 1997: 3). Er beansprucht dabei einen erkenntnistheoretischen Standunkt für sich, der sich von einer historisch-relativen Erkenntnisfähigkeit, die er den abendländischen Historikern zuschreibt, unterscheidet. Seine Darstellung resultiere insofern nicht aus irgendeinem Standpunkt heraus, sondern ,aus zeitloser Höhe“ (Spengler 1997: 47). Der Erfolg des Buches erfolgte nicht trotz sondern gerade wegen des in hohem Maße apodiktischen Charakters seiner Argumentation.

Im Mittelpunkt seiner Großstadtfeindschaft steht die These, dass die Entwicklung der Kulturen und der Übergang zur Zivilisation an ein sich wiederholendes Verstädterungsmuster geknüpft sind. Zusammengefasst ergibt sich dabei folgender Ablauf: Die Frühzeit einer Kultur ist durch die Kleistadt, die Mittelphase durch die Großstadt und die Zivilisation durch die Weltstadt geprägt.

Am Anfang einer jeden Kultur steht die Herausbildung der Stadt aus dem bäuerlichen Dorf. Die Frühphase einer neuen Kultur beginnt daher immer mit der Frühphase eines neuen Städtewesens (vgl. Spengler 1997: 662). Die Städte stehen von Beginn an im Mittelpunkt der Kultur. Alle Erscheinungen, die sie hervorbringt - Wissenschaft, Kunst, Religion, Politik, Staat und Völker - sind ein Produkt der Stadt (vgl. Spengler 1997: 661). Stadt definiert sich bei Spengler nicht in erster Linie über die Einwohnerzahl, sondern unterscheidet sich vom Dorf durch die geistige Haltung seiner Bewohner. Die Stadt ist nach Spengler ein seelischer Ort, von dem aus das Land als etwas anderes und Untergeordnetes gesehen und wahrgenommen wird (vgl. Spengler 1997: 662). In der Frühphase einer Kultur drücke die Stadt in ihrer Architektur und Formensprache noch die Erdverbundenheit des Landes und des Bauern aus. Sie enthalte architektonische Stilelemente des Dorfes. Mit der Zeit wird die seelische Distanz zwischen den Städten und dem sie umgebenden Land immer größer. Den Hauptausdruck der Absonderung der Städte vom ländlichen und bäuerlichen Leben sieht Spengler in der zunehmenden Vergeistigung des Stadtlebens: „Geist ${ }^{\circ}$ ist die spezifisch städtische Form des verstehenden Wachseins“ (Spengler 1997: 664).

Dem erdverbundenen Bauern werden die vergeistigten Produkte der Städte immer fremder, er verstehe zunehmend die Sprache der Städte nicht mehr, die insgesamt identisch mit der Sprache der Kultur als solcher wird. Zugleich hebe sich die Formsprache der Städte immer stärker vom Landschaftsbild und von der Natur ab. Ihre Architektur verneine zunehmend die Landschaft und die Natur (vgl. Spengler 1997: 666). Im weiteren Verlauf sänken auch die 
Kleinstädte zur Provinz herab und das Zentrum der Entwicklung verlagere sich in eine kleiner werdende Zahl von Großstädten, die der ländlichen Lebensform noch ferner stünden.

Spengler macht die zunehmende Absonderung der Großstädte vom Land an zwei ineinander verschränkten Phänomenen fest: Vergeistigung und Geldwirtschaft. So schreibt er: „Die Stadt bedeutet nicht nur Geist, sondern auch Geld“" (Spengler 1997: 670). Spengler versteht die Geldwirtschaft als ein ausschließliches Charakteristikum einer großstädtischen Ökonomie, die dem ländlichen und bäuerlichen Denken entgegenstehe. Die ländliche Ökonomie kennzeichnet Spengler demgegenüber durch einen Gütertausch, in dem jeder „erzeugt und verbraucht". Das auf dem Land vorherrschende Denken in Gütern wird in den Großstädten zu einem Denken in Geld, da die städtischen Marktteilnehmer keine innere Bindung mehr zum Boden und damit zu dem Gut haben, mit dem sie handeln. Der Geldbegriff sei losgelöst von den Gütern und ist daher ein reines Abstraktum, „,welches vom Dinge den Wert begrifflich trennt und in eine fiktive oder metallene Größe bindet, deren Bestimmung es von da an ist, das ,andere“, ,die Ware' zu messen“" (Spengler 1997: 670). Dem abstrakten und wurzellosen Geld stellt Spengler den Boden gegenüber, der etwas Konkretes und Natürliches sei (vgl. Spengler 1997: 671). Spengler gelangt hierdurch zu dem Fazit, dass der Unterschied zwischen Bauer und Bürger „nicht nur den Unterschied von Land und Stadt, sondern auch den von Gut und Geld [bedeute]“" (Spengler 1997: 1166).

Spengler denkt bei seiner Analyse des Unterschiedes zwischen der ländlichen und der großstädtischen Ökonomie in den Kategorien des von Marx analysierten Waren- und Geldfetischs. Wie bereits in Kapitel 3.3. ausgeführt wurde, hat Moishe Postone herausgearbeitet, dass die als abstrakt wahrgenommene Seite des Kapitals (Geld, Zirkulation, Finanzkapital) zugleich als wurzellos erscheint. Spengler ist in diesen organizistischen und konkretistischen Denkschemata verhaftet, wenn er das Geld zu einem wurzel- und bodenlosen und daher großstädtischen Abstraktum erklärt.

Die seelische Erd- und Heimatverbundenheit der Menschen, die für Spengler die Entstehung einer Kultur erst ermöglichen, werden durch die Entstehung der Weltstädte, die den Übergang einer Kultur zur Zivilisation markieren, zerstört. Die Weltstadt stehe am Ende des Lebenslaufes einer jeden Kultur (vgl. Spengler 1997: 673). Der von ihm beschriebene Prozess der zunehmenden Absonderung des städtischen Lebens von den Lebensbedingungen der ländlichen Bevölkerung erreicht in den Weltstädten seinen Höhepunkt:

Die Weltstadt bedeutet den Kosmopolitismus an Stelle der ,Heimat', den kühlen Tatsachensinn an Stelle der Ehrfurcht vor dem Überlieferten und Gewachsenen, die 
wissenschaftliche Irreligion als Petrefakt der voraufgegangenen Religion des Herzens, die ,Gesellschaft' an Stelle des Staates, die natürlichen statt der erworbenen Rechte. Das Geld als anorganische, abstrakte Größe, von allen Beziehungen zum Sinn des fruchtbaren Bodens, zu den Werten einer ursprünglichen Lebenshaltung gelöst. (Spengler 1997: 46)

In der Zivilisation, die Spengler zufolge in den abendländischen Gesellschaften um 1800 beginnt und sich bis in das Jahr 2000 erstrecken wird, konzentriert sich die gesellschaftliche und historische Entwicklung nunmehr in vier oder fünf Weltstädten, die sich in ihrer Formsprache immer ähnlicher werden: „Man kann gehen, wohin mal will, man trifft Berlin, London und New York überall wieder“ (Spengler 1997: 685). Die Konzentration der Weltgeschichte in den Weltstädten gehe einher mit einer zunehmenden Entvölkerung des zur Provinz hinabgesunkenen Rests des Landes. Nach Spengler können sich die Menschen den Verlockungen der Weltstädte, „der ganzen Schönheit dieses letzten Wunders aller Geschichte“, nicht widersetzen (Spengler 1997: 677). In seinem 1933 erscheinen Buch Jahre der Entscheidung sieht er den Hauptgrund für die Abwanderung in die Großstädte in den sich den Menschen dort bietenden Verlockungen:

Aber dieser vulgäre Luxus der großen Städte - wenig Arbeit, viel Geld, noch mehr Vergnügen - übte eine verhängnisvolle Wirkung auf die hart arbeitenden und bedürfnislosen Menschen des flachen Landes aus. [...] Der Bauer hatte es satt, Arbeit ohne Lohn zu tun, während die Stadt ihm Lohn ohne Arbeit versprach. So ging er davon und wurde ,Proletarier'. (Spengler 1933: 117)

Die Anpassung der Menschen an den Takt der Weltstädte, der durch den Intellekt und die Geldwirtschaft geprägt ist, führt nach Spengler dazu, dass die Menschen ihre natürlichen Anschauungen verlieren. Anstelle der bäuerlichen Schlauheit trete die weltstädtische Intelligenz, die durch eine Spannung des Wachseines charakterisiert ist. Aus dieser bis zu einem Maximum gesteigerten Vergeistigung des Großstadtmenschen resultiert nach Spengler seine Unfruchtbarkeit. Die bis zum Äußersten gesteigerte Intelligenz lasse keine Gründe für die Existenz von Kindern zu (vgl. Spengler 1997: 679). Auf dieser Stufe der Entwicklung, schlussfolgert Spengler, beginne in allen Zivilisationen ein mehrhundertjähriges Stadium der Entvölkerung (vgl. Spengler 1997: 681). Die Weltstadt sauge das Land so weit aus, „bis sie inmitten einer kaum noch bevölkerten Wüste ermattet und stirbt“ (vgl. Spengler 1997: 676677).

Das seit den Schriften von Riehl weitverbreitete Stereotyp von der Unfruchtbarkeit der Großstadtbevölkerung dient Spengler zur Erläuterung und Erklärung seiner geschichtsphilosophischen Deutung des Niedergangs der abendländischen Gesellschaften, deren Endpunkt die Zivilisation mit ihren Weltstädten markiert. Im Gegensatz zu den Schriften von Hansen und Ammon musste Spengler seine These von dem Geburtenrückgang 
in den Städten nicht mit statistischem Material versuchen zu belegen, um seine Leserschaft von seinen Argumenten zu überzeugen. Als Der Untergang des Abendlandes 1918 erschien, existierte in Deutschland längst ein tradiertes (Nicht-)Wissen über die fatale Wirkung der Verstädterung und des Großstadtlebens auf die Bevölkerung. Die Feindschaft gegenüber den modernen Großstädten war fester Bestandteil eines antiliberalen Diskurses im wilhelminischen Kaiserreich, der sich in einem modernitätsfeindlichen kulturellen Lager entwickelte, wie es Volkov in ihrer Untersuchung über die politische Kultur des Kaiserreiches herausgearbeitet hat (vgl. Kapitel 3.4.).

Spengler verwendete Begriffs- und Denkschemata, die diesem politischen Lager vertraut waren: „Blut und Boden“, den Gegensatz von Abstraktheit und Künstlichkeit einerseits, die negative Fokussierung auf die Geldwirtschaft und den Intellekt als Ausdruck für eine unpersönliche, subjektlose Herrschaftsform moderner Vergesellschaftung andererseits. Die assoziative Verbindung des Bauerntums mit dem Ideal einer Boden- und Erdverbundenheit sowie die Identifizierung der Großstädte mit Geld, Intellekt und Wurzellosigkeit machten Spenglers Großstadtfeindschaft anschlussfähig für den modernen Antisemitismus. Von seinen Ausführungen über die Groß- und Weltstädte war es kein großer Schritt dahin, die Verbindung zwischen Großstadt, Geld und Wurzellosigkeit auf Juden und Jüdinnen zu projizieren. Ohne explizit antisemitisch $\mathrm{zu}$ argumentieren, folgte Spengler in seiner Großstadtfeindschaft der Logik und den Denkstrukturen des modernen Antisemitismus. 


\section{Zur Theorie der Großstadtfeindschaft}

Bis in das 19. Jahrhundert hinein war die europäische Geschichte durch einen starken Kontrast zwischen Stadt und Land geprägt. Wer in der Stadt wohnte, unterschied sich hinsichtlich seines sozialen Status und seiner Alltagskultur deutlich von der Landbevölkerung. Die Stadt war ein spezifisch sozialer Ort, indem sich eine andere politische und soziale Entwicklung vollzog als in dem die Stadt umgebenden Land. Die europäische Städtelandschaft bildete sich im Hochmittelalter heraus, und eine bis in die Gegenwart reichende Bedeutung kommt dabei der Emanzipation des Stadtbürgers zum Wirtschafts- und politischen Subjekt und seiner Befreiung aus der Feudalherrschaft zu (vgl. Siebel 1999: 122). In der mittelalterlichen Stadt wurde das System des Feudalismus abgelöst und durch eine (vor-)kapitalistische Produktionsweise und eine demokratische Selbstverwaltung ersetzt. Die Stadt des Mittelalters, so Walter Siebel, ist der Ort, an dem die bürgerliche Gesellschaft entstand und die kapitalistische Moderne seinen Anfang nahm (vgl. Siebel 1998: 266). Max Weber bezeichnete in seiner Charakterisierung der okzidentalen Stadt das im Mittelalter entwickelte Stadtbürgerrecht daher als revolutionär (vgl. Weber 1985 [1922]: 727). Die Herauslösung des Bürgers aus der geschlossenen Hauswirtschaft und seine Partizipation als anonymer Marktteilnehmer am städtischen Handelsplatz, waren die Grundlage dafür, dass sich in den Städten eine besondere, eine spezifisch städtische Lebensweise herausbilden konnte (vgl. Siebel 1998). Die Differenz von Stadt- und Landleben war dabei nicht nur eine der Haltung und Gesittung, sondern auch eine der physischen Unterteilung von Stadt und Land: Stadtmauern grenzten das städtische Bürgertum vom feudalen Land ab (vgl. Siebel 2004: 11). In räumlicher Hinsicht kannte das Stadtleben bis in das 19. Jahrhundert hinein ein eindeutig voneinander zu unterscheidendes Binnen- und Außenverhältnis.

Während des 19. Jahrhunderts veränderten sich das europäische Stadtwesen und damit auch das Verhältnis von Stadt und Land grundlegend. Das rapide Anwachsen der Städte im Zuge der zweiten industriellen Revolution in der zweiten Hälfte des Jahrhunderts zerstörte die städtebauliche Gestalt der Bürger- und Residenzstädte. Während es im Ruhrgebiet zur Herausbildung neuer Industriestädte kam, die Teil einer Industrielandschaft ohne urbanes Zentrum waren, vollzog sich in den Bürgerstädten ,eine industrielle Überformung der vorhandenen vorindustriellen Stadtlandschaft“" (Schott 2014: 220). Eine hohe Fluktuation und starke Wanderungsbewegungen zwischen den immer stärker wachsenden Großstädten und den ländlichen Gegenden prägten das Verhältnis der Städte zu ihrem Umland, nicht mehr ihre 
Abgeschlossenheit. Das qualitativ Neue an dem Prozess der Verstädterung - der für sich genommen kein Phänomen der Moderne war - waren die mit ihm einhergehenden sozialen, politischen und kulturellen Umbrüche des Industriezeitalters, die nicht nur die Stadt, sondern die Gesellschaft als solche transformierten. Dies hatte zur Folge, dass die Entwicklung in den Großstädten nicht mehr von einer gesamtgesellschaftlichen Entwicklung zu trennen war. Die Verstädterung verband sich, wie Jürgen Reulecke hervorhebt, mit Urbanisierung, Industrialisierung und weiteren Prozessen einer allgemeinen Modernisierung „ohne daß im einzelnen eindeutig festgelegt werden könnte, was Ursache und was Folgeerscheinung war“ (Reulecke 1985: 9).

Der quantitative Prozess der Verstädterung, der den Anteil der Großstadtbevölkerung an der Gesamtbevölkerung immer stärker ansteigen und die Einwohnerzahl der Städte emporschnellen ließ, verstärkte zunächst die Differenz zwischen den Großstädten und ihrer Umwelt. Die sich in den modernen Großstädten zuerst herausbildende großstädtisch-urbane Lebensweise, verstanden als eine räumlich ausgeformte soziale Beziehungsstruktur, die bestimmt ist von Individualisierung, Fremdheit und Kontingenz (vgl. Dirksmeier 2006: 224), griff zunehmend auf die gesamte Gesellschaft über und minderte dadurch den Gegensatz von Stadt und Land auf lange Sicht wieder, „ohne daß dadurch aber bereits Unterschiede der soziokulturellen Milieus des Dorfes, der Klein-, Mittel- und Großstadt völlig verwischt worden wären“ (Reulecke 1985: 11).

Eine Theorie der Großstadtfeindschaft, die nicht von der Existenz einer überhistorischen Stadtfeindschaft ausgeht, muss den Bedeutungsverlust, den der Stadt-Land-Gegensatz in der Moderne erfährt, reflektieren. Dies hat zur Folge, dass die Ursache für großstadtfeindliche Ressentiments nicht aus einem Stadt-Land-Antagonismus abgeleitet werden kann. Diese These vertritt jedoch der amerikanische Soziologie Michael J. Thompson, nach dem es sich bei der Großstadtfeindschaft um eine konservative Einstellung handelt, die sich unter den Bedingungen einer ländlichen („,nonurban“) Sozialisation entwickelt (vgl. Thompson 2009a). Seiner Theorie der Großstadtfeindschaft liegt die Annahme zugrunde, dass es einen direkten Zusammenhang zwischen räumlichen Faktoren und den mentalen bzw. kognitiven Dispositionen der diese Räume bewohnenden Subjekte gibt:

The link between the material/spatial organization of society and the experiential and mental organization of the subjects that inhabit it is therefore the place where an understanding of antiurbanism can be most clearly understood. [...] I think that the spatial organization of nonurban life is a central explanatory variable leading to distinct attitudes and sensibilities that shape certain cognitive (specifically social) views toward urban areas. Antiurbanism is produced and reproduced by the ways that individuals are shaped by their social environment, 
and by this I mean the various ways that kinds of interaction can shape epistemological habits of thought and ways of interpreting the world. (Thompson 2009a: 14-15)

Thompsons These muss in zweierlei Hinsicht kritisiert werden: In der Stadt- und Raumsoziologie wird darauf hingewiesen, dass es bisher an Studien mangele, die belegten, dass sich räumliche Faktoren direkt auf die Persönlichkeitsstruktur auswirken und ausschlaggebend für unterschiedliche Lebensstile oder politische Präferenzen von Land- und Stadtbewohnern sind (vgl. Otte/Baur 2008). Die Stadtsoziologen Hartmut Häußermann und Walter Siebel sehen in der Annahme, dass die Großstadt als unabhängige Variable soziale Phänomene erklären kann, eine strukturelle Ähnlichkeit $\mathrm{zu}$ den Argumenten der großstadtfeindlichen Kulturkritik, da diese These ihnen zu folge auf dem Denkfehler beruht, die Großstadt mit der Gesellschaft zu verwechseln (vgl. Häußermann/Siebel 2004: 93, 1978: 495). Soziale Prozesse in der Moderne sind ihnen zufolge stets als gesamtgesellschaftliche Phänomene zu begreifen, die nicht auf eine strikte Stadt-Land-Dichotomie zurückgeführt werden können:

Diejenigen Versuche, die nach wie vor eine Theorie der Stadt auf vorherrschenden Verhaltensstilen aufbauen, sind ihrem kritisierten Gegenentwurf, der konservativ-reaktionären Stadtkritik insofern verbunden, als sie dieselbe Ebene der Analyse und Theorieformulierung wie diese wählen: die äußerlichen Formen des städtischen Lebens. (Häußermann/Siebel 1978: 495)

Thompsons These weist insofern Gemeinsamkeiten mit großstadtfeindlichen Topoi auf, als er annimmt, dass Umweltfaktoren unmittelbar dazu führten, dass Stadt- und Landbewohner ein unterschiedliches Bewusstsein ausbilden. Seine Theorie kann empirisch auch insofern in Frage gestellt werden, als die überwältigende Mehrheit der Textproduzten und Propagandisten der Großstadtfeindschaft in den Großstädten lebten bzw. leben. Die historiographische Forschung hat hinlänglich nachgewiesen, dass großstadtfeindliche Schriften im Besonderen von einem großstädtischen Publikum Zuspruch erfuhren und dass Ideen und Ansätze für eine Großstadtflucht von Großstadtbewohnern entwickelt wurden. Diese Feststellung trifft auch auf die Geschichte der Großstadtfeindschaft in den USA zu, die Thompson als Anschauungsmaterial für seine theoretischen Überlegungen dient (vgl. Lees 1985; Conn 2014).

Hiermit ist in quantitativer Hinsicht noch keine Aussage darüber getroffen, ob Großstadtoder Landbewohner großstadtfeindlichen Thesen stärker zuneigen. Die geschichtswissenschaftliche Forschung hat jedoch eindeutig nachgewiesen, dass die modernen Großstädte den ideengeschichtlichen Ursprungsort der Großstadtfeindschaft bilden und insofern Ansätze nicht überzeugen können, die die Entstehungsbedingungen der 
Großstadtfeindschaft mit einer ländlichen Sozialisation oder Lebensweise in Verbindung bringen.

In der theoretischen Diskussion über die Großstadtfeindschaft nimmt Arnold Rose die Gegenposition zu Thompson ein. Er begreift die Großstadtfeindschaft explizit als ein Phänomen, das seine Ursache in einer affektgeladenen Wahrnehmung der Großstädte unter den Bewohnern und Bewohnerinnen der Großstädte hat (vgl. Kapitel 3.2.). Rose führt negative Einstellungen gegenüber dem Großstadtleben auf das Empfinden von Großstadtbewohnern zurück, sich der Großstadt nicht anpassen zu können. Ressentiments gegenüber den modernen Großstädten vollziehen sich ihm zufolge auf einer symbolischen Ebene und manifestieren sich in der Form einer projektiven Identifizierung der Juden mit dem Großstadtleben. Da Juden und Jüdinnen zum Symbol für das Großstadtleben gemacht werden, wird das großstadtfeindliche Ressentiment an ihnen ausagiert und richtet sich nicht direkt gegen die Großstädte, so dass Großstadtfeinde weiterhin Großstadtbewohner bleiben können. Rose versteht Großstadtfeindschaft daher explizit nicht als Ausdruck eines Antimodernismus, der auf der Idee einer Rückkehr in eine vormoderne Agrarordnung beruht.

Betrachtet man die historische Genese der Großstadtfeindschaft, so kann nicht davon gesprochen werden, dass diese in einer Fundamentalopposition zur Moderne steht: Ihre Anhänger und Anhängerinnen bejahten nämlich in ihrer großen Mehrheit die Grundprinzipien der ersten Modernisierung: Leistungsprinzip, funktionale Differenzierung und technischwissenschaftliche Rationalität. Große Teile der mit der industriellen Moderne entstehenden Zivilisationskritik des 19. und 20. Jahrhunderts bezogen speziell zur Frage der Großstädte und der Technik/industriellen Produktion konträre Positionen. Das großstadtfeindliche Lager teilte die Annahme, dass die moderne Großstadt eine existentielle Gefahr für das Volk und den Nationalstaat darstellt und dass Gegenmaßnahmen nötig sind um ihrem schädlichen Einfluss entgegenzuwirken. Die in diesem Zusammenhang entwickelten Ideen basierten jedoch auf einer grundsätzlichen Akzeptanz der modernen Technik und des Produktivkapitals. Dies wird ersichtlich an den vieldiskutierten und in Ansätzen auch verwirklichten Konzepten einer Dezentralisierung der Industrie und der damit verbundenen Verlagerung von Fabriken und Industriebetrieben in ländliche, weniger besiedelte Gebiete. Die nationalsozialistische Raumund Stadtplanung griff speziell in den Jahren von 1933 bis 1936 diesen Ansatz auf und versuchte ihn in die Tat umzusetzen (vgl. Kapitel 4.5).

Von grundlegender Bedeutung war der Gedanke einer Versöhnung von moderner Technik und Natur für die Gartenstadtbewegung. Sowohl Ebenezer Howards als auch Theodor 
Fritschs‘ Konzeption sahen vor, dass die Gartenstädte ein Ort der industriellen Produktion sein sollten. In der zweiten Ausgabe seines Buches Die Stadt der Zukunft aus dem Jahr 1912 Fritschs Großstadtfeindschaft hatte sich seit der Veröffentlichung der ersten Auflage im Jahr 1896 deutlich radikalisiert - sprach er in Bezug auf die Gartenstädte von einer ,neuen Stadt auf industrieller Grundlage“ (Fritsch 1912: 16). Die deutliche Mehrheit der ländlichen Siedlungsversuche im Kaiserreich und der Weimarer Republik basierten zudem mehrheitlich auf der Nutzung moderner Maschinen und lehnten die industrielle Welt nicht grundsätzlich ab (vgl. Rohkrämer 2007: 54). Dies macht deutlich, dass das Produktivkapital und die moderne Technik in agrarromantische Denkmuster und in eine Blut-und-Boden-Ideologie grundsätzlich integrierbar sind. Wie Postone hervorhebt, lässt sich die Verherrlichung der Natur, des Bodens, des Blutes, der konkreten Arbeit und der Gemeinschaft durchaus mit der Akzeptanz von industriellem Kapital und Technik verbinden (vgl. Kapitel 3.3.).

Der Grad der Bejahung von moderner Technik und Industrie war unter den Großstadtfeinden unterschiedlich stark ausgeprägt. Für Oswald Spengler und für Teile der Konservativen Revolution in der Weimarer Republik kann eine entgegengesetzte Großstadt- und Technikrezeption konstatiert werden. Die Großstädte und Metropolen wurden als Symbole des Liberalismus und Kosmopolitismus scharf attackiert, die moderne Technik wurde hingegen als ein Garant nationaler Stärke glorifiziert (vgl. Herf 1993). Besonders deutlich wird dies bei Spengler, dem einflussreichsten großstadtfeindlichen Ideologen der Weimarer Republik. Er machte die Großstädte für den Niedergang der abendländischen Gesellschaften verantwortlich und forderte zugleich eine vorbehaltlose Bejahung von industrieller Produktion und Technik (vgl. Rohkrämer 1999: 285-293).

Die völkische Bewegung schlug hingegen einen deutlich zivilisationskritischeren Ton an. Hierzu gehörte auch die wiederholt vorgetragene Kritik an einer entfremdeten und ungesunden Fabrikarbeit. Dies bedeutet jedoch nicht, dass sie die Industrialisierung pauschal ablehnte, wenngleich sie die Potentiale des technischen Fortschritts deutlich skeptischer einschätzte als Spengler. Eine positive Stellung zur Technik kann in besonderer Weise für den Nationalsozialismus festgehalten werden, dessen Technikrezeption von pragmatischen bis vorbehaltlos technikbegeisterten Stimmen reichte. Dies trifft auch auf exponierte Vertreter einer nationalsozialistischen Großstadtfeindschaft $\mathrm{zu}$, die aus dem Umfeld der völkischen Bewegung stammen. So schlug Alfred Rosenberg einerseits eine Begrenzung der Einwohnerzahlen von Großstädten vor, zugleich führte er die Technik der Gegenwart auf einen „germanischen Antrieb“ zurück. (vgl. Rosenberg 1932: 142-143). Auch Richard 
Walther Darré war weit davon entfernt, ein rückwärtsgewandter Agar- und Bauernromantiker zu sein. Die modernen Großstädte waren für ihn Ausdruck des zur Herrschaft gelangten wurzellosen ,jüdischen Finanz- und Handelskapitals“. In seiner Vorstellung sollte das Bauerntum bzw. ein aus dem Bauerntum hervorgehender „Neuadel“ die Grundlage des Staates bilden, von dem aus sich, ,die Stadt und die Industrie in den Volkskörper [eingliedern]“ (Darré 1941 [1930]: 27).

Die Großstadtfeindschaft zivilisationskritischer und modernitätsfeindlicher Gruppierungen und Strömungen basierte mehrheitlich nicht auf einer Technik- und Industriefeindschaft. Technik und industrielle Produktion wurden als ein unverzichtbarer Bestandteil einer anders zu gestaltenden Moderne gesehen (vgl. Rohkrämer 1999). Für die modernen Großstädte galt dies nicht in gleicher Weise. Städte wurden zwar strömungsübergreifend als Knotenpunkte des Handels, der Kultur und der Industrie anerkannt; hierunter wurden aber in der Regel keine Großstädte und nie die als Weltstädte apostrophierten Millionenstädte verstanden. Der gemeinsame Nenner der Großstadtfeinde bestand darin, eine alternative Moderne zu gestalten, in der zentrale Aspekte des Modernisierungsprozesses beibehalten werden, die Bedeutung der Großstädte in quantitativer und qualitativer Hinsicht jedoch herabgemindert werden sollte. Für die Geschichte der Großstadtfeindschaft in Deutschland ist es charakteristisch, dass der Zustand der modernen Großstädte und der Verlauf der Verstädterung nicht tatenlos hingenommen wurden. Für ein Verständnis von Großstadtfeindschaft ist es daher von grundlegender Bedeutung, dass sie in ihrer Geschichte auch immer eine praktische Dimension mit einschloss. Diese umfasste sowohl städtebauliche Versuche einer Umgestaltung der Großstädte wie auch Ansätze zur Stärkung des Landlebens. Arnold Rose irrt daher in seiner Annahme, dass das Projizieren großstadtfeindlicher Affekte auf Juden und Jüdinnen die Großstädte als solche unberührt lasse. Insofern lässt sich gut begründet von einer Großstadtfeindschaft sprechen, die im Unterschied zu einer Technik- und Industriefeindschaft ein zentraler Bestandteil politischer Bewegungen werden konnte.

Vor diesem Hintergrund wird in dieser Studie für den Begriff der Großstadtfeindschaft und nicht für den des Antiurbanismus plädiert, der in der englischsprachigen Forschung etabliert ist. Der Terminus Großstadtfeindschaft ist insofern exakter, als er dem Umstand Rechnung trägt, dass Urbanität ein amorphes Begriffsgebilde darstellt, das mit dem Großstadtleben nicht identisch ist und somit dem Missverständnis nicht Vorschub leistet, ein Einstellungsmuster zu sein, das keinem klar konturierten Feindbild zugrunde liegt. Aus der großstadtfeindlichen Literatur geht unverkennbar hervor, dass in den modernen Großstädten eine distinkte soziale 
Entität gesehen wird, die strikt von einen zum Gegenentwurf stilisierten Landleben abgegrenzt wird. Die modernen Großstädte werden von Großstadtfeinden nicht als Verdichtungsräume sozialer und politischer Prozesse gesehen, die für die Gesellschaft als Ganzes prägend sind, sondern als soziale Orte, die eigenen (negativen) Gesetzmäßigkeiten unterliegen. Der Begriff der Großstadtfeindschaft lässt sich überdies über das Quellenmaterial begründen: Die Ausführungen im großstadtfeindlichen Schrifttum beziehen sich auf einer semantischen Ebene mehrheitlich auf „die Großstadt“ und/oder „die Großstädte“, jedoch nur sehr selten auf den Begriff der Urbanität. Wenn in großstadtfeindlichen Schriften von „Stadt“ die Rede ist, so lässt sich in den meisten Fällen aus dem Kontext erschließen, dass hiermit die moderne Großstadt gemeint ist. Insofern trifft der in der Forschungsliteratur gelegentlich anzutreffende Begriff der Stadtfeindschaft nicht den Kern der Sache: Die Idealsierung und Glorifizierung der Kleinstadt ist ein zentraler Bestandteil großstadtfeindlichen Denkens.

Im Mittelpunkt der großstadtfeindlichen Literatur steht die These einer Unvereinbarkeit von Großstadt- und Landleben. Wie bereits ausgeführt wurde, basiert sie auf der Wahrnehmung, dass bestimmte soziale Prozesse und Phänomene ein ausschließliches Spezifikum der modernen Großstädte seien. In der großstadtfeindlichen Literatur zeigt sich dieser Sachverhalt besonders in Bezug auf die Diskussion über einen Zusammenhang zwischen Großstadt und Geldwirtschaft. Ein immer wiederkehrendes Motiv stellt die Behauptung dar, dass die moderne Geldwirtschaft ein genuin großstädtisches Phänomen sei, für das die Landbewohnerschaft und im Besonderen der Bauernstand kein Verständnis besitze. Bereits Riehl warnte davor, dass die Bauern nicht in die Abhängigkeit der großstädtischen Geldwirtschaft geraten dürften. Dieser Gedanke gipfelte in Spenglers manichäischer und auf dem Waren- und Geldfetisch beruhender Unterscheidung von Großstadt und Land als einem Gegensatz von abstraktem Geld und konkretem Boden.

Auch Georg Simmel definierte in seinem Aufsatz Die Großstädte und das Geistesleben die Geldwirtschaft als ein zentrales Charakteristikum der modernen Großstadt (vgl. Simmel 1903). Im Unterschied zu Spengler und anderen Großstadtfeinden sah er jedoch darin nicht die Begründung für einen unüberbrückbaren Gegensatz großstädtischer und ländlicher Lebenswelten. Für Simmel war die Großstadt der Jahrhundertwende - als Anschauungsmaterial diente ihm Berlin - ein Ort, an dem sich soziale Entwicklungen zeigten und studieren ließen, die der Industriegesellschaft als solcher ihr Gepräge geben.

Für viele großstadtfeindliche Ideologen verband sich mit dem Ressentiment gegen die städtische Geldgier, „dem Mammonismus“, die Kritik an abstrakten Formen bürgerlicher 
Vergesellschaftung. Es ist daher nicht verwunderlich, dass die Ablehnung der Geldwirtschaft mit einem ausgeprägten Antiintellektualismus verbunden wird. Der Bauernstand erscheint in diesem Zusammenhang als Verkörperung eines konkreten und organischen Prinzips, die modernen Großstädte symbolisieren hingegen die als abstrakt wahrgenommenen Aspekte der warenproduzierenden Gesellschaft (Geld, Handel, Finanzkapital). Großstadtfeindschaft kann daher auch Elemente des von Postone beschriebenen fetischisierten Antikapitalismus enthalten - was im Besonderen für die völkische und nationalsozialistische Großstadtfeindschaft zutrifft.

Mit Siebel gedacht, ist ein zentrales Merkmal, das Stadt und Land bis in die Gegenwart voneinander trennt, die mit der europäischen Stadt verbundene Emanzipationsgeschichte (vgl. Siebel 1998, 1999, 2004): Die Geschichte der europäischen Stadt verbindet sich von Beginn an mit der Hoffnung auf ein besseres Leben. Europäische Urbanität, so Siebel, ,ist nicht zu denken ohne diese utopische Dimension, die von Anfang an mit der Kultur der Stadt verknüpft ist“" (Siebel 1999: 121). Siebel nennt fünf Emanzipationsversprechen, die mit der Stadtgeschichte zusammenhängen (vgl. Siebel 1999: 121-124):

Am Beginn der Entstehung städtischer Siedlungen steht die Emanzipation der Stadtbewohner von der Natur. Städter unterschieden sich von Landbewohnern darin, dass ihr Alltag nicht mehr vom Rhythmus der Natur bestimmt ist. Sie mussten nicht mehr jeden Tag mit einer unkultivierten Natur ums Überleben kämpfen. Stadtbewohner zu sein definierte sich seit der Gründung der ersten Städte darüber, nicht an der landwirtschaftlichen Produktion von Lebensmittel beteiligt sein zu müssen. Der von der Landbevölkerung erzielte Überschuss an Ernährungsgütern war die Voraussetzung für die Entstehung städtischer Siedlungen. Diese Befreiung der Stadtbewohner von der Natur ging daher zusammen mit der Befreiung von notwendiger Arbeit - das zweite urbane Emanzipationsversprechen. In der griechischen Polis war die Verwirklichung des Reiches der Freiheit jenseits des Reichs der Notwendigkeit (Marx) einer stadtansässigen Aristokratie vorbehalten, deren Befreiung vom Zwang zur Arbeit auf der Haltung von Sklaven und auf der Unterwerfung des den Stadtstaat umgebenen Landes basierte (vgl. Siebel 1998: 265).

In der Industriegesellschaft aktualisiert sich dieses Versprechen unter demokratischen und massenindustriellen Vorzeichen. Die Entwicklung der modernen Großstädte und der modernen städtischen Infrastruktur ermöglicht nun denjenigen die Befreiung von Arbeit und Verantwortung, die über genügend finanzielle Mittel verfügen: „Heute beruht die Attraktivität der Stadt auf einem ähnlichen Versprechen. Die moderne Stadtmaschine mit ihren 
Infrastrukturen, Gütern und Dienstleistungen ermöglicht es jedem, sofern er nur über genügend Geld verfügt, sich von Arbeit und Verantwortung frei zu machen" (Siebel 2004: 2223). Das seit der Antike mit dem Stadtleben verbundene Versprechen auf ein Leben frei von Entbehrungen und notwendiger Arbeit lässt sich in der modernen Großstadt grundsätzlich verwirklichen. In den modernen Metropolen gibt es kaum ein noch so ausgefallenes Bedürfnis, das sich nicht befriedigen ließe.

Das dritte Emanzipationsversprechen sieht Siebel in der bereits weiter oben ausgeführten politischen, ökonomischen und sozialen Emanzipation des Stadtbürgers im Mittelalter:

Die europäische Stadt des Mittelalters ist der Ort einer dreifachen Emanzipation: der Emanzipation des Wirtschaftsbürgers, des Bourgeois, als ökonomisch selbständiger Marktteilnehmer aus den geschlossenen Kreisläufen der Oikoswirtschaft, der Emanzipation des politischen Bürgers, des Citoyen, aus dem politischen Herrschaftssystem des Feudalismus und auf dieser Basis der Emanzipation des bürgerlichen Individuums in der Polarität von Öffentlichkeit und Privatheit aus den persönlichen Abhängigkeiten und den direkten Kontrollen vormoderner Sozialbeziehungen. (Siebel 1998: 268)

Die modernen Großstädte mit ihrer Größe, Dichte, Anonymität und Heterogenität ermöglichen, als vierten Emanzipationsschritt einen hohen Grad an Individualisierung. Die Großstädte des 20. und 21. Jahrhunderts symbolisieren - das fünfte Emanzipationsversprechen - die Hoffnung auf Integration und sozialen Aufstieg.

Die Großstadtfeindschaft gewinnt einen wesentlichen Teil ihrer Dynamik daraus, dass sie die Hoffnungen, die sich historisch mit dem Stadtleben verbinden, aufgreift, sie zugleich jedoch abwehrt und sie zur Anklage gegen die Großstädte nutzt. Dies kann an Aussagen veranschaulicht werden, die den in die Großstädte abwandernden Menschen vorhalten, ein selbstbezogenes und auf Genusssucht abstellendes Leben frei von Arbeit und Entbehrungen zu suchen. Mit dieser These ist die Vorstellung verknüpft, dass das Großstadtleben mit einer parasitären Existenz identisch sei. So sah Riehl die Anziehungskraft, die von den Großstädten ausgeht, in der Möglichkeit begründet, in ihnen „ernten zu können, ohne gesät zu haben“ (Riehl 1861a: 95; vgl. Kapitel 5.1.). Dieser Gedanke wurde von Spengler aufgegriffen und gleichsam radikalisiert. Nach ihm versprechen die Großstädte der abwanderungswilligen Landbevölkerung einen „vulgären Luxus“ und „Lohn ohne Arbeit““ (Spengler 1933: 117; vgl. Kapitel 5.4.).

Die Realität kann die Wirkmächtigkeit solcher Argumente indes nicht schmälern. Die schlechten Lebensverhältnisse des Industrieproletariats im späten 19. und im frühen 20. Jahrhundert hinderte großstadtfeindliche Ideologen nicht daran, die Großstädte als frivole 
Lasterparadiese zu beschreiben, in denen kollektiv dem sinnlichen Nichtstun gefrönt werde. Die Großstadtfeindschaft richtet sich gegen das mit dem Stadtleben verbundene Emanzipationsversprechen und deutet diese Utopie in ihren Schriften zu einer Wirklichkeitsbeschreibung großstädtischer Lebensverhältnisse um.

Die hier exemplarisch aufgeführten Zitate von Riehl und Spengler lassen die Annahme als begründet erscheinen, dass neben Hass und Ablehnung auch Faszination und Bewunderung die großstadtfeindliche Wahrnehmung der Großstädte prägt (vgl. Rose 1948; Buruma/Margalit 2004; Beauregard 2009: 36; Kahmann 2015). Die von Großstadtfeinden empfundene Faszination für das Stadtleben kann in diesem Zusammenhang als sich nicht eingestandene und unterdrückte Sehnsüchte und Begierde begriffen werden. Die Analyse großstadtfeindlicher Literatur zeigt, dass bei der Entstehung großstadtfeindlicher Ressentiments der psychische Mechanismus der pathischen Projektion eine zentrale Rolle spielt, worunter Adorno und Horkheimer ,die Übertragung gesellschaftlich tabuierter Regungen des Subjekts auf das Objekt“"verstehen (Horkheimer/Adorno 2010: 201).

Der projektive Charakter, der der Großstadtfeindschaft zu Eigen ist, verweist auf eine strukturelle Ähnlichkeit zum modernen Antisemitismus. Diese sind zudem über die modernitätsfeindliche und degenerationstheoretische Grundausrichtung von moderner Großstadt- und Judenfeinschaft begründet. Während jedoch die antisemitische Literatur seit dem Kaiserreich durchzogen ist mit antiurbanen Motiven, spielte der Antisemitismus für die Mehrheit der großstadtfeindlichen Bewegungen eine untergeordnete Rolle. Diese Differenz erklärt sich aus dem unterschiedlichen Welterklärungsanspruch und Rationalitätsgrad, die Antisemitismus und Großstadtfeindschaft inhärent sind: Der moderne Antisemitismus verband sich seit jeher mit einer umfassenden Weltanschauung und Welterklärung, die nicht der Wirklichkeit anpasst sind, sondern umgekehrt, nur eine Wirklichkeit kennen, die im Einklang mit den eigenen, irrationalen Überzeugungen steht. Die Feindschaft gegenüber der Großstadt verdichtete sich hingegen nicht notwendigerweise zu einem hermetischen Weltbild, das mit dem Anspruch verbunden war, den Strukturwandel der Moderne erklären zu können. Ruft man sich in Erinnerung, dass die im letzten Drittel des 19. Jahrhunderts rapide wachsenden Großstädte und Metropolen den Menschen als eine „terra incognita“ (vgl. Lindner 2004: 11) vorkommen mussten, wird deutlich, dass eine durch Unsicherheit und Abwehr geprägte Haltung zu den Großstädten durchaus nachvollziehbar ist und sich im Rahmen einer rationalen Auseinandersetzung mit den gesellschaftlichen Umbrüchen der Zeit bewegen konnte. Anders verhält es sich beim Antisemitismus: Bereits der „gemäßigte“ 
Antisemitismus des Konservatismus war stark weltanschaulich eingefärbt (vgl. Rürup 1987: 115).

Eine Auseinandersetzung mit einer Theorie der Großstadtfeindschaft macht es notwendig, die strukturelle Anschlussfähigkeit an den modernen Antisemitismus mitzudenken und zu berücksichtigen. Dabei dürfen jedoch nicht die Unterschiede aus dem Blick geraten, die darin zu sehen sind, dass die Großstadtfeindschaft im Unterschied zum Antisemitismus einen deutlich rationaleren Bezug zur Wirklichkeit erkennen lässt. Zwar beruht die negative Bewertung der Großstädte auf einer verzerrten und falschen Wahrnehmung nicht nur der Großstädte, sondern der Gesellschaft als solchen, sie basiert jedoch nicht grundsätzlich auf einer umfassenden Weltanschauung, mit der die unterschiedlichen Entwicklungen und Erscheinungen der Moderne erklärt und eingeordnet werden können. Es war der Antisemitismus, der die bereits seit Ende des 18. Jahrhunderts bestehenden Ressentiments gegen das moderne Stadtleben in sein Welterklärungsanspruch integrierte: In der Wahrnehmung der Antisemiten sind Juden unmittelbar für Verstädterung und Urbanisierung verantwortlich.

Zusammenfassend lässt sich mit Blick auf eine Theorie der Großstadtfeindschaft festhalten, dass großstadtfeindliches Denken auf der Unfähigkeit beruht zu erkennen, dass die Umbrüche der Moderne kein ausschließliches Phänomen der Großstädte sind, sondern die Gesellschaft als solche prägen. Großstadtfeinde sitzen dem Denkfehler auf, wie es Häußermann und Siebel formuliert haben, die moderne Großstadt mit der Gesellschaft zu verwechseln. Obwohl großstadtfeindliche Ressentiments auf einer verzerrten Wahrnehmung des Großstadtlebens beruhen, spiegeln die der Großstadtfeindschaft zu Grunde liegenden Projektionen zugleich auch reale Aspekte der Stadtgeschichte wider. So findet das Konstrukt von der sündhaften und dekadenten Großstadt seine Entsprechung in der Wirklichkeit darin, dass die Vergnügungs- und Amüsierbetriebe der Großstädte und Metropolen die Nachfrage nach einer die gesellschaftlichen Konventionen auch transzendierenden Ausschweifung entstehen lassen und bedienen und die Geschichte der europäischen Stadt seit der Antike mit der utopischen Hoffnung auf ein besseres Leben und der Befreiung von Arbeit, Entbehrungen und Elend verbunden ist. Da es sich um tabuisierte Regungen handelt, gegen die das antiurbane Ressentiment sich wendet, ist davon auszugehen, dass Großstadtfeinde eine ambivalente Haltung gegenüber den Großstädten einnehmen, die durch eine Gleichzeitigkeit von Hass und Bewunderung gekennzeichnet ist. Eine entscheidende Ursache für die Herausbildung einer großstadtfeindlichen Haltung ist nicht die ambivalente Großstadterfahrung als solche, diese ist 
vielmehr ein Charakteristikum der Moderne (vgl. Siebel 2016), sondern die Tatsache, dass diese Amivalenz nicht verarbeitet werden kann und projektiv abgespalten wird. 
7. Methodologische Grundlagen der Studie

7.1. Methode der qualitativen Inhaltsanalyse

Die Untersuchung der völkischen Texte in dieser Studie orientiert sich an der Verfahrensweise der qualitativen Inhaltsanalyse. Im Hinblick auf mein Erkenntnisinteresse, zentrale Topoi und Argumentationsmuster der antisemitisch-völkischen Diskussion über die Großstadt zu untersuchen, bietet sich die qualitative Inhaltsanalyse als Untersuchungsmethode der Texte an. So geht es mir im Unterschied zu empirischen Studien aus der Antisemitismusforschung, die sich auf die objektive Hermeneutik ${ }^{26}$ beziehen, nicht um die Analyse einer grundlegenden Struktur der antisemitischen Semantik, von der angenommen wird, dass sie für alle Erscheinungsformen des (modernen) Antisemitismus in seiner nunmehr fast 150-jährigen Geschichte Gültigkeit beanspruchen könne. ${ }^{27}$ Die These einer inhaltlichen Kohärenz des Antisemitismus ist wenig überzeugend. Lars Rensmann zufolge gibt es allenfalls eine psychische Konsistenz des Antisemitismus; verstanden als „konsistenter Wunsch nach antijüdischer Abwertung und Gewalt“. Er verweist darauf, dass Juden und Jüdinnen in der Geschichte unterschiedliche und sich wiedersprechende Stereotype zugeschrieben wurden (vgl. Rensmann 2006: 71-72). Überdies ist diese Studie nicht vergleichend angelegt. Die untersuchten völkischen Texte werden nicht mit Kontrastbeispielen abgeglichen und somit nicht in Beziehung zu anderen Erscheinungsformen des Antisemitismus gesetzt.

Gleichwohl davon ausgegangen wird, dass zentrale Sinndimensionen, die das antisemitische Bild von den Großstädten maßgeblich strukturieren - z.B. Gemeinschaft vs. Gesellschaft, Bodenverbundenheit vs. Wurzellosigkeit, Kosmopolitismus vs. Regionalismus -, für den modernen Antisemitismus insgesamt charakteristisch sind, erklärt sich die Fokussierung auf

\footnotetext{
${ }^{26}$ Die objektive Hermeneutik, die maßgeblich von dem Frankfurter Soziologen Ulrich Oevermann entwickelt wurde, versteht Texte als protokollierte Interaktionen. Ziel des Ansatzes ist es, die Regeln zu rekonstruieren, auf deren Grundlage diese Interaktionstexte objektive Bedeutungsstrukturen konstituieren. Es wird dabei davon ausgegangen, dass protokollierte Texte eine eigene soziale Realität konstituieren, die unabhängig von den Handlungsdispositionen und psychischen Begleitumständen des Produzenten oder der Rezipienten reproduziert werden kann (vgl. Oevermann et al. 1979: 378-379). Seit der Studie von Klaus Holz zum nationalen Antisemitismus (vgl. 2010) ist die objektive Hermeneutik in der sozialwissenschaftlichen Antisemitismusforschung als Methode der Textanalyse etabliert.

${ }^{27}$ Die Frage nach der Gewichtung von sozialpsychologischen und autoritarismustheoretischen Ansätzen einerseits und semantisch-deskriptiven Untersuchungsmethoden andererseits war zentraler Bestandteil der Kontroverse zwischen Lars Rensmann und Klaus Holz im Jahr 2006, die zu einer starken Polarisierung der sozialwissenschaftlichen Antisemitismusforschung in Deutschland beigetragen hat. Ich teile die Ansicht Rensmanns, dass sozialpsychologische Ansätze für die Antisemitismusforchung unabdingbar sind.
} 
den völkischen Antisemitismus daraus, dass die Großstadtfeindschaft nicht in gleicher Weise für einen linken, sekundären oder israelbezogenen Antisemitismus charakteristisch ist. Die Großstadtfeindschaft stellt einen spezifischen Aspekt des völkisch-rassistischen Antisemitismus dar. Der Fokus dieser Studie ist daher auf Texte aus der völkischen Bewegung des Kaiserreichs, der Weimarer Republik und aus der Zeit der NS-Herrschaft gerichtet.

Die große Stärke der qualitativen Inhaltsanalyse für mein Forschungsinteresse besteht einerseits in der Möglichkeit, einen vergleichsweise großen Textkorpus in die Analyse einzubeziehen, sowie in der Explikation des theoretischen Vorverständnisses. Um dominante Argumentationsmuster aus dem Material herausfiltern zu können, ist eine Methode gefordert, die es erlaubt, eine größere Menge an Texten gezielt zum Zusammenhang von Antisemitismus und Großstadtfeindschaft $\mathrm{zu}$ befragen. Je mehr Texte in die Analyse einbezogen werden können, desto sicherer lassen sich Aussagen über die Bedeutung einzelner Topoi und Argumentationsmuster in der antisemitisch-völkischen Debatte über die Großstadt machen. Im Unterschied zu sequenzanalytischen Ansätzen werden die Texte jedoch nicht in ihrer sequenziellen Struktur analysiert, sondern Textsegmente werden vom Forscher und der Forscherin in von ihm bzw. ihr konstruierte Sinnzusammenhänge gestellt (vgl. Rosenthal 2005: 199). Die qualitative Inhaltsanalyse stößt somit dann an ihre Grenzen, wenn über den Untersuchungsgestand wenig oder gar nichts bekannt ist und wenn Aussagen über die Sinnstruktur eines Textes gemacht werden sollen. Die qualitative Inhaltsanalyse eignet sich im Besonderen nicht für explorative Studien, die mit einer offenen Fragestellung arbeiten, wie dies zu meist bei (ethnographischen) Feldforschungen und offenen Interviews der Fall ist. Die qualitative Inhaltsanalyse bietet sich in solchen Forschungsarbeiten an, in einem weiteren Schritt Aussagen über die Häufigkeitsverteilung bestimmter Ausprägungen im empirischen Material zu treffen.

Als sozialwissenschaftliche Methode der Textanalyse kennzeichnet die qualitative Inhaltsanalyse eine für die qualitative Sozialforschung vergleichsweise starke Theorieorientierung und ein an die Theorie sowie an das empirische Material rückgebundenes und durch diese begründetes Kategoriensystem, unter das Textstellen, aber auch ganze Texte subsumiert werden können. Die qualitative Inhaltsanalyse wird in dieser Studie als eine auf anerkannten Regeln, Verfahrensweisen und Prüfkriterien beruhende Methode verstanden, mit der der gesellschaftliche und ideologische Gehalt von Texten analysiert werden kann. In Anlehnung an Philipp Mayring wird die qualitative Inhaltsanalyse als eine regel- und 
theoriegeleitete Methode der Textanalyse begriffen, die dem Anspruch nach intersubjektiver Nachvollziehbarkeit gerecht werden möchte.

Die Forderung nach einer Explikation des theoretischen Vorwissens bedeutet jedoch nicht, dass eine subjektiv beliebige Vormeinung die Analyse leiten soll; hierunter wird der Rekurs auf bereits formuliertes Wissen, begründete Thesen und Informationen über den Untersuchungsgegenstand verstanden ( Mayring 2010: 12-13).

Trotz der Orientierung an einem regelgebundenen und theorieorientierten Vorgehen in der Analyse versteht sich die qualitative Inhaltsanalyse zugleich als eine Methode, die der Komplexität, der Bedeutungsfülle sowie der Interpretationsbedürftigkeit des sprachlichen Materials angemessen sein möchte (vgl. Mayring 2010: 10). Sie hat daher den Anspruch, über die Reproduktion des manifesten Inhalts von Texten hinauszugehen, und versteht sich dementsprechend als eine Methode, mit der auch verborgene und latente Sinngehalte entschlüsselt werden können. Der vergleichsweise hohe Stellenwert, der der Theorie und dem durch die Fragestellung theoretisch begründeten Kategoriensystem beigemessen wird, bedeutet zugleich nicht, dass das Kategoriensystem starr auf das empirische Material angewendet wird und somit nur Aspekte identifiziert werden können, die das theoretische Vorwissen bestätigen.

Mit Werner Meinefeld gesprochen verläuft die Diskussion über den Stellenwert des Vorwissens und der Theorie in der empirischen Sozialforschung nicht entlang der Trennlinie zwischen quantitativen und qualitativen Forschungsmethoden. Als qualitative Studie hat diese Arbeit den Anspruch, „die Formulierung von Hypothesen mit dem Rekonstruieren gegenstandsspezifischer Bedeutungsgehalte zu vereinbaren“ (Meinefeld 2010: 272). In der Forschungspraxis gestaltet sich dieser Ansatz in der Weise aus, dass die Kategorien aus einem sich überlagernden Zwischenspiel zwischen der Reflexion des theoretischen Vorwissens und einem mehrstufigen Materialdurchlauf hervorgehen. In diesem Prozess wird das Kategoriensystem durch die wiederholte Analyse des empirischen Materials dem neuen Erkenntnistand angepasst, ist zugleich jedoch an die Fragestellung der Studie rückgebunden und wird mit dem theoretischen Vorwissen abgeglichen. Somit lassen sich neue und bereits bekannte Merkmale im Material voneinander unterscheiden und Rückschlüsse darauf ziehen, an welchen Stellen die Studie über den Forschungsstand hinausgeht.

Die Auswertung der in dieser Studie untersuchten Texte ist an die Analysetechnik angelehnt, die Mayring als inhaltliche Strukturierung bezeichnet (vgl. Mayring 2010: 65-66). Ziel ist es 
hierbei, Material zu bestimmten Inhaltsbereichen und Aspekten zu extrahieren und unter Kategorien zusammenzufassen. Dabei ist es von zentraler Bedeutung, dass die Zuordnung von Textstellen zu bestimmten Kategorien festgelegt wird. Mayring schlägt hierbei drei Regeln vor (2010: 92): Die Kategorien müssen definiert werden. Es können zudem Ankerbeispiele aus dem empirischen Material gewählt werden, anhand derer die Zuordnung $\mathrm{zu}$ einer Kategorie festgelegt wird. Bei Abgrenzungs- und Zuordnungsschwierigkeiten müssen zudem Regeln formuliert werden, die die Zuordnung zu einer Kategorie festlegen.

\subsection{Auswahl des empirischen Materials}

Der Zusammenhang zwischen Antisemitismus und Großstadtfeindschaft wird in dieser Studie anhand völkischer Texte empirisch untersucht, die für die antisemitische Großstadtfeindschaft einen paradigmatischen Charakter haben. Die Wahl fiel einerseits auf die zwischen 1902 und 1940 herausgegebene Zeitschrift Hammer. Blätter für deutschen Sinn und andererseits auf die Schriften Richard Walther Darrés. In diesem Kapitel wird die Auswahl des empirischen Materials begründet.

Die Zeitschrift Hammer. Blätter für deutschen Sinn stand im Zentrum der publizistischen Aktivitäten der völkischen Bewegung und fungierte in ihrer Geschichte als ein strömungsübergreifendes Medium, in dem Autoren aus allen Bereichen und Segmenten des völkischen Spektrums publizierten (vgl. Breuer 2004: 1010-1011, 2008: 104; Puschner 2001: 60-61, 2004: 60-61, 2010: 62). Die Spannbreite der Autoren, die für die Zeitschrift schrieben, reichte von Anhängern des völkischen Flügels der Lebensreformbewegung, wie Heinrich Pudor, einer der Schlüsselfiguren der Nacktkulturbewegung, Vertretern einflussreicher politischer Verbände, wie dem Bund der Landwirte und dem Alldeutschen Verband, über Rassentheoretiker wie beispielsweise Willibald Hentschel bis hin $\mathrm{zu}$ dem nordischen Ideologen und Nationalsozialisten Johann von Leers.

Der Hammer ist zugleich eine der am längsten aufgelegten Zeitschriften der völkischen Bewegung. Die völkische Bewegung maß der Publizistik eine vergleichsweise große Bedeutung zu (vgl. Ziege 2002: 116-117; Ulbricht 1999), und eine entsprechend hohe Anzahl von zum Teil auch kurzlebigen Periodika prägte die publizistischen Aktivitäten der Bewegung. Mit einer ununterbrochenen Erscheinungszeit von fast 40 Jahren - das erste Heft 
erschien im Januar 1902, das letzte im März 1940 - unterscheidet sich der Hammer von vielen anderen völkischen Zeitschriften, die oftmals nur für wenige Jahre aufgelegt wurden.

Gegründet wurde der Hammer 1902 in Leipzig vom antisemitischen Verleger Theodor Fritsch. Fritsch, ein gelernter Maschinenbauer und studierter Ingenieur, war vor, aber auch während seiner Aktivitäten in der antisemitischen Bewegung als Interessenvertreter des Mittelstandes aktiv. 1880 gründete er den Deutschen Müllerbund, 1898 die Mittelstandvereinigung im Königreiche Sachsen. Eine antisemitische Agitation verband Fritsch bereits mit seiner ersten verlegerischen Unternehmung, mit der ab 1880 herausgegebenen Monatsschrift Kleines Mühlen-Journal (vgl. Piefel 2004: 55-57). Seit 1885 verlegte er zudem die Antisemitische Correspondenz, die sich dem Ziel der Aufhebung der Judenemanzipation verschrieb. Anfang der 1890er Jahre wurde sie in Deutsch-Soziale Blätter umbenannt und fungierte als Organ der Deutsch-Sozialen Partei, an deren Gründung Fritsch beteiligt war. Aufgrund seines rassenantisemitischen Weltbildes, das in der sich als „gemäßigt“ antisemitisch verstehenden Partei nicht mehrheitsfähig war, wurde er 1894 dazu gedrängt, die Herausgabe der Blätter an Max Liebermann von Sonnenberg abzugeben (vgl. Herzog 1999: 153).

Bis Fritsch 1902 den Hammer-Verlag und die gleichnamige Zeitschrift herausgab, publizierte er eine Reihe antisemitischer und auf den Mittelstand zugeschnittene Schriften. Zu seinen bekanntesten und einflussreichsten Büchern gehört der erstmals 1897 erschienene Antisemiten-Katechismus, der ab 1907 unter dem Titel Handbuch der Judenfrage vertrieben wurde und es bis 1944 auf 44 Auflagen brachte. Es handelt sich dabei um sein einflussreichstes Machwerk, das auch führende Köpfe des Nationalsozialismus beeinflusste (vgl. Zumbini 2003 629-631): In dem Vorwort zur 30. Auflage des Buches gab Hitler darüber Auskunft, dass er das Buch bereits in seiner Wiener Zeit studierte und dass es dem Antisemitismus des Nationalsozialismus den Weg bereitet habe (vgl. Zimmermann 1978: 99; Zumbini 2003: 321). Als Fritsch im September 1933 starb, gewährte die NS-Führung ihm ein Staatsbegräbnis und führende Nationalsozialisten kondolierten öffentlich seiner Witwe.

Fritsch rief den Hammer im Dezember 1901 mit der Intention ins Leben die antisemitische Bewegung neu beleben zu wollen und den Antisemitismus jenseits der Parteipolitik, die er für gescheitert hielt, einem größeren Publikum zugänglich zu machen (vgl. Bönisch 1996: 344345; Herzog 1999: 153-155). Der überparteiliche Anspruch des Hammers spiegelte sich in dem zwischen 1911 und 1926 geänderten Untertitel, Parteilose Zeitschrift für nationales 
Leben, wider. 1922 kehrte Fritsch jedoch in die Parteipolitik zurück und saß für die Deutschvölkische Freiheitspartei im Reichstag.

Der Hammer erschien zunächst monatlich, ab 1903 zweiwöchig. Die Erstauflage betrug laut Fritsch 10000 Exemplare, von denen jedoch nur die Hälfte verkauft werden konnte. Ein Massenpublikum erreichte die Zeitschrift indessen nie. Es wird geschätzt, dass die Zeitschrift 1904 um die 2000 bzw. 19053000 Abonnenten hatte (vgl. Ulbricht 1996: 286; Breuer 2004: 1015). Fritsch entwickelte mit der Herausgabe der Zeitschrift einen großen missionarischen Eifer. So zählte er zu ihren ,produktivsten“ Autoren und publizierte regelmäßig Beiträge unter verschiedenen Pseudonymen. Herzog geht davon aus, dass der Hammer in den ersten acht Jahren ein Verlustgeschäft war, das Fritsch aus eigenen finanziellen Mitteln am Leben hielt (vgl. Herzog 1999: 159). Die These wird durch die Tatsache untermauert, dass in den Heften der ersten Jahrgänge nur sehr wenige Werbeanzeigen $\mathrm{zu}$ finden sind. Fritsch verschickte zudem auf eigene Kosten nicht verkaufte Exemplare ungefragt an Personen des öffentlichen Lebens, an Zeitungsredaktionen und an Lesezimmer.

Um den Leserkreis zu erweitern, wurden überdies einzelne Artikel auf sogenannten HammerFlugblättern nachgedruckt, die zum Preis von 1 oder 2 Pfenning verkauft, zum Teil aber auch umsonst an mittelose Personen ausgegeben wurden. Den Flugblättern kam eine hohe Bedeutung für die Verbreitung der Inhalte der Zeitschrift zu. So ließ Fritsch nach eigenen Angaben im Dezember 1911 in mehreren deutschen Großstädten sechs Flugblätter mit einer Gesamtauflage von 2 Millionen verteilen (vgl. Fritsch 1912a). Die Distribution übernahmen sogenannte Hammer-Bünde, die sich in mehreren deutschen Großstädten bildeten. Die Bünde dienten als Treffpunkte „für deutschbewusste Männer“, wie es in einer Reklame im Hammer hieß, ,zum Zwecke der Erhaltung und Förderung einer gesunden deutschen Eigenart“. Der Hammer-Bund wurde definiert als ,zwanglose Vereinigung von Freunden der HammerBestrebungen“, die sich für eine ,allgemeine Volksaufklärung durch Verbreitung der im Hammer vertretenen Gedanken“ und für die „Gewinnung neuer Anhänger und Leser für das Blatt“ einsetzt (o.A. 1912a: 133). Interessenten mussten für ihre Aufnahme versichern, dass weder sie noch ihre Ehefrauen jüdische Vorfahren hätten. 1912 wurden die einzelnen Ortsgruppen zum sogenannten Reichshammer-Bund zusammengeschlossen. Mit diesem Zusammenschluss, so Herzog, „war der ,Hammer“ nicht mehr nur eine Zeitschrift und ein Verlag, sondern eine deutschlandweit agierende antisemitische Organisation“ (Herzog 1999: 169). 1919 fusionierte der Reichshammer-Bund mit dem Alldeutschen Verband und der Deutschvölkischen Partei zum Deutschvölkischen Schutz- und Trutzbund. 
Haben Antisemitismus und Großstadtfeindschaft eine konstitutive Bedeutung für die völkische Bewegung im Allgemeinen, so gilt dies für den Hammer im Besonderen. Beide Ideologien gehören zum Selbstverständnis der Zeitschrift und durchdringen sich in den Artikeln der Zeitschrift in vielfältiger Weise. Besonders deutlich wird dies in Textpassagen, in denen die Redaktion ihre Weltanschauung erläutert. In einem 1920 erschienen Text, dessen Autor namentlich nicht genannt wird, bei dem es sich aber mit großer Wahrscheinlichkeit um Theodor Fritsch handelt, werden die Juden als Hindernis auf dem Weg zu einer „Erneuerung und Gesundung unseres Volkslebens auf allen Gebieten“ hervorgehoben:

Die Dinge liegen nun einmal so, daß es eine Gesundung und Erneuerung unseres Volkslebens nicht geben kann, so lange der fressende Judenkrebs an unserem Volkskörper zehrt. [...] Gesund aber ist unser Volk zur Zeit nicht, und die Geistesluft, in der es lebt, ist nur geeignet, es immer kränker zu machen. Darum müssen wir erst die Sümpfe austrocknen, aus denen die giftigen Miasmen aufsteigen. Solche Sümpfe sind die vergifteten Künste und Literaturen, die fälschenden und verwirrenden Zeitungen, die Irrtümer in Schul- und Kirchenlehre, die den Geist unseres Volkes mißleiten. Auch die scheinbar harmlosesten Vergnügungen, die Konzerte, Kino, Theater - alles ist von einem verderblichen Geiste durchhaucht. Und überall entdecken wir als Vergifter - den Hebräer. Darum gilt ihm zuerst unser Kampf. (o. A. 1920: 348)

Die Autoren des Hammer waren darum bemüht, den Antisemitismus nicht als ein negatives und verneinendes Programm darzustellen. Sie verstanden die Judenfeindschaft als den zentralen Aspekt einer völkischen Politik, deren Ziel in der Gesundhaltung und Gesundmachung des deutschen Volkes gesehen wurde. Der in dem Zitat anklingenden Feindschaft gegen das moderne Großstadtleben, die sich auch immer gegen großstädtische Kultur- und Vergnügungseinrichtungen wendet, kam im Hammer eine programmatische Funktion zu. In einer Rückschau anlässlich der Herausgabe des 20. Jahrgangs der Zeitschrift betont Fritsch die Pionierrolle, die der Zeitschrift im publizistischen und praktischen Kampf gegen die Großstädte zukomme:

Der ,Hammer' ist das erste Blatt gewesen, das die verzehrende Wirkung des Großstadtlebens aufgedeckt und den Gedanken einer Geschlechtererneuerung durch Niederlassung auf dem Lande befürwortet hat. So ist der Siedlungs-Gedanke in Verbindung mit der BodenEntschuldung und der rassischen Zucht von jeher im ,Hammer' gepflegt worden. Ja, wir sind bei den bloßen Gedanken nicht stehen geblieben, sondern zur Tat geschritten. Hammer-Leute haben im Jahre 1909 die völkische Siedlung Heimland in der Mark Brandenburg geschaffen. (Fritsch 1921: 4)

Auch andere Hammer-Autoren betonten die Vorreiterrolle der Zeitschrift für die völkische Großstadtfeindschaft (vgl. Gerlach 1928: 304). Die These von einer verzehrenden Wirkung der Großstädte war jedoch keineswegs neu, was allein die regelmäßigen Referenzen im Hammer auf die empirischen Studien von Georg Hansen und Atto Ammon belegen. Die Großstadtfeindschaft des Hammers beschränkte sich dabei nicht auf einen bestimmten Flügel 
oder ein spezifisches Segment der Bewegung. Sie findet sich bei Autoren unterschiedlicher Strömungen und kann in allen Jahrgängen der Zeitschrift nachgewiesen werden. Die Analyse zeigt, dass sich die Texte, in denen großstadtfeindliche und antisemitische Inhalte identifiziert werden konnten, gleichmäßig über den Erscheinungszeitrum der Zeitschrift verteilen. Die großstadtfeindlichen Motive und Stereotype weisen in dem untersuchten Zeitraum eine starke Kontinuität und Beständigkeit auf, so dass davon gesprochen werden kann, dass die Großstadtfeindschaft ein konstantes Motiv sowohl der völkischen Bewegung des Kaiserreiches als auch der Weimarer Republik ist.

Signifikante Hoch- oder Tiefphasen der gegen die Großstädte gerichteten Agitation ließen sich bis auf eine leichte Tendenz einer Abnahme großstadtfeindlicher Inhalte in den Jahrgängen der 1930er Jahre nicht feststellen. Es steht zu vermuten, dass der leichte Rückgang an großstadtfeindlichen Inhalten in den Heften der zweiten Hälfte der 1930er Jahre damit zusammenhängt, dass die Nationalsozialisten, allen voran Richard Walther Darré, zentrale Forderungen der völkischen Bewegung nach einer Stärkung des Landlebens und des Bauernstandes schnell in ihre Politik integrierten und somit dieses Thema an Dringlichkeit verlor.

Auffällig ist überdies, dass es vergleichsweise wenige Aufsatztitel gibt, die auf einen großstadtfeindlichen Inhalt schließen lassen. Die Themen Großstadt und Verstädterung stehen nur in sehr wenigen Aufsätzen im Mittelpunkt der Betrachtungen. Auch in den Sach- und Stichwortverzeichnissen, die einigen der gebundenen Jahrgängen des Hammers hintenangestellt wurden, tauchen die Begriffe Großstadt, Stadt, Verstädterung und Urbanität nur selten auf - und das, obwohl diese Themen in den verschiedenen Heften der jeweiligen Jahrgänge verhandelt werden. Dieser Umstand legt den Schluss nahe, dass die Großstadtfeindschaft ein fester Bestandteil des ideologischen Selbstverständnisses der völkischen Bewegung war, die in nur sehr geringfügiger Weise von konjunkturellen Faktoren, wie wirtschaftlichen Krisen oder dem Ersten Weltkrieg, abhing, und dass es sich bei ihr um einen Meta-Diskurs handelte, deren Existenz keiner tiefergehenden Erläuterungen bedurfte und von der angenommen wurde, dass die Leserschaft von ihr bereits Kenntnis genommen hatte.

Das dieser Studie zugrunde liegende empirische Material bezieht sich des Weiteren auf die Schriften Richard Walther Darrés. Darré schrieb nicht für den Hammer, stammt jedoch auch aus dem völkisch-antisemitischen Lager der Weimarer Republik und lag mit seinem radikalen Antisemitismus und seiner Großstadtfeindschaft ganz auf der Linie des Blattes. So kann es 
wenig überraschen, dass Hentschel im Hammer Darrés Buch über Das Bauerntum als Lebensquell der nordischen Rasse positiv besprach und auch Fritsch seine Gedanken zum Bauerntum als Träger der „nordischen Rasse“ würdigte, wenngleich er dem nordischen Gedanken nicht vorbehaltlos anhing (vgl. Hentschel 1929; Fritsch 1929). Die Entscheidung, die Schriften von Darré in die Analyse mit einzubeziehen, erklärt sich aus dem Umstand, dass dieser derjenige völkische Ideologe war, der das umfangreichste Schrifttum einer antisemitischen Großstadtfeindschaft hinterlassen hat.

Nach einem Studium zum Diplomlandwirt und der Landwirtschaft mit dem Schwerpunkt der Viehzucht und der Vererbungslehre setzte Mitte der 1920er Jahre seine Tätigkeit als Publizist in der völkischen Bewegung ein. Seine Vorstellungen von einer Rassenzucht verbanden sich dabei mit der Überzeugung, dass sich diese nur fernab der Großstädte vollziehen lasse. Im Bauerntum machte Darré die Trägerschicht dieser Menschenzucht aus. In seinem ersten Buch aus dem Jahr 1929, Das Bauerntum als Blutsquell der nordischen Rasse, prädisponierte er das Bauerntum, in quantitativer Hinsicht das Menschenmaterial für die „nordische Rasse“ zu liefern; in seinem ein Jahr später erschienenen Werk Neuadel aus Blut und Boden stand hingegen eine aus dem Bauerntum hervorzugehende rassisch-agrarischen Elite im Mittelpunkt, die in seiner Vorstellung auf sogenannten Hegehöfen gezüchtet werden sollte. Mit der Beauftragung des Aufbaus des agrarpolitischen Apparats der NSDAP 1930 und der Übernahme der Leitung des neu gegründeten Rasse- und Siedlungsamtes der SS 1931 avancierte Darré zum einflussreichsten Ideologen einer auf der Idee der ländlichen Rassezucht basierenden Blut-und-Boden-Ideologie. Als Angehöriger der nordischen Bewegung bewegte er sich in jenen völkischen Kreisen, in denen die Großstadtfeindschaft am radikalsten vertreten wurde. So war er Mitglied im Bundschuh, einer Schwesterorganisation der Artamanen (vgl. Breuer 2010a: 273). Er veröffentlichte zudem in der von dem Artamanen August Georg Kenstler herausgegebenen Zeitschrift Blut und Boden.

Den Höhepunkt seiner Macht bildete die zu Beginn der NS-Herrschaft mit dem Gesetz zur Neubildung des deutschen Bauerntums und dem Reichserbhofgesetz eingeleitete rassenorientierte Bauernpolitik, die in den Zuständigkeitsbereich des von ihm geleiteten Reichsministeriums für Ernährung und Landwirtschaft fiel. In den folgenden Jahren schwand der Einfluss Darrés zunehmend. 1938 trat er nach inhaltlichen Differenzen mit Himmler von der Leitung des Rasse- und Siedlungshauptamtes der SS zurück. Hierdurch verlor Darré eine Schlüsselstellung in der nationalsozialistischen Siedlungspolitik. Diese Entwicklung führte schließlich dazu, dass Hitler per geheimen „Führererlass“ die Verantwortung für die 
Siedlungspolitik in den besetzten Gebieten Osteuropas Himmler übertrug (vgl. Mai 2002: 114-131). Am 16. Mai 1942 wurde Darré schließlich aus vorgeblich gesundheitlichen Gründen beurlaubt und de facto seines Amtes als Landwirtschaftsminister enthoben. Im Wilhelmstraßen-Prozess wurde er 1949 zu sieben Jahren Zuchthaus verurteilt, jedoch bereits 1953 aus der Haft entlassen.

In der Forschung lassen sich sehr unterschiedliche Einschätzungen über die Rolle Darrés im NS-Staat und über seine Bedeutung für die NS-Ideologie finden. Die amerikanische Historikerin Anna Bramwell versucht in ihrer politischen Biographie, Darré als den führenden Kopf einer Gruppe radikaler und ökologisch orientierter Agrarideologen darzustellen, der gegen den Krieg gewesen sei und nur wenige Gemeinsamkeiten mit der NS-Ideologie aufgewiesen habe, da er mit seiner Verherrlichung des Bauerntums eine Gegenposition zu der industrie- und technikfreundlichen Haltung des Nationalsozialismus eingenommen habe (vgl. Bramwell 1985: 203). Ihrer apologetischen Biographie wurde von der neueren Forschung vehement widersprochen. Wie auch in dieser Studie gezeigt wurde war Darré kein rückwärtsgewandter Agrarutopist, der mit der industriellen Produktion in einen ideologischen Konflikt geriet (vgl. Eidenbenz 1993; siehe auch Breuers Einschätzung des Rassenaristokratismus: Breuer 2010a: 277-278).

\subsection{Das Kategoriensystem}

Das Kategoriensystem, das der empirischen Untersuchung zugrunde liegt, ist aus der Materialanalyse hervorgegangen und wurde mit dem theoretischen Vorwissen abgeglichen und in Beziehung gesetzt. Die Kategorien sind daher sowohl theoretisch begründet als auch an das empirische Material rückgebunden. Der Textkorpus basiert auf der Durchsicht aller Jahrgänge der Zeitschrift Hammer sowie den Texten von Darré nach Textstellen, die einen Bezug zum Thema Antisemitismus und Großstadtfeindschaft aufweisen. Im Hammer wurden insgesamt 52 Texte identifiziert, die diesbezügliche Textstellen enthalten; im Werk von Darré sind es 12 Publikationen. Diese Zahl deckt nicht alle gefundenen und identifizierten Textstellen ab, da im Laufe der Analyse eine theoretische Sättigung in der Form eintrat, dass sich Argumente bis hin zu ihren Formulierungen glichen. Die 64 Texte bildeten die Grundlage für die Auswahl der Textstellen, die den jeweiligen Kategorien zugeordnet wurden. Ich habe mich dafür entscheiden, dass jeweils eine längere Textpassage einer 
Kategorie zugeordnet wird und dass weitere Belege aus dem empirischen Material herangezogen werden, um Sachverhalte besser zu erläutern. Die angeführten Zitate repräsentieren demnach ein im Material wiederholt auftretendes Argumentationsmuster. Die Analyse ergab die Bildung von drei Hauptkategorien:

1. Personifizierung der Verstädterung in den Juden

2. Unterschiedliche Anpassungsfähigkeit von Juden und Deutschen an die Großstadt

3. Sexualität, Judentum und Großstadt

Ein Vorteil der qualitativen Inhaltsanalyse besteht darin, benennen zu können, welche durch das Material identifizierten Aspekte in der theoretischen Diskussion bereits enthalten sind und welche durch die empirische Analyse aufgedeckt wurden und dadurch das Verständnis des Untersuchungsgegenstandes erweitern. Die drei Hauptkategorien der Untersuchung finden sich in unterschiedlicher Ausprägung in der diskutierten Forschungsliteratur wieder: Die Personifizierung sozialer Transformations- und Modernisierungsprozesse in den Juden wurde von der Forschung eingehend theoretisch diskutiert und vielfach empirisch belegt. Vor diesem Hintergrund war es zu erwarten, dass sich in dem untersuchten Material Stellen finden lassen werden, die die Verstädterung als einen von Juden und Jüdinnen gelenkten Prozess beschreiben. Unter die erste Kategorie wurden sämtliche Textstellen subsumiert, die die Verstädterung und das Anwachsen der Großstädte auf das Handeln jüdischer Akteure zurückführen.

Der völkische Topos einer entgegengesetzten Anpassungsfähigkeit von Juden und Deutschen an das moderne Großstadtleben, wovon die zweite Hauptkategorie handelt, wird von Arnold Rose in seiner Antisemitismus-Theorie thematisiert. Hierbei handelte es sich jedoch bisher um eine These, die noch nicht empirisch überprüft wurde. Diese Lücke schließt meine Untersuchung. Dieser Kategorie wurden Aussagen zugeordnet, die entweder eine schädliche Entwicklung von den Großstädten für die Deutschen, respektive die Germanen, ausgehen sehen und/oder Juden und Jüdinnen die Eigenschaft zuschreiben, in den Großstädten leben zu können, ohne dass ihre Gesundheit daran Schaden nehme.

Die Forschung zur Großstadtwahrnehmung hat bereits nachgewiesen, dass Großstadtbilder und Großstadtmythen eine geschlechtsspezifische Komponente und Konnotation haben können und dass den Großstädten ein unmittelbarer Einfluss auf die geschlechtliche und sexuelle Identität zugeschrieben wird (vgl. Frank 2003; Bergius 1986; Omran 2000; Mancini 
2009). Dieser Zusammenhang wurde bisher jedoch nicht in Bezug auf die völkische Bewegung und ihre Großstadtfeindschaft untersucht. Hierbei handelt es sich um einen Aspekt völkischer Ideologie, der von der Forschung bisher nur unzureichend reflektiert wurde. Für diese Kategorie waren Textstellen von Relevanz, die der modernen Großstadt eine verführerische Rolle zuschreiben, dem Großstadtleben eine sexuell und sinnlich stimulierende Wirkung attestieren, einen sittlichen Verfall in den Großstädten konstatieren und hinter dem großstädtischen System der Verführungen und Reizungen die Juden als Verursacher identifizieren. 
8. Antisemitismus und Großstadtfeindschaft in völkischen Texten

8.1. Die Personifizierung der Verstädterung in den Juden

8.1.1. Die entwurzelnde Wirkung des ,jüdischen Geistes“

Die Personifizierung sozialer Prozesse und Phänomene, die im Zuge der Herausbildung der bürgerlich-kapitalistischen Gesellschaft im 19. Jahrhundert zu Tage traten, stellt einen zentralen Aspekt antisemitischer Projektionen und Feindbildkonstruktionen dar. Die Identifizierung von Modernisierungsprozessen mit dem Judentum vollzieht sich auf der Grundlage einer verdinglichten Wahrnehmung von Gesellschaft. Die historische und die soziale Genese der gesellschaftlichen Verhältnisse bleiben dabei unerkannt, und die Ambivalenz, die Krisenhaftigkeit und die Kontingenz moderner Vergesellschaftung werden perhorresziert und an den Juden festgemacht. Der moderne Antisemitismus sieht den komplexen, vielgestaltigen, vielschichtigen und widersprüchlichen Modernisierungsprozess von einem realiter nicht existierenden Zentrum aus gesteuert, in dem allen Fäden zusammenlaufen und das diesem Prozess eine auf die Zerstörung der Völker abzielende Richtung gibt. Der moderne Antisemitismus gewinnt seine Triebfeder wesentlich aus dem Unverständnis moderner Vergesellschaftung. Juden und Jüdinnen erscheinen dem Antisemiten demgemäß als eine abstrakte Macht, die die Fäden hinter den Kulissen von Politik, Ökonomie und Kultur zieht.

Bei der Verstädterung und der mit ihr zusammenhängenden Urbanisierung handelte es sich um Ursache, Ausdruck und Produkt eines allgemeinen Modernisierungsprozesses, der alle gesellschaftlichen Teilsysteme affizierte. Das kontinuierliche Anwachsen der großstädtischen Bevölkerung und der modernen industriellen Großstädte war für zeitgenössische Beobachter das sichtbarste und augenscheinlichste Zeichen für die sozialen und kulturellen Umbrüche, die den Übergang von der Agrar- in die Industriegesellschaft geprägt und begleitet haben. In der vom Antisemitismus bestimmten Großstadtwahrnehmung der völkischen Bewegung wurde daher der These, dass die Juden für die Verstädterung verantwortlich seien, einen größeren Platz eingeräumt. In dem untersuchten Material lässt sich wiederholt die Behauptung finden, dass das Anwachsen der Großstädte mit dem Handeln als jüdisch identifizierter Akteure zu tun habe. Der Bedeutungszuwachs der Großstädte wird, wie es Theodor Fritsch pointiert in einem seiner zahlreichen Aufsätze formuliert, nicht als der Ausdruck „eines unaufhaltsamen Zuges der Zeit“ gesehen, sondern als das Produkt dunkler, 
ergo ,jüdischer“ Mächte, die auf den Untergang des deutschen Volkes hinarbeiten würden (vgl. Fritsch 1921: 1-2).

In dem ebenfalls im Hammer erschienenen Text Der Triumph des jüdischen Schrifttums erläutert der namentlich nicht genannte Autor, dass eine jüdische Dominanz in Kultur und Kunst zu einer jüdischen Herrschaft über den „deutschen Geist“ geführt habe. Das jüdische Schrifttum wirke darauf hin, die den Deutschen angeborenen Regungen nach „Ordnung, Recht, Maß, Selbstbeherrschung“ und der Niederhaltung „minderwertiger Instinkte“ zu zerstören. Die geistig-intellektuellen Erzeugnisse jüdischer Literaten sind in der Vorstellung des Autors auf die geistige Verfassung einer großstädtischen Bevölkerung abgestimmt, so dass ein Zusammenhang zwischen einem als jüdisch bezeichneten Intellektualismus und der Verstädterung konstatiert wird:

Wer ist schuld daran, daß sich die Hälfte der Deutschen in Steinwüsten zusammendrängt ohne sicheres Heim, ohne Hoffnung auf irgendeine Bodenverwurzelung, ohne feste Daseinsmöglichkeit, das Elend der kommenden Generation vor Augen? Ganz gewiß nicht der Jude allein! Leute ohne Zukunft und meist auch ohne Vergangenheit, wie sie das großstädtische Proletariat aus allen Schichten darstellt, sehen kaum etwas anderes als die Möglichkeit, dem Augenblicksgenuß zu leben. Menschen, die ein eiskalter Mammonismus und Materialismus in jüdischer Lieblosigkeit nur als Nummern wertet und behandelt, kommen schließlich zu einer Lebensauffassung, die der bürgerlich-christlichen widerstrebt. Das Dasein erscheint ihnen als sinnlose Last. Gar zu leicht sehen sie in jedem Besitz, und sei er noch so redlich in Generationen aufgebaut, das Ergebnis von Raub und Schiebung. Da sie wurzellos sind, stehen sie dem historisch Gewordenen ohne Verständnis gegenüber. Neben der einförmigen Arbeit lieben sie als Ausgleich den Rausch, die Sensation. Auf eine solche Seelenverfassung des unharmonischen, hoffnungslosen Großstädters ist nun das jüdische Schrifttum in erster Linie eingestellt. (o. A. 1926a: 425-426)

Auffällig ist zunächst, dass für die Bezeichnung der Großstädte ein Synonym gewählt wird („Steinwüste“). Die Gleichsetzung von Wüste und Großstadt stellt ein wiederkehrendes Motiv der großstadtfeindlichen Literatur des Kaiserreichs und der Weimarer Republik dar. Es rekurriert auf die These einer in der Wüste vorherrschenden nomadischen Lebensweise, aus der sich das moderne Großstadtleben entwickelt haben soll. Mit dieser These korreliert die weit über völkische Kreise hinaus verbreitete Annahme, dass die Anpassungsfähigkeit von 
Kollektiven und Großgruppen an die Großstädte danach unterschieden werden könne, ob ihre Vorfahren an einem Leben im Wald oder in der Wüste gewöhnt waren. Popularisiert und prominent vertreten wurden diese Vorstellung von Werner Sombart, der - wie bereits gezeigt (vgl. Kapitel 3.3.) - die den Juden unterstellte Bindung an das Großstadtleben mit einer nomadischen Lebensweise erklärte und in den modernen Großstädten die „unmittelbare Fortsetzung der Wüste“" sah (Sombart 1911: 415). Das Narrativ einer wurzellosen und nomadischen Lebensweise in der Wüste und in der Großstadt findet dabei seine Entsprechung in der Vorstellung einer mit dem Bauerntum identifizierten bodenverwurzelten Existenz. Der im ersten Satz des Zitats postulierte Gegensatz zwischen „Steinwüste“ und „Bodenverwurzelung“ entspringt diesem dichotomen Denken.

In dem Zitat werden zwei Kräfte aufgeführt, die auf die Seelenverfassung der großstädtischen Bevölkerung einwirken und die mit dem Judentum identifiziert werden: „Mammonismus“ und „Materialismus“ einerseits, ein als jüdisch apostrophiertes Schrifttum andererseits. Der Autor stellt hierbei eine assoziative Verbindung zwischen Geld, Intellekt, Judentum und Großstadt her, die für die antisemitische Großstadtfeindschaft der völkischen Bewegung insgesamt charakteristisch ist. Dem völkischen Denken gelten Geld und Intellekt als zwischengeschaltete und abstrakte Größen, die dem völkischen Ideal der Bodenverbundenheit nicht nur entgegenstehen, sondern es unmittelbar bedrohen. Wie sich an dem Zitat veranschaulichen lässt, werden die moderne Geldwirtschaft und der Intellektualismus in den Juden personifiziert und zugleich als ein Charakteristikum der Großstädte ausgewiesen.

Das in der Textsequenz zum Ausdruck gebrachte Argument, dass die Großstadt einen direkten Einfluss auf kognitive und psychologische Dispositionen der Großstadtbewohner ausübe, wurde von allen Fraktionen der Großstadtfeinde im Kaiserreich und in der Weimarer Republik geteilt. In der vorgestellten Textsequenz verbindet sich diese großstadtfeindliche These mit dem völkischen Antisemitismus: Die Großstadtbewohner und ihre „Seelenverfassung“ sind einerseits von großstädtischen Lebensbedingungen geprägt, die im Text als jüdisch identifiziert werden (Mammonismus, Materialismus) andererseits wird konstatiert, dass ein als jüdisch bezeichnetes Schrifttum die bereits existierenden psychischen Dispositionen der Großstadtbewohner verstärke und damit die Menschen auf die für sie schädlichen Lebensbedingungen in den Großstädten einstimme.

In einem anderen im Hammer publizierten Aufsatz sieht Fritsch die Rolle einer, wie er es nennt, „semtischen Presse“ darin begründet, das deutsche Volk über sein eigenes Unheil zu täuschen und ihm den Weg in die Verderbnis zu weisen. Die jüdisch dominierte Presse, so 
seine These, locke die Deutschen ,nach der Stadt, wo der Geist der Wüste haust und die Ehrenhaften zugrunde gehen“" (Fritsch 1910: 97).

Die sich hierin ausdrückende Wahnidee, dass Juden und Jüdinnen auf eine zunehmende Verstädterung des deutschen Volkes hinarbeiten würden, wurde in der völkischen Literatur versucht durch Verschwörungstheorien zu belegen. Dies kann an dem Antisemitismus Richard Walther Darrés exemplifiziert werden: Sein Denken kreist um die Vorstellung eines sich durch die Geschichte der Menschheit ziehenden Kampfes zwischen nomadisch veranlagten Juden und bäuerlichen Germanen. Ein wiederkehrendes Motiv in seinen Schriften ist die These, dass jüdische Gelehrte das deutsche Volk glauben machen möchten, dass diese nicht von dem bodenverwachsenen Bauerngeschlecht der Germanen, sondern - wie auch die Juden - von einem nomadischen Wandervolk abstammten. Darré spricht in diesem Zusammenhang davon, dass die Juden das deutsche Bauerntum mit der Intention bekämpften, es zu vernichten (vgl. Darré 1941 [1933/1934]: 71).

In den untersuchten völkischen Texten wird eine der Ursachen dafür, dass das deutsche Volk in seiner Mehrheit kein „wurzelstarkes“ Bauervolk mehr sei, das im Einklang mit der heimatlichen Scholle lebe, in dem Einfluss als jüdisch identifizierter Ideen gesehen, die die Deutschen geistig „entwurzeln“ und sie an das Großstadtleben gewöhnen würden. In der von ihnen ausgemachten geistigen Entfremdung des Volkes von seinem bäuerlichen Ursprung sehen die Völkischen eine der zentralen Voraussetzungen für die dominante Stellung der modernen Großstädte in der Gegenwart. Im Fazit des oben zitierten Textes wird folglich eine Emanzipation vom ,jüdischen Geist“ gefordert. Da diese noch nicht erfolgt sei, so der Autor des Aufsatzes, trügen die Deutschen eine Mitschuld an ihrer Unterdrückung durch die Juden (vgl. o.A. 1926: 426). Die im zweiten Satz der Textsequenz getroffene Aussage, dass die Juden nicht alleine schuld daran seien, dass die Deutschen in den Großstädten lebten, stellt somit keine Relativierung des antisemitischen Aussagehalts dar, sondern verstärkt diesen noch, da sie in der Forderung kulminiert, die jüdische Bevölkerung aus dem öffentlichen Leben zu verdrängen.

\subsubsection{Die entwurzelnde Wirkung von Geld und Handel}

Der Annahme einer durch den ,jüdischen Intellekt“ herbeigeführten „geistigen Entwurzelung“ des deutschen Volkes wird im untersuchten Material die These zur Seite 
gestellt, dass von dem als jüdisch imaginierten Handel und der mit den Juden identifizierten Geldwirtschaft die gleiche Wirkung ausgehen und sie daher unmittelbar mit der Verstädterung zusammenhingen. Ein prägnantes Beispiel hierfür ist der von Darré verfasste Text Zur Wiedergeburt des Bauerntums, der 1931 in der dem Alldeutschen Verband nahestehenden Zeitschrift Deutschlands Erneuerung. Monatsschrift für das deutsche Volk erschien und im Folgenden in seiner Gesamtheit analysiert wird. Die Zeitschrift erschien zwischen 1917 und 1943 in dem für die völkische und antisemitische Bewegung wichtigen Verlag von Julius Friedrich Lehmann (1864-1935) und war eines der publizistischen Flaggschiffe der völkischen Rechten in der Weimarer Republik. Zu den Herausgebern gehörten unter anderem Houston Stewart Chamberlain (1855-1927) und ab 1927 auch der Rassentheoretiker Hans F.K. Günther (1891-1968). Darré, der zum Zeitpunkt der Veröffentlichung des Aufsatzes bereits mit dem Aufbau des agrarpolitischen Apparates innerhalb der NSDAP betraut war, nutzte den Aufsatz dazu, seine Vorstellungen von einer sich auf dem Bauerntum gründenden Gesellschaftsordnung in völkischen Kreisen fester zu verankern.

Darré beginnt den Text mit der Feststellung, dass die durch den Kapitalismus bedingte Abkehr vom Bauerntum zu einer Gegenbewegung in nationalen und völkisch gesinnten Kreisen geführt habe, die er als Bauernromantik bezeichnet. Nach ihm handelt es sich hierbei um eine emotionale Regung, die in dem Moment in einem Volk entstehe, in dem den Menschen klar werde, dass der Kapitalismus die Volkswirtschaft dominiere. Nach Darré handelt es sich bei der Verherrlichung des Bauerntums um eine Geisteshaltung, die nicht die eigentlichen Ursachen für den Niedergang des Bauerntums erkenne und nur die Symptome dieser Entwicklung bekämpfe. Die Ursache hierfür sieht er darin begründet, dass die Ansätze zur Rettung des Bauerntums einem „entwurzelten städtischen Intellektualismus“ entspringen und drohen eine Gefahr zu werden, sollte die völkische Bewegung nicht über die Bauernromantik hinauskommen. Die entscheidende Bedingung für ihre Überwindung und für eine Wiedergeburt des Bauerntums sieht Darré in einer Differenzierung von Ursache und Wirkung im Hinblick auf den von ihm konstatierten Niedergang des Bauerntums. Verantwortlich für die Zerstörung des Bauerntums ist ihm zufolge der Kapitalismus, der die Voraussetzung für den Untergang aller Staaten war, die sich ihm ausgeliefert haben. Dieser unhistorischen Betrachtung der Entwicklung des Kapitalismus lässt Darré eine Definition des Kapitalismus folgen, die diesen auf die Zirkulationssphäre reduziert und damit die Warenproduktion implizit als nichtkapitalistisch ausweist: 
Die dem Kapitalismus zugrunde liegende Arbeitsteilung birgt Darré zufolge die grundsätzliche Gefahr der Herausbildung von Lebensbedingungen „für zwei ganz verschiedene Entwicklungsrichtungen der menschlichen Veranlagung“(Darré 1931: 643): auf der einen Seite ein für die Gütererzeugung veranlagtes Menschentum, dem ein von Natur aus unproduktives Menschentum, das mit der Güterbewegung vertraut ist, auf der anderen Seite gegenübersteht. Der Handel bleibt nach Darré solange ein „Diener der Volkswirtschaft“, wie die Wirtschaft von Männern geführt werde, die ein Verständnis für die Gütererzeugung besitzen. Der für die Güterbewegung veranlagte Händler will Darré zufolge diese Form der ökonomischen Ordnung zerschlagen und ein System etablieren, das nicht der wirtschaftlichen Bedürfnisbefriedigung des Volkes dient. In diesem Zustand findet nach Darré der Handel im Judentum seine Führung, das ,seit Jahrtausenden von der Organisierung der Herrschaft des Handels und der Wege dazu lebt“" (Darré 1931: 643):

Mit dem Augenblick, wo das Judentum sich mit dem Handel verbinden kann, erhält das von Natur aus unproduktive Menschentum im Judentum eine zielbewußte Führung und damit auch die Oberhand in den Kreisen des Handels, dessen Gesetze es von nun an immer stärker beeinflusst.

(Darré

1931:

Von diesem Zeitpunkt an werden nach Darré alle Güter in eine „,bewegliche Ware“ verwandelt und alle Bindungen, die der Mobilisierung des Wertes entgegenstehen, von den Juden gezielt aufgelöst. Betroffen seien hiervon nicht nur materielle Dinge, sondern auch die geistige Verfassung der Bevölkerung.

Die durch das Judentum in Bewegung gesetzten materiellen Güter und geistigen Anschauungen hängen nach Darré unmittelbar mit dem Anwachsen der Städte zusammen. So führt er aus, dass die ökonomische Dominanz des Handels mit einer „Massierung der Menschen an bestimmten Orten vor sich geht“ und hierin „die Wurzel für das Aufblähen der Stadt zu suchen ist“ (Darré 1931: 644). Die durch die Herrschaft des Handels bedingte Abwanderung der Massen in die Städte stellt für Darré eine Gefahr dar, da die Stadt in 
bevölkerungspolitischer Hinsicht steril und ,in jeder Beziehung ein Moloch für die rassische Volkskraft" sei (Darré 1931: 644). Der Zusammenhang zwischen einem als Kapitalismus fetischisierten Handel und der Verstädterung wird von Darré im Anschluss an diese Ausführungen im Text hervorgehoben:

Die Entvölkerung des Landes und die Massierung der Menschen in den sich aufblähenden Städten ist das sicherste Zeichen für den zur Herrschaft gelangten Kapitalismus. Mit unbedingter Sicherheit folgt der Zusammenbruch des betreffenden Staates bei außenpolitischen

Belastungen.

(Darré

1931:

Das Anwachsen der Städte hat nach Darré zur Folge, dass nun nicht mehr ländliches, sondern städtisches Denken der Staatsführung sein Gepränge gibt. Dies ist der Zeitpunkt, an dem sich in den betroffenen Staaten die Bauernromantik heraus entwickelt, an einem Punkt der Entwicklung also, an dem das Volk bereits in hohem Maße verstädtert ist und begriffen hat, „dass sein Untergang besiegelt ist, wenn sein Bauerntum vernichtet wird“ (Darré 1931: 645). Darré wiederholt seine These, dass die Bauerromantik nicht an den Ursachen ansetze, was bedeuten müsste, „die Oberherrschaft des Handels über die Volkswirtschaft erst einmal zu brechen, gesunde volkswirtschaftliche Grundsätze einzuführen und die ganze Volkswirtschaft auf eine Bedarfsbefriedigungswirtschaft umzustellen“ (Darré 1931: 644). Voraussetzung für solch eine Ökonomie sei die Sicherung der Ernährungsgrundlage durch den völkischen Staat, dessen Aufgabe Darré darin sieht, die Ernährung auf der eigenen Scholle sicherzustellen. Darré schlussfolgert hieraus, dass die Schaffung eines „wahrhaft völkischen Staats“ davon abhängt, dass dieser, wie auch Industrie und Handel, auf dem Fundament einer starken Landwirtschaft aufgebaut wird. Die Errichtung von ländlichen Siedlungen und Eigenheimen kann für Darré erst nach der Zerschlagung des Kapitalismus ihre rassenhygienische Wirkung entfalten, da diese dann die selbstverständlichen Ergebnisse eines ,auf den Grundsätzen der Arbeit und nicht des Handels aufgebauten Staates“ seien: „Siedlungen und Eigenheime sind dann die Folge wirtschaftlicher Vernunft und sozialen Friedens, nicht deren Ursache“ (Darré 1931: 646).

Darrés Ausführungen über den Zusammenhang zwischen der Herrschaft eines als wurzellos und als jüdisch beschriebenen Handels und einer Entwurzelung und Verstädterung der Menschen, beruhen wesentlich auf dem von Postone beschriebenen fetischisierten 
Antikapitalismus. Diejenigen Aspekte des kapitalistischen Verwertungsprozesses, die dem völkischen Denken als bodenverwachsen und produktiv gelten, wie die mit körperlicher Arbeit assoziierte Industriearbeit und das klein- und mittelständische Handwerk, werden zu Eigenschaften des deutschen Volkes erklärt und von einem mit dem Judentum identifizierten Kapitalismus abgespalten. Der Zirkulationssphäre der Kapitalverwertung - Geld, Handel, Finanzkapital - schreibt Darré hingegen eine entwurzelnde Wirkung und einen direkten Einfluss auf die Entstehung der modernen Großstädte zu. An seinem Text Zur Wiedergeburt des Bauerntums lässt sich exemplarisch aufzeigen, dass es im völkischen Denken einen Zusammenhang zwischen der Großstadtfeindschaft und einem fetischisierten Antikapitalismus gibt.

Zusammenfassung der ersten Kategorie

Geld und Intellekt fungieren im völkischen Denken als dem Großstadtleben zugerechnete Antipoden zu einer bodenverwachsenen Existenz, die die Völkischen durch das Bauerntum verkörpert sehen. Die moderne Geldwirtschaft und der Intellektualismus und das mit ihnen in Verbindung gebrachte abstrakte und wurzellose Denken sind in der Vorstellungswelt des völkischen Antisemitismus den Deutschen wesensfremd und ein Instrument des Judentums zur „Zersetzung“. Die Behauptung des Einflusses eines antisemitisch konnotierten Mammonismus und Intellektualismus auf das Geistesleben in Deutschland wird in dem untersuchten empirischen Material für den Bedeutungszuwachs und die steigende Akzeptanz der Großstädte verantwortlich gemacht und zugleich als der Hauptgrund gesehen, wieso das deutsche Volk sich von seinem bäuerlichen Ursprung entfernt habe. Juden erscheinen dabei als die handelnden Subjekte hinter dem sich ab der Mitte des 19. Jahrhunderts in Deutschland vollziehenden Prozesses der Verstädterung und Urbanisierung. Sie werden in der völkischen Literatur als das wahrgenommen, wie es Postone treffend formuliert hat, „was hinter dem ,Asphaltdschungel' der wuchernden Metropolen, hinter der ,vulgären, materialistischen, modernen Kultur' und generell, hinter allen Kräften, die zum Niedergang althergebrachter sozialer Zusammenhänge, Werte und Institutionen führen, steht“ (Postone 1982: 15). 
8.2. Unterschiedliche Anpassungsfähigkeit von Juden und Deutschen an die Großstadt

8.2.1. Der nichtstädtische Charakter der Germanen

In der sozialwissenschaftlichen Antisemitismusforschung ist in den letzten Jahren der Fokus verstärkt auf die Komplementarität von antisemitischem Judenbild und dem Selbstbild der den Antisemitismus artikulierenden Wir-Gruppe gelenkt worden. Klaus Holz, der die Bedeutung dieses Zusammenhangs für die semantische Analyse nationaler Artikulationsformen des Antisemitismus aufgezeigt hat, führt diesbezüglich aus, dass Fremdbilder nur angemessen analysiert werden können, „wenn man das komplementäre Selbstbild berücksichtigt. Fremdbilder dienen als Gegenbegriffe für die Konstruktion von Selbstbildern“ (Holz 2004: 45). Die in dem untersuchten Material wiederholt vorkommende Behauptung, dass die Deutschen ihrem Wesen und ihrer Entwicklung nach für das Großstadtleben ungeeignet seien, kann vor diesem Hintergrund als die Kehrseite der in den völkischen Texten vorgenommenen Assoziation der Juden mit dem Großstadtleben gesehen werden. Das antisemitische Konstrukt des ,jüdischen Urbantyps“ (vgl. Schlör 1995) findet in der Darstellung des bäuerlichen und nichtstädtischen Charakters der Deutschen seine Entsprechung.

Die im Material wiederholt vorgefundene These einer Unvereinbarkeit des deutschen Volkes mit dem Stadtleben ist dabei verbunden mit einer Interpretation der Geschichte der Germanen, die dazu dient, dieser Distanz eine historische Tiefe zu geben. Hierin drückt sich eine in der völkischen Bewegung festverankerte Germanenideologie aus, die auf der Überzeugung basiert, dass das deutsche Volk Rassenmerkmale der Germanen Unverfälschtheit, Ursprünglichkeit und Jugendlichkeit - geerbt habe (vgl. Puschner 2001: 9299).

Zugleich ist der Bezug auf die Geschichte der Germanen Teil einer rechtsextremen ${ }^{28}$ bzw. völkischen Geschichtspolitik. Nach Samuel Salzborn (2014: 25-28) setzt sich die

${ }^{28}$ In der Forschung besteht keine Einigkeit darüber, ob sich der Begriff des Rechtsextremismus auf antidemokratische und rechte Bewegungen und Parteien des Kaiserreichs und der Weimarer Republik rückdatieren lässt. Von einigen Forschern und Forscherinnen wird der Begriff ausschließlich als ein Sammelbegriff für rechts-nationale, rassistische und neonazistische Parteien, Organisationen und Bewegungen verwendet, die nach 1945 entstanden sind. Die von mir vorgenommene Einstufung der völkischen Bewegung als rechtsextrem basiert auf ihrer Selbstwahrnehmung als einer nationalistischen und oppositionellen Kraft im Kaiserreich und im Besonderen im politischen System der Weimarer Republik. Der hier verwendete Rechtsextremismusbegriff grenzt sich bewusst von einer extremismustheoretischen Sichtweise ab, wie sie von den Politikwissenschaftlern Eckhard Jesse und Uwe Backes (vgl. 1996) vertreten wird und auf der Annahme 
Geschichtspolitik im Rechtsextremismus aus drei Bestandteilen zusammen: Erstens einem Phantasma im Sinne einer Phantasie über die Wirklichkeit, wie sie hätte sein sollen bzw. sein müssen. Die Formen der Geschichtsinterpretation reichen dabei von einer Dekontextualisierung bis zur Leugnung von historischen Fakten. Das konstruierte Geschichtsbild kann Teilelemente der tatsächlichen Geschichte enthalten, aber auch gänzlich darauf verzichten. Die rechtsextreme Geschichtspolitik basiert zweitens auf der Bildung eines homogenen Kollektivs. Sie zielt auf eine Homogenisierung und Kollektivierung der Erinnerung, die Widersprüche und Ambivalenzen innerhalb des Kollektivs negiert und damit die Freiheit des Individuums suspendiert. Hiermit hängt drittens die Stiftung einer historischen Identität zusammen, die keine individuellen Identitätsangebote zulässt, sondern nur eine kollektive Zwangsidentität, bei der Individual- und Kollektiverinnerung in eins fallen. Die homogenisierte Vergangenheit wird so zu einer kollektiven Utopie umgedeutet. Zusammenfassend stellt Salzborn fest, dass der Umgang mit der Vergangenheit im Rechtsextremismus ,als Legitimation des eigenen Handels, als Vision für die Zukunft und als Appell zur binnenstrukturellen Festigung“ dient (Salzborn 2014: 25).

Exemplarisch für eine die Großstadtfeindschaft legitimierende Bezugnahme auf die germanische Geschichte, die nach 1933 schließlich zur Legitimationsgrundlage für eine rassistische Bauern- und Agrarpolitik wurde (vgl. Kapitel 4.5.), steht die folgende Textstelle aus dem Buch Neuadel aus Blut und Boden von Richard Walther Darré. Sie ist dem Kapitel entnommen, das von den Möglichkeiten der Errichtung eines neuen Adels nach altgermanischem Brauch handelt, der sich aus dem auf sogenannten Hegehöfen lebenden deutschen Bauerntum rekrutieren soll. In dem Begriff des Hegehofes, so Darré, kommt „das zu Hegende an Blut und Boden unmißverständlich zum Ausdruck“ (Darré 1930: 54). Die Stadt wird im Gegensatz dazu in einer überhistorischen Perspektive als eine Lebensumwelt beschrieben, die in seelischer und physischer Hinsicht ungünstige Bedingungen für die Aufzucht rassisch hochwertiger, germanischer Kinder darstellt:

basiert, der politische Extremismus sei kein sozial erklärbares Phänomen, sondern eine pathogene Abweichung von einer normativ bestimmten demokratischen Mitte. 
Tatsache ist ja jedenfalls, daß die germanische Familie ohne das ausgleichende Gegengewicht vorhandenen Landbesitzes noch niemals in der Stadt oder in sonstwie vom Landleben losgelösten Verhältnissen auf längere Zeit zu blühen bzw. sich am Leben zu erhalten vermochte. [...] Andere Rassen und Völker scheinen für das von Grund und Boden und dem Landleben losgelöste Dasein der Stadtbevölkerung entwicklungsgeschichtlich besser vorbereitet worden zu sein, vielleicht, weil ihre Ahnen einmal als Nomaden an unstete Lebensweise und an steinreiche Wüsten bzw. baumlose Steppen ohne Grün und Waldstriche gewöhnt worden sind. Für die Germanen treffen solche entwicklungsgeschichtlich günstigen Vorbedingungen für das städtische Leben nicht zu, und seit wir den Germanen in der Geschichte kennen, haßt er, wohl aus einem gesunden Gefühl heraus, die Stadt mit allen Fasern seines Herzen. Wo der Germane zum Städter wurde, ist dies offensichtlich immer zwangsweise geschehen und ist ihm ohne das Gegengewicht eines Landbesitzes auch nie gut bekommen. (Darré 1930: 52-53)

An der Textstelle fällt auf, dass Darré unterschiedliche Begründungen für die Unvereinbarkeit der Germanen mit dem Stadtleben aufführt. Im ersten Satz wird die mangelnde Anpassungsfähigkeit an die Stadt zu einem unveränderbaren Rassenmerkmal der Germanen erklärt. Sie wird als eine Eigenschaft diskutiert, die die Germanen schon immer geprägt habe und die ihnen als „Rasse“ und Volk von sich aus zukomme. Wie es für die völkische Großstadtfeindschaft insgesamt charakteristisch ist, wird in dem ersten Satz die Differenz zwischen einer städtischen und ländlichen Lebensumwelt als eine existentielle Frage für den Fortbestand der „germanischen Rasse“ und des deutschen Volkes gedeutet.

Im zweiten Satz der Textsequenz wird das Verhältnis der Germanen zur Stadt in Relation zu anderen „Rassen“ und Völkern gesetzt, die sich von ihnen darin unterscheiden würden, dass sie auf die städtischen Lebensverhältnisse besser vorbereitet worden seien. Die Ursache für die unterschiedliche Anpassungsfähigkeit an das Stadtleben begründet Darré in diesem Fall mit einer Milieutheorie und der dazugehörigen Annahme einer gruppenspezifischen Gewöhnung an eine tradierte Lebensweise und Lebensumwelt. Er schließt dabei an den weitverbreiteten Topos der nomadischen Lebensweise in der Wüste als des entwicklungsgeschichtlichen Ursprungs der städtischen bzw. großstädtischen Lebensweise an.

Im vorletzten Satz (Z 7-10) verschiebt sich der Fokus der Argumentation zurück zu einer rassenbiologischen Deutung der These von einer Unvereinbarkeit der Germanen mit dem Stadtleben. Der Hass der Germanen gegen die Städte, der Darré zufolge aus einem ,gesunden Gefühl“" heraus entstehe, wird als eine Eigenschaft diskutiert, die den Germanen von Natur aus zu eigen ist und damit angeboren und vererbt sei. Dieser biologische Determinismus 
schließt die Möglichkeit einer historisch bedingten Anpassung der Germanen an das Stadtleben im Sinne einer Umwelt- und Milieutheorie aus.

Die in der zitierten Textstelle zum Ausdruck kommende Argumentation läuft darauf hinaus, die Germanen zu derjenigen „Rasse“ bzw. die Deutschen zu demjenigen Volk zu erklären, das im Unterschied zu allen anderen Völkern und „Rassen“ die geringste Anpassungsfähigkeit an das Stadtleben besitzt und die größte Distanz zu den Städten einnimmt. Der letzte Satz unterstreicht dieses Argument ein weiteres Mal, in dem Darré hervorhebt, dass die Germanen in ihrer Geschichte stets gegen ihren Willen zu Stadtbewohnern gemacht worden seien. Das Stadtleben und die Verstädterung werden somit als Phänomene beschrieben, die den biologisch determinierten Lebensgesetzen der Germanen wiedersprächen und diametral entgegenstünden.

\subsubsection{Die Großstadt als „Rassengrab“ und als Ort negativer Selektion}

Die Annahme eines schädlichen Einflusses der Großstadt einerseits und einer Unvereinbarkeit des deutschen Volkes mit dem Stadtleben andererseits bildet die Grundlage für das im untersuchten Material am häufigsten auftretende Argument der völkischen Großstadtfeindschaft: Völkische Autoren sind sich darin einig, dass das deutsche Volk in den Großstädten aussterbe und die Verstädterung daher zu einem biologischen Substanzverlust an Volk und Nation führt. Die Autoren der analysierten Texte stimmen darin überein, dass die Bevölkerung der Großstädte in wenigen Generationen aussterben werde, sollte der stetige Zuzug von Menschen aus den ländlichen Gegenden ausbleiben. Die These von einer „,volksverzehrenden“ Wirkung der Großstädte findet in den Texten ihren Ausdruck in einer drastischen und unmissverständlichen Bildersprache: So bezeichnet Fritsch die Großstadt als eine „Auslebungs- und Verwüstungs-Stätte der völkischen Kraft“ und als den „großen Totenacker der Nationen“ (Fritsch 1914: 286). Darré prägt den widersprüchlichen Begriff von der Großstadt als einer „Unfruchtbarkeitsmaschine“ (vgl. Darré 1929: 72). An anderer Stelle im Hammer werden die Großstädte als das ,seelische und wirtschaftliche Grab der blonden und germanischen Rasse“ (Lanz-Liebenfels 1910: 456) und als „Verbrennungsherde der nationalen Kraft" beschrieben (o.A. 1912: 57). Willibald Hentschel (1906: 251) fasst diese Überlegungen in dem Satz zusammen: „Der Städter ist der aussterbende Mensch“. 
Die empirische Untersuchung zeigt zugleich, dass der Landbevölkerung die Fähigkeit abgesprochen wird, die Großstadtbevölkerung auch in Zukunft durch Zuwanderung zu erneuern. Begründet wird dies einerseits mit dem quantitativen Rückgang des Anteils der Landbewohnerschaft an der Gesamtbevölkerung und andererseits mit einer qualitativen Verschlechterung der genetischen Veranlagung der Landbevölkerung. In Anlehnung an Otto Ammon wird angenommen, dass rassisch besonders hochwertige, begabte und tüchtige Bevölkerungsgruppen in die Großstädte abwanderten und dass unter ihren stadtgeborenen Nachkommen ein starker Geburtenrückgang zu verzeichnen sei, während Bevölkerungsteile mit einem schlechteren Erbgut eine hohe Geburtenrate aufweisen würden.

Sah Ammon in diesem Prozess noch eine natürliche Auslese am Werk, wird er im völkischen Diskurs als eine negative Selektion oder als eine „Gegenauslese“ bezeichnet. Die Feststellung einer differentiellen Geburtenrate zwischen der Ober- und Mittelschicht einerseits und der Unterschicht andererseits führte seit den 1870er Jahren unter Eugenikern zu der Annahme eines dramatischen Degenerationsprozesses (vgl. Weingart et al. 1988: 18-19). Wie Weingart et al. (1988: 19) hervorheben, ermöglicht die ideologische Ambivalenz der Rassenhygiene und Eugenik sowohl einen Fortschrittsoptimismus im Sinne einer Utopie der Höherentwicklung als auch die kulturpessimistische Deutung eines Degenerationsprozesses.

Die Verbindung dieser beiden Pole findet sich in der rassenhygienischen Betrachtung der Bedeutung der Großstädte in dem Text Bauerntum als Bluterneuerungsquell des NSPublizisten und Hochschullehrer Johann von Leers (1902-1965) ${ }^{29}$, der bereits unter dem Eindruck der nationalsozialistischen Agar- und Bauernpolitik verfasst wurde und ein Plädoyer für die Agar- und Rassenpolitik des Ernährungs- und Landwirtschaftsministers Darré darstellt:

\footnotetext{
${ }^{29}$ Von Leers gehörte zu den „produktivsten“ antisemitischen Publizisten der NS-Zeit und verfügt über eine schillernde Vita. Politisch sozialisiert in der völkischen und nordischen Bewegung der 1920er Jahre, trat er 1929 in die NSDAP ein, wurde Mitglied der SS, Herausgeber der zwischen 1933 und 1937 erschienenen Zeitschrift Nordische Welt und erhielt 1940 eine ordentlicher Professor für „Geschichte auf rassischer Grundlage“ an der Universität Jena. 1956 übersiedelte er nach einer Zwischenstation in Argentinien nach Kairo, konvertierte zum Islam und arbeitete als Übersetzer an der Verbreitung antizionistischer und antisemitischer Propaganda des ägyptischen Staats mit (vgl. Finkenberger 2008, 2011).
} 
Ohne den bäuerlichen Kindereichtum muß Deutschland sterben. Neben dieser quantitativen Bedeutung für unsere Bevölkerungspolitik besitzt das Bauerntum auch einen qualitativen geburtenpolitischen Wert. Zwar ist die Erbmasse an sich unveränderlich. Aber die Großstadt übt durch ihre widernatürlichen Lebensbedingungen, die z.B. das kriminelle und manches andere Untermenschentum begünstigen, auch eine erbwertmäßige Gegenauslese aus, d.h. sie wählt durch entsprechende Vermehrung nicht das gute, sondern das schlechte Menschenmaterial aus. [...] Hinzu kommt in gewissem Sinne eine rassenwertmäßige Gegenauslese der Großstadt. Denn sie tötet den natürlichen Rasseinstinkt und fördert dadurch unerwünschte Rassenmischung. Ehen zwischen Deutschen und Juden oder Negern, die in der Großstadt vorkommen, sind auf einem gesunden Bauernhof oder in einer gesunden Landarbeiterfamilie unmöglich. Ebenso ermöglicht die Stadt in verstärktem Maße Ehen zwischen einem erbgesunden Mann und einer erbkranken Frau oder umgekehrt, weil die Lebensverhältnisse eines kinderlosen Beamten in einer 2,5-Neubauzimmerwohnung mit Zentralheizung und elektrischer Waschküche auch eine kranke Frau gestatten. Ein ländlicher Haushalt dagegen ist ohne eine gesunde Frau unmöglich. In besonderem Maße lähmt die Großstadt den Lebenswillen der nordisch-fälischen Grundrasse des deutschen Volkes, so daß eine ganz bestimmte und nicht erwünschte Rassenverschiebung (Günther) dadurch eintritt, daß die Grundrasse wenig Kinder hat und bestimmte Einschlagrassen viele Kinder haben. Denn die städtischen Umweltverhältnisse sind den letzteren anscheinend günstig. Zwar zieht die Stadt infolge ihrer geistig-kulturellen Rolle immer wieder bestes Menschenmaterial an; aber sie verdammt es durch ihre widernatürlichen Lebensbedingungen gleichzeitig zu Kinderarmut und Kinderlosigkeit, d.h. zum Aussterben, ohne das als Fluch zu empfinden. (Leers 1935: 214215)

Wie es für die völkische Großstadtfeindschaft insgesamt charakteristisch ist, werden im ersten Abschnitt bis zur Auslassung (Z 1-7) sowohl die quantitative als auch die qualitative Bedeutung des Bauernstandes für eine völkische Bevölkerungspolitik hervorgehoben. Das Bauerntum wird als Größe dargestellt, die sowohl den Geburtenrückgang der großstädtischen Bevölkerung als auch eine als Degenerationsprozess verstandene Vermehrung minderwertiger Bevölkerungsgruppen durch die Zufuhr an gesunden Menschen zu kompensieren habe. Hinter dem zweiten Aspekt steht der Gedanke, dass als rassisch minderwertig eingestufte Bevölkerungsgruppen - Leers bezieht sich in diesem Zitat auf „Kriminelle“ - in einer ländlichen Lebensumwelt nicht überlebensfähig seien und nur in großstädtischen Lebensverhältnissen eine Existenzgrundlage fänden. Die sich in dem Zitat ausdrückende Idee einer ländlich-bäuerlichen Rassenzucht markiert die „positive“ Seite der völkischen Eugenik 
und Rassenhygiene, deren Kehrseite die Ausmerzung als „minderwertig“ erachteten Lebens bildet.

In Zeile 7-11 wird die „Rassenmischung“ als ein weiterer Aspekt der großstädtischen „Gegenauslese“ eingeführt, die als ein ausschließlich großstädtisches Phänomen beschrieben wird. Zwei Interpretationen sind im Hinblick auf die These möglich, dass eine „Rassenmischung“ auf einem Bauernhof nicht möglich sei: entweder weil es in der Vorstellung des Autors keine Juden und als „Neger“ inkriminierte Menschen auf dem Land gibt oder weil der „Rasseinstinkt““, im Unterschied zur Großstadtbevölkerung, in der Landbevölkerung noch in Takt ist. Da der Topos der „Rassenmischung“ mit einem Verschwinden des „Rasseinstinkts“ verbunden wird (Z 7-9), liegt es nahe, dass Leers in diesem Zusammenhang von unterschiedlichen kognitiven Dispositionen der Land- und Stadtbevölkerung ausgeht. Hierbei handelt es sich um einen für die Großstadtfeindschaft zentralen Begründungszusammenhang, wie auch die These von der Schädlichkeit einer Vermischung von „Rassen“ zu den Grunddogmen der Rassenhygiene gehört (vgl. Weingart et al. 1988: 102).

In den darauffolgenden beiden Sätzen (Z 11-15) wandert der Fokus erneut auf die Form der „Gegenauslese“, die sich in dem Verständnis von Leers innerhalb der deutschen Bevölkerung vollzieht. In diesem Fall wird eine konkrete Ursache für die „Gegenauslese“ benannt: Die Eheschließung zwischen „erbgesunden“ und „,erbkranken“ Menschen hängt Leers zufolge mit einer Überzivilisierung der großstädtischen Lebensweise zusammen, die eine natürliche Selektion, wie sie auf dem Land existiere, verhindere. Mit dem Verweis auf das Ausstattungsniveau großstädtischer Wohnungen wird ein soziologisches Argument eingeführt.

Im darauffolgenden Satz greift Leers zum zweiten Mal die Behauptung eines unmittelbaren Einflusses der Großstadt auf kognitive Dispositionen der Großstadtbevölkerung auf („Lebenswille“) und erklärt den Umstand, dass die „nordisch-fälische Grundrasse“ in den Großstädten weniger Kinder bekomme als die sogenannten „Einschlagrassen“, zu einer nicht näher erklärungsbedürftigen Eigenschaft dieser „Rassen“. Dies veranschaulicht, dass die für die Großstadtfeindschaft wichtige These eines Zusammenhangs zwischen großstädtischer Umwelt und kognitiven und psychischen Dispositionen der sie bewohnenden Subjekte sowohl mit sozialen, wie mit nichtsozialen, biologistischen Faktoren erklärt werden kann, ohne dass diese sich ausschließen. 
In Zeile 14-22 artikuliert sich schließlich eine mit der Großstadtfeindschaft eng verbundene Untergangsprophezeiung: Die „nordische Rasse“, verstanden als die „Grundrasse des deutschen Volkes“, ${ }^{30}$ sterbe in den Großstädten aus. Leers schließt hierbei an die Großstadtfeindschaft der nordischen Bewegung an, vor allem an die Ausführungen des namentlich genannten Hans F.K. Günther in seinem kurz vor Leers Artikel erschienene Buch, in dem dieser sich mit den Gefahren der Verstädterung auseinandersetzt (vgl. Günther 1934).

\subsection{3. „Zersetzung“ völkischer Identität in den Großstädten}

In einem engen Zusammenhang mit der Annahme einer Veränderung kognitiver Dispositionen der Großstadtbevölkerung steht die These, dass die Deutschen in den Großstädten ihre völkische Identität verlören. Modernes Großstadtleben und deutsche bzw. völkische Identität werden hierbei zu einem Widerspruch erklärt. So hält Fritsch in einem seiner Texte fest, dass „,die Charakterzüge und Lebenssitten, die einst den Stolz des deutschen Wesens ausmachten“ heutzutage ,,am wenigsten in dem chaotischen Trubel und den TollhausGefahren der Großstadt“ zu finden seien (Fritsch 1926: 585).

Dem deutschen Volk bzw. der „germanischen Rasse“ wird dabei die geringste Anpassungsfähigkeit an das Stadtleben attestiert. Wie bereits dargelegt wurde, differieren die Annahmen über den Grad der Anpassungsfähigkeit zwischen den verschiedenen „Rassen“ und Völkern im völkischen Denken. Auf diesen Zusammenhang stellt die folgende Textsequenz ab, die dem Text Rassentod und Semitismus entnommen ist, den der Schriftsteller Walther August Gottfried Kabel (1878-1935) unter dem Pseudonym Weka veröffentlichte. Der Aufsatztitel bezieht sich auf die These, dass eine verderbliche Sexualmoral zu einer „rassischen Entartung“ der Germanen führe, in deren Folge es zu einer „Rassenmischung“ mit Juden und Jüdinnen komme, die für den Autor den Typus des „Entartungsmenschen“ verkörpern. Kabel plädiert infolgedessen dafür, dass das von der Zeitschrift Hammer initiierte Siedlungsprojekt Heimland nur Deutschen die Mitgliedschaft gewähren solle, die geistig und moralisch gesund seien. Über das moderne Großstadtleben ist im Text hingegen zu erfahren:

\footnotetext{
${ }^{30}$ Hans F.K. Günther, auf den sich Leers bezieht, spricht davon, dass die „nordische Rasse“ im Gesamtdurchschnitt $60 \%$ des „deutschen Blutes“ ausmache, wobei der Anteil in der nördlichen Hälfte des deutschen Sprachgebiets 70\% und in der südlichen Hälfte etwas 50\% beträgt. Der Anteil der deutschen Bevölkerung, die als „reinrassig“ nordisch gelten könne, liegt ihm zufolge bei 10\% (vgl. Günther 1922: 186187).
} 
Dazu kommt noch, daß gerade der Germane, als eine hoch-organisierte Art, im modernen Städteleben am ersten entartet. Er degeneriert schon dort, wo die Sitten- und LebensVerhältnisse dem gröber organisierten Slaven oder Romanen noch ganz zuträglich sind. Man sehe sie sich einmal an, die Bewohner unserer auf germanischem Rassengrunde aufgebauten Großstädte. Sind diese blutleeren kraftlosen Gestalten mit den ausgezehrten Gesichtern und den glanz- und seelenlosen Augen wirklich noch Germanen zu nennen? Sie sind die Schlacken von solchen, nichts weiter, und sie kommen für die Rasse der Zukunft nicht mehr in Betracht. Sie sind auf dem Wege, Semiten, Neu-Juden zu werden; und einer der Bahnbereiter zu diesem Ziele ist die geschlechtliche Ausschweifung. (Weka 1909:

Im ersten Satz wird die These proklamiert, dass die Germanen im modernen Stadtleben zuerst „entarten“ würden. Hierin drückt sich eine Relation aus, die im zweiten Satz konkretisiert wird: Slaven und Romanen werden als andere „Rassen“ eingeführt, die in städtischen Lebensverhältnissen nicht „degenerieren“, die für die Germanen bereits schädlich seien und zur „Entartung“ und „Degeneration“ führten. Das Adverb „noch“ in Zeile drei verweist darauf, dass auch diese Gruppen bei einer Verschärfung bzw. Verschlechterung der städtischen Sitten- und Lebensverhältnisse „,degenerieren“ würden. Die verschiedene Anpassungsfähigkeit von Germanen einerseits und Romanen/Slaven andererseits wird daher als ein gradueller Unterscheid gedacht. Es handelt sich hierbei um eine symmetrische Zuschreibung askriptiver Merkmale. Diese symmetrische Unterteilung von „Rassen“ wird in Zeile 8-9 in Bezug auf die Juden um eine asymmetrische Zuschreibung erweitert und ergänzt: Es wird behauptet, dass die Bewohner der Großstädte zu „Neu-Juden“ würden, womit die vorab getroffene Feststellung eines degenerierenden Einflusses der modernen Großstädte auf verschiedene „Rassen“ für Juden nicht zutrifft. Juden sind in dieser Logik das/die einzige Volk/Rasse/Nation, dem/der das moderne Großstadtleben nicht schadet.

Antisemiten sehen in den Juden insofern kein beliebig anderes Volk oder eine andere Nation oder „Rasse“, sondern sie gelten dem Antisemitismus als die Verkörperung von NichtIdentität und der Möglichkeit einer Aufhebung der Ordnung der Welt nach rassischen und/oder nationalen Kategorien. Juden und Jüdinnen fungieren im antisemitischen Diskurs daher, wie es Klaus Holz herausgearbeitet hat, als die Figur des Dritten (vgl. Holz 1998, 2004, 2010; Holz/Weyand 2015). Juden werden von den Antisemiten zwar auch als ein Ethnos bestimmt - wahlweise als Volk, Nation, oder „Rasse“ - das über einen Nationalcharakter verfügt; insofern handelt es sich um eine symmetrische Unterscheidung in Abgrenzung zu der 
eigenen Wir-Gruppe. Auf der Ebene der Zuschreibungen wird diese Symmetrie jedoch gebrochen: Juden wird ein Anti-Ethos zugeschrieben, das das Ethos anderer Völker untergrabe. In der Vorstellung der Antisemiten besteht das innere Band der Juden aus Prinzipien, die auf alle anderen Völker ,zersetzend“ wirken. Ihnen werden von den Antisemiten Eigenschaften zugeschrieben, die das eigene Volk und alle anderen Völker materiell und ideell zersetzen (vgl. Holz/Weyand 2015: 174-175). Dieser Aspekt spiegelt sich in der völkischen Großstadtwahrnehmung, wie sie in der zitierten Textstelle zum Ausdruck kommt, wider: Die Anpassung an die modernen Großstädte, die als eine Eigenschaft der Juden gesehen wird, führe bei anderen „Rassen“ (Germanen, Slaven und Romanen) zu einer Entartung und Degeneration.

Die jüdische Identität bzw. Nicht-Identität kann daher nur als zweideutig, wurzellos, unfassbar und zersetzend vorgestellt werden (vgl. Holz 1998: 15). Diese Eigenschaften und Zuschreibungen konstituieren im antisemitischen und völkischen Denken die Figur des Juden als Großstadtbewohner par excellence. Die Aussage in Zeile 8, dass die Bewohner der Großstädte zu „Neu-Juden“ würden, meint vor diesem Hintergrund, dass sie eine neue Identität erlangen würden - eben eine ,jüdische“ - die zugleich jedoch eine Nicht-Identität ist, da in den Großstädten die Herausbildung und Festigung einer nationalen und rassischen Identität im völkischen Sinne nicht möglich sei. Sieferle hat in diesem Zusammenhang hervorgehoben, dass in der völkischen Vorstellung von Gemeinschaft der Mensch seine Identität durch die Teilhabe an der Einheit von Volk und Heimat erhalte, wobei Heimat gleichbedeutend mit Landschaft sei. Geht diese Bindung verloren „so bedeutet dies für ihn den Untergang, das Versinken in der Beliebigkeit und Leere einer amorphen Großstadtkultur, die keine eigentümliche Heimat mehr bietet und in der Teilhabe an völkischer Gemeinschaft nicht mehr möglich ist“" (Sieferle 1984: 187-188).

An dieser Textstelle lässt sich zugleich veranschaulichen, dass die Konstitutionsbedingungen des modernen Antisemitismus in keiner relevanten Relation zur Existenz der jüdischen Bevölkerung stehen. In diesem Fall wird explizit kein Bezug zu real existierenden Juden und Jüdinnen hergestellt. Der Fokus ist auf eine Gruppe von Nicht-Juden gerichtet, die Gefahr laufe ,jüdisch“ zu werden. Die Konstruktion des antisemitischen Judenbildes ist insofern von jeder historischen und empirischen Erfahrung von jüdischer Geschichte oder den Eigenschaften der jüdischen Bevölkerung oder einzelner Juden abgekoppelt. Sartre fand für diese für das Verständnis des modernen Antisemitismus wichtige Erkenntnis die pointiere Formulierung: „Wenn es den Juden nicht gäbe, der Antisemit müsste ihn erfinden“ (Sartre 
2010 [1944]: 12). Der Antisemitismus richtet sich historisch betrachtet zwar nicht zufällig gegen Juden und Jüdinnen; die antisemitische Projektionsorientierung ist jedoch letztlich willkürlich, da sie sich, mit Parsons (1969: 118) gedacht, der den Antisemitismus als eine „free floating agression“ beschreibt, auch gegen andere Personengruppen richten kann. Salzborn hebt hervor, dass die historische Entwicklung des modernen Antisemitismus durch eine Abstraktionsleistung gekennzeichnet ist, in deren Folge Juden und Jüdinnen als Projektionsobjekte durch ein fiktives und völkisch bestimmtes Judenbild substituiert wurden, das „lediglich durch die Antisemit(inn)en definiert wird“ (Salzborn 2010: 320).

Im letzten Satz der Textsequenz wird schließlich auf die Hauptthese des Textes Bezug genommen und der Prozess der Entartung und Degeneration in den Großstädten in einen Kausalzusammenhang mit einer ,geschlechtlichen Ausschweifung“ gebracht. Ein Verweis auf diese These findet sich bereits in Zeile 2, in der ein direkter Zusammenhang zwischen einem Degenerationsprozess und vorherrschenden Sitten- und Lebensverhältnissen behauptet wird. Hierbei zeigt sich ein zentraler Aspekt völkischer Großstadtfeindschaft, der im nächsten Kapitel näher analysiert wird: die Verbindung der völkischen Großstadtfeindschaft mit einer ausgeprägten Lust- und Sexualitätsfeindlichkeit.

\subsubsection{Anpassungsfähigkeit der Juden an die Großstadt}

Die in der vorhergehenden Textsequenz zum Ausdruck kommende Ansicht, dass den Juden das Großstadtleben im Unterschied zu anderen Völkern oder „Rassen“ nicht schade, wird in den völkischen Texten des Untersuchungsmaterials auch expressis verbis erklärt. Die Anpassungsfähigkeit der Juden an die Umweltbedingungen der Großstädte wird dabei in einen Kontrast zu der mangelnden Anpassungsfähigkeit der Deutschen gestellt, was eine dichotomische Gegenüberstellung des urbanen Charakters der Juden und des nichtstädtischen Charakters der Deutschen zur Folge hat.

Darré bringt diese Vorstellung prägnant auf den Punkt, wenn er in einem seiner Texte erklärt, dass der „Lebensverbundenheit des deutschen Volkes mit Grund und Boden“ das Judentum, „welches immer in städtischen Verhältnissen gelebt habe, polar gegenüberstehe“ (Darré 1941 [1931]: 55). Für die Erklärung der entgegengesetzten Eignung von Deutschen und Juden für das Großstadtleben werden verschiedene Begründungszusammenhänge miteinander verbunden, wie aus der folgenden Textsequenz ersichtlich wird, die aus dem Text Biologische 
Vorteile der jüdischen Nation von Ludwig Neuner entnommen ist. Die den Juden zugeschriebene Anpassungsfähigkeit an das Großstadtleben wird in diesem Text als entscheidende Voraussetzung für die den Juden unterstellte Allmacht diskutiert:

Häufig wurden sie in besondere Stadtviertel verwiesen und das flache Land blieb ihnen meistens als dauernder Aufenthalt ganz verschlossen. Das entsprach übrigens durchaus ihrer eigenen Abneigung gegen schwere körperliche Arbeit und ihrer Vorliebe für Handelsgeschäfte. An Siedlungsgenossenschaften sind sie wohl nirgends beteiligt. Es scheint nun, daß die Juden sich im Laufe der Zeit dem Stadtleben angepaßt haben und seine Schädlichkeiten zu ertragen vermögen, soweit sie wirklich unvermeidlich sind. Die Deutschen, deren Sinn mehr auf Feld und Wald gerichtet ist, nehmen, wenn sie vom Land in die Stadt ziehen, offenbar viel zu wenig Rücksicht auf die gesundheitlichen Nachteile und Gefahren, denen sie sich damit aussetzen. Ihre Familien sterben infolgedessen oft schon nach wenigen Generationen aus. Bei den Juden ist das viel weniger der Fall. Wenn man die maßgebende Bedeutung inbetracht zieht, welche die Großstädte in der Gegenwart bei uns gewonnen haben, erkennt man ohne weiteres, daß die ausdauernde Stellung des Judentums in diesen Brennpunkten des öffentlichen Lebens für seine Macht und seinen Einfluss günstig sein muss. Dies umsomehr, als gleichzeitig die von ihnen beherrschte Geldwirtschaft sich immer höher entwickelt und die Ansammlung großer Kapital-Reichtümer daselbst ermöglicht hat. Die Juden haben es trefflich verstanden, alle Vorteile auszunutzen und sind auf diese Weise die reichste Nation der Erde geworden. (Neuner 1923: 357-358)

Die Verbindung von Judentum und Stadtleben wird im ersten Satz auf eine historische Gesetzgebung zurückgeführt, die den Juden den Aufenthalt auf dem Land untersagt haben soll. Die Ursache für die Anpassungsfähigkeit der Juden an das Stadtleben wird also zunächst nicht bei den Juden, sondern bei der nichtjüdischen Umwelt gesucht. Es entspricht einem seit dem 18. Jahrhundert weitverbreiteten Ansatz, Eigenschaften der jüdischen Bevölkerung als Produkt ihrer sozialen Umwelt zu interpretieren, auf die sie keinen oder einen nur geringen Einfluss haben. Dieses soziologische Erklärungsmuster wird im darauffolgenden Satz jedoch zugleich wieder eingeschränkt, da behauptet wird, dass diese Regelungen den natürlichen Veranlagungen der Juden entsprochen hätten. Die ihnen unterstelle Abneigung gegen körperliche Arbeit und die Vorliebe für Handelsgeschäfte werden als natürliche und daher angeborene Dispositionen von Juden begriffen, die sie für das Großstadtleben prädisponieren. Dem soziologischen wird damit ein biologistischer Erklärungsansatz zur Seite gestellt. 
Zudem wird im zweiten Satz des Zitats ein Kontrast zwischen Landleben und körperlicher Arbeit einerseits und Stadtleben und Handelsgeschäften andererseits hergestellt. Dies rekurriert auf den in der völkischen Literatur weitverbreiteten Konnex von Großstadt, moderner Geldwirtschaft und Judentum. Dieser Zusammenhang wird von Neuner in Zeile 1415 wieder aufgegriffen, wenn er das für den modernen Antisemitismus zentrale Theorem der Personifizierung des Geldes in den Juden großstadtfeindlich interpretiert. An der zitierten Textstelle lässt sich exemplarisch aufzeigen, dass es einen - wie bereits im Theoriekapitel diskutiert wurde - Zusammenhang zwischen der Personifizierung des Tauschwerts in den Juden und ihrer Wahrnehmung als Großstadtbewohner gibt.

In Zeile 4-6 wird die Anpassungsfähigkeit der Juden an das Großstadtleben als das Ergebnis einer entwicklungsgeschichtlichen Gewöhnung an die negativen Umwelteinflüsse der Großstadt diskutiert. Diese Fähigkeit wird im nächsten Satz mit der historisch bedingten Unfähigkeit der Deutschen, sich den Gefahren des Großstadtlebens bewusst zu werden, kontrastiert. Erklärt wird die mangelnde Anpassungsfähigkeit der Deutschen an die Großstädte mit der in der völkischen Literatur tradierten Theorie einer Bindung der Deutschen an eine bodenverbundene Lebensweise im Wald und auf dem Feld. Neuner bezieht somit auch eine milieutheoretische und entwicklungsgeschichtliche Betrachtungsweise des Verhältnisses von Juden respektive Deutschen zu den Großstädten in seine Argumentation ein. Die Anpassungsfähigkeit an das Großstadtleben wird in der zitierten Textstelle sowohl biologistisch (Abneigung der Juden gegenüber körperlicher Arbeit), entwicklungsgeschichtlich/milieutheoretisch (Gewöhnung an städtische Lebensverhältnisse bei Juden/Orientierung der Deutschen auf Wald/Feld) und soziologisch (antijüdische Gesetzgebung) gedeutet.

Die Fähigkeit, die schädlichen und ungesunden Einflüsse der Großstadt besser ertragen zu können, lässt die Juden in der zitierten Textstelle den Deutschen gegenüber als überlegen erscheinen. In diesem Text, in dem sich der Autor um Objektivität bemüht zeigt und von hasserfüllten Auslassungen absieht, artikuliert sich eine beobachtbare Bewunderung für Juden und Jüdinnen. Die Dialektik von Hass und Neid, die das antisemitische Judenbild prägen, kann mit - Arnold Rose gesprochen - zum ideologischen Kern des modernen Antisemitismus gezählt werden (vgl. Rose 1948) 
Zusammenfassung zweite Kategorie

Ein zentrales Element der antisemitischen Großstadtfeindschaft in den untersuchten Texten stellt die Diskussion über eine entgegengesetzte Anpassungsfähigkeit von Deutschen und Juden an das Großstadtleben dar. Völkische Autoren schließen hierbei an den Topos der Großstadt als einer krankmachenden Umwelt an, der die Wahrnehmung der Großstadtentwicklung in Deutschland seit der Mitte des 18. Jahrhunderts geprägt hat. Diese These wird in völkischen Texten rassentheoretisch interpretiert, da angenommen wird, dass die großstädtischen Umwelteinflüsse auf Völker und „Rassen“ unterschiedlich wirken. In dieser Wahrnehmung tragen die modernen Großstädte bei allen als Abstammungsgemeinschaft definierten Kollektiven zu einer „Degeneration“ bei - mit der Ausnahme des Judentums. Mit der den Juden unterstellten Fähigkeit, sich den Großstädten gefahrlos anpassen zu können, korrespondiert das Selbstbild von den Deutschen als dasjenige Volk, das die geringste Eignung und Veranlagung für das moderne Großstadtleben besitze.

Die unterschiedliche Anpassungsfähigkeit von Juden und Deutschen an das Großstadtleben wird in den untersuchten Texten wahlweise mit umwelt- und milieutheoretischen, soziologischen oder biologistischen Faktoren erklärt; oftmals werden diese drei Faktoren miteinander verbunden, so dass die eine Erklärung die andere nicht ausschließt. An diesem Punkt zeigt sich, dass der völkische Antisemitismus in seinen Begründungszusammenhängen inkonsistent ist. Die Erklärung für die unterschiedliche Anpassungsfähigkeit von Juden und Deutschen an die Großstädte changiert zwischen einer soziologischen Milieu- und Umwelttheorie einerseits und einem rassenbiologischen Determinismus andererseits.

Die empirische Analyse konnte zudem zeigen, dass der Antisemitismus-Theorie von Arnold Rose eine hohe empirische Plausibilität zukommt. Seine These, wonach Antisemiten bei sich eine mangelnde Anpassungsfähigkeit für das Großstadtleben wahrnehmen und zugleich in Juden und Jüdinnen ein Symbol des Großstadtlebens sehen, konnte im Hinblick auf die untersuchten Texte bestätigt werden. 


\subsection{Sexualität, Großstadt und Judentum}

\subsubsection{Die (weiblichen) Verlockungen der Großstadt}

Seit den Schriften von Georg Hansen und Otto Ammon bestimmte unter Großstadtfeinden die Vorstellung die Wahrnehmung der modernen Großstädte, dass diese nur auf Grund eines beständigen Zuzugs aus dem Land wachsen und die von ihnen hervorgerufene Kinderlosigkeit ausgleichen könnten. Die Behauptung, dass die Großstädte sich nicht aus sich selbst heraus reproduzieren bzw. „am Leben“ erhalten könnten, basiert wesentlich auf der Darstellung der Großstädte und des Landes als zweier miteinander verwobener Organismen, zwischen denen ein immerzu währender Austausch an Nahrungsmitteln und Menschen stattfinde. Diese Vorstellung findet ihren unverkennbaren Ausdruck in Redewendungen, die davon handeln, dass das Land allmählich ,ausblute“ und die Großstädte auf die Zuführung „frischen Blutes“ angewiesen seien. Der großstädtische Organismus wird daher in der großstadtfeindlichen Literatur nicht selten in der Form eines Stadtkörpers vorgestellt: So vergleicht Darré in dem untersuchten Material die Großstädte mit einem Polypen und das über die Grenzen der Stadt hinausreichende Verkehrsnetz mit ,weit hinlangende[n] Arme[n], mit denen sich die Stadt ihre Nahrung herbeisaugt" (Darré 1930: 91). Der Vergleich der Großstädte mit einer Krake und anderen Tieren oder Organismen mit weitausgreifenden Extremitäten stellt ein wiederkehrendes Motiv in der großstadtfeindlichen Literatur des Kaiserreichs und der Weimarer Republik dar. In dieser Bildersprache drückt sich die Vorstellung aus, dass die Großstädte die menschlichen und materiellen Ressourcen des Landes rücksichtlos aufzehren würden.

Die Überzeugung, dass sich der ökonomische und kulturelle Aufschwung der Großstädte auf Kosten des Landes vollziehe, ohne dass dieses davon profitiere, ist auch in der völkischen Bewegung fest verankert. Sie kulminiert in der These, dass die Existenz der Großstädte auf einem parasitären Prinzip basiere. In einer volkswirtschaftlichen Analyse zum Stadt-LandVerhältnis heißt es diesbezüglich in einem Hammer-Artikel: „Wer es ganz nüchtern betrachten will, muß sich gestehen, daß Stadt und Industrie eine Art parasiterisches [sic!] Dasein auf dem Rücken des Land-Volkes“ führen (o. A. 1908: 67). Bei Darré heißt es hierzu: „Die lebensgesetzliche Grundlage der Stadt ist ihr Schmarotzertum“(Darré 1930: 91).

Die empirische Analyse zeigt, dass völkische Autoren den parasitären Charakter, den sie den Großstädten zuschreiben, auf die großstädtische Lebensweise übertragen. Diese wird darüber definiert, dass sie Luxus und Genuss ohne Arbeit ermögliche und nicht an dem Gesamtwohl 
des Volkes, sondern an egoistischen und materiellen Interessen orientiert sei. Die Großstadt steht in der völkischen Wahrnehmung für das Versprechen auf eine Befreiung von körperlicher Arbeit und der Entfaltung und Kultivierung eines lustbesetzten Nichtstun.

Verbunden ist damit die Vorstellung, dass die Verlockungen und der parasitäre Lebensstil der Großstädte einen starken Abwanderungswillen unter den Landbewohnern auslösen, auf den die Großstädte aufgrund ihrer Unfähigkeit zur Selbstreproduktion angewiesen seien. In dem nicht namentlich gekennzeichneten Text Verwahrlosung der gebildeten Jugend werden die Verlockungen des Großstadtlebens als ein zentraler Faktor bestimmt, der negativ auf die deutsche Jugend einwirke. Diese wird, dem völkischen Antiintellektualismus entsprechend, als verbildet, lebensfremd und der körperlichen und praktischen Arbeit gegenüber negativ eingestellt dargestellt: Und wie lockt das rauschende Großstadt-Leben mit all seinen verborgenen Reizen! Dort zieht's uns hin, dort schillert's und braust es und brodelt's im Sumpfe, - dort ist der Kulminations-Punkt des Lebens, dort kann man etwas scheinen, ohne etwas sein zu müssen. Dort ist der Platz für alle Lebemänner, für alle Hochstapler. Also: hinein in den Strudel! Es ist ja unsere Bestimmung! Die innere Stimme sagt es uns ja, und ihr soll man nicht widersprechen... Lieber ein genialer Lotterbube sein und im Sumpf untergehen, als sich in den Pflug spannen lassen! Lieber brennen als ackern und bauen! - So ist es die Weisheit der modernen Jugend. So kommen die edlen Früchte zustande, die die Zierde des modernen Lebens bilden: die Durchgänger-Naturen. (o.A. 1903: 476-477)

In diesem Zitat werden gängige Charaktersierungen des Großstadtlebens um die Jahrhundertwende zusammengeführt. Bei den Begriffen Sumpf und Strudel handelt es sich um weitverbreite Großstadt-Metaphern, die der Überzeugung Ausdruck verleihen, dass die Menschen in der modernen Großstadt untergehen und von ihr absorbiert würden. Mit dem Bild des „Großstadtsumpfs“ verbinden sich zudem Assoziationen um die Auflösung moralischer Werte und Vorstellungen von einem sozial devianten Verhalten. Das Schlagwort avancierte um die Jahrhundertwende zu einem Synonym für die großstädtische Kriminalität, die als das Produkt einer ungesunden und daher die Moral zersetzenden Umwelt gesehen wurde. 
Dem Bild des „Großstadtsumpfes“ ist jedoch auch eine sexuelle Konnotation eingeschrieben, sofern mit dieser Metapher auf ein lasterhaftes Treiben in den Großstädten angespielt wird. Diese Sinndimension des Begriffes zeigt sich im ersten Satz, in dem die Rede von verborgenen Reizen des Großstadtlebens ist, die die Menschen in die Städte locken und in Zeile 2, in der die beiden Adjektive „brausen“ und „brodeln“ zur Charakterisierung des (Großstadt-)Sumpfes herangezogen werden. Die Ausführungen stellen auf die bewusst oder unbewusst formulierte Annahme einer körperlich und sexuell stimulierenden Wirkung des Großstadtlebens ab. Die Welt der Großstadt erhält hierbei eine körperlich und sinnlich erfahrund spürbare sowie eine geschlechterspezifische Dimension. Als handelnde Subjekte der Großstädte werden in dieser Textsequenz ausschließlich Männer vorgestellt: Lebemänner, Hochstapler und Lotterbuben. Die Großstadt und ihre verführerischen Reize erhalten somit implizit weibliche Charakterzüge zugesprochen.

Susanne Frank hat in ihrer Studie zum Verhältnis von Stadt und Geschlecht darauf hingewiesen, dass Stadtbilder und Stadtmythen in der europäischen Geschichte sehr eng mit Geschlechterbildern und Vorstellungen von Männlichkeit und Weiblichkeit zusammenhängen. Stadtbilder transportieren ihr zufolge auch immer Vorstellungen von einer Ordnung der Geschlechterverhältnisse, deren Erosion folglich auf eine Unordnung der Stadt zurückgeführt wird (vgl. Frank 2003: 23). Stadtmythen der Antike und der Bibel, wie das der Hure Babylon, identifizieren die Verlockungen, die Ausschweifungen und das Chaos der Stadt mit der Frau. Wenngleich keine überhistorische Stadtfeindschaft existiert, so werden überlieferte Bilder und Stereotype des Stadtlebens in Zeiten sozialer Umbrüche und Transformationsprozesse aktualisiert und neu formuliert und dienen als Chiffren für die Selbstbeschreibungen westlicher Gesellschaften (vgl. Frank 2003: 23-28). So wurde der Mythos der Hure Babylon seit Ende des 19. Jahrhunderts mit den Großstädten und im Besonderen mit Berlin in Verbindung gebracht (vgl. Bergius 1986).

In der zitierten Textsequenz wird das Großstadtleben in einem starken Kontrast zum Landleben beschrieben: Die Großstadt ermögliche eine Existenz, die auf einem unehrlichen, der Täuschung beruhenden Verhalten basiere, die nicht auf Arbeit gründet, sondern ganz auf den äußeren Schein ausgerichtet sei. Das in Zeile 6 bemühte Bild des ,genialen Lotterbubens“ unterstreicht das Stereotyp des geistvollen und zugleich unproduktiven Großstadtlebens. Dem Duden zufolge handelt es sich bei einem Lotterbuben um einen sich herumtreibenden Faulenzer. ${ }^{31}$ Das Landleben wird hingegen mit den schöpferischen und arbeitsamen

\footnotetext{
${ }^{31}$ http://www.duden.de/rechtschreibung/Lotterbube (18.02.2016).
} 
Attributen „bauen“ und „ackern“ charakterisiert. Hierbei vollzieht sich eine Unterscheidung von Land und Großstadt anhand der Gegenüberstellung von körperlicher Produktivität und geistig-intellektueller Unproduktivität.

Die sich hierin ausdrückende Affirmation der Arbeit lässt eine Sozialisation des Autors in einem protestantischen Milieu vermuten. Die von ihm zum Ideal erhobene asketische Lebensweise und die Verklärung von Arbeit erinnern in frappierender Weise an die von Max Weber in seiner Studie zur protestantischen Ethik und den Geist des Kapitalismus beschriebenen Berufsethik des asketischen Protestantismus. Den Ursprung hat die bürgerliche Arbeitsethik nach Weber in dem Verständnis von Arbeit als einem von Gott vorgeschriebenen Selbstzweck, der der Mehrung des göttlichen Ruhmes dienen solle. Nicht die Muße oder der Genuss, ,sondern nur Handeln dient nach dem unzweideutig geoffenbarten Willen Gottes zur Mehrung seines Ruhmes“. Die Zeitvergeudung durch „Geselligkeit, ,faules Gerede“, Luxus“ wird daher als die erste und prinzipiell schwerste aller Sünden begriffen“ (Weber 1934: 167). Die protestantische Askese, schlussfolgert Weber, wendet sich mit voller Gewalt gegen ,das unbefangene Genießen des Daseins und dessen, was es an Freuden zu bieten hat" (Weber 1934: 183). Wie bereits im vorausgehenden Kapitel aufgezeigt wurde, hängt die völkische Großstadtfeindschaft mit einer Idealisierung von körperlicher Arbeit zusammen, da diese als ein Charakteristikum des Landlebens ausgewiesen wird.

\subsubsection{Sexualisierung des Großstadtlebens}

Der im vorhergehenden Zitat angeschnittene Aspekt einer Sexualisierung des Großstadtlebens stellt einen zentralen und dominanten Topos der Großstadtwahrnehmung in den untersuchten Texten dar. Die von völkischen Autoren vertretene These einer von den Großstädten ausgehenden Erosion der Moral und eines fortschreitenden Prozesses der Entsittlichung entspricht einer gegen Ende des 19. Jahrhunderts und in der ersten Hälfte des 20. Jahrhunderts weitverbreiteten Ansicht zu den Großstädten. Sie macht zugleich deutlich, dass die Haltung einer Mehrheit der Völkischen zu den Themen Sexualität, Geschlechterrollen und Geschlechterverhältnisse einer christlich-protestantischen Moralvorstellung entspringt.

In den Texten des Untersuchungsmaterials wird wiederholt davor gewarnt, dass das Großstadtleben eine übersteigerte Sinnlichkeit unter den Großstädtern hervorrufe, die mit dem Begehren nach Genuss, Ausschweifung, Müßiggang und Eitelkeit zusammenhänge. 
Völkische Großstadtfeinde gehen davon aus, dass innere Werte und idealistische Überzeugungen in den Großstädten einer Ich-Sucht und einem Materialismus weichen würden. Eine weitverbreitete Überzeugung stellt in diesem Zusammenhang die These dar, dass die Großstädte zu einer Herrschaft des Geldes beitrügen. Das Geld wird dabei zu einer wurzellosen und abstrakten Macht verdinglicht, die für den verzehrenden und degenerierenden Charakter des Großstadtlebens mit verantwortlich gezeichnet wird. Dem Geld wird nicht nur eine materielle, sondern auch eine sinnliche Dimension zugesprochen: Die Akkumulation von Geld wird im völkischen Denken einerseits als ein lustbesetzter Vorgang aufgefasst, wovon der im empirischen Material wiederholt auftretende Begriff der „Mammons-Jagd“ zeugt. Andererseits gilt das Geld als ein Mittel, mit dem eine materielle und zugleich sinnliche Bedürfnisbefriedigung hergestellt wird.

Herbert Marcuse charakterisiert die Abwehr irdischen Glücks und die ethische Verklärung der Armut, des Opfers und des Dienstes in einem Aufsatz für die Zeitschrift für Sozialforschung aus dem Jahr 1934 als ein zentrales Ideologem der völkischen Ideologie. Ihm zufolge soll die Abwertung „,der materiellen Sphäre des Daseins“ über den Widerspruch hinwegtäuschen, der durch den Kontrast zwischen der sozioökonomischen Situation der Menschen einerseits und der völkischen Verklärung der wirtschaftlichen und sozialen Verhältnisse als einer natürlichen Ordnung andererseits, zu Tage tritt. Den Kampf gegen den Materialismus begreift Marcuse daher als eine Notwendigkeit des von ihm so bezeichneten heroisch-völkischen Realismus in Theorie und Praxis. Dieser „muß das irdische Glück der Menschen, das die von ihm gemeinte Gesellschaftsordnung nicht bringen kann, prinzipiell desavouieren zugunsten, ideeller ${ }^{6}$ Werte (Ehre, Sittlichkeit, Pflicht, Heroismus usw.)“ (Marcuse 1968: 40).

Marcuse weist darauf hin, dass diesem ,idealistischen“ Moment ein zynischer und harter Realismus im völkischen Denken zur Seite steht: Dieser fordert die Anpassung der Menschen an die Produktionsverhältnisse und insofern eine dauernde Anpassung ,in der Besorgung der zu produzierenden ,irdischen" Güter". Arbeit findet in dieser Vorstellung jedoch ausschließlich um ihrer selbstwillen statt und darf nicht der Befriedigung materieller Bedürfnisse dienen. In Anlehnung an Max Weber sieht er die völkische Weltanschauung durch eine lebensweltliche Askese charakterisiert, die das Leben unter den Kategorien des Dienstes und der Arbeit fasst. Die völkische Ideologie ist für ihn demgemäß durch eine Zweideutigkeit bestimmt: Sie propagiert einen harten Realismus, dem alles Schwache und Weltfremde verächtlich ist, und glorifiziert zugleich ,ideelle“ Werte und ruft zur Rettung des „Geistes“ auf (vgl. Marcuse 1968: 40-41). 
Der Kampf gegen Materialismus und ein damit in Verbindung gebrachtes unsittliches Verhalten verbindet sich in den untersuchten völkischen Texten mit der Feindschaft gegenüber den modernen Großstädten. Für die Bezeichnung des unmoralischen und lasterhaften Charakters der modernen Großstädte wird in dem untersuchten Material eine Vielzahl von Synonymen verwendet: Die Großstadt wird wahlweise als Sündenpfuhl, Lasterparadies (vgl. Fritsch 1914: 282, 286), Lasterhöhle (Fritsch 1920: 462) oder als modernes Paradies (Wehleid 1905: 376) bezeichnet. Dem Leben in den Großstädten wird dabei, wie im vorhergehenden Kapitel bereits gezeigt, eine körperlich, sinnlich und erotisch erfahrbare Dimension zugewiesen. Hiervon zeugen wiederholt vorgetragene Charaktersierungen des Großstadtlebens als „,verwüstend“ und „,ausschweifendend“ (o.A. 1904: 97-98) oder die Behauptung, dass das Großstadtleben geprägt sei von „Annehmlichkeiten und prickelnden Reizen“ (Fritsch 1914: 282).

Eng verbunden ist damit die Überzeugung, dass das Großstadtleben zur Entfesselung eines unnatürlichen Geschlechtstriebs führe und dass dieser sich vom Fortpflanzungstrieb ablöse. Diese Angst war in zivilisationskritischen und kulturpessimistischen Strömungen der Jahrhundertwende weit verbreitet und spielte im Besonderen in der großstadtfeindlich grundierten Diskussion um die Prostitution eine bedeutende Rolle (vgl. Omran 2000: 156). Die in der völkischen Bewegung diskutierte Annahme einer sexualisierten, auf Eitelkeit und Genusssucht abstellenden Lebensweise in den Großstädten hängt unmittelbar mit Untergangsprophezeiungen zusammen. In dem untersuchten Material ließ sich die Behauptung finden, dass die Großstadtkultur eine aufzehrende Wirkung auf ihre Bewohner ausübe und diese schließlich an ihrem Reichtum und Wohlstand zugrunde gehen würden. Der Logik einer strikten Gegenüberstellung von Land und Großstadt folgend, wird das Landleben hierbei mit einem der Großstadt entgegengesetzten Geschlechtstrieb und einer intakten moralischen Ordnung identifiziert.

E. Meinhold erklärt in seinem Aufsatz Der Kampf zweier Weltanschauungen Deutsche und Juden zu Verkörperungen zweier sich entgegenstehender Weltanschauungen. Die Weltanschauung der Deutschen begreift er als idealistisch, die der Juden als materialistisch. Dem Autor zufolge sind Weltanschauungen sowohl durch Abstammung und Vererbung als auch durch Erziehung und Erfahrung geprägt. Diesen Faktoren wird zudem eine geographisch-räumliche Unterscheidung hinzugefügt: Stadt und Land tragen dem Autor zufolge zur Entwicklung entgegengesetzter Anschauungen bei. Während das Landleben ein geistig-ideelles Bewusstsein fördere, führe die Großstadt zur Herausbildung einer „,sinnlich- 
materiellen“ und damit ,jüdischen“"Weltanschauung. Die hier aufgeführte Textsequenz über die Wirkungen des modernen Großstadtlebens steht daher in einem dezidiert antisemitischen Sinneszusammenhang:

Schon Stadt und Land an sich, unabhängig vom Beruf, wirken verschieden auf die Denkart des Menschen ein. Die moderne Groß-Stadt bietet zahllose Gefahren, die den Hang zu Eitelkeit und Genußsucht unterstützen. Jedes Schaufenster ist eine Gelegenheit für Müßiggänger beiderlei Geschlechts, sich zu spiegeln. Dem schaulustigen Auge wird auf Schritt und Tritt ein Eindruck vorbeigeführt, der eifersüchtiges Begehren erweckt. So wird die Sucht zu prunken, die Gedanken-Richtung auf Sinnlichkeit und Genußsucht großgezogen. [...] In der Weitläufigkeit des Landlebens dagegen fällt das fortgesetzte Schauen und Vergleichen und damit die Abziehung der Gedanken nach der Außenseite weg. Dadurch tritt Beruhigung, Sammlung, Konzentration nach Innen und Vertiefung ein. Der äußere Schein verliert, da er nicht Bewunderer findet, seinen Wert. Die Reizungen der Eitelkeit, der Begehrlichkeit und Sinnlichkeit finden nur im Menschen-Gewirr der Stadt ihren Nährboden, indeß Zufriedenheit, Schlichtheit und Natürlichkeit in der ländlichen Abgeschlossenheit gedeihen; darüber darf sich der Beobachter nicht durch glatte gewandte Formen einerseits und Schüchternheit oder Derbheit andererseits täuschen lassen. (Meinhold 1909: 589-590)

Die im ersten Satz aufgestellte Behauptung, dass die Großstädte einen unmittelbaren Einfluss auf das Denken und Fühlen der Bewohnerschaft hätten, ist eine Grundannahme, die vom großstadtfeindlichen Lager in Deutschland vorbehaltlos geteilt wurde. Im Anschluss daran wird der Denkinhalt konkretisiert: Großstadt und Land bieten in der Perspektive des Autors entgegengesetzte Gelegenheitsstrukturen, die der Herausbildung einer sexualisierten Affektbildung förderlich bzw. abträglich seien. Während die physische Nähe und Dichte des „Gewirres“ des Großstadtlebens die Verkehrsformen ihrer Bewohner und Bewohnerinnen auf das äußere optische Erscheinungsbild reduziere und dadurch ein sinnliches und zugleich materielles Begehren wecke, ermögliche die Weitläufigkeit des Landlebens eine Innerlichkeit, die auf dem Nichtvorhandensein sinnlicher Reize und der Wahrnehmung des anderen Geschlechts basiere. In Kontrast zur großstädtischen Sexualität wird in dieser Textsequenz ein das Landleben charakterisierender natürlicher und kontrollierter Geschlechtstrieb gestellt, der nicht auf einem sinnlich-materiellen Begehren beruhe. Diese Unterscheidung wird im letzten Satz in einem dreifachen Gegensatzpaar ausgedrückt: Eitelkeit/Schlichtheit, Begehrlichkeit/Zufriedenheit und Sinnlichkeit/Natürlichkeit. 
Der Text und das Zitat veranschaulichen, dass es in der völkischen Bewegung die Annahme gibt, dass das Großstadtleben zur Herausbildung einer als ,jüdisch“ apostrophierten Geisteshaltung und Denkart führe, die durch ein sinnlich-materielles Begehren geprägt seien. Antisemitismus und Großstadtfeindschaft sind im völkischen Denken auch über die Assoziation von Großstadt und Judentum mit einer unnatürlichen, dem völkischen Fortpflanzungsdiktat zuwiderlaufenden Sexualität miteinander verbunden.

\subsubsection{Erosion der Geschlechterdifferenz in den Großstädten}

Die unter den völkischen Autoren des Untersuchungsmaterials weitverbreitete Annahme der Herausbildung eines unnatürlichen Geschlechtstriebs, der als das Resultat einer Reizüberflutung des modernen Großstadtlebens gedeutet wird, korrespondiert mit der Überzeugung, dass die Großstädte auch einen Einfluss auf die Geschlechtsidentität hätten und zu einer Erosion der Geschlechterdifferenz beitrügen. Susanne Omran hat darauf hingewiesen, dass seit Beginn des 20. Jahrhunderts das Einwirken der Großstädte auf die geschlechtliche Identität mit dem Argument problematisiert wurde, dass der als krankmachend interpretierte Druck der Anpassung an die Großstädte Differenzen nivelliere würde. Sie hebt hervor, dass „,die Stadt als der wesentliche Schauplatz moderner Irritationen des Geschlechtsverhältnisses [gilt]“ (Omran 2000: 97-98). Die Angst vor einem Wandel der Geschlechterrollen und dem Verschwinden von Geschlechtergrenzen verband sich im Kaiserreich und in der Weimarer Republik mit einer negativen Wahrnehmung des Großstadtlebens. „The breakdown of traditional gender roles and the greater visibility of alternative gender expressions", hebt Elena Mancini hervor, "became synonymous with the urban metropolises like Berlin” (Mancini 2009: 92).

Die in dieser Studie vorgenommene Untersuchung hat ergeben, dass eine Gefahr für die den bürgerlichen Subjekten zur zweiten Natur gewordene Geschlechterdifferenz im Besonderen in dem Erfolg der Warenhäuser gesehen wird. In der Agitation gegen die Warenhäuser verdichteten sich zu Beginn des 20. Jahrhunderts die mittelständische Wirtschafts- und Interessenspolitik, der Antisemitismus und die Großstadtfeindschaft in der völkischen Bewegung (vgl. Hoffmann 1996; Gellately 1993).

Eine entsprechend hohe Bedeutung kommt dem publizistischen Kampf gegen die Warenhäuser im Hammer zu, zu dem im Besonderen Theodor Fritsch mit zahlreichen 
Artikeln beiträgt. Im Mittelpunkt der Ausführungen über die Warenhäuser steht neben der Warnung vor einer ökonomischen Verdrängung des Einzelhandels die Behauptung, dass die unter jüdischer Botmäßigkeit stehenden Warenhäuser die Moral und das sittliche Empfinden untergrüben und zu einer Pervertierung der großstädtischen Bevölkerung beitrügen. An diese Beobachtung schließen sich geschlechtsspezifische Betrachtungen an.

Dies drückt sich einerseits in der Annahme aus, dass in den großstädtischen Warenhäusern eine der Frau und der Weiblichkeit innewohnende Natürlichkeit verloren gehe, die ,in der Stadt schutzlos den urbanen Lebensformen zum Opfer fällt" (Omran 2000: 132). Die Warenhauskritik der Völkischen schließt andererseits an den in der zeitgenössischen Zivilisationskritik weit verbreiteten Topos an, dass die Entfaltung des Kapitalismus mit einer Entmännlichung der Kultur zusammenhänge (vgl. Omran 2000: 202).

Diese Annahme hängt maßgeblich mit der Wahrnehmung des Konsums um die Jahrhundertwende zusammen. Der Konsum war zu Beginn des 20. Jahrhunderts eine der wenigen öffentlichen Sphären, in denen Frauen sichtbar waren; er galt mithin als eine weibliche Domäne und die Warenhäuser als ein öffentlicher Raum, in dem sich Frauen treffen konnten, ohne dass dies ihrem gesellschaftlichen Ansehen schadete (vgl. Haupt 1997: 406409). Die Figur der weiblichen Konsumentin, die in den Warenhäusern verkehrt und die Einkaufsstraßen der Innenstädte frequentiert, stand sinnbildlich für die Rolle der (bürgerlichen) Frau in der Großstadt bei Tag. Männliche Kaufhauskunden standen daher stets im Verdacht, die Geschlechtergrenzen zu unterlaufen. Diese Wahrnehmung korrespondiert mit der grundsätzlichen Furcht von dem Verschwinden der geschlechtlichen Identität des Mannes in den Großstädten, die in der im Hammer wiederholt formulierten These einer verweichlichenden Wirkung des Großstadtlebens ihren Ausdruck findet (vgl. z.B. Meurer 1903: 361-362; o. A. 1905: 531; Fritsch 1918: 246-247). Die mit dem „Weichsein“ assoziierte Schwäche wird - darauf haben nicht zuletzt die Studien zur Authoritarian Personality hingewiesen - von Antisemiten mit Unmännlichkeit und mit Weiblichkeit identifiziert, so dass der Schwache als effeminiert gilt (vgl. Stögner 2014: 47).

In dem Aufsatz Die Untergrabung der öffentlichen Moral durch die Warenhäuser, den Fritsch unter dem Pseudonym F. Roderich-Stoltheim im Hammer veröffentlichte, wird der Warenhausdiebstahl von weiblichen Konsumentinnen als ein Symptom der Entsittlichung und der Erosion der moralischen Ordnung diskutiert. Fritschs Hass auf die Warenhäuser, der pathologische Züge annimmt, richtet sich einerseits gegen die Juden, denen er die Rolle zuweist, die Menschen mit Heimtïcke und zu ihrem Schaden in die Warenhäuser zu locken; 
und er richtet sich andererseits gegen die Warenhauskundschaft, denen er ein mangelndes Anstandsgefühl und eine Instinktlosigkeit attestiert. In seiner Vorstellung entfalten die Warenhäuser eine geschlechterspezifische Wirkung auf ihre Kundschaft:

Die Warenhaus-Diebereien aber sind mehr als nur ein Zeichen der zunehmenden laxen Moral: das ganze Warenhaus-Unwesen ist ein Zeugnis tiefer seelischer Erkrankung des heutigen Geschlechts. Es sind keine normalen Menschen, die die Warenhäuser füllen; es sind die hysterischen Frauen und die entmannten Männer, die ein unwiderstehlicher Drang in die Warenhäuser treibt, dorthin treibt, wo blendender Trug die Sinne betört, wo das Unvernünftige und Unlogische seinen Zauber übt, es sind die Perversen, die Menschen von verlorenen Instinkten, die Untermenschen und Untergangs-Menschen. Darum dürfte jeder Versuch der Belehrung vergeblich seien. - Laßt sie zugrunde gehen, wie sie es verdienten, haltet euch aber abseits von diesem erkrankten Geschlecht! (Roderich-Stoltheim [Fritsch] 1914: 326)

Zu Beginn der Textsequenz wird die Behauptung aufgestellt, dass die Warenhäuser zu einer seelischen Erkrankung ihrer Kunden beitrügen. Dieser Zusammenhang wird von Fritsch geschlechterspezifisch gedeutet: Die Behauptung einer unter Frauen auftretenden Hysterie schließt sowohl an der unter Großstadtfeinden weitverbreiteten These einer Nervenerkrankung in den modernen Großstädten als auch an das misogyne Bild der Frau als eines nicht vernunftbegabten Wesens an. Die männlichen Kaufhauskunden litten hingegen nicht unter einer Zerrüttung ihrer Nerven, sondern würden in den Warenhäusern ihrer Männlichkeit beraubt. Die von Fritsch artikulierte Kastrationsangst bezieht sich auf eine geistige „Entmannung“ des deutschen Mannes. An dieser Stellte lässt sich exemplarisch der von Freud konstatierte Zusammenhang zwischen Antisemitismus und Kastrationsangst aufzeigen. Freud begreift den Kastrationskomplex als die ,tiefste unbewußte Wurzel des Antisemitismus, denn schon in der Kinderstube hört der Knabe, daß dem Juden etwas am Penis - er meint, ein Stück Penis - abgeschnitten werde, und dies gibt ihm das Recht, den Juden zu verachten“ (Freud 1993 [1909]: 271, FN 1).

In der zitierten Textsequenz wird die Angst vor der „Entmannung“ mit der verführerischen Wirkung („Betörung der Sinne“) der von den Juden beherrschten Warenhäuser in Beziehung gesetzt. Die Warenhäuser erscheinen hierbei als ein Teil des großstädtischen Systems der Verführung und Pervertierung der Massen und als der Ort, an dem Männer einer geschlechtlichen Nivellierung ausgesetzt sind. Die Warenhauskritik der Völkischen steht 
somit auch im Kontext der These einer „Entmännlichung“ des Mannes in der modernen Großstadtkultur. 


\subsubsection{Prostitution, Judentum und Großstadt}

Neben den Warenhäusern werden in dem dieser Analyse zugrunde liegenden Material sämtliche großstädtischen Vergnügungsstätten und Kultureinrichtungen unter jüdischem Einfluss gewähnt. Hierdurch erlangt das Narrativ einer das Großstadtleben bestimmenden Sucht nach Ausschweifung, Müßiggang und Genuss eine dezidiert antisemitische Stoßrichtung. Ein jüdischer Einfluss wird auf die Schankstätten und Spirituosengeschäfte, auf Kino und Film (vgl. Miller 1928), auf das Theater und auf „Vergnügungslokale aller Art“ ausgemacht, wie es Fritsch in einem seiner Texte formuliert (vgl. Fritsch 1928: 81). Diese Einrichtungen werden als Werkzeuge der Juden begriffen, mit deren Hilfe eine „Volksvergiftung“ (Fritsch) betrieben werde, durch die das deutsche Volk gefügig gemacht werden solle. So spricht Alfred Miller in einem Aufsatz davon, dass das ,jüdische Prinzip“ auf eine Formel gebracht nichts anderes heiße als eine Förderung des Lebensgenusses (vgl. Miller 1928: 201).

Ein wirksamer Schutz vor der entsittlichten und degenerierenden Wirkung der Großstadt und den Verlockungen jüdischer Vergnügungsstätten wird in der Widerstandskraft der bäuerlichen Lebensweise gesehen, die darüber gekennzeichnet wird, dass sie für Entwicklungen, die dem Volkswohl und der Volksgesundheit nicht zuträglich sind, nicht empfänglich sei. In dem Text An der Zeitenwende von Theodor Fritsch, der davon handelt, dass das zunehmende Bewusstsein über den negativen Einfluss der Juden ein neues Kapitel in der deutschen Geschichte einleite, wird die Lasterhaftigkeit der Großstädte als eine existentielle Gefahr für das deutsche Volk hervorgehoben:

Ja, die Deutsch-Empfindenden mehren sich heute von Tag zu Tag. Ist das nicht bewundernswert? Ein Volk von solcher Widerstands-Fähigkeit muß Riesenkräfte in sich bergen. Es ist von jener unverwüstlichen Bauern-Gesundheit, die nicht klein zu kriegen ist. Am deutschen Volke wird die jüdische Schlange sich ihre Giftzähne ausbeißen. Alle Verderbnis und aller Verfall, die uns sichtlich umgeben, sollen uns nicht schrecken. Gewiß, der verlumpte Teil dieses Volkes, der in großstädtischen Lasterhöhlen sein verdorbenes Blut, seine zerütteten Nerven und seinen wirren Geist austoben läßt, der ist nicht mehr zu retten. Wir geben ihn preis. Vielleicht sollte man noch mehr Laster-Paradiese schaffen, um seinen Untergang zu beschleunigen. Aber dieser Auswurf ist nicht das deutsche Volk. Auf dieses Gesindel jedoch gerade baut der Volks-Verräter seine Hoffnungen; die Lotterbuben und Lotterdirnen hält er sich warm; sie sind ihm Gehilfen der Zerstörung; er zählt sie zur ,roten 
Armee'. Gelingt es den jüdischen Aufrührern, diese vertierten Massen nochmals gegen die gesittete Menschheit loszulassen, so möge diese Gelegenheit dazu dienen, gründlich mit diesem Menschheits-Auswurf aufzuräumen. (Fritsch 1920: 463)

Die Textstelle enthält eine für die völkische Großstadtfeindschaft zentrale Unterscheidung zwischen Bauerntum und Gesundheit einerseits und Judentum, Krankheit und Großstadt andererseits. Der Antisemitismus wird über das Medium der Tiermetapher kommuniziert, mit dem in völkisch-antisemitischen Schriften eine Dehumanisierung von Juden und Jüdinnen bezweckt wurde. In Zeile 5-7 wird über die assoziative Verbindung von „großstädtischen Lasterhöhlen“ und „verdorbenem Blut“ ein Konnex zwischen Sexualität und „Rasse“ bzw. rassischer Degeneration postuliert. Die Verbindung von Sexualität und Blut, die im rassischen Antisemitismus ihren Ausdruck in dem Ideal der „Reinheit des Blutes“ und in seinem negativen Äquivalent der „Rassenschande“ erfährt, entspringt der christlichen Tradition der Unterscheidung zwischen „reinem“ und „unreinem Blut“. Während Ersteres auf den Erlöser, den Märtyrer oder die jungfräulich gebärende Muttergottes verweist, wird die Verunreinigung mit jeder Form des Blutes assoziiert, die mit Sexualität und Weiblichkeit in Verbindung gebracht wird (vgl. von Braun 1995: 180).

In dem Zitat werden insgesamt drei konkrete Personengruppen identifiziert, die mit den Großstädten in Verbindung gebracht werden: als „Volksverräter“ und „Aufrührer“ bezeichnete Juden, die sich der nervenkranken und „undeutschen“ Massen bemächtigen; „Lotterbuben“332 und als Prostituierte imaginierte „Lotterdirnen“, die als Gehilfen der Juden an der Zerstörung des Volkes mitwirken. Der in Zeile 5-9 postulierte Zusammenhang zwischen einer in den Großstädten vorherrschenden sexuellen Ausschweifung („Lasterparadiese“) und einer rassischen Degeneration („Auswurf ist nicht das deutsche Volk“) spiegelt sich in der antisemitischen Konstruktion dieser Personengruppen wider.

Eine zentrale Bedeutung kommt dabei der Sozialfigur der Prostituierten und des jüdischen Zuhälters zu. Fritsch zählt die Prostituierten neben den sogenannten „Lotterbuben“ zur „roten Armee“, ohne in seinem Aufsatz zu erläutern, was er hierunter versteht. Den Anführungszeichen nach $\mathrm{zu}$ urteilen handelt es sich offensichtlich um eine ironische

\footnotetext{
${ }^{32}$ Wie bereits erwähnt, handelt es sich dem Duden zufolge bei einem „Lotterbuben“ um einen Faulenzer. Es ist jedoch auch möglich, dass Fritsch mit diesem Begriff männliche Prostituierte im Sinn gehabt hat. Die männliche, gleichgeschlechtliche Prostitution war bereits im Kaiserreich ein weitverbreitetes Phänomen in Berlin (vgl. Beachy 2015).
} 
Anspielung auf die seit 1918 existierende Rote Armee der Sowjetunion. Es steht daher zu vermuten, dass Fritsch in ihr ein Symbol des gesellschaftlichen Umsturzes sieht. Das Adjektiv „rot“ könnte sich zugleich auch auf den Berufsstand der Prostituierten beziehen und somit Weiblichkeit und Sünde symbolisieren. Diese Vermutung liegt insofern nahe, als Fritsch die Prosituierten als eine feindliche Macht darstellt, die von den Juden befehligt werde und gegen das deutsche Volk gerichtet sei. Die Imagination einer Aufzehrung der „Volkskraft“ in den „Lasterhöhlen“ der Großstädte erhält somit auch eine weibliche bzw. misogyne Konnotation.

In dem Bild der großstädtischen Prostituierten und ihres jüdischen Zuhälters verbindet sich die Angst vor einer selbstbestimmten weiblichen Sexualität mit der Furcht vor einer entgrenzten Sexualität im großstädtischen Raum. Die Beschäftigung mit der Figur der „Hure“ prägte die westliche Großstadtwahrnehmung bis weit in das 20. Jahrhundert hinein. Die Prostituierte fungiert dabei als Symbol des großstädtischen Systems der weiblichen Verführung und steht für eine Aufhebung der Trennung von Öffentlichem und Privatem. Im Bild der Hure, konstatiert Susanne Frank, „kommen einerseits die gleichermaßen verlockenden und abstoßenden Eigenschaften von Stadt, Masse, Frau und Nacht zusammen“ (Frank 2003: 69).

In der Sozialfigur der „Hure“ kristallisiert sich überdies eine dem Geld zugesprochene sinnliche Dimension. Die käufliche Sexualität der Prostitution verleiht dem Geld als allgemeinem Äquivalent des Warentausches eine leibliche und sinnlich-materielle Realität. Die Prostituierte wird, analog zum Stereotyp des „Geldjuden“, zur Personifikation des Tauschwerts (vgl. Stögner 2014: 116-123). Auf die Wahrnehmung einer Wesensverwandtschaft zwischen Prostitution und Geldwirtschaft hat Georg Simmel in seiner Philosophie des Geldes aufmerksam gemacht. Der Befriedigung einer temporären Begierde, der die Prostitution alleine dient, ist ihm zufolge nur das Geld als allgemeines Äquivalent angemessen. Die Indifferenz des Geldes, ,in der es sich jeder Verwendung darbietet, die Treulosigkeit, mit der es sich vom Subjekt löst, weil es mit keinem eigentlich verbunden war, die jede Herzensbeziehung ausschließende Sachlichkeit, die ihm als reinem Mittel eignet alles dies stiftet eine verhängnisvolle Analogie zwischen ihm und der Prostitution“ (Simmel 2014 [1900]: 514).

In der Wahrnehmung des völkischen Antisemitismus entzieht sich die Prostituierte nicht nur der der Frau zugedachten Rolle als Hüterin über die „Reinheit des Blutes“, sondern vollzieht den Sexualverkehr grundsätzlich mit jedem Mann, mit dem sie sich handelseinig wird. Die Prostituierte tauscht ihre Sexualität, wie Karin Stögner ausführt, nicht gegen den Samen des 
Mannes, mit dem die Scholle befruchtet werden soll, sondern im Austausch mit Geld. In ihrer Doppelfunktion als Händlerin und Ware, als Tauschende und Getauschte tritt sie als Vermittlerin zwischen Abstraktem und Konkretem in Erscheinung. Da die Prostituierte Lust um ihrer selbstwillen verspricht und sich dem völkischen Fortpflanzungsdiktat damit widersetzt, gilt sie, wie das Geld, als lebensfeindlich und als eine Gefahr für das Volk (vgl. Stögner 2014: 116-123).

Eine komplementäre Funktion kommt hierbei dem Bild des jüdischen Zuhälters zu, der den weiblichen Körper zu einer Ware macht und ihn somit dem „Volkskörper“ entreißt. Das Stereotyp einer jüdisch gelenkten Prostitution, das oftmals von dem Bild des besonders pervers veranlagten jüdischen Freiers flankiert wurde, existiert mindestens seit dem 17. Jahrhundert in Deutschland (vgl. Henschel 2008: 103). Die Behauptung eines engen Zusammenhanges zwischen Judentum, Prostitution und Mädchenhandel fand in unterschiedliche politische Bewegungen Eingang. Sie beeinflusste beispielweise die Arbeit des auf die Abschaffung der Prostitution abzielenden Flügels der Frauenbewegung (vgl. Omran 2000: 148-154).

Die Sozialfiguren der Prostituierten und des jüdischen Zuhälters personifizieren die im völkischen Denken stark ausgeprägte Vorstellung einer triebhaften und sexualisierten Komponente des Großstadtlebens. Karin Stögner hebt in ihrer Studie zum Verhältnis von Antisemitismus und Sexismus hervor, dass sexuelle Begierden, die sich nicht dem Primat der Fortpflanzung unterordnen lassen, mit der Abscheulichkeit einer ungeläuterten Natur und mit dem „Juden“ und der „Frau“ identifiziert werden (vgl. Stögner 2014: 33). Juden verkörpern hierbei sowohl ein Zuviel an Zivilisation als auch eine ungezügelte und triebhafte Sexualität. Weil Juden sich aus in der Sicht der Antisemiten am weitesten von der Natur entfernt haben, werden sie mit bloßer Natur identifiziert (vgl. Stögner 2014: 40). 
Die modernen Großstädte und die Juden symbolisieren bzw. verkörpern in der Wahrnehmung völkischer Ideologen ein System von Verführung, Entsittlichung und genussvoller Ausschweifung. Die Verlockungen der Großstädte, die die Menschen in ihren Bann schlagen, sie vom Landleben losreißen und an denen sie schließlich zugrunde gehen, haben in der Vorstellungswelt der Völkischen nicht nur eine antisemitische, sondern auch eine sexuelle und eine effeminierte Konnotation. Stark ausgeprägt ist die Idee, dass das Großstadtleben eine Befreiung von körperlicher Arbeit und eine Hinwendung zu einem sinnlichen und materiellen Genusssterben und Müßiggang ermögliche. Die sich hierin ausdrückende Überzeugung, dass in den Großstädten materieller Reichtum und Luxus ohne eigenes Zutun zu haben seien, ist ein dominanter Topos der Großstadtfeindschaft und verweist auf eine protestantisch geprägte Sozialisation völkischer Autoren. Die These eines unnatürlichen und übersteigerten Geschlechtstriebs in den Großstädten findet seinen Kulminationspunkt in dem Bild der von Juden beherrschten großstädtischen Vergnügungsstätten und wird über die Figur der im Dienst der Juden stehenden Prostituierten mit einer als lebens- und volksfeindlich wahrgenommenen weiblichen Sexualität in Verbindung gebracht. Hierbei zeigt sich nicht nur ein Zusammenhang von Antisemitismus und Sexismus, sondern auch eine enge Verbindung zwischen Großstadtfeindschaft und einer Lust- und Sexualitätsfeindlichkeit im völkischen Denken. 


\subsection{Gesamtzusammenfassung empirisches Kapitel}

Die in dem empirischen Kapitel dargestellten Topoi und Argumentationsmuster lassen sich zu einem Gesamtbild zusammenfügen, in dem, wie es ein Hammer-Autor prägnant formuliert, die Juden als „hauptsächliche Erzeuger, Träger und Nutznießer“ der „großstädtischen Asphaltkultur Mittel- und Westeuropas“ erscheinen (o. A. 1926: 291). Im völkischen Denken werden die modernen Großstädte als ein jüdisches Mittel und Instrument zur Beherrschung, Kontrolle und schließlich zur Zerstörung des deutschen Volkes diskutiert. Zentrale Thesen dieser intensiv geführten Debatte sind kein genuines geistiges Produkt der völkischen Bewegung, sondern sind fester Bestandteil der großstadtfeindlichen Literatur, die sich im Anschluss an die Schriften von Wilhelm Heinrich Riehl seit Mitte des 19. Jahrhunderts in Deutschland entwickelte. Die Anschuldigungen, die die Völkischen gegen die Großstädte hervorbringen, sind auch in anderen politischen Spektren, sozialreformerischen Bewegungen oder Professionen fest verankert, die mit der völkischen Bewegung, wie im Fall der Lebensreformbewegung oder der Rassenhygiene, personell verbunden sind. Die Haltung der Völkischen zu den Großstädten unterscheidet sich von der im Kaiserreich weit verbreiteten Großstadtfeindschaft darin, dass sie am radikalsten mit einer antisemitischen Feindbildkonstruktion verbunden ist. Die Gefahren, die man von den Großstädten für das deutsche Volk ausgehen sieht, hängen in der Wahrnehmung der Völkischen in der einen oder anderen Weise stets mit dem Handeln als jüdisch phantasierter Mächte zusammen.

Wie sich anhand der untersuchten Schriften zeigt, wird die Verstädterung als ein von den Juden gelenkter Prozess imaginiert. Den Juden wird die Intention zugeschrieben, die Deutschen in die Großstädte zu locken und sie für die großstädtische Kultur empfänglich machen zu wollen. Um dies erreichen zu können, müssen die Juden in der Wahrnehmung der Völkischen die geistige Bindung des deutschen Volkes an die Heimatscholle und das bäuerliche Leben lösen. Der modernen Geldwirtschaft und dem Intellektualismus wird eine hierfür förderliche Wirkung attestiert. Die Völkischen schließen hierbei an Vorstellungen von einer geistigen Entwurzelung der Menschen an, die in der großstadtfeindlichen Literatur mit einer negativen Wahrnehmung von Geld und Intellekt verbunden ist. Die Völkischen sehen in ihnen untrennbar miteinander verbundene Phänomene, die zu einem Charakteristikum des Großstadtlebens erklärt und in den Juden personalisiert werden.

Die Analyse hat bestätigt, dass es einen Zusammenhang zwischen der Personifizierung des Geldes in den Juden und ihrer Wahrnehmung als Repräsentanten der Großstadtkultur gibt. 
Das Ressentiment gegenüber dem das als abstrakt und wurzellos erscheinenden Geld und der Hass auf eine imaginierte Herrschaft des Geldes, des „Mammonismus“, um es in der Diktion der Völkischen auszudrücken, bilden einen Kernbestandteil der antisemitischen Großstadtfeindschaft.

Der Diskussion um eine jüdisch forcierte Verstädterung kommt in der völkischen Großstadtrezeption ein zentraler Stellenwert zu, da in den modernen Großstädten eine Lebensumwelt gesehen wird, die nicht nur einer positiven Entwicklung des Volkes abträglich sei, sondern, sofern keine Gegenmaßnahmen ergriffen werden, den Untergang der Deutschen bewirke. Der These einer Unvereinbarkeit der Deutschen mit dem Großstadtleben wird die Behauptung einer Anpassungsfähigkeit der Juden an die Großstädte entgegengehalten. Juden werden hierbei als die einzige Bevölkerungsgruppe bzw. das einzige Volk imaginiert, auf dessen Gesundheit die Großstädte keinen negativen Einfluss ausüben. Mit den modernen Großstädten, so die Überzeugung völkischer Autoren, hätten die Juden eine Lebensumwelt geschaffen, die dem eigenen Volk zuträglich sei oder ihm zumindest nicht schade und die zum Niedergang aller anderen Völker führe, wovon die Deutschen zuerst betroffen seien. Die den Juden zugeschriebene Fähigkeit in den Großstädten überlebensfähig zu sein, trägt dabei zur Festigung ihres Status als ein „Gegen-Volk“ bzw. einer „Gegenrasse“ (Adorno/Horkheimer) bei.

Zu der Überzeugung einer jüdischen gelenkten Großstadtentwicklung steht komplementär die Sorge, dass die Verstädterung zu einem Geburtenrückgang im deutschen Volk führe. Die von völkischen Autoren konstatierte Unfruchtbarkeit der Großstadtbevölkerung wird als eine direkte Folge eines sich in den Großstädten entwickelnden unnatürlichen Geschlechtstriebs und eines auf den sinnlichen und materiellen Genuss ausgerichteten Lebens gesehen. Das System der Verlockung und Verführung, für das die Großstädte im völkischen Denken stehen, basiert in ihre Vorstellungswelt auf einem als ,jüdisch“ phantasierten Prinzip der Sinnlichkeit und des Materialismus.

Kulminationspunkt der These einer jüdischen Sexualisierung des Großstadtlebens ist die Konstruktion der Figur des jüdischen Zuhälters, der nach Überzeugung der Völkischen die deutsche Frau dem „Volkskörper“ und dessen Fortpflanzungsprimat entreiße und sie der „Rassenschade“ zuführe. Der in der völkischen Debatte fest verankerte Topos der „sündhaften Stadt" macht deutlich, dass tradierte Stadtbilder und Stadtmythen aus der christlichen Mythologie in die Großstadtperzeption der völkischen Bewegung eingeflossen sind. Die 
empirische Analyse zeigt überdies, dass eine Lust- und Sexualitätsfeindschaft eine wichtige Antriebsfeder der völkischen Großstadtfeindschaft und des Antisemitismus sind.

Die Untersuchung macht zudem deutlich, dass die von Marcuse herausgearbeitete Abwehr irdischen Glücks und die Bekämpfung des Materialismus in der völkischen Ideologie mit einer Abwertung des Großstadtlebens verbunden sind. Als Ursache für den Befund einer „verzehrenden“ Wirkung des Großstadtlebens werden in der völkischen Literatur zwar auch schlechte Wohn- und Arbeitsverhältnisse genannt; eine weitaus größere Bedeutung wird in diesem Zusammenhang jedoch einer mit den modernen Großstädten assoziierten Ausschweifung und Dekadenz beigemessen. Die völkische Großstadtrezeption ist sich darin einig, dass die Menschen von den Großstädten angezogen werden, weil sie dem Land- und Bauerleben mitsamt seinen Entbehrungen und körperlichen Anstrengungen entgehen möchten und danach trachten, es gegen ein Leben einzutauschen, das bestimmt sei von einem materiellen und sinnlichen Genussstreben. Die Großstadtdarstellung der Völkischen nimmt hierbei bewusst und/oder unbewusst Bezug auf das mit der Gesichte der europäischen Stadt verbundene Emanzipationsversprechen, auf das im Besonderen Walter Siebel und Hartmut Häußermann hingewiesen haben (vgl. Siebel 1998, 1999, 2004; Häußermann 2001; vgl. Kapitel 6). Das urbane Emanzipationsversprechen, das sich nur für einen verschwindend geringen Teil der Bevölkerung bewahrheitet hat, wird in der völkischen Literatur pauschalisiert und als ein allgemeines Charakteristikum des Großstadtlebens ausgegeben.

Die der Großstadtfeindschaft zugrunde liegenden Projektionen sind insofern nicht nur wahnhaft und irrational, sondern finden in der Realität des modernen Großstadtlebens in Teilen eine Entsprechung. Die in der völkischen Literatur kommunizierten Großstadtbilder schließen daher auch an die Großstadterfahrungen völkischer Autoren an und beziehen sich auf Phänomene, die sich in dem Untersuchungszeitraum dieser Studie tatsächlich nur in den Großstädten und Metropolen beobachten lassen konnten. So spiegelt etwa der völkische Topos von der „sündhaften Großstadt“ die Tatsache wider, dass Nachtclubs und Nachtcafés ein Charakteristikum der Großstädte waren und Berlin international für sein ausschweifendes Nachtleben, seine Drogenkultur und für seine relativ offene, da von der Polizei geduldeten, Homosexuellen-Szene bekannt war. In diesen Punkten unterschied sich die deutsche Hauptstadt von fast allen anderen Metropolen Europas und Nordamerikas um die Jahrhundertwende (vgl. Beachy 2015).

Berlin fungierte für die völkische Großstadtfeindschaft als eine Negativfolie, bildete auf einer semantischen Ebene jedoch nicht den Bezugspunkt der großstadtfeindlichen Literatur der 
völkischen Bewegung. Die Dominanz des Begriffes „Großstadt“ in der Eigenliteratur der Völkischen macht deutlich, dass dieser im völkischen Denken zu einer Chiffre für den Kulturzerfall und für eine angenommene rassische und nationale Degeneration wurde - eine Chiffre, auf die sich alle Strömungen und Segmente der Bewegung einigen konnten.

Die obsessive Beschäftigung völkischer Ideologen mit der Großstadt legt die Vermutung nahe, dass nicht nur Gefühle von Hass und Abscheu, sondern auch von Faszination und Verlangen die Wahrnehmung des Großstadtlebens prägen. Bei den dem Großstadtleben zugeschriebenen Eigenschaften - u.a. sexuelle Ausschweifung, Müßiggang und Prunksucht handelt es sich um gesellschaftlich tabuisierte Regungen. Die bürgerlichen Subjekte unterdrücken diese und projizieren sie als verleugnete Anteile ihrer selbst auf einen außerhalb der eigenen Wir-Gruppe stehenden Personenkreis. Die verdrängten Regungen werden somit personifiziert und können bekämpft werden.

Arnold Rose hat in seiner Antisemitismus-Theorie hervorgehoben, dass Antisemiten ihre ambivalenten Gefühle für die Großstädte auf Juden projizieren, um den mentalen Konflikt zu lösen, den ihnen die zugleich anziehende und abstoßende Wirkung der Großstädte bereitet (vgl. Rose 1948). Mit Rose kann davon ausgegangen werden, dass Antisemiten und Antisemitinnen ihre unterdrückte Faszination und ihren Hass für das Großstadtleben auf Juden und Jüdinnen projizieren. Nach Zygmunt Baumann fungieren Juden und Jüdinnen im Antisemitismus als ein Symbol der Ambivalenz als solcher, die auf Antisemiten gleichermaßen anziehend und abstoßend wirkt und sie daran erinnert, „,was man gerne wäre, aber zu ängstlich ist, zu sein“ (Baumann 1995: 49).

Als Großstadtbewohner par excellence verkörpern die Juden, so meine Schlussfolgerung, die ambivalente Großstadterfahrung der (völkischen) Antisemiten. Sowohl die Großstadtfeindschaft als auch der Antisemitismus resultieren im völkischen Denken aus dem psychologischen Bedürfnis, die Ambivalenz, Krisenhaftigkeit und Kontingenz moderner Vergesellschaftung von dem Ideal eines nicht fragmentierten und homogenen Volkes abzuspalten und sie gleichermaßen an einer Personengruppe und an einem geographischen Ort festzumachen. Das Landvolk und das Landleben erscheinen demgemäß als die einzigen Bezugsgrößen in der modernen Gesellschaft, die frei von ,jüdischem Einfluss“ sind, und stehen daher im Zentrum der völkischen Bestrebung einer Erneuerung und Gesundung des „Volkslebens“. 


\section{Fazit und Ausblick}

Der moderne Antisemitismus und die Großstadtfeindschaft haben ihren Ursprung in der Übergangsepoche zwischen der zweiten Hälfte des 18. Jahrhunderts und dem letzten Drittel des 19. Jahrhunderts, als sich die Transformation der ständisch-feudalen Ordnung zur bürgerlich-kapitalistischen Gesellschaft vollzog. Die ideologische Ausformung der Großstadtfeindschaft steht zudem in einem Zusammenhang mit dem Funktionswandel und der Modernisierung des Städtewesens. Die sich im Zuge des sozialen Strukturwandels der Moderne vollziehende Öffnung der Städte, die zu einem der wesentlichen Charakteristika der modernen Großstädte wurde, war die Voraussetzung dafür, dass eine ablehnende Haltung gegenüber dem Verstädterungsprozess und dem modernen Großstadtleben entstehen konnte, die von dem Gedanken bestimmt war, dass von den modernen Großstädten eine Gefahr für den Nationalstaat und für die Bevölkerung ausgeht. Die Großstadtfeindschaft entstand insofern zu einem Zeitpunkt in der europäischen und deutschen Geschichte, als die seit dem Mittelalter existierende strikte Trennung zwischen Stadt und Land erodierte und die StadtLand-Differenzen langfristig betrachtet an Bedeutung zu verlieren begannen.

Der moderne Antisemitismus und die Großstadtfeindschaft entwickelten sich gegen Ende des 19. Jahrhunderts zu heterogenen Bewegungen, die sich kritisch bis ablehnend gegenüber den Modernisierungsprozessen positionierten. Beide Bewegungen verfolgten unterschiedliche politische Zielsetzungen, so dass es längere Zeit nur schwach ausgeprägte Berührungspunkte gab. Das großstadtfeindliche Lager zielte vornehmlich darauf ab, das Anwachsen der Großstädte zu bremsen und den Anteil der in der Landwirtschaft tätigen Bevölkerung zu erhöhen oder zumindest zu erhalten. Die großstadtfeindliche Literatur des Kaiserreichs war Bestandteil mehrerer Spezialdebatten, für die die Analyse des Verstädterungsprozesses und des Großstadtlebens eine zentrale und konstitutive Bedeutung hatte, die zugleich jedoch nicht notwendigerweise auf antisemitische Feindbilder angewiesen waren. Dieser Sachverhalt lässt sich an dem rassenhygienischen und sozialdarwinistischen Diskurs über die Binnenwanderung in die Großstädte veranschaulichen, zu dem im Besonderen Otto Ammon und Georg Hansen beitrugen. Diese Debatte war unzweifelhaft Ausdruck einer antidemokratischen und modernitätsskeptischen bis -feindlichen Haltung, war im Ergebnis aber nicht vom Antisemitismus dominiert.

Obwohl Wilhelm Heinrich Riehl bereits in der Mitte des 19. Jahrhunderts in seinen Schriften Ansätze einer Personifizierung des gesellschaftlichen Strukturwandels in den Juden erkennen 
ließ und durch die von ihm aufgemachte Dichotomie Bauer/Jude Anknüpfungspunkte für eine Zusammenführung von Antisemitismus und Großstadtfeindschaft lieferte, war ihm und anderen einflussreichen Großstadtfeinden der Gedanke fremd, dass der Prozess der Verstädterung von einer kleinen Bevölkerungsgruppe bewusst und gezielt vorangetrieben werde. Hansen und Ammon begriffen die Abwanderung in die Großstädte explizit als einen natürlichen und organischen Vorgang, der Teil eines von Naturgesetzen bestimmten Ausleseund Selektionsvorgangs ist.

Eine wechselseitige Durchdringung von Antisemitismus und Großstadtfeindschaft vollzog sich erst zu dem Zeitpunkt, als der moderne Antisemitismus sich zu einer Welterklärung verdichtete und schließlich im völkischen Denken zum integralen Bestandteil einer Wiedergeburts- und Erneuerungsrethorik wurde, die von agrarromantischen Denkmustern durchzogen war. Die völkische Großstadtfeindschaft unterschied sich von der Großstadtrezeption anderer Bewegungen und Ideologien primär darin, dass sie die Verstädterung als einen von Juden gelenkten Prozess imaginierte und als solchen in ihrer Literatur kommunizierte. Hiermit fügte sie der Großstadtfeindschaft eine neue und entscheidende Facette hinzu und führte einen Begründungszusammenhang in die Diskussion ein, den es bis zu diesem Zeitpunkt in der großstadtfeindlichen Literatur nicht gegeben hatte.

Die Identifizierung der Juden mit dem Verstädterungsprozess und dem modernen Großstadtleben speiste sich in der völkischen Bewegung aus dem psychologischen Bedürfnis und Drang, den Modernisierungsprozess und die damit verbundene Verstädterung in den Juden zu personifizieren. Alle Phänomene, die die Völkischen den Großstädten zuschrieben, wurden nach den Maßstäben des völkischen Antisemitismus gedeutet und bewertet. Die völkische Großstadtperzeption knüpfte an eine bereits existierende und sich gegen Ende des 19. Jahrhunderts zunehmend ausdifferenzierende und radikalisierende Großstadtfeindschaft an und führte zentrale Stereotype und Theoreme des antisemitischen und des großstadtfeindlichen Diskurses zusammen, so dass „Großstadt“ und „Judentum“ als eine identische Gefahr für Volk und Nation rezipiert wurden.

Nahezu alle Aspekte der Moderne, die unter das Verdikt der völkischen Zivilisationskritik fielen, besaßen sowohl eine antisemitische als auch eine großstadtfeindliche Konnotation: Liberalismus, Marxismus, Materialismus, Kosmopolitismus, Geldwirtschaft, Genusssucht und sinnliche Ausschweifung wurden als ,jüdische“ und „großstädtische“ Charakteristika der Gegenwartsgesellschaft apostrophiert. 
Die modernen Großstädte erschienen in der völkischen Wahrnehmung daher als Verwirklichungen eines ,jüdischen Prinzips“, und der jüdischen Bevölkerung wurde komplementär hierzu eine hohe Anpassungsfähigkeit an die krankmachenden und die „Volkskraft“ aufzehrenden Großstädte zugeschrieben. Die strikte und binäre Trennung zwischen Großstadt und Land, die die gesamte großstadtfeindliche Literatur des Kaiserreichs und der Weimarer Republik dominierte, avancierte im völkischen Denken zu einem rassischen Gegensatz zwischen Juden und Deutschen. Der völkische Nationalismus wirkte mit seiner kaum überschaubaren Eigenliteratur über den eigenen Rezipientenkreis hinaus und hatte einen untrüglichen Anteil daran, dass die assoziative Verbindung von „Judentum“ und „Großstadt“ sich in der deutschen Gesellschaft verfestigte. Insofern trug die völkische Ideologie zur kulturellen Segmentierung im Kaiserreich bei und prägte die inhaltliche Ausformung der von Volkov beschriebenen modernitätsfeindlichen Kultur.

Die modernen Großstädte waren dasjenige Phänomen der Moderne, an dem sich das Unbehagen der völkischen Ideologen an der Moderne am stärksten und radikalsten ausagierte. Im Unterschied zur modernen Technik und dem Industriekapital waren die Großstädte nicht in die völkische Ideologie integrierbar, da sie in der antisemitischen Wahrnehmung der Völkischen Orte der „Zersetzung“ und der Auflösung völkischer Identität darstellten. Völkische Vorstellungen von einer anderen und alternativen Moderne bezogen sich mehrheitlich auf das Ideal eines industrialisierten Deutschlands, in der mindestens die Hälfte der Bevölkerung in der Landwirtschaft beschäftigt ist und die Größe und das Wachstum der Großstädte begrenzt werde. Städte wurden zwar als notwendige Knotenpunkte des kulturellen, politischen und ökonomischen Lebens anerkannt, damit waren jedoch nicht die unkontrolliert wachsenden Großstädte gemeint, mit denen die völkischen Autoren aus eigener Anschauung bestens vertraut waren.

Völkische Vorstellungen von städtischem Leben orientierten sich an dem Ideal einer nach ideologischen Maßstäben gegliederten und geordneten Kleinstadt von nicht mehr als 30000 Einwohnern, die für eine Symbiose aus einer als deutsch verstandenen Stadtkultur und dem bäuerlichen Leben stehen sollte. Exemplarisch hierfür steht die breite Rezeption des Gartenstadtgedankens, der nicht zufällig von einer der Galionsfiguren der völkischen Bewegung des Kaiserreichs und der Weimarer Republik, Theodor Fritsch, auf das Tapet gebracht wurde. Ein starker Indikator dafür, dass führende Köpfe der Völkischen die Großstädte bzw. ihren innenstädtischen Raum als Lebensumfeld ablehnten, kann in der 
Tatsache gesehen werden, dass viele von ihnen aus den Innenstädten an die Ränder der Großstädte oder in Vororte zogen und sich dort niederließen (vgl. Puschner 2001: 164-165).

Im völkischen Schrifttum wurde nicht in Zweifel gezogen, dass die Städte Orte der industriellen Produktion sein sollten, die durch ein Eisbahn- und Verkehrsnetz mit anderen industriellen Standorten verbunden sein sollten. Industriefeindlich war die völkische Bewegung des Kaiserreichs und der Weimarer Republik daher nur insofern als damit die Konzentration von Menschen in großstädtischen Ballungs- und Industriezentren und eine Marginalisierung der in der Landwirtschaft tätigen Bevölkerung gemeint war. Eine grundsätzliche Ablehnung von Technik und Industrie verbarg sich hinter antiindustriellen Invektiven jedoch nicht; die Akzeptanz von Technik und Industrie war vielmehr mit der Agrarromantik und der Blut-und-Boden-Ideologie der völkischen Bewegung vereinbar.

Die Vereinbarkeit der Agrarromantik mit der Akzeptanz von Technik und Industrie hat auch einen geschichtlichen Hintergrund, da die ersten Fabriken und Industriebetriebe nicht in den Städten, sondern auf dem Land, in unmittelbarer Nähe zu den Rohstoffquellen, entstanden sind (vgl. Häußermann/Siebel 2004: 19). Die Großstadtfeindschaft der Völkischen war ohne jeden Zweifel modernitätsfeindlich, aber es verband sich mir ihr kein Antimodernismus dergestalt, dass mit ihr der Wunsch nach einer Rückkehr in eine vorindustrielle Ordnung verbunden war. Die Völkischen waren mehrheitlich der Überzeugung, dass eine Industrienation wie Deutschland nicht nur nicht auf die Existenz von Großstädten und Metropolen angewiesen sei, sondern, dass eine Begrenzung der Größe der großstädtischen Ballungsräume eine zentrale Voraussetzung für eine völkische Erneuerung im Zeitalter der Industrialisierung sei. An ihrer Haltung gegenüber den modernen Großstädten lässt sich die von Stefan Breuer (vgl. 2005, 2008, 2010a) gewonnene Erkenntnis empirisch untermauern, dass die völkische Bewegung der einfachen bzw. ersten Modernisierung (Leistungsprinzip, wissenschaftlich-technische Rationalität, funktionale Differenzierung) zugestimmt hat, jedoch nicht der reflexiven Modernisierung (Veränderung der Lebens- und Arbeitsformen der Kleinfamilie und der patriarchalen Geschlechterordnung), für die aus Sicht der Völkischen das moderne Großstadtleben die Negativfolie abgab.

Die völkische Großstadtfeindschaft war in dem Sinne irrational, dass sich die Vorstellungen, die mit ihr verbunden waren, in einer im hohen Maße industrialisierten und verstädterten Gesellschaft wie der deutschen zur Zeit des Kaiserreichs und speziell während der Weimarer Republik, nicht umsetzen ließen. Dennoch, oder gerade deswegen, fanden zentrale Elemente der völkischen Großstadtfeindschaft nach 1933 Eingang in Politikfelder des NS-Staates, 
womit die Nationalsozialisten unter Beweis stellten, dass sich in einem der modernsten Industriestaaten der Welt politische Maßnahmen umsetzen ließen, die auf großstadtfeindlichen Ideologemen und Prämissen beruhten.

Die auf der nationalsozialistischen Rassenideologie basierende Agar-, Bauern- und Siedlungspolitik war zwar in hohem Maße ineffizient und trat deshalb ab 1936 hinten den Imperativen der Aufrüstung und Militarisierung zurück. Die großstadtfeindlich grundierte Politik der Nationalsozialisten macht zugleich jedoch deutlich, dass die völkische Großstadtfeindschaft keine abstrakte Idee blieb, sondern auf ihre Verwirklichung drängte. Die Großstadtfeindschaft muss vor dem Hintergrund ihrer historischen Genese und ihrer Etablierung als eines kulturellen Paradigmas als eine „Erfolgsgeschichte“ gesehen werden, die fester Bestandteil einer antiwestlichen, antidemokratischen und radikalnationalistischen Ideologietradition in Deutschland wurde und die Wahrnehmung der Großstädte bis weit in die zweite Hälfte des 20. Jahrhunderts hinein - und zum Teil bis heute - geprägt hat. Im völkischen Denken und in der Ideologie und Praxis des Nationalsozialismus ist die Großstadtfeindschaft ein integrales Moment des Antisemitismus geworden.

Die Beschäftigung mit der völkischen Großstadtfeindschaft wirft die Frage auf, welche Erkenntnisse aus ihrer Analyse für die Gegenwart gewonnen werden können. Aus der vorliegenden Untersuchung $\mathrm{zu}$ dem Zusammenhang von Antisemitismus und Großstadtfeindschaft im völkischen Denken ergeben sich Fragen und Hinweise zu zwei Themenfeldern, die für eine gegenwartsbezogene Beschäftigung mit Großstadtfeindschaft und Antisemitismus von Interesse sind: Das erste Forschungsfeld betrifft Manifestationen großstadtfeindlichen Denkens und großstadtfeindlicher Praktiken in der extremen Rechten der Gegenwart. Wie in der Studie gezeigt wurde, wirkt die völkische Großstadtfeindschaft in der extremen Rechten bis in die Gegenwart nach. In den letzten Jahren war zu beobachten, dass großstadtfeindliche Schriften und praktische Ansätze, wie beispielsweise die Siedlungsarbeit, eine verstärkte Resonanz in der rechtsextremen und neonazistischen Szene erfahren haben. Ein größeres Forschungsdesiderat stellt die Frage dar, wie sich die Großstadtfeindschaft nach dem Ende der NS-Herrschaft in der extremen Rechten als auch insgesamt in Deutschland entwickelt hat. Eine Untersuchung der historischen Entwicklung der Großstadtfeindschaft in der Bundesrepublik steht nachwievor aus.

Der Zusammenhang zwischen Antisemitismus und Großstadtfeindschaft im rechtsextremen und konservativen Denken ist zugleich im europäischen Kontext von Interesse. Die Politikwissenschaftlerin Magdalena Marsovszky hat wiederholt darauf hingewiesen, dass es 
seit dem ersten Machtantritt von Viktor Orbán 1998 in Ungarn zu einer Revitalisierung großstadtfeindlicher Stereotype und Bilder gekommen ist (vgl. Marsovszky 2006: 216). Budapest wird in konservativen und rechtsextremen Kreisen erneut zu einem Feindbild erklärt (,sündhafte Stadt"), wovon nicht zuletzt die Verwendung des antisemitischen Schlagworts „Judapest“ als pejorative Bezeichnung für die Hauptstadt durch Mitglieder der völkischen Partei Jobbik zeugt. In diesem Zusammenhang hebt Marsovszky hervor, dass es in Ungarn seit Ende des 19. Jahrhunderts einen antisemitischen Diskurs über die Großstädte gibt, der sich - vergleichbar mit dem in Deutschland - in der Zwischenkriegszeit der 1920er und 30er Jahre radikalisierte (vgl. Marsovszky 2006, 2009). Insofern bieten sich sowohl Länderstudien über Großstadtfeindschaft im gegenwärtigen Rechtsextremismus als auch komparatistische Studien im Rahmen einer vergleichenden Rechtsextremismusforschung an. Es ist ein Anliegen der vorliegenden Studien Impulse für die Erforschung gegenwärtiger Manifestationen von Großstadtfeindschaft und Antisemitismus in der extremen Rechten in Deutschland und Europa zu liefern.

Im Anschluss an die Überlegungen von Ian Buruma und Avishai Margalit (vgl. 2004: 13-47) zur Bedeutung der Großstadtfeindschaft für eine antiwestliche und antisemitische Ideologie, die sich in der zweiten Hälfte des 20. Jahrhunderts von der westlichen in die nichtwestliche Welt verlagert hat, stellt sich die Frage, inwieweit Erkenntnisse aus der Forschung zur völkischen Großstadtfeindschaft zur Erforschung von Stadtfeindschaft in Bewegungen beitragen kann, die unter anderen geographischen, sozialen und historischen Bedingungen entstanden sind. Buruma und Margalit entwickeln ihre Gedanken zu dieser Ideologie, die sie Occidentalism nennen, unter dem Eindruck der islamistischen Terroranschläge auf das World Trade Center am 11. September 2001. Sie interpretieren die Zerstörung eines der Wahrzeichen der Stadt New York als ein antiurbanes Fanal, dessen Movens der Hass auf die sündhafte, die göttliche Ordnung verachtende Stadt ist: „Hubris, empire building, secularism, individualism, and the power and attraction of money - all these are connected to the idea of the sinful City of Man“ (Buruma/Margalit 2004: 16).

Der islamistische Terroranschlag auf die als „verwestlicht“ geltende indische Finanz- und Filmmetropole Mumbai am 26. November 2008, dem 174 Menschen zum Opfer fielen, wird als ein weiteres Beispiel für einen antiurbanen und zugleich antisemitischen Impetus des Islamismus diskutiert (vgl. Kahmann 2011: 114). Nach einem ähnlichen Muster verliefen die Terroranschläge in Paris am 13. November 2015, bei dem 130 Menschen ermordet wurden. Sowohl die Anschlagsziele als auch das Bekennerschreiben des „Islamischen Staates“ (IS) 
offenbaren, dass der islamitissche Terrorismus sich gegen jede Form von urbanem Amüsement richtet. In der deutschsprachigen Version des Bekennerschreibens des IS wird Paris als „die Hauptstadt der Prostitution und des Lasters“633 bezeichnet. Diese Wortwahl erinnert in frappierender Weise an die europäische und deutsche Großstadtfeindschaft des 19. und 20. Jahrhunderts und an die sich in ihr ausdrückende Lust- und Sexualitätsfeindschaft.

Es ist offenkundig, dass der Bannstrahl islamistischer Moralvorstellungen Aspekte der sozialen Alltagswelt trifft, die in besonderer Weise für das Großstadtleben charakteristisch sind. Hierzu kann ein öffentlicher Raum gezählt werden, in dem die Präsenz von Frauen als eigenständig handelnde Subjekte selbstverständlich ist, Entfaltungsräume für alternative sexuelle und geschlechtliche Identitäten oder das Vorhandensein von Bars, Cafés oder Nachtclubs, die ein Mindestmaß an Genuss und Ausschweifung ermöglichen. Vor diesem Hintergrund stellt sich die Frage, ob und wie sich der städtische Raum unter der Herrschaft eines islamitischen Regimes verändert. Die Übernahme der Millionenstadt Mossul im Norden des Iraks im Sommer 2014 durch die islamistischen Terrormilizen des IS wirft die Frage auf, wie sich der Alltag in einer Millionen-Metropole unter einer Besatzungsmacht verändert, die radikalen und fundamentalistischen Moral- und Sittenvorstellungen anhängt.

Die Frage nach einer Vergleichbarkeit von großstadtfeindlichen Ressentiments im Islamismus und im europäischen Rechtsextremismus bzw. Faschismus muss dabei auch vor dem Hintergrund einer zeitlichen Überschneidung der Entstehung der faschistischen Bewegungen und Regime in Europa in den 1920er und 30er Jahren und der Herausbildung des Islamismus als einer politischen Bewegung analysiert werden. Nach Marchand sind alle faschistischen Regierungen Westeuropas in unterschiedlicher Weise mit den modernen Großstädten in einen ideologischen Konflikt geraten (vgl. Marchand 1999: 39). Der Islamismus kennt zwar keinen dem Faschismus vergleichbaren Rassismus und auch keine mit der völkischen und nationalsozialistischen Ideologie verbundene Idee von „Blut-und-Boden“. Gemeinsamkeiten zwischen Islamisten und europäischen Faschisten ergeben sich jedoch aus der Ablehnung der Großstadt als eines Symbols einer verhassten Moderne, die mit Amerika und dem Judentum identifiziert wird. Der Vergleich zwischen großstadtfeindlichen und antisemitischen Motiven im Islamismus und im europäischen Faschismus/Rechtsextremismus kann daher ein aufschluss- und erkenntnisreicher Untersuchungsgegenstand sein. Die Erforschung antiurbaner Elemente im Islamismus kann als eine Leerstelle in der bisherigen Forschung zum Islamismus betrachtet werden.

\footnotetext{
${ }^{33}$ https://pbs.twimg.com/media/CTzEVewW4AAxN6v.jpg:large (15. November 2015)
} 
Im Zusammenhang mit diesem Untersuchungsgegenstand müsste auch eine tiefergehende Analyse des Zusammenhanges zwischen Großstadtfeindschaft und Antiamerikanismus stehen, der in dieser Studie nur angeschnitten werden konnte. Es kann dabei davon ausgegangen werden, dass die Großstadtfeindschaft ein verbindendes Element zwischen dem Antisemitismus und dem Antiamerikanismus bildet. Wie bereits angedeutet wurde, spielt bei der Wahrnehmung der Amerikaner als einer städtisch und großstädtisch geprägten Bevölkerung die assoziative Verbindung zwischen den USA und der Geldwirtschaft bzw. dem Finanzkapital eine entscheidende Rolle. Zu untersuchen wäre zudem, inwieweit bei ablehnenden Reaktionen auf Modernisierungs- und Verstädterungsprozesse amerikanische Großstädte und Metropolen eine Negativfolie abgeben. 


\section{Literaturverzeichnis}

\section{Primärliteratur}

Reichserbhofgesetz (REG). Vom 29. September 1933 (RGBL I S. 685) (1944). In: Heinrich Schönfelder (Hg.): Deutsche Reichsgesetze. Sammlung des Verfassungs-, Gemein-, Strafund Verfahrenrechts für den täglichen Gebrauch. Dreizehnte, ergäntze Auflage. München, Berlin: Beck'sche Verlagsbuchhandlung, S. 1-11.

o. A. (1896): Die Großstädte und das Land. In: Das Land. Zeitschrift für die sozialen und volkstümlichen Angelegenheiten auf dem Lande. Organ für die gesamte ländliche Wohlfahrtspflege 5 (2), S. 26.

o. A. (1902): Körperliche Tüchtigkeit der großstädtischen und der ländlichen Bevölkerung. In: Politisch-anthropologische Revue. Monatsschrift für das soziale und geistige Leben der Völker 1 (2), S. 149.

o. A. (1903): Verwahrlosung der gebildeten Jugend. In: Hammer. Zeitschrift für deutschen Sinn 2 (32), S. 473-477.

o. A. (1904): Ein Zucht-Problem. In: Hammer. Blätter für deutschen Sinn 3 (41), S. 97-99.

o. A. (1905): Volks-Erschöpfung. In: Hammer. Blätter für deutschen Sinn 4 (83), S. 529-534.

o. A. (1908): Landflucht u. Freizügigkeit. In: Hammer. Blätter für deutschen Sinn 7 (143), S. 65-69.

o. A. (1912): Der Rassen-Verfall in England. In: Hammer. Blätter für deutschen Sinn 11 (231), S. $57-61$.

o. A. (1912a): Zur Organisation der Hammerbund-Gemeinden. In: Hammer. Blätter für deutschen Sinn 11 (233), S. 133-134.

o. A. (1913): Der Weg auf's Land als Schutz vor Entartung. In: Hammer. Blätter für deutschen Sinn 12 (256), S. 99-100.

o. A. (1920): Hammer-Ziele. In: Hammer. Parteilose Zeitschrift für nationales Leben 19 (438), S. $347-348$.

o. A. (1926): Biologische Vorteile des Judentums. In: Hammer. Parteilose Zeitschrift für nationales Leben 25 (576), S. 291. 
o. A. (1926a): Der Triumph des jüdischen Schrifttums. In: Hammer. Parteilose Zeitschrift für nationales Leben 25 (581), S. 424-426.

Ammon, Otto (1893): Die natürliche Auslese beim Menschen. Auf Grund der Ergebnisse der anthropologischen Untersuchungen der Wehrpflichtigen in Baden und anderer Materialien. Jena: Verlag von Gustav Fischer.

Ammon, Otto (1894): Die Bedeutung des Bauernstandes für den Staat und die Gesellschaft. Sozialanthropologische Studie. Berlin: Crowiksch \& Sohn.

Ammon, Otto (1895): Die Gesellschaftsordnung und ihre natürlichen Grundlagen. Entwurf einer Sozial-Anthropologie zum Gebrauch für alle Gebildeten, die sich mit sozialen Fragen befassen. Jena: Verlag von Gustav Fischer.

Arndt, Ernst Moritz (1938 [1814]): Über künftige ständische Verfassungen in Deutschland. In: W. O. W. Terstegen (Hg.): Ernst Moritz Arndt. Agrarpolitische Schriften. Goslar: Blut und Boden, S. 277-281.

Arndt, Ernst Moritz (1938 [1815]): Über den Bauernstand und über seine Stellvertretung im Staate. In: W. O. W. Terstegen (Hg.): Ernst Moritz Arndt. Agrarpolitische Schriften. Goslar: Blut und Boden, S. 283-323.

Baur, Erwin; Fischer, Eugen; Lenz, Fritz (1921): Grundriß der menschlichen Erblichkeitslehre und Rassenhygiene. Band 1. München: J.f. Lehmanns Verlag.

Chamberlain, Houston Stewart (1901): Die Grundlagen des neunzehnten Jahrhunderts. 1. Hälfte. 3. Aufl. München: F. Bruckmann A.G.

Darré, Richard Walther (1929): Das Bauerntum als Lebensquell der Nordischen Rasse. München: J.f. Lehmanns Verlag.

Darré, Richard Walther (1930): Neuadel aus Blut und Boden. München: J.f. Lehmanns Verlag.

Darré, Richard Walther (1931): Zur Wiedergeburt des Bauerntums. In: Deutschlands Erneuerung. Monatsschrift für das deutsche Volk 15 (11), S. 641-646.

Darré, Richard Walther (1941 [1930]): Blut und Boden als Lebensgrundlage der nordischen Rasse. In: Richard Walther Darré: Um Blut und Boden. Reden und Aufsätze. 3. Aufl. München: Zentralverlag der NSDAP, S. 17-29. 
Darré, Richard Walther (1941 [1931]): Die Lebensgrundlage des deutschen Volkes. In: Richard Walther Darré: Um Blut und Boden. Reden und Aufsätze. 3. Aufl. München: Zentralverlag der NSDAP, S. 55-59.

Darré, Richard Walther (1932): Landvolk in Not und seine Rettung durch Adolf Hitler. München: Franz-Eher-Verlag,

Darré, Richard Walther (1941 [1932/1933]): Bauer und Landwirt. In: Richard Walther Darré: Um Blut und Boden. Reden und Aufsätze. 3. Aufl. München: Zentralverlag der NSDAP, S. 177209.

Darré, Richard Walther (1941 [1933/34]): Unser Weg. In: Richard Walter Darré: Um Blut und Boden. Reden und Aufsätze. 3. Aufl. München: Zentralverlag der NSDAP, S. 69-106.

Darré, Richard Walther (1941 [1935]): Blut und Boden, ein Grundgedanke des nationalsozialistischen Rechts. In: Richard Walther Darré: Um Blut und Boden. Reden und Aufsätze. 3. Aufl. München: Zentralverlag der NSDAP, S. 295-312.

Feder, Gottfried (1939): Die neue Stadt. Versuch der Begründung einer neuen Stadtplanungskunst aus der sozialen Struktur der Bevölkerung. Berlin: Julius Springer.

Fritsch, Theodor (1888): Antisemiten-Katechismus: Eine Zusammenstellung des wichtigsten Materials zum Verständniß der Judenfrage. 6. Aufl. Leipzig: Fritsch.

Ab 1907: Handbuch der Judenfrage. Eine Zusammenstellung des wichtigsten Materials zur Beurteilung des jüdischen Volkes. 26. Auflage. Hamburg: Hanseatische Dr.- u. Verl.-Anst

Fritsch, Theodor (1896): Die Stadt der Zukunft. Leipzig.

Fritsch, Theodor (1910): Die geistige Unterjochung Deutschlands. In: Hammer. Blätter für deutschen Sinn 9 (184), S. 93-100.

Fritsch, Theodor (1912): Die Stadt der Zukunft: (Gartenstadt). Zweite Ausgabe. Leipzig: HammerVerlag

Fritsch, Theodor (1912a): Zu unserer Flugblatt-Verbreitung. In: Hammer. Blätter für deutschen Sinn 11 (230), S. 46-48.

Fritsch, Theodor (1914): Landsiedlung und entgegenstehende Bedenken. In: Hammer. Parteilose Zeitschrift für nationales Leben 13 (287), S. 281-287. 
Fritsch, Theodor (1918): Junge Mädchen auf's Land. In: Hammer. Parteilose Zeitschrift für nationales Leben 17 (384), S. 246-247.

Fritsch, Theodor (1920): An der Zeitenwende. In: Hammer. Parteilose Zeitschrift für nationales Leben 19 (444), S. 461-464.

Fritsch, Theodor (1921): Was wollen wir? In: Hammer. Parteilose Zeitschrift für nationales Leben 20 (445), S. 1-6.

Fritsch, Theodor (1924): Kulturkampf? In: Hammer. Parteilose Zeitschrift für nationales Leben 23 (537), S. 405-408.

Fritsch, Theodor (1926): Deutsche Kultur-Erneuerung. Eine Anregung für Denker, Dichter und Künstler. In: Hammer. Parteilose Zeitschrift für nationales Leben 25 (587), S. 585-589.

Fritsch, Theodor (1926a): In eigner Sache. In: Hammer. Parteilose Zeitschrift für nationales Leben 25 (575), S. 202-204.

Fritsch, Theodor (1928): Ist die Judenmacht noch zu brechen? In: Hammer. Blätter für deutschen Sinn 27 (616), S. 81-86.

Fritsch, Theodor (1929): Der Untergang des Bauerntums und der Verfall der nordischen Rasse. In: Hammer. Blätter für deutschen Sinn 28 (654), S. 457-462.

Gansel, Jürgen (2007): Der Globalisierungs-Angriff auf den ländlichen Raum. Online verfügbar unter http://www.ab-rheinneckar.de/frankfurt/dateien/unterseiten/hintergrund/artikel/globalisierungsangriff.html.(18.11. 2015)

Gerlach, Kurt (1928): Volk mit Raum - Volk ohne Raum? In: Hammer. Blätter für deutschen Sinn 27 (624), S. 302-304.

Gerstenhauer, Max Robert (1933): Der völkische Gedanke in Vergangenheit und Zukunft. Aus der Geschichte der völkischen Bewegung. Leipzig: Armanen-Verlag.

Glagau, Otto (1876): Der Börsen- und Gründungs-Schwindel in Berlin. Leipzig: Verlag von Paul Frohberg.

Glagau, Otto (1879): Deutsches Handwerk und historisches Bürgerthum. 5. Aufl. Osnarbrück: Wehberg. 
Goebbels, Joseph (1935 [1927]): Antworten Sie, Genosse! In: Joseph Goebbels: Der Angriff. Aufsätze aus der Kampfzeit. München: Zentralverlag der NSDAP, S. 24-26.

Goebbels, Joseph (1935 [1927a]): Wir warten auf den Kadi! In: Joseph Goebbels: Der Angriff. Aufsätze aus der Kampfzeit. München: Zentralverlag der NSDAP, S. 21-23.

Goebbels, Joseph (1935 [1928]): Der Weltfeind. In: Joseph Goebbels: Der Angriff. Aufsätze aus der Kampfzeit. München: Zentralverlag der NSDAP, S. 333-335.

Günther, Hans F.K (1922): Rassenkunde des deutschen Volkes. München: J.f. Lehmanns Verlag.

Günther, Hans F.K (1934): Die Verstädterung. Ihre Gefahren für Volk und Staat vom Standpunkte der Lebensforschung und der Gesellschaftswissenschaft. Leipzig, Berlin: B.G. Teubner.

Hansen, Georg (1889): Die drei Bevölkerungsstuften. Ein Versuch, die Ursachen für das Blühen und Altern der Völker nachzuweisen. München: J. Lindauer`sche Buchhandlung.

Hentschel, Willibald (1906): Gründe und Abgründe des Verfalles. In: Hammer. Blätter für deutschen Sinn 5 (93), S. 251-255.

Hentschel, Willibald (1923): Was soll nun aus uns werden? In: Deutsche Bauern-Hochschule. Vierteljahrs-Zeitschrift für deutsche Bauernkultur und den germanischen Volkshochschulgedanken 3 (3), S. 44-45.

Hentschel, Willibald (1929): Rezension zu: R. Walter Darré: Das Bauerntum als Lebensquell der nordischen Rasse. In: Hammer. Blätter für deutschen Sinn 28 (642), S. 160-161.

Hering, Johannes (1915): Ist Siedland in Europa für uns nötig? In: Heimdall. Zeitschrift für reines Deutschtum und All-Deutschtum 20 (7/8), S. 69-73.

Hitler, Adolf (1961): Hitlers zweites Buch. Ein Dokument aus dem Jahr 1928. Eingeleitet und kommentiert von Gerhard L. Weinberg. Stuttgart: Deutsche Verlags-Anstalt.

Hoffmann, Fritz Hugo (1928): Artam. In: Nordische Blätter. Zeitschrift für nordisches Leben 4 (3), S. $33-35$.

Howard, Ebenezer (1898): To-Morrow. A Peaceful Path to Real Reform. London u.a.: Swan Sonnenschein \& Co.

Höcke, Björn (2015): Rede auf einer AfD-Kundgebung in Erfurt am 23.09.2015. Online verfügbar unter: https://www.youtube.com/watch?v=iHnjuJ3fdwE (1.10.2015). 
Jäger, Hermann (1920): Der innere Zusammenhang der völkischen Forderungen. In: Hammer. Parteilose Zeitschrift für nationales Leben 19 (437), S. 320-323..

Jurisch, Stephan (2010): "Rückkehr - Die Artamanenbewegung als Beispiel alternativer Lebensgestaltung". In: hier \& jetzt. radikal rechte Zeitung. Online verfügbar unter https://ahnenreihe.wordpress.com/2015/12/19/rueckkehr-die-artamanenbewegung-alsbeispiel-alternativer-lebensgestaltung/ (22.02.2016).

Jünger, Ernst (2001 [1926]): Gross-Stadt und Land. In: Sven Olaf Berggötz (Hg.): Ernst Jünger. Politische Publizistik. 1919-1933. Stuttgart: Klett-Cotta, S. 229-236.

Langbehn, Julius (1890): Rembrandt als Erzieher. 14. Aufl. Leipzig: C.L. Hirschfeld.

Lanz-Liebenfels, Jörg (1910): Schriftsteller-Elend und Rassen-Verfall. In: Hammer. Blätter für deutschen Sinn 9 (197), S. 454-458.

Leers, Johann von (1935): Bauerntum als Bluterneuerungsquell. In: Hammer. Blätter für deutschen Sinn 34 (791/792), S. 214-217.

Lenz, Fritz (1921): Grundriß der menschlichen Erblichkeitslehre und Rassenhygiene. Band II: Menschliche Auslese und Rassenhygiene. München: J.f. Lehmanns Verlag.

Looff, Hans Joachim et al. (1931): Das nationalrevolutionäre Manifest der deutschen Bauernschaft. In: Blut und Boden. Monatsschrift für wurzelstarkes Bauerntum, für deutsche Wesensart und nationale Freiheit 3 (4), S. 145-153.

Marr, Wilhelm (1879): Der Sieg des Judenthums über das Germanenthum. Vom nicht confessionellen Standpunkt aus betrachtet. 7. Auflage. Bern: Rudolph Costenoble.

Meinhold, E. (1909): Der Kampf zweier Welt-Anschauungen. In: Hammer. Blätter für deutschen Sinn 8 (175), S. 589-594.

Meurer, Georg (1903): Über deutsche Erziehung. In: Hammer. Blätter für deutschen Sinn 2 (27), S. 360-363.

Miller, Alfred (1928): Die Vernichtung des deutschen Volkes. In: Hammer. Blätter für deutschen Sinn 27 (620), S. 197-202.

Neuner, Ludwig (1923): Biologische Vorteile der jüdischen Nation. In: Hammer. Parteilose Zeitschrift für nationales Leben 22 (510), S. 357-360. 
Pudor, Heinrich (1906): Deutsche Ideale. In: Hammer. Blätter für deutschen Sinn 5 (85), S. 13-16.

Reinecke, Adolf (1907): Entartung und Verfall. Das Hauptstück der völkischen Frage. In: Heimdall. Zeitschrift für reines Deutschtum und All-Deutschtum 12 (2), S. 13-18.

Riehl, Wilhelm Heinrich (1858): Die Naturgeschichte des Volkes als Grundlage einer deutschen Social-Politik. Zweiter Band. Die bürgerliche Gesellschaft. 5. Aufl. Stuttgart, Augsburg: J.G. Cotta`scher Verlag.

Riehl, Wilhelm Heinrich (1861): Die Familie. Stuttgart: J.G. Cotta`scher Verlag.

Riehl, Wilhelm Heinrich (1861a): Die Naturgeschichte des Volkes als Grundlage einer deutschen Social-Politik. Erster Band. Land und Leute. 5. Aufl. Stuttgart: J.G. Cotta`scher Verlag.

Rosenberg, Alfred (1932): Der Mythus des 20. Jahrhunderts. Eine Wertung der seelisch-geistigen Gestaltungskämpfe unserer Zeit. 4. Auflage. München: Hoheneichen-Verlag.

Rosenberg, Alwiß (1927): Artamanengeist und Bauerntum. In: Deutsche Bauern-Hochschule. Sendschrift für Deutsche Art an alle Stände im Reich und jenseits der Grenzen und Meere 7 (2. und 3. Folge), S. 362-365.

Schmidt-Gibichenfels, Otto (1922): Die Rassenlehre und die Völkischen. In: Hammer. Parteilose Zeitschrift für nationales Leben 21 (469), S. 7-8.

Sohnrey, Heinrich (1896): Die Bedeutung der Landbevölkerung im Staate und unsere besonderen Aufgaben auf dem Lande. Berlin: Trowitzsch \& Sohn.

Sombart, Werner (1911): Die Juden und das Wirtschaftsleben. Leipzig: Duncker \& Humblot.

Spengler, Oswald (1933): Jahre der Entscheidung. Deutschland und die weltgeschichtliche Entwicklung. München: C.H. Beck.

Spengler, Oswald (2007): Der Untergang des Abendlandes. Umrisse einer Morphologie der Weltgeschichte. Düsseldorf: Albatros (Albatros im Patmos Verlagshaus).

Springmann, Baldur (1995): Bauer mit Leib und Seele. Band 2: Heimat aus Licht. Koblenz: Bublies.

Stoltheim, F. Roderich (Theodor Fritsch) (1914): Die Untergrabung der öffentlichen Moral durch die Warenhäuser. In: Hammer. Parteilose Zeitschrift für nationales Leben 13 (288), S. 324-326. 
Stoltheim, F. Roderich (Theodor Fritsch) (1924): Oswald Spengler und die Völkischen. In: Hammer. Parteilose Zeitschrift für nationales Leben 23 (526), S. 188-191.

Tanzmann, Bruno (1923): Die Sendung der deutschen Jugend! In: Deutsche Bauern-Hochschule. Vierteljahrs-Zeitschrift für deutsche Bauernkultur und den germanischen Volkshochschulgedanken 3 (1 u. 2), S. 2-8.

Wahle, Engelbert (1927): Grundlagen und Geschichte der Artamanenbewegung. In: Deutsche Bauern-Hochschule. Sendschrift für Deutsche Art an alle Stände im Reich und jenseits der Grenzen und Meere 7 (2. und 3. Folge), S. 369-372.

Wehleid, Hans (1905): Großstadt-Herrlichkeit. In: Hammer. Blätter für deutschen Sinn 4 (76), S. 376-377.

Weka (Walther August Gottfried) (1909): Rassentod und Semitismus. In: Hammer. Blätter für deutschen Sinn 8 (158), S. 46-50. 


\section{Forschungsliteratur}

o. A. (1996): Unabhängige Ökologen Deutschlands (UÖD). In: Jens Mecklenburg (Hg.): Handbuch deutscher Rechtsextremismus. Berlin: Elefanten Press (Antifa Edition), S. 315-316.

o. A. (2009): Anti-Urbanism. In: John Scott und Gordon Marshall (Hg.): Oxford Dictionary of Sociology. 3. Aufl. Oxford u.a.: Oxford University Press, S. 24-25.

Adorno, Theodor W. et al. (1950): The Authoritarian Personality. New York: Harper.

Ahrens, Rüdiger (2015): Bündische Jugend. Eine neue Geschichte 1918-1933. Göttingen: Wallstein.

Akngren, Birgitta; Hecker-Stanpehl, Jan; Piper, Ernst (2008): Alfred Rosenberg und die Nordische Gesellschaft. Der „nordische Gedanke“ in Theorie und Praxis. In: NORDEUROPAforum (2), S. 7-51.

Altenbockum, Jasper von (1994): Wilhelm Heinrich Riehl 1823-1897. Sozialwissenschaft zwischen Kulturgeschichte und Ethnographie. Köln, Weimar, Wien: Böhlau (Münstersche historische Forschungen, 6).

Aly, Götz (2012): Warum die Deutschen? Warum die Juden? Gleichheit, Neid und Rassenhass 1800 1933. Frankfurt am Main: Fischer.

Bahrdt, Hans-Paul (1998): Die moderne Großstadt. Soziologische Überlegungen zum Städtebau. Opladen: Leske + Budrich.

Ball, Harry V. (1971): The Sociology of Arnold M. Rose. In: Social Problems 18 (3), S. 287-298.

Barlösius, Eva (1997): Naturgemäße Lebensführung. Zur Geschichte der Lebensreform um die Jahrhundertwende. Frankfurt, New York: Campus.

Barth, Reinhard (2006): Jugend in Bewegung. Die Revolte von Jung gegen Alt in Deutschland im 20. Jahrhundert. Berlin: Vorwärts Buch.

Baumann, Zygmunt (1995): Große Gärten, kleine Gärten. Allosemitismus: Vormodern, Modern, Postmodern. In: Michael Werz (Hg.): Antisemitismus und Gesellschaft. Zur Diskussion um Auschwitz, Kulturindustrie und Gewalt. Frankfurt am Main: Neue Kritik, S. 44-61. 
Baumgärtner, Maik; Wrede, Jesko (2009): "Wer trägt die schwarze Fahne dort..." Völkische und neurechte Gruppen im Fahrwasser der Bündischen Jugend heute. Braunschweig: Bildungsvereinigung Arbeit und Leben Niedersachsen.

Beachy, Robert (2015): Das andere Berlin. Die Erfindung der Homosexualität. Eine deutsche Geschichte 1867-1933. München: Siedler.

Beauregard, Robert A. (2009): Antiurbanism in the United States, England, and China. In: Michael Thompson (Hg.): Fleeing the City. Studies in the Culture and Politics of Antiurbanism. New York: Palgrave Macmillan, S. 35-52.

Beck, Ulrich; Bonß, Wolfgang; Lau, Christoph (2001): Theorie reflexiver Modernisierung Fragestellungen, Hypothesen, Forschungsprogramme. In: Ulrich Beck und Wolfgang Bonß (Hg.): Die Modernisierung der Moderne. Frankfurt am Main: Suhrkamp, S. 11-62.

Becker, Peter Emil (1988): Zur Geschichte der Rassenhygiene. Wege ins Dritte Reich. Stuttgart, New York: Georg Thieme.

Berding, Helmut (1988): Moderner Antisemitismus in Deutschland. Frankfurt am Main: Suhrkamp.

Bergius, Hanne (1986): Berlin als Hure Babylon. In: Jochen Boberg, Tilman Fichter und Eckhart Gillen (Hg.): Die Metropole. Industriekultur in Berlin im 20. Jahrhundert. München: C.H. Beck, S. 102-119.

Bergmann, Klaus (1970): Agrarromantik und Großstadtfeindschaft. Meisenheim am Glan: Verlag Anton Hain.

Bergmann, Werner (1996): Völkischer Antisemitismus im Kaiserreich. In: Uwe Puschner, Walter Schmitz und Justus H. Ulbricht (Hg.): Handbuch zur "Völkischen Bewegung". 1871-1918. München u.a.: K. G. Saur, S. 449-463.

Bergmann, Werner (2004): Starker Auftakt - schwach im Abgang. Antisemitismusforschung in den Sozialwissenschaften. In: Werner Bergmann und Mona Körte (Hg.): Antisemitismusforschung in den Wissenschaften. Berlin: Metropol, S. 219-239.

Bering, Dietz (1978): Die Intellektuellen. Geschichte eines Schimpfwortes. Stuttgart: Klett-Cotta.

Beyme, Klaus von (2013): Konservatismus: Theorien des Konservatismus und Rechtsextremismus im Zeitalter der Ideologien 1789-1945. Wiesbaden: Springer. 
Biddiss, Michael (1993): Das Schicksalsbuch eines ganzen Zeitalters. Weltgeschichte, Stadtgeschichte und Kulturpessimismus bei Oswald Spengler. In: Peter Alter (Hg.): Im Banne der Metropolen. Berlin und London in den zwanziger Jahren. Göttingen: Vandenhoeck \& Ruprecht, S. 279-297.

Bleker, Johanna (1983): Die Stadt als Krankheitsfaktor. Eine Analyse ärztlicher Auffassungen im 19. Jahrhundert. In: Medizinhistorisches Journal 18 (1/2), S. 118-136.

Bönisch, Michael (1996): Die "Hammer"-Bewegung. In: Uwe Puschner, Walter Schmitz und Justus H. Ulbricht (Hg.): Handbuch zur "Völkischen Bewegung". 1871-1918. München u.a.: K. G. Saur, S. 341-365.

Böse, Christian (2008): Die Entstehung und Fortbildung des Reichserbhofgesetzes. Frankfurt am Main u.a.: Peter Lang.

Botsch, Gideon (2012): Die extreme Rechte in der Bundesrepublik Deutschland. 1949 bis heute. Bonn: Lizenzausgabe für die Bundeszentrale für politische Bildung.

Botsch, Gideon; Kopke, Christoph (2012): "Im Grunde genommen sollten wir schweigen..." Jüdische Studien ohne Antisemitismus- Antisemitismusforschung ohne Juden? In: Irena A. Dickmann et al. (Hg.): "... und handle mit Vernunft". Beiträge zur europäisch-jüdischen Beziehungsgeschichte. Festschrift zum 20jährigen Bestehen des Moses Mendelssohn Zentrums. Hildesheim, Zürich, New York: Georg Olms Verlag, S. 303-320.

Bramwell, Anna (1985): Blood and Soil. Richard Walther Darré and Hitler's "Green Party". Abbotsbrook, Bourne End, Buckinghamshire: Kensal Press.

Brauckmann, Stefan (2005): Die Artamanen als völkisch-nationalistische Gruppierung innerhalb der deutschen Jugendbewegung 1924-1935. In: Archiv der deutschen Jugendbewegung (Hg.): Historische Jugendforschung. Jahrbuch des Archives der deutschen Jugendbewegung. Schwalbach/Ts: Wochenschau Verlag (2), S. 176-196.

Brauckmann, Stefan (2012): Nach dem Vorbild der Artamanen: völkische Siedlungsbewegung. In: Politische Ökologie (131), S. 52-58.

Braun, Christina von (1995): Antisemitische Stereotype und Sexualphantasien. In: Jüdisches Museum der Stadt Wien (Hg.): Die Macht der Bilder. Antisemitische Vorurteile und Mythen. Wien: Picus, S. 180-191. 
Breuer, Stefan (1995): Anatomie der Konservativen Revolution. Darmstadt: Wiss. Buchges.

Breuer, Stefan (2004): Gescheiterte Milieubildung. Die Völkischen im deutschen Kaiserreich. In: Zeitschrift für Geschichtswissenschaft 52 (11), S. 995-1016.

Breuer, Stefan (2004a): Retter des Abendlandes. Spenglerkritik von rechts. In: Sabine Becker (Hg.): Jahrbuch zur Kultur und Literatur der Weimarer Republik. München: Edition Text + Kritik (Band 9), S. 165-193.

Breuer, Stefan (2005): Von der antisemitischen zur völkischen Bewegung. In: Aschkenas. Zeitschrift für Geschichte und Kultur der Juden 15 (2), S. 499-535.

Breuer, Stefan (2008): Die Völkischen in Deutschland. Kaiserreich und Weimarer Republik. Darmstadt: Wiss. Buchges.

Breuer, Stefan (2009): Die "Nordische Bewegung" in der Weimarer Republik. In: Zeitschrift für Geschichtswissenschaft 57 (6), S. 485-509.

Breuer, Stefan (2010): Der Streit um den "nordischen Gedanken" in der völkischen Bewegung. In: Zeitschrift für Religions- und Geistesgeschichte 62 (1), S. 1-27.

Breuer, Stefan (2010a): Die radikale Rechte in Deutschland 1871-1945. Eine politische Ideengeschichte. Stuttgart: Reclam.

Bullock, Nicholas; Read, James (1985): The Movement for Housing Reform in Germany and France 1840-1914. Campridge u.a.: Campridge University Press.

Buruma, Ian; Margalit, Avishai (2004): Occidentalism. The West in the Eyes of its Enemies. New York: Penguin Books.

Clapp, James A. (2009): The Origins of Antiurbanism. In: Michael Thompson (Hg.): Fleeing the City. Studies in the Culture and Politics of Antiurbanism. New York: Palgrave Macmillan, S. 53-67.

Claussen, Detlev (1988): Vom Judenhaß zum Antisemitismus. Materialien einer verleugneten Geschichte. Darmstadt: Luchterhand.

Claussen, Detlev (2005 [1987]): Grenzen der Aufklärung. Die gesellschaftliche Genese des modernen Antisemitismus. Frankfurt am Main: Fischer. 
Conn, Steven (2014): Americans Against The City. Anti-Urbanism in the Twentieth Century. New York: Oxford University Press.

Conte, Domenico (2004): Oswald Spengler. Eine Einführung. Leipzig: Leipziger Univ.-Verl.

Corni, Gustavo; Gies, Horst (1994): "Blut und Boden". Rassenideologie und Agrarpolitik im Staat Hitlers. Idstein: Schulz-Kirchner.

Diehl, Paula (2005): Macht - Mythos - Utopie. Die Körperbilder der SS-Männer. Berlin: AkademieVerlag.

Dietz, Bernhard (2008): Countryside-versus-City in European Thought: German and British AntiUrbanism between the Wars. In: The European Legacy: Toward New Paradigms 13 (7), S. 801-814.

Dirksmeier, Peter (2006): Habituelle Urbanität. In: Erdkunde. Archiv for Scientific Geography 60 (3), S. 221-230.

Ditfurth, Jutta (1996): Entspannt in die Barbarei. Esoterik, (Öko-)Faschismus und Biozentrismus. Hamburg: Konkret Literatur.

Dupeux, Louis (2005): Die Intellektuellen der "Konservativen Revolution" und ihr Einfluß zur Zeit der Weimarer Republik. In: Walter Schmitz und Clemens Vollnhals (Hg.): Völkische Bewegung - Konservative Bewegung - Nationalsozialismus. Aspekte einer politisierten Kultur. Dresden: Thelem, S. 3-20.

Eidenbenz, Mathias (1993): "Blut und Boden". Zu Funktion und Genese der Metaphern des Agrarismus und Biologismus in der nationalsozialistischen Propaganda R.W. Darrés. Bern u.a: Peter Lang.

Elias, Norbert (1997 [1938]): Über den Prozess der Zivilisation. Soziogenetische und psychogenetische Untersuchungen. Erster Band. 17. Aufl. Frankfurt am Main: Suhrkamp.

Essner, Cornelia (1994): Im Irrgarten der "Rassenlogik" oder nordische Rassenlehre und nationale Frage. In: Historische Mitteilungen 7 (1), S. 81-101.

Feld, Reinhard (1979): Subkultur, Lebensreform und Jugendbewegung in Deutschland von 1890 bis zum Faschismus. In: Verein zur Herausgabe des Mehrwerts e.V. (Hg.): Einfach anders leben? Ökonomie und Utopie. Osnarbrück: mehrwert, S. 11-42. 
Felken, Detelf (1988): Oswald Spengler. Konservativer Denker zwischen Kaiserreich und Diktatur. München: Beck.

Finkenberger, Martin (2008): „Während meines ganzen Lebens habe ich die Juden erforscht, wie ein Bakteriologe einen gefährlichen Bazillus studiert“ - Johann von Leers (1902-1965) als antisemitischer Propagandaexperte bis 1945. In: Bulletin des Deutschen Historischen Instituts Moskau (2), S. 88-99.

Finkenberger, Martin (2011): Johann von Leers und die „faschistische Internationale“ der fünfziger und sechziger Jahre in Argentinien und Ägypten. In: Zeitschrift für Geschichtswissenschaft 59 (6), S. 522-543.

Fleck, Christian (2007): Transatlantische Bereicherungen. Zur Erfindung der empirischen Sozialforschung. Frankfurt am Main: Suhrkamp.

Foucault, Michel (2014): Der Wille zum Wissen. Sexualität und Wahrheit 1. 20. Aufl. Frankfurt am Main: Suhrkamp.

Frank, Susanne (2003): Stadtplanung im Geschlechterkampf. Stadt und Geschlecht in der Großstadtentwicklung des 19. und 20. Jahrhunderts. Opladen: Leske + Budrich.

Frecot, Janos (1976): Die Lebensreformbewegung. In: Klaus Vondung (Hg.): Das wilhelminische Bildungsbürgertum. Zur Sozialgeschichte seiner Ideen. Göttingen: Vandenhoeck \& Ruprecht, S. $138-152$.

Freud, Sigmund (1993): Analyse der Phobie eines fünfährigen Knaben. In: Anna Freud et al. (Hg.): Sigmund Freud. Gesammelte Werke. Werke aus den Jahren 1906-1909. Frankfurt am Main: S. Fischer (Siebenter Band), S. 243-377.

Fritzen, Florentine (2006): Gesünder Leben. Die Lebensreformbewegung im 20. Jahrhundert. Stuttgart: Franz Steiner.

Gasimov, Zaur; Antonius, Carl; Duque, Lemke (2013): Oswald Spengler als europäisches Phänomen. Die Kultur- und Geschichtsmorphologie als Auslöser und Denkrahmen eines transnationalen Europa-Diskurses. In: Zaur Gasimov und Carl Antonius Lemke Duque (Hg.): Oswald Spengler als europäisches Phänomen. Der Transfer der Kultur- und Geschichtsmorphologie im Europa der Zwischenkriegszeit 1919-1939. Göttingen: Vandenhoeck \& Ruprecht (Veröffentlichungen des Instituts für Europäische Geschichte Mainz. Beiheft, 99), S. 7-14. 
Gebhardt, Eike (1988): Die Stadt als moralische Anstalt. Zum Mythos der kranken Stadt. In: Klaus R. Scherpe (Hg.): Die Unwirklichkeit der Städte. Großstadtdarstellungen zwischen Moderne und Postmoderne. Reinbek: Rowohlt, S. 279-303.

Geden, Oliver (1999): Rechte Ökologie. Umweltschutz zwischen Emanzipation und Faschismus. 2. Aufl. Berlin: Elefanten Press.

Gellately, Robert (1993): An der Schwelle der Moderne. Warenhäuser und ihre Feinde in Deutschland. In: Peter Alter (Hg.): Im Banne der Metropolen. Berlin und London in den zwanziger Jahren. Göttingen: Vandenhoeck \& Ruprecht, S. 131-156.

Gerhard, Gesine (2005): Breeding Pigs and People for the Third Reich. Richard Walther Darré's Agrarian Ideology. In: Franz-Josef Brüggemeier, Mark Cioc und Thomas Zeller (Hg.): How green were the Nazis? Nature, Environment, and Nation in the Third Reich. Athens: Ohio University Press (Ohio University Press series in ecology and history), S. 129-146.

Gerhardt, Uta (1992): Die soziologische Erklärung des nationalsozialistischen Antisemitismus während des Zweiten Weltkrieges in den USA. Zur Faschismustheorie Talcott Parsons. In: Wolfgang Benz (Hg.): Jahrbuch für Antisemitismusforschung. Frankfurt am Main, New York: Campus (1), S. 253-273.

Gerhardt, Uta (1993): Talcott Parsons on National Socialism. New York: De Gruyter.

Giesen, Bernhard; Junge, Kay; Kritschgau, Christian (1994): Vom Patriotismus zum völkischen Denken: Intellektuelle als Konstrukteure der deutschen Identität. In: Helmut Berding (Hg.): Nationales Bewußtsein und kollektive Identität. Studien zur Entwicklung des kollektiven Bewußtseins in der Neuzeit 2. Frankfurt am Main: Suhrkamp, S. 345-393.

Globisch, Claudia (2013): Radikaler Antisemitismus. Inklusions- und Exklusionssemantiken von links und rechts in Deutschland. Wiesbaden: VS Verlag für Sozialwissenschaften.

Gornik, Dorota (2007): Anstiftung zum Hass. Antiamerikanismus in den Karikaturen des Stürmers während des 2. Weltkrieges. Saarbrücken: VDM, Müller.

Gräfe, Thomas (2010): Antisemitismus in Deutschland 1815 - 1918: Rezensionen Forschungsüberblick - Bibliographie. Norderstedt: Books on Demand GmbH.

Greiert, Andreas (2011): Reflex oder Reflexion. Zivilisationskritik und Antisemitismus in der deutschen Jugendbewegung. In: Zeitschrift für Geschichtswissenschaft 59 (11), S. 897-919. 
Greive, Hermann (1983): Geschichte des modernen Antisemitismus in Deutschland. Darmstadt: Wiss. Buchges.

Grigat, Stephan (2007): Fetisch und Freiheit. Über die Rezeption der Marxschen Fetischkritik, die Emanzipation von Staat und Kapital und die Kritik des Antisemitismus. Freiburg [Br.]: Ça Ira.

Grill, Johnpeter Horst (1982): The Nazi Party's Rural Propaganda before 1928. In: Central European History 15 (2), S. 149-185,

Hagen, Joshua (2004): The Most German of Towns: Creating an Ideal Nazi Community in Rothenburg ob der Tauber. In: Annals of the Association of American Geographers 94 (1), S. $207-227$.

Hagen, Joshua (2006): Preservation, Tourism and Nationalism: The Jewel of the German Past. Aldershot u.a.: Ashgate.

Hahn, Hans-Jochaim; Kistenmacher, Olaf (Hg.) (2015): Beschreibungsversuche der Judenfeindschaft. Zur Geschichte der Antisemitismusforschung vor 1944. Berlin, München, Boston: De Gruyter.

Harlander, Tilman (1995): Zwischen Heimstätte und Wohnmaschine. Wohnungsbau und Wohnungspolitik in der Zeit des Nationalsozialismus. Basel, Boston: Birkhäuser (Stadt, Planung, Geschichte, 18).

Harten, Hans-Christian (2014): Himmlers Lehrer. Die Weltanschauliche Schulung in der SS 19331945. Paderborn: Ferdinand Schöningh.

Haupt, Heinz-Gerhard (1997): Konsum und Geschlechterverhältnisse. Einführende Bemerkungen. In: Hannes Siegrist, Hartmut Kaelble und Jürgen Kocka (Hg.): Europäische Konsumgeschichte. Zur Gesellschafts- und Kulturgeschichte des Konsums (18. bis 20. Jahrhundert). Frankfurt am Main, New York: Campus, S. 395-410.

Haury, Thomas (2002): Antisemitismus von links. Kommunistische Ideologie, Nationalismus und Antizionismus in der früheren DDR. Hamburg: Hamburger Edition.

Haury, Thomas (2004): Die Ideologie, die nicht vergehen will. 35 Jahre antisemitischer Antizionismus in der Neuen deutschen Linken. In: AG Antifa/Antira im StuRa der Uni Halle 
(Hg.): trotz und wegen Auschwitz. Antisemitsmus und nationale Identität nach 1945. Münster: Unrast, S. 93-114.

Häußermann, Hartmut (2001): Die europäische Stadt. In: Leviathan. Zeitschrift für Sozialwissenschaft 29 (2), S. 237-256.

Häußermann, Hartmut; Siebel, Walter (1978): Thesen zur Soziologie der Stadt. In: Leviathan. Zeitschrift für Sozialwissenschaft 6, S. 484-500.

Häußermann, Hartmut; Siebel, Walter (2000): Soziologie des Wohnens. Eine Einführung in Wandel und Ausdifferenzierung des Wohnens. 2. Aufl. Weinheim; München: Juventa-Verl.

Häußermann, Hartmut; Siebel, Walter (2004): Stadtsoziologie. Eine Einführung. Frankfurt am Main: Campus.

Hecht, Jennifer Michael (2000): Vacher de Lapouge and the Rise of Nazi Science. In: Journal of the History of Ideas 61 (2), S. 285-304.

Heinemann, Isabel (2003): "Rasse, Siedlung, deutsches Blut". Das Rasse- und Siedlungshauptamt der SS und die rassenpolitische Neuordnung Europas. Göttingen: Wallstein Verlag.

Heinrich, Michael (2005): Kritik der politischen Ökonomie. Eine Einführung. Stuttgart: Schmetterling Verlag.

Henschel, Gerhard (2008): Neidgeschrei. Antisemitismus und Sexualität. Hamburg: Hoffmann und Campe.

Herf, Jeffrey (1984): Reactionary Modernism. Technology, Culture and Politics in Weimar and the Third Reich. Cambridge [u.a.]: Cambridge Univ. Press.

Herf, Jeffrey (1993): Reaktionäre Modernisten und Berlin. Die Ablehnung der kosmopolitischen Metropole. In: Peter Alter (Hg.): Im Banne der Metropolen. Berlin und London in den zwanziger Jahren. Göttingen: Vandenhoeck \& Ruprecht, S. 237-258.

Hermand, Jost (1988): Der alte Traum vom neuen Reich. Völkische Utopien und Nationalsozialismus. Frankfurt am Main: Athenäum.

Herzog, Andreas (1999): Theodor Fritschs Zeitschrift Hammer und der Aufbau des "ReichsHammerbundes" als Instrumente der antisemitischen völkischen Reformbewegung (1902- 
1914). In: Mark Lehmstedt und Andreas Herzog (Hg.): Das bewegte Buch. Buchwesen und soziale, nationale und kulturelle Bewegung um 1900. Wiesbaden: Harrassowitz, S. 153-182.

Heuser, Marie-Luise (1991): Was grün begann endete blutigrot. Von der Naturromantik zu den Reagrarisierungs- und Entvölkerungsplänen der SA und SS. In: Dieter Hassenpflug (Hg.): Industrialismus und Ökoromantik. Geschichte und Perspektive der Ökologisierung. Wiesbaden: Deutscher Universitäts-Verlag, S. 43-64.

Hoffmann, Heike (1996): Völkische Kapitalismus-Kritik: Das Beispiel Warenhaus. In: Uwe Puschner, Walter Schmitz und Justus H. Ulbricht (Hg.): Handbuch zur "Völkischen Bewegung". 1871-1918. München, New Providence, London, Paris: K. G. Saur, S. 558-573.

Holz, Klaus (1998): Gemeinschaft und Identität. Über den Zusammenhang nationaler und antisemitischer Semantiken. In: Österreichische Zeitschrift für Soziologie 23 (3), S. 3-25.

Holz, Klaus (2004): Die antisemitische Konstruktion des "Dritten" und die nationale Ordnung der Welt. In: Christina von Braun und Eva-Maria Ziege (Hg.): "Das 'bewegliche' Vorurteil. Aspekte des internationalen Antisemitismus. Würzburg: Königshausen \& Neumann, S. 4362.

Holz, Klaus (2010): Nationaler Antisemitismus. Wissenssoziologie einer Weltanschauung. Hamburg: Hamburger Edition.

Holz, Klaus (2010a): Theorien des Antisemitismus. In: Wolfgang Benz (Hg.): Handbuch des Antisemitismus. Judenfeindschaft in Geschichte und Gegenwart. Band 3: Begriffe, Theorien, Ideologien. Berlin, New York: De Gruyter Saur, S. 316-328.

Holz, Klaus; Weyand, Jan (2015): Von der Judenfrage zur Antisemitenfrage. Frühe Erklärungsmodelle von Antisemitismus. In: Hans-Jochaim Hahn und Olaf Kistenmacher (Hg.): Beschreibungsversuche der Judenfeindschaft. Zur Geschichte der Antisemitismusforschung vor 1944. Berlin, München, Boston: De Gruyter, S. 172-190.

Honhart, Michael (1990): Company Housing as Urban Planing in Germany, 1870-1940. In: Central European History 23 (1), S. 3-21.

Horkheimer, Max; Adorno, Theodor W. (2010 [1944]): Dialektik der Aufklärung. Philosophische Fragmente. Frankfurt am Main: Fischer. 
Jesse, Eckhard; Backes, Uwe (1996): Politischer Extremismus in der Bundesrepublik Deutschland. Bonn: Bundeszentrale für politische Bildung.

Joas, Hans; Knöbl, Wolfgang (2013): Sozialtheorie. Zwanzig einführende Vorlesungen. 4. Aufl. Berlin: Suhrkamp.

Jovy, Michael (1984): Jugendbewegung und Nationalsozialismus. Zusammenhänge und Gegensätze. Versuch einer Klärung. Münster: Lit.

Kahmann, Bodo (2011): Antiurbanismus und Antisemitismus. Zur Geschichte und Aktualität eines innigen Verhältnisses. In: Tribüne. Zeitschrift zum Verständnis des Judentums 50 (197), S. 108-115.

Kahmann, Bodo (2015): Antisemitism and Antiurbanism, Past and Present. Empirical and Theoretical Approaches. In: Alvin H. Rosenfeld (Hg.): Deciphering the New Antisemitism. Bloomington: Indiana University Press, S. 482-507.

Kahmann, Bodo (2015a): Norbert Elias`Soziologie des deutschen Antisemitismus. Eine Frühschrift der sozialwissenschaftlichen Antisemitismusforschung. In: Hans-Jochaim Hahn und Olaf Kistenmacher (Hg.): Beschreibungsversuche der Judenfeindschaft. Zur Geschichte der Antisemitismusforschung vor 1944. Berlin, München, Boston: De Gruyter, S. 385-402.

Kalazny, Jerzy (2005): "Caviar fürs Volk" oder Wilhelm Heinrich Riehl (1823-1897) als Popularisator der Volkskunde und Kulturgeschichte. In: Zeitschrift für Germanistik 15 (1), S. 48-60.

Kater, Michael H. (1971): Die Artamanen - Völkische Jugend in der Weimarer Republik. In: Historische Zeitschrift (213), S. 577-638.

Kieval, Hillel J. (1999): Antisemitism and the City: A Beginner`s Guide. In: Ezra Mendelsohn (Hg.): People Of The City. Jews and the Urban Challenge. New York, Oxford: Oxford University Press (Studies in contemporary Jewry, 15), S. 3-18.

Knaut, Andreas (1991): Ernst Rudorff und die Anfänge der deutschen Heimatbewegung. In: Edeltraud Klueting (Hg.): Antimodernismus und Reform. Beiträge zur Geschichte der deutschen Heimatbewegung. Darmstadt: Wiss. Buchges, S. 20-49.

Knoll, Joachim H. (1988): Typisch deutsch? Die Jugendbewegung. Ein essayistischer Deutungsversuch. In: Joachim H. Knoll und Julius H. Schoeps (Hg.): Typisch deutsch: Die 
Jugendbewegung. Beiträge zu einer Phänomengeschichte. Opladen: Leske + Budrich, S. 1133.

Knothe, Holger (2009): Eine andere Welt ist möglich - ohne Antisemitismus. Antisemitismus und Globalisierungskritik bei Attac. Bielefeld: transcript.

Köllmann, Wolfgang (1992): Verstädterung im deutschen Kaiserreich. In: Blätter für deutsche Landesgeschichte 128, S. 199-220.

Krabbe, Wolfgang R. (1974): Gesellschaftsveränderung durch Lebensreform. Strukturmerkmale einer sozialreformerischen Bewegung im Deutschland der Industrialisierungsperiode. Göttingen: Vandenhoeck \& Ruprecht.

Krabbe R., Wolfgang (1985): Die Wohnungsfrage in der Kommunalpolitik deutscher Großstädte vor dem ersten Weltkrieg: Ursprünge des sozialen Wohnungsbaus. In: Geschichte in Wissenschaft und Unterricht 36 (6), S. 426-438.

Krabbe, Wolfgang R. (1989): Die deutsche Stadt im 19. und 20. Jahrhundert. Eine Einführung. Göttingen: Vandenhoeck \& Ruprecht.

Krah, Franziska (2016): „Ein Ungeheuer das wenigstens theoretisch besiegt sein muß“. Pioniere der Antisemitismusforschung in Deutschland. Frankfurt am Main: Campus.

Krämer, Steffen (2013): Entartung und Urbanität. Krankheits- und Verfallsmetaphorik als Großstadtkritik im 19. und 20. Jahrhundert. In: Schriftenreihe der Winckelmann Akademie für Kunstgeschichte München Textbeitrag Nr. 7, S. 2-36. Online verfügbar unter: http://www.winckelmann-akademie.de/data/mediapool/entartung_und_gro stadt.pdf (1.12.2016).

Lane, Barbara Miller (1986): Architektur und Politik in Deutschland 1918-1945. Braunschweig/Wiesbaden: Friedr. Vieweg \& Sohn (Schriften des Deutschen Architekturmuseums zur Architekturgeschichte und Architekturtheorie).

Laqueur, Walter Z. (1962): Die deutsche Jugendbewegung. Eine historische Studie. Köln: Wissenschaft und Politik.

Lees, Andrew (1979): Critics of Urban Society in Germany, 1854-1914. In: Journal of the History of Ideas 40 (1), S. 61-83. 
Lees, Andrew (1985): Cities Perceived. Urban Society in European and American Thought, 18201940. Manchester: Manchester University Press.

Lees, Andrew (2002): Cities, Sin, and Social Reform in Imperial Germany. Ann Arbor, Mich: The University of Michigan Press.

Lees, Andrew; Lees, Lynn Hollen (2007): Cities and the Making of Modern Europe, 1750-1914. Campridge u.a.: Campridge University Press.

Lenk, Kurt; Meuter, Günter; Otten, Henrique Ricardo (1997): Heroischer Realismus: Oswald Spengler. In: Kurt Lenk, Günter Meuter und Henrique Ricardo Otten Lenk (Hg.): Vordenker der Neuen Rechten. Frankfurt am Main, New York: Campus Verlag, S. 39-58.

Lichtsinn, Hilkea (1987): Otto Ammon und die Sozialanthropologie. Frankfurt am Main u.a.: Peter Lang.

Lindner, Rolf (2004): Walks on the Wild Side. Eine Geschichte der Stadtforschung. Frankfurt am Main: Campus.

Linse, Ulrich (1976): Die Jugendkulturbewegung. In: Klaus Vondung (Hg.): Das wilhelminische Bildungsbürgertum. Zur Sozialgeschichte seiner Ideen. Göttingen: Vandenhoeck \& Ruprecht, S. 119-137.

Linse, Ulrich (1982-1983): Siedlungen und Kommunen der deutschen Jugendbewegung. In: Stiftung Jugendburg Ludwigstein und Archiv der deutschen Jugendbewegung (Hg.): Jahrbuch des Archivs der deutschen Jugendbewegung. Witzenhausen (14), S. 13-28.

Linse, Ulrich (1983): Zurück, o Mensch, zur Mutter Erde. Landkommunen in Deutschland 18901933. München: dtv.

Linse, Ulrich (1993): Antiurbane Bestrebungen in der Weimarer Republik. In: Peter Alter (Hg.): Im Banne der Metropolen. Berlin und London in den zwanziger Jahren. Göttingen: Vandenhoeck \& Ruprecht, S. 314-347.

Linse, Ulrich (1996): Völkisch-rassische Siedlungen der Lebensreform. In: Uwe Puschner, Walter Schmitz und Justus H. Ulbricht (Hg.): Handbuch zur "Völkischen Bewegung". 1871-1918. München, New Providence, London, Paris: K. G. Saur, S. 397-410. 
Linse, Ulrich (2014): Völkisch-jugendbewegte Siedlungen im 20. und 21. Jahrhundert. In: Gideon Haverkampf und Josef Botsch (Hg.): Jugendbewegung, Antisemitismus und rechtsradikale Politik. Vom "Freideutschen Jugendtag" bis zur Gegenwart. Berlin: De Gruyter, S. 29-73.

Lövenich, Friedhelm (1992): Verstaatlichte Sittlichkeit. Die konservative Konstruktion der Lebenswelt in Wilhelm Heinrich Riehl 'Naturgeschichte des Volkes'. Opladen: Leske + Budrich.

Lowenstein, Steven M. (1980): The Rural Community and the Urbanization of German Jewry. In: Central European History 8 (1), S. 218-235.

Lowenthal, Leo (1990 [1949]): Falsche Probheten. Studien zum Autoritarismus. Frankfurt am Main: Suhrkamp (Leo Löwenthal Schriften, 3).

Lutzhöft, Hans-Jürgen (1971): Der Nordische Gedanke in Deutschland. 1920-1940. Stuttgart: Ernst Klett.

Maccabelli, Terenzio (2008): Social Anthroplogy in Economic Literature at the End of the 19th Century: Eugenic and Pacial Explanations of Inequality. In: American Journal of Economics and Sociology 67 (3), S. 481-528.

Mai, Uwe (2002): "Rasse und Raum". Agrarpolitik, Sozial- und Raumplanung im NS-Staat. Paderborn u.a.: Ferdinand Schöningh.

Mancini, Elena (2009): Boys in the City: Homoerotic Desire and the Urban Refuge in Early Twentieth-Century Germany. In: Michael Thompson (Hg.): Fleeing the City. Studies in the Culture and Politics of Antiurbanism. New York: Palgrave Macmillan, S. 91-110.

Marchand, Bernhard (1999): Nationalsozialismus und Großstadtfeindschaft. In: Die alte Stadt. Zeitschrift für Stadtgeschichte, Stadtsoziologie und Denkmalpflege 26 (1), S. 39-50.

Marcuse, Herbert (1968): Der Kampf gegen den Liberalismus in der totalitären Staatsauffassung. In: Herbert Marcuse: Kultur und Gesellschaft 1. 7. Aufl. Frankfurt am Main: Suhrkamp, S. 1755.

Marsovszky, Magdalena (2006): Neue völkische Bewegung und Antisemitismus in Ungarn. In: Samuel Salzborn (Hg.): Minderheitenkonflikte in Europa. Fallbeispiele und Lösungsansätze. Innsbruck Wien Bozen: Studien Verlag, S. 201-222. 
Marsovszky, Magdalena (2009): Völkisches Denken, antisemitische Mobilisierung und drohende Gewalt in Ungarn. In: Wolfgang Benz (Hg.): Jahrbuch für Antisemitismusforschung. Berlin: Metropol (18), S. 183-211.

Marx, Karl (1871 [1867]): Das Kapital. Kritik der politischen Ökonomie. Erster Band, Buch 1: Der Produktionsprozeß des Kapitals. Berlin: Dietz (Marx Engels Werke (MEW), 23).

Massing, Paul W. (1959): Vorgeschichte des politischen Antisemitismus. Frankfurt am Main: Europäische Verlagsanstalt.

Maurer, Trude (1992): Die Entwicklung der jüdischen Minderheit in Deutschland (1780-1933). Neuere Forschungen und offene Fragen. Tübingen: Max Niemeyer Verlag (4. Sonderheft Internationales Archiv für Sozialgeschichte der deutschen Literatur).

Mayring, Philipp (2010): Qualitative Inhaltsanalyse. Grundlagen und Techniken. 11. Aufl. Weinheim, Basel: Beltz.

Meinefeld, Werner (2010): Hypothesen und Vorwissen in der qualitativen Sozialforschung. In: Uwe Flick, Ernst von Kardorff und Ines Steineke (Hg.): Qualitative Forschung. Ein Handbuch. Hamburg: Rowohlt, S. 265-275.

Mommsen, Hansen (2005): Das Trugbild der "nationalen Revolution". Betrachtungen zur nationalistischen Gegenkultur in der Weimarer Republik. In: Walter Schmitz und Clemens Vollnhals (Hg.): Völkische Bewegung - Konservative Bewegung - Nationalsozialismus. Aspekte einer politisierten Kultur. Dresden: Thelem, S. 21-30.

Mosse, George L. (1964): The Crisis of German Ideology. Intellectual Origins of the Third Reich. New York: Grosset \& Dunlap.

Müller, Tim B. (2010): Krieger und Gelehrte. Herbert Marcuse und die Denksysteme im Kalten Krieg. Hamburg: Hamburger Edition.

Münk, Dieter (1993): Die Organisation des Raumes im Nationalsozialismus. Eine soziologische Untersuchung ideologisch fundierter Leitbilder in Architektur, Städtebau und Raumplanung des Dritten Reiches. Bonn: Pahl-Rugenstein.

Münkel, Daniela (1996): Nationalsozialistische Agrarpolitik und Bauernalltag. Frankfurt am Main, New York: Campus. 
Niemeyer, Christian (2013): Die dunklen Seiten der Jugendbewegung. Vom Wandervogel bis zur Hitlerjugend. Tübingen: Francke.

Nye, Robert A. (1985): The Bio-Medical Origins of Urban Sociology. In: Journal of Contemporary History 20 (4), S. 659-675.

Oevermann, Ulrich; Allert, Tilman; Konau, Eliasbeth; Krambeck, Jürgen (1979): Die Methodologie einer "objektiven Hermeneutik" und ihre allgemeine forschungslogische Bedeutung in den Sozialwissenschaften. In: Hans-Georg Soeffner (Hg.): Interpretative Verfahren in den Sozialund Textwissenschaften. Stuttgart: J.B. Metzlersche Verlagsbuchhandlung, S. 352-433.

Omran, Susanne (2000): Frauenbewegung und "Judenfrage". Diskurse um Rasse und Geschlecht nach 1900. Frankfurt am Main, New York: Campus.

Oppenheimer, Franz (1925): Der Antisemitismus im Lichte der Soziologie. In: Der Morgen. Monatszeitschrift der deutschen Juden 1 (2), S. 148-161.

Otte, Gunnar; Baur Nina (2008): Urbanism as a way of life? Räumliche Variationen der Lebensführung in Deutschland. In: Zeitschrift für Soziologie 37 (2), S. 93-116.

Parsons, Talcott (1937): The Structure of Social Action. New York: McGraw Hill.

Parsons, Talcott (1951): The Social System. London: Routledge \& Kegan Paul Ltd.

Parsons, Talcott (1969): The Sociology of Modern Anti-Semitism. In: Isacque Graeber und Steuart Henderson Britt (Hg.): Jews in a Gentile World. The Problem of Anti-Semitism. Westport: Greenwood Press, S. 101-122.

Pfeil, Elisabeth (1972): Großstadtforschung. Entwicklung und gegenwärtiger Stand. 2. Aufl. Hannover: Gebr. Jänecke (Veröffentlichungen der Hochschule für Wirtschaft und Politik, Hamburg, 65).

Piefel, Matthias (2004): Antisemitismus und völkische Bewegung im Königreich Sachsen 1879 1914. Göttingen: Vandenhoeck \& Ruprecht.

Piefel, Matthias (2005): Bruno Tanzmann. Ein völkischer Agitator zwischen wilhelminischen Kaiserreich und nationalsozialistischem Führerstaat. In: Walter Schmitz und Clemens Vollnhals (Hg.): Völkische Bewegung - Konservative Bewegung - Nationalsozialismus. Aspekte einer politisierten Kultur. Dresden: Thelem, S. 255-280. 
Piper, Ernst (2005): Alfred Rosenberg. Hitlers Chefideologe. München: Karl Blessing.

Postone, Moishe (1982): Die Logik des Antisemitismus. In: Merkur. Deutsche Zeitschrift für europäisches Denken 36 (1), S. 13-25.

Postone, Moishe (2005): Deutschland die Linke und der Holocaust. Politische Interventionen. Freiburg [Br.]: Ça Ira.

Preuß, Reinhard (1991): Verlorene Söhne des Bürgertums. Linke Strömungen in der deutschen Jugendbewegung 1913-1919. Köln: Verlag Wissenschaft und Politik (Edition Archiv der Deutschen Jugendbewegung, 8).

Puschner, Uwe (2001): Die völkische Bewegung im wilhelminischen Kaiserreich. Sprache - Rasse Religion. Darmstadt: Wiss. Buchges.

Puschner, Uwe (2003): Strukturmerkmale der völkischen Bewegung (1900-1945). In: Michel Grunewald und Uwe Puschner (Hg.): Das konservative Intellektuellen-Milieu in Deutschland, seine Presse und seine Netzwerke (1890-1960). Bern: Peter Lang, S. 445-468.

Puschner, Uwe (2004): Anti-Semitism and German Voelkish Ideology. In: Hubert Cancik und Uwe Puschner (Hg.): Antisemitismus, Paganismus, Völkische Religion. München: K. G. Saur, S. $55-63$.

Puschner, Uwe (2010): Völkische Bewegung und Jugendbewegung. In: Stefan Vogt (Hg.): Ideengeschichte als politische Aufklärung: Festschrift für Wolfgang Wippermann zum 65. Geburtstag. Berlin: Metropol, S. 54-70..

Rehberg, Karl-Siegbert (1988): Das Bild des Judentums in der frühen deutschen Soziologie. "Fremdheit" und "Rationalität" als Typusmerkmale bei Werner Sombart, Max Weber und Georg Simmel. In: Otto Horch (Hg.): Judentum, Antisemitismus und europäische Kultur. Tübingen: Francke, S. 151-186.

Rensmann, Lars (2004): Demokratie und Judenbild. Antisemitismus in der politischen Kultur der Bundesrepublik Deutschland. Wiesbaden: VS Verlag für Sozialwissenschaften.

Rensmann, Lars (2006): Parameter einer selbstreflexiven Antisemitismusforschung. In: Sozialwissenschaftliche Literatur Rundschau SLR (52), S. 63-79.

Reulecke, Jürgen (1985): Geschichte der Urbanisierung in Deutschland. Frankfurt am Main: Suhrkamp. 
Richarz, Monika (1990): Landjuden - ein bürgerliches Element im Dorf? In: Wolfgang Jacobeit, Josef Mooser und Bo Strath (Hg.): Idylle oder Aufbruch? Das Dorf im bürgerlichen 19. Jahrhundert. Ein europäischer Vergleich. Berlin: Akademie-Verlag, S. 181-190.

Richarz, Monika (1999): Vom Land in die Stadt. Aspekte der Urbanisierung deutscher Juden im 19. Jahrhundert. In: Fritz Mayrhofer (Hg.): Juden in der Stadt. Linz, Donau: Österreich. Arbeitskreis für Stadtgeschichtsforschung (Beiträge zur Geschichte der Städte Mitteleuropas, 15), S. 327-339.

Rodenstein, Marianne (1988): "Mehr Licht, mehr Luft": Gesundheitskonzepte im Städtebau seit 1750. Frankfurt, New York: Campus Verlag.

Rohkrämer, Thomas (1999): Eine andere Moderne? Zivilisationskritik, Natur und Technik in Deutschland 1880-1933. Paderborn: Schöningh.

Rohkrämer, Thomas (2007): Bewahrung, Neugestaltung, Restauration? Konservative Raum- und Heimatvorstellungen in Deutschland 1900-1933. In: Wolfgang Hardtwig (Hg.): Ordnungen in der Krise. Zur politischen Kulturgeschichte Deutschlands 1900-1933. München: R. Oldenburg, S. 49-68.

Rose, Arnold (1948): Anti-Semitism's Root in City-Hatred. A Clue to the Jew's Position as Scapegoat. In: Commentary 3 (6), S. 374-378.

Rosenthal, Gabriele (2005): Interpretative Sozialforschung. Eine Einführung. Weinheim, München: Juventa.

Rürup, Reinhard (1987): Die "Judenfrage" der bürgerlichen Gesellschaft und die Entstehung des modernen Antisemitismus. In: Reinhard Rürup: Emanzipation und Antisemitismus. Studien zur "Judenfrage" in der bürgerlichen Gesellschaft. München, S. 93-119.

Rürup, Reinhard (1987a): Judenemanzipation und bürgerliche Gesellschaft in Deutschland. In: Reinhard Rürup: Emanzipation und Antisemitismus. Studien zur "Judenfrage" in der bürgerlichen Gesellschaft. München, S. 13-45.

Rürup, Reinhard (1987b): Zur Entwicklung der modernen Antisemitismusforschung. In: Reinhard Rürup: Emanzipation und Antisemitismus. Studien zur "Judenfrage" in der bürgerlichen Gesellschaft. München, S. 145-159. 
Rürup, Reinhard (2004): Der moderne Antisemitismus und die Entwicklung der historischen Antisemitismusforschung. In: Werner Bergmann und Mona Körte (Hg.): Antisemitismusforschung in den Wissenschaften. Berlin: Metropol, S. 117-136.

Salzborn, Samuel (2010): Antisemitismus als negative Leitidee der Moderne. Sozialwissenschaftliche Theorien im Vergleich. Frankfurt, New York: Campus.

Salzborn, Samuel (2012): Weltanschauung und Leidenschaft. Überlegungen zu einer integrativen Theorie des Antisemitismus. In: Zeitschrift für politische Theorie 3 (2), S. 187-203.

Salzborn, Samuel (2014): Rechtsextremismus. Erscheinungsformen und Erklärungsansätze. BadenBaden: Nomos.

Satre, Jean-Paul (2010 [1944]): Überlegungen zur Judenfrage. Reinbek: Rowohlt.

Schenk, Dietmar (1991): Die Freideutsche Jugend, 1913-1919/20. Eine Jugendbewegung in Krieg, Revolution und Krise. Münster: Lit (Geschichte der Jugend, 17).

Schildt, Axel (1994): NS-Regime, Modernisierung und Moderne. Anmerkungen zur Hochkonjunktur einer andauernden Diskussion. In: Dan Diner und Frank Stern (Hg.): Tel Aviver Jahrbuch für deutsche Geschichte. Nationalsozialismus aus heutiger Perspektive. Gerlingen: Bleicher Verlag (23), S. 3-22.

Schlör, Joachim (1995): "Der Urbantyp". Stadtbewohner par excellence. In: Julius H. Schoeps und Joachim Schlör (Hg.): Antisemitismus. Vorurteile und Mythen. München: Piper, S. 229-240.

Schlör, Joachim (2005): Das Ich der Stadt. Debatten über Judentum und Urbanität 1822-1938. Göttingen: Vandenhoeck \& Ruprecht.

Schott, Dieter (2014): Europäische Urbanisierung (1000-2000). Eine umwelthistorische Einführung. Köln, Weimar, Wien: Böhlau.

Schubert, Dirk (2004): Die Gartenstadtidee zwischen reaktionärer Ideologie und pragmatischer Umsetzung. Theodor Fritschs völkische Version der Gartenstadt. Dortmund: Inst. für Raumplanung.

Siebel, Walter (1998): Urbanität. In: Hartmut Häußermann (Hg.): Großstadt. Soziologische Stichworte. Opladen: Leske + Budrich, S. 262-270.

Siebel, Walter (1999): Ist Urbanität eine Utopie? In: Geographische Zeitschrift 87 (2), S. 116-124. 
Siebel, Walter (2004): Einleitung: Die europäische Stadt. In: Walter Siebel (Hg.): Die europäische Stadt. Frankfurt am Main: Suhrkamp, S. 11-48.

Siebel, Walter (2015): Die Kultur der Stadt. Frankfurt am Main: Suhrkamp.

Sieferle, Rolf Peter (1984): Fortschrittsfeinde? Opposition gegen Technik und Industrie von der Romantik bis zur Gegenwart. München: C.H. Beck.

Sieferle, Rolf Peter (1995): Zivilisation als Schicksal: Oswald Spengler. In: Rolf Peter Sieferle (Hg.): Die Konservative Revolution. Fünf biographische Skizzen. Frankfurt am Main: Fischer Taschenbuch Verlag, S. 106-131.

Sieferle, Rolf Peter; Zimmermann, Clemens (1992): Die Stadt als Rassengrab. In: Manfred Smuda (Hg.): Die Großstadt als > Text<. München: Wilhelm Fink, S. 53-72.

Simmel, Georg (1903): Die Großstädte und das Geistesleben. In: Gehe-Stiftung zu Dresden (Hg.): Die Großstadt. Vorträge und Aufsätze zur Städteausstellung. Dresden: v. Zahn \& Jaensch (Jahrbuch der Gehe-Stiftung zu Dresden, IX), S. 185-206.

Simmel, Georg (2014 [1900]): Philosophie des Geldes. Frankfurt am Main: Suhrkamp.

Speit, Andreas (2012): Projekte und Positionen völkischer Ideologie. In: Heinrich Böll Stiftung Mecklenburg Vorpommern (Hg.): Braune Ökologen. Hintergründe und Strukturen am Beispiel Mecklenburg-Vorpommerns. Berlin: Heinrich-Böll-Stiftung (Schriften zur Demokratie, 26), S. 62-75.

Sprondel, Walter M. (1986): Kulturelle Modernisierung durch antimodernistischen Protest. Der lebensreformerische Vegetarismus. In: Friedhelm Neidhardt, Rainer Lepsius und Johannes Weiss (Hg.): Kultur und Gesellschaft. Opladen: Westdeutscher Verlag (Kölner Zeitschrift für Soziologie und Sozialpsychologie, Sonderhefte, 27), S. 314-330.

Spülbeck, Susanne (1997): Ordnung und Angst. Russische Juden aus der Sicht eines ostdeutschen Dorfes nach der Wende: Eine ethnologische Studie. Frankfurt, New York: Campus.

Stern, Fritz (1961): The Politics of Cultural Despair. A Study in the Rise of the Germanic Ideology. Berkeley u.a.: University of California Press.

Stögner, Karin (2014): Antisemitismus und Sexismus. Historisch-gesellschaftliche Konstellationen. Baden-Baden: Nomos. 
Taylor, Robert R. (1974): The Word in Stone. The Role of Architecture in the National Socialist Ideology. Berkeley: University of California Press.

Thompson, Michael (Hg.) (2009): Fleeing the City. Studies in the Culture and Politics of Antiurbanism. New York: Palgrave Macmillan.

Thompson, Michael (2009a): What is Antiurbanism? A Theoretical Perspective. In: Michael Thompson (Hg.): Fleeing the city. Studies in the Culture and Politics of Antiurbanism. New York: Palgrave Macmillan, S. 9-34.

Tönnies, Ferdinand (1912 [1887]): Gemeinschaft und Gesellschaft. Grundbegriffe der reinen Soziologie. 2. Aufl. Berlin: Karl Curtius.

Tourlamain, Guy (2014): Völkisch Writers and National Socialism. A Study of Right-Wing Political Culture in Germany, 1890-1960. Oxford u.a.: Peter Lang.

Ulbricht, Justus H. (1995): Die Heimat als Umwelt des Volkes. Ökologische Denkfiguren in Ideologie und Programmatik "neurechter" Organisationen. In: Richard Faber, Hajo Funke und Gerhard Schoenberner (Hg.): Rechtsextremismus. Ideologie und Gewalt. Berlin: Publikation der Gedenkstätte Haus der Wannsee-Konferenz, S. 221-240.

Ulbricht, Justus H. (1996): Das völkische Verlagswesen im deutschen Kaiserreich. In: Uwe Puschner, Walter Schmitz und Justus H. Ulbricht (Hg.): Handbuch zur "Völkischen Bewegung". 18711918. München, New Providence, London, Paris: K. G. Saur, S. 277-301..

Volkov, Shulamit (2000): Antisemitismus als kultureller Code. In: Shulamit Volkov: Antisemitismus als kultureller Code. Zehn Essays. 2. Aufl. München: C.H. Beck, S. 14-36.

Volkov, Shulamit (2000a): Das geschriebene und das gesprochene Wort. Über Kontinuität und Diskontinuität im deutschen Antisemitismus. In: Shulamit Volkov: Antisemitismus als kultureller Code. Zehn Essays. 2. Aufl. München: C.H. Beck, S. 54-75.

Walkenhorst, Peter (2007): Nation - Volk - Rasse. Radikaler Nationalismus im Deutschen Kaiserreich 1890-1914. Göttingen: Vandenhoeck \& Ruprecht.

Walter, Franz (1986): Nationale Romantik und revolutionärer Mythos. Politik und Lebensweisen im frühen Weimarer Jungsozialismus. Berlin: Verlag Europäische Perspektiven. 
Walz, Manfred (1980): Gegenbilder zur Großstadt: von den nationalsozialistischen Versuchen zur Auflösung der Stadt bis zu den Wiederaufbauphasen nach 1945. In: Stadtbauwelt: Vierteljahresheft der Bauwelt 71 (65), S. 473-482.

Weber, Max (1934): Die protestantische Ethik und der Geist des Kapitalismus. Tübingen: J.C.B. Mohr.

Weber, Max (1985 [1922]): Wirtschaft und Gesellschaft. Grundriss einer verstehenden Soziologie. Fünfte, revidierte Auflage. Tübingen: J.C.B. Mohr.

Wedemeyer-Kolwe, Bernd (2004): "Der neue Mensch". Körperkultur im Kaiserreich und in der Weimarer Republik. Würzburg: Königshausen \& Neumann.

Weikart, Richard (1993): The Origins of Social Darwinism in Germany, 1859-1895. In: Journal of the History of Ideas 54 (3), S. 469-488.

Weikart, Richard (2003): Progress through Racial Extermination: Social Darwinism, Eugenics, and Pacifism in Germany, 1860-1918. In: German Studies Review 26 (2), S. 273-294.

Weingart, Peter; Kroll, Jürgen; Bayertz, Kurt (1988): Rasse, Blut und Gene. Geschichte der Eugenik und Rassenhygiene in Deutschland. Frankfurt am Main: Suhrkamp.

Weyand, Jan (2015): Die Entstehung der Antisemitismustheorie aus der Debatte über die Judenemanzipation. In: Hans-Jochaim Hahn und Olaf Kistenmacher (Hg.): Beschreibungsversuche der Judenfeindschaft. Zur Geschichte der Antisemitismusforschung vor 1944. Berlin, München, Boston: De Gruyter, S. 47-65.

Winnecken, Andreas (1991): Ein Fall von Antisemitismus. Zur Geschichte und Pathogenese der deutschen Jugendbewegung vor dem Ersten Weltkrieg. Köln: Wissenschaft und Politik.

Wirth, Loius (1938): Urbanism as a Way of Life. In: The American Journal of Sociology 44 (1), S. 124.

Wischermann, Clemens (1986): Wohnungsmarkt, Wohnungsversorgung und Wohnmobilität in deutschen Großstädten 1870-1913. In: Hans-Jürgen Teuteberg (Hg.): Stadtwachstum, Industrialisierung, Sozialer Wandel. Beiträge zur Erforschung der Urbanisierung im 19. und 20. Jahrhundert. Berlin: Duncker \& Humblot, S. 101-133.

Wyrwa, Ulrich (2010): Die Reaktion des deutschen Judentums auf den Antisemitismus im deutschen Kaiserreich: Eine Rekapitulation. In: Ulrich Wyrwa (Hg.): Einspruch und Abwehr. Die 
Reaktion des europäischen Judentums auf die Entstehung des Antisemitismus (1879-1914). Frankfurt am Main: Campus, S. 25-42.

Ziege, Eva-Maria (2002): Mythische Kohärenz. Diskursanalyse des völkischen Antisemitismus. Konstanz: UVK.

Ziege, Eva-Maria (2011): Arendt, Adorno und die Anfänge der Antisemitismusforschung. In: Liliane Weissberg (Hg.): Affinität wider Willen? Hannah Arendt, Theodor W. Adorno und die Frankfurter Schule. Frankfurt am Main, New York: Campus, S. 85-102.

Zimmermann, Moshe (1978): Two Generations in the History of German Antisemitism: The Letters of Theodor Fritsch to Wilhelm Man. In: Leo Baeck Institute Yearbook 23 (1), S. 89-100.

Zumbini, Massimo Ferrari (2003): Die Wurzeln des Bösen. Gründerjahre des Antisemitismus: Von der Bismarckzeit zu Hitler. Frankfurt am Main: Vittorio Klostermann. 